\title{
Direct liquefaction of coal with coal-derived solvents to produce precursors for carbon products
}

\author{
David Christopher Fenton \\ West Virginia University
}

Follow this and additional works at: https://researchrepository.wvu.edu/etd

\section{Recommended Citation}

Fenton, David Christopher, "Direct liquefaction of coal with coal-derived solvents to produce precursors for carbon products" (2001). Graduate Theses, Dissertations, and Problem Reports. 1156.

https://researchrepository.wvu.edu/etd/1156

This Thesis is protected by copyright and/or related rights. It has been brought to you by the The Research Repository @ WVU with permission from the rights-holder(s). You are free to use this Thesis in any way that is permitted by the copyright and related rights legislation that applies to your use. For other uses you must obtain permission from the rights-holder(s) directly, unless additional rights are indicated by a Creative Commons license in the record and/ or on the work itself. This Thesis has been accepted for inclusion in WVU Graduate Theses, Dissertations, and Problem Reports collection by an authorized administrator of The Research Repository @ WVU. For more information, please contact researchrepository@mail.wvu.edu. 


\title{
Direct Liquefaction of Coal with Coal-Derived Solvents to Produce Precursors for Carbon Products
}

\section{David Fenton}

\author{
Thesis submitted to the \\ College of Engineering and Mineral Resources \\ at West Virginia University \\ in partial fulfillment of the requirements \\ for the degree of \\ Master of Science \\ in \\ Engineering
}

John W. Zondlo, Ph.D., Chair

Peter G. Stansberry, Ph.D.

Alfred H. Stiller, Ph.D.

\author{
Department of Chemical Engineering \\ Morgantown, West Virginia
}

2001

Keywords: Coal, Carbon Products, Coal Liquefaction

Copyright 2001 David Fenton 


\title{
ABSTRACT \\ Direct Liquefaction of Coal with Coal-Derived Solvents to Produce Precursors for Carbon Products
}

\author{
David Fenton
}

\begin{abstract}
Direct liquefaction (hydrogenation) of coal has frequently been pursued as one avenue for the production of value-added products from coal. In previous work, model solvents such as tetralin were employed as the hydrogen-donor solvent to produce carbon precursors such as pitch directly from coal. The focus of this research was to evaluate five coal-derived liquids as substitutes for tetralin in the coal hydrogenation process. A mid-distillate by-product liquid from the production of high quality char was obtained from Antaeus Technical Services, Inc. and split into three fractions, the original liquid (RACL), its heavy fraction (DACL-H), and its light fraction (DACL-L). The other two liquids were heavy creosote oil (HCO) and carbon black base \#1 (CBB) from Koppers Industries, Inc. These liquids were used as hydrogenation solvents under varying reaction conditions such as gas pressure, gas composition, and solvent-to-coal ratio. The products were separated by filtration and vacuum distillation to produce three fractions, the THF insolubles, pitch, and recycle solvent. The coal-alone conversions were calculated for each hydrogenation reaction and the pitch fractions were characterized as possible carbon-product precursors by softening point, ash content, coke yield, elemental analysis, and optical texture. The results showed that DACL-L was the most effective solvent at producing soluble coal species. However, the coke of the pitch fraction showed an isotropic optical texture. The cokes of the pitch fractions for reactions with all the other solvents exhibited an anisotropic optical texture. The coalalone conversion was slightly increased as the initial gas pressure in the reactor was increased, and the coal-alone conversion was higher using hydrogen rather than argon in the gas phase. The ash content of the pitches was very low $(\leq 0.1 \%)$ for all the reactions. The coke yield depended linearly on the pitch softening point but showed no dependence on the reaction conditions or the hydrogenation solvent. Finally, the elemental composition of the pitches was similar regardless of the gas pressure or composition, leading to the possibility of pitch production at lower pressures in an inert atmosphere.
\end{abstract}




\section{ACKNOWLEDGEMENTS}

The author would like to thank his research advisor, Dr. John W. Zondlo for his continuous guidance and friendship. The author would also like to extend his appreciation to the committee members, Dr. Alfred H. Stiller and especially to Dr. Peter G. Stansberry for his constant support and guidance.

Funding for this research was provided by ACTD Support for Advanced Fuels Research and Coal Characterization Program, contract number 990700364, sponsored by Concurrent Technologies Corp.

The author expresses a special thanks to his parents for their encouragement, insight, and constant support without which this would not have been possible.

Finally, I would like to dedicate this to my wife, Jennifer, for her sacrifices, understanding, and encouragement throughout this process. 


\section{TABLE OF CONTENTS}

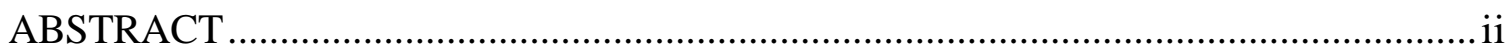

ACKNOWLEDGEMENTS ................................................................................

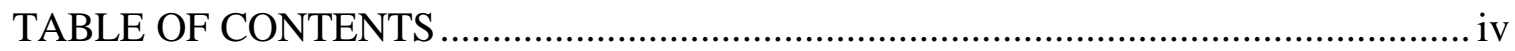

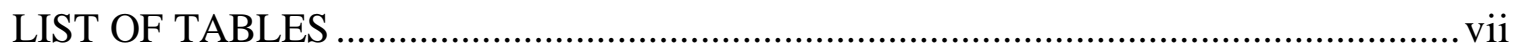

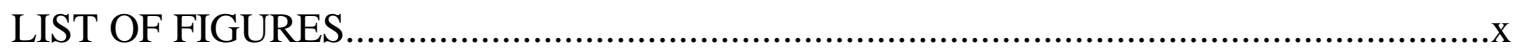

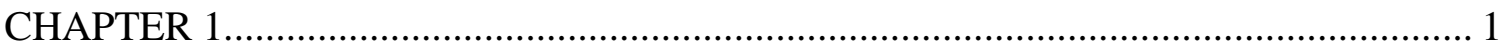

1.1 Research Objectives ............................................................................... 3

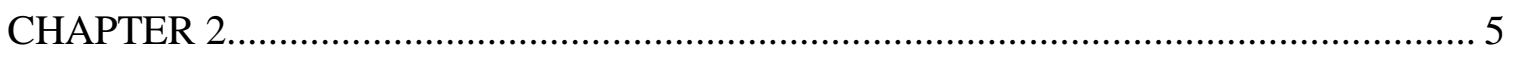

2.1 Carbon and Carbon Products ........................................................................ 5

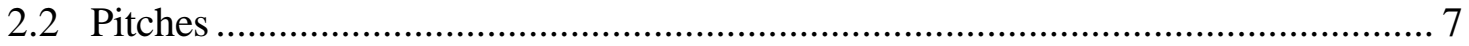

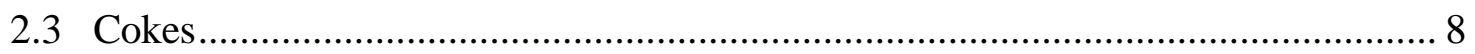

2.4 Characterization Techniques for Cokes and Pitches ........................................ 10

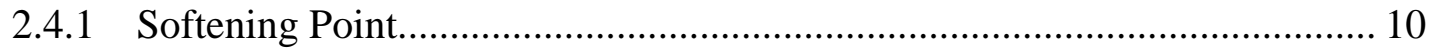

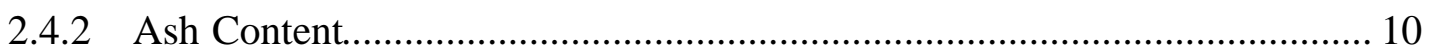

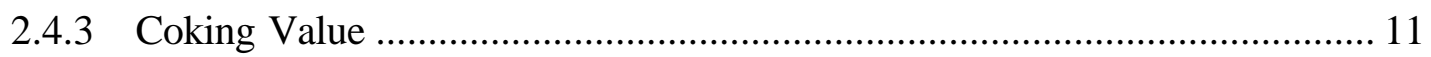

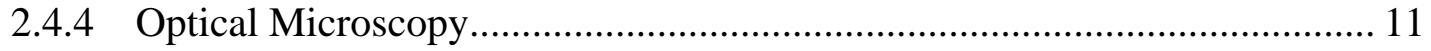

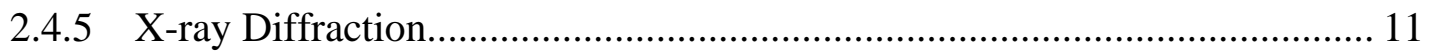

2.5 Carbon Products from Coal....................................................................... 12

2.5.1 Coal - Formation, Composition, and Classification .................................. 12

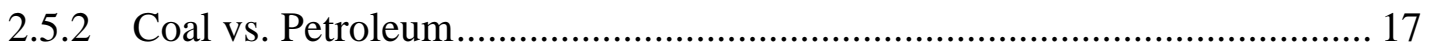

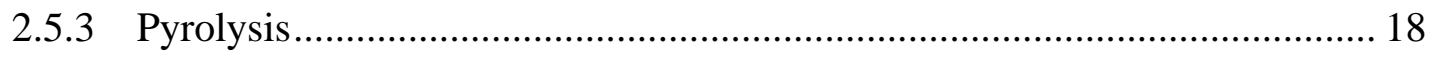

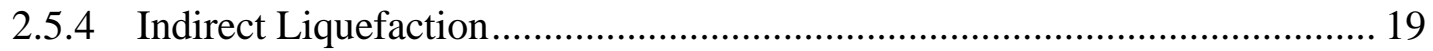

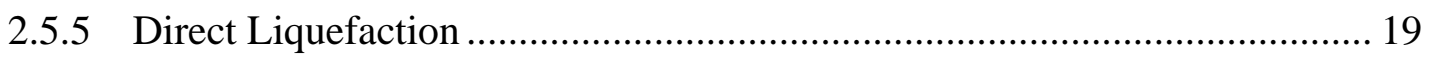

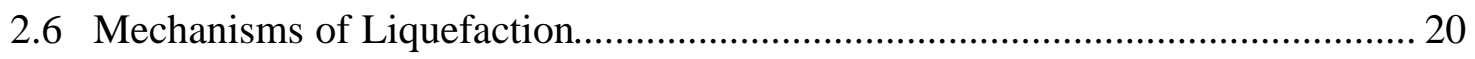

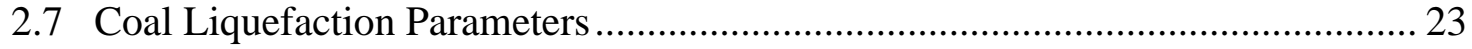

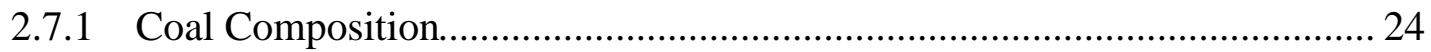

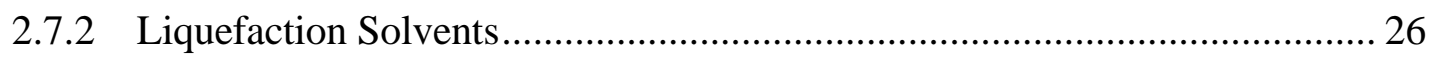

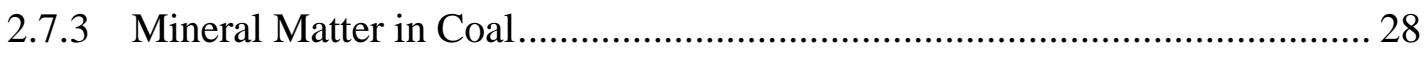

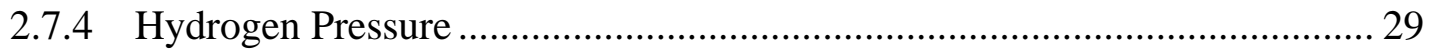




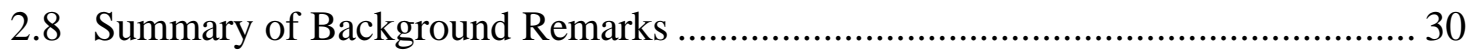

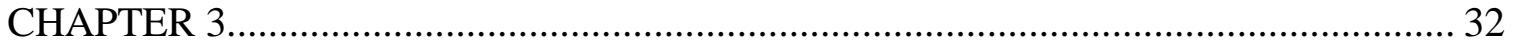

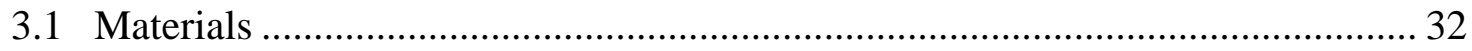

3.2 Experimental Procedure for Hydrogenation Reactions ........................................... 34

3.2.1 Overview of Hydrogenation Reaction.......................................................... 34

3.2.2 Fluidized Sand Bath Preparation................................................................ 37

3.2.3 Reactor Preparation.................................................................................... 39

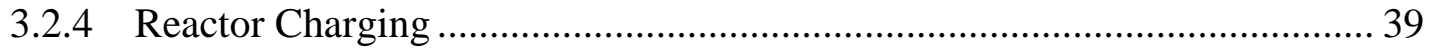

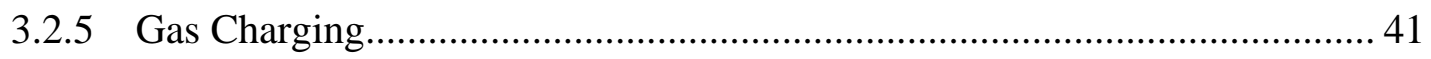

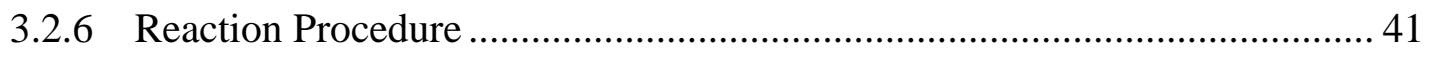

3.2.7 Product Collection................................................................................. 42

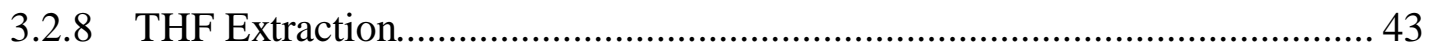

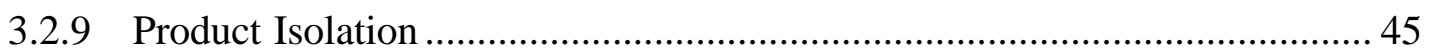

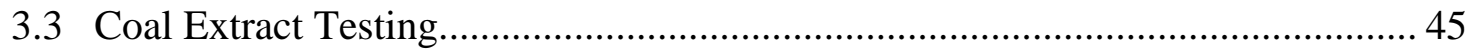

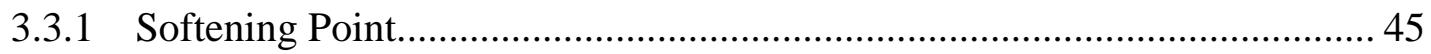

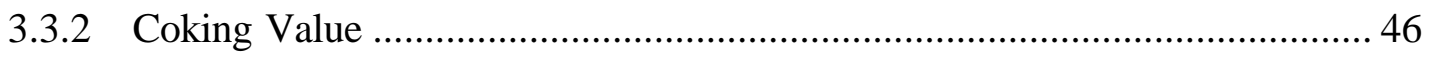

3.3.3 Ash Content.............................................................................................. 47

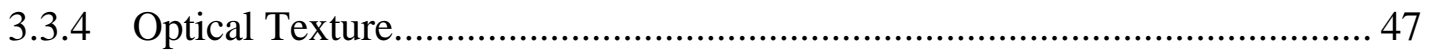

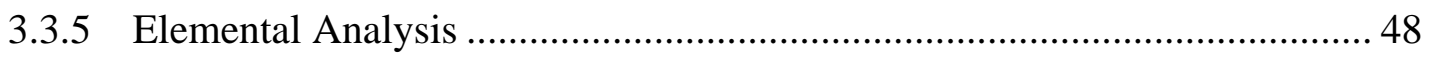

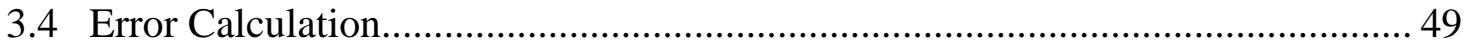

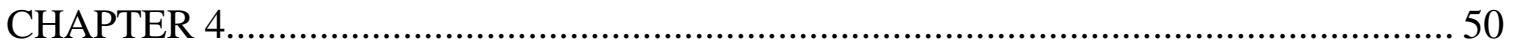

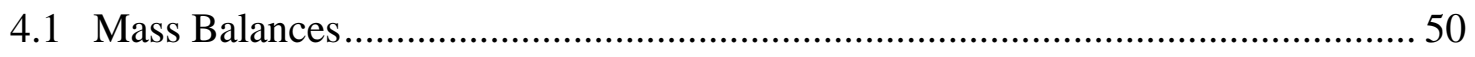

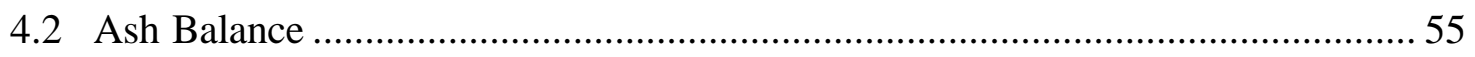

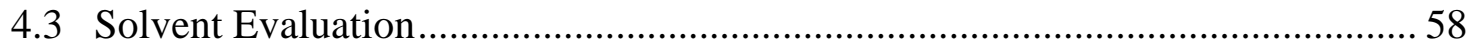

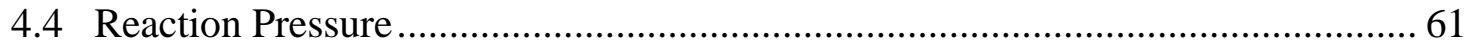

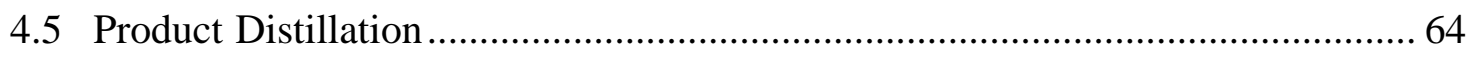

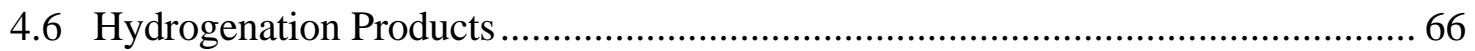

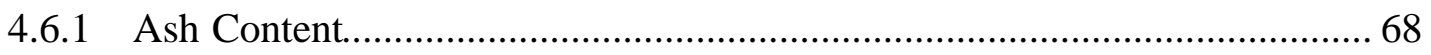

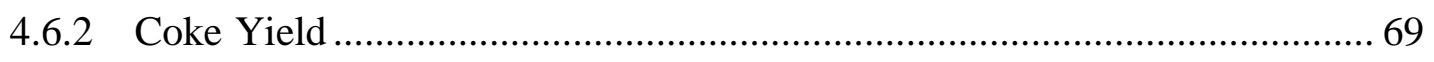

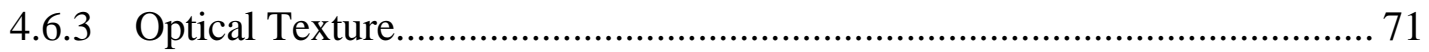

4.6.4 Elemental Analysis .............................................................................. 74 
4.7 Variation of Hydrogenation Parameters .......................................................... 78

4.7.1 Effect of Pressure and Atmosphere ......................................................... 78

4.7.2 Effect of Solvent-to-Coal Ratio ............................................................ 91

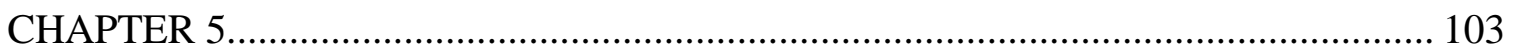

5.1 Recommendations for Future Work............................................................ 105

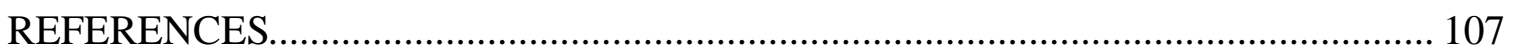

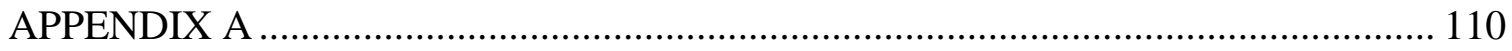

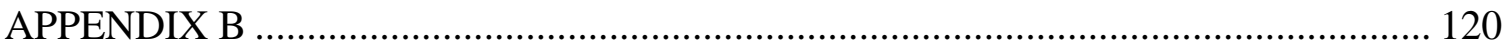

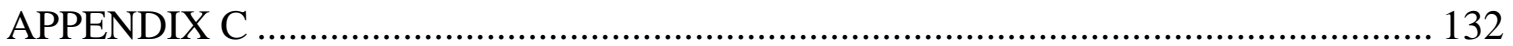




\section{LIST OF TABLES}

Table 1.1 Production Yields from Coal Carbonization [34] ..............................................2

Table 2.2 The ASTM System for Classifying Coals by Rank [31] ....................................15

Table 2.3 Percent Elemental Composition of Various Coal Ranks [11] ..............................15

Table 2.4 Typical Compositions of Coals and Liquid Hydrocarbons ${ }^{\mathrm{a}}$ [23] .........................17

Table 2.5 Definition of Primary Liquids from Berkowitz [5].........................................22

Table 2.6 Fundamental Properties Important in Coal Liquefaction [5] ...............................23

Table 2.7 Effectiveness of Some Solvents for Hydrogenation [30]...................................28

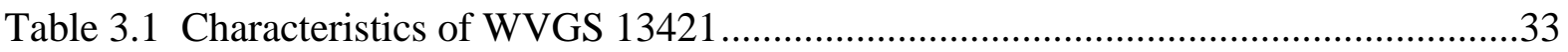

Table 3.2 Elemental Compositions ${ }^{\mathrm{a}}$ of WVGS 13421 and Coal-derived Solvents ................33

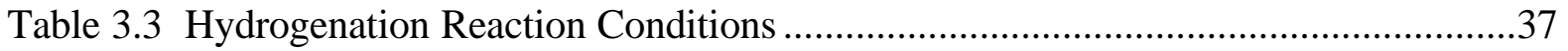

Table 4.1 Overall Mass Balances of the Coal Hydrogenation Reactions .............................51

Table 4.2 Ash Balance of Hydrogenation Reactants and Products for All Runs ...................56

Table 4.3 Softening Point of Pitch and Ash Content of Pitch and THF Insoluble

Fractions of Hydrogenation Products ...........................................................69

Table 4.4 Elemental Composition of Select Hydrogenation Products .................................76

Table 4.5 Elemental Carbon Balance for Hydrogenation Reactants and Products for Selected Runs

Table 4.6 Elemental Hydrogen Balance for Hydrogenation Reactants and Products for Selected Runs

Table 4.7 Ash content of pitch and THF insoluble fractions of pitch produced while varying the initial reactor pressure and gaseous atmosphere .88

Table 4.8 Elemental composition of select pitches produced from hydrogenation reactions (CBB solvent, $400{ }^{\circ} \mathrm{C}, 3 / 1$ solvent-to-coal ratio, 1 hour) with different initial pressures and atmospheres: 5B) 1000 psig Hydrogen, 6D) 1000 psig Argon, 7A) 500 psig Hydrogen, 8D) 500 psig Argon, 9B) 100 psig Hydrogen, and 10D) 100 psig Argon

Table 4.9 Carbon balance of select pitches produced from hydrogenation reactions with different initial pressures and atmospheres: 5B) 1000 psig Hydrogen, 6D) 
1000 psig Argon, 7A) 500 psig Hydrogen, 8D) 500 psig Argon, 9B) 100 psig

Hydrogen, and 10D) 100 psig Argon.

Table 4.10 Hydrogen balance of select pitches produced from hydrogenation reactions with different initial pressures and atmospheres: 5B) 1000 psig Hydrogen, 6D) 1000 psig Argon, 7A) 500 psig Hydrogen, 8D) 500 psig Argon, 9B) 100 psig Hydrogen, and 10D) 100 psig Argon

Table 4.11 Ash content of pitch and THF insoluble fractions of selected hydrogenation runs with decreasing solvent-to-coal ratio with reaction conditions of $\mathrm{HCO}$ solvent, $400{ }^{\circ} \mathrm{C}, 1000$ psig hydrogen, and 1 hour

Table 4.12 Elemental analysis of selected hydrogenation trials as the solvent-to-coal ratio was lowered but all other reaction conditions were kept constant at $\mathrm{HCO}$ solvent, $400{ }^{\circ} \mathrm{C}, 1000$ psig hydrogen, and 1 hour

Table A.1 Hydrogenation Reactants and Subsequent Product Masses

Table A.2 Hydrogenation Pitch Softening Point $\left(\mathrm{Tsp}^{\circ} \mathrm{C}\right)$ and Coke Yield and Ash Content of Pitch and Insoluble Fraction.

Table A.3 Reactor Pressures of Hydrogenation Reactions with DACL-L under conditions of $400{ }^{\circ} \mathrm{C}, 1000$ psig Hydrogen, 3/1 Solvent-to-Coal Ratio and 1 hour

Table A.4 Reactor Pressures of Hydrogenation Reactions with DACL-H under conditions of $400{ }^{\circ} \mathrm{C}, 1000$ psig Hydrogen, 3/1 Solvent-to-Coal Ratio and 1 hour 115

Table A.5 Reactor Pressures of Hydrogenation Reactions with RACL under conditions of $400{ }^{\circ} \mathrm{C}, 1000$ psig Hydrogen, 3/1 Solvent-to-Coal Ratio and 1 hour

Table A.6 Reactor Pressures of Hydrogenation Reactions with HCO under conditions of $400{ }^{\circ} \mathrm{C}, 1000$ psig Hydrogen, 3/1 Solvent-to-Coal Ratio and 1 hour....

Table A.7 Reactor Pressures of Hydrogenation Reactions with CBB under conditions of $400{ }^{\circ} \mathrm{C}, 1000$ psig Hydrogen, 3/1 Solvent-to-Coal Ratio and 1 hour.

Table A.8 Reactor Pressures of Hydrogenation Reactions with CBB under conditions of $400{ }^{\circ} \mathrm{C}, 1000$ psig Argon, 3/1 Solvent-to-Coal Ratio and 1 hour.

Table A.9 Reactor Pressures of Hydrogenation Reactions with CBB under conditions of $400{ }^{\circ} \mathrm{C}, 500$ psig Hydrogen, 3/1 Solvent-to-Coal Ratio and 1 hour 
Table A.10 Reactor Pressures of Hydrogenation Reactions with CBB under conditions of $400{ }^{\circ} \mathrm{C}, 500$ psig Argon, 3/1 Solvent-to-Coal Ratio and 1 hour..........................118

Table A.11 Reactor Pressures of Hydrogenation Reactions with CBB under conditions of $400{ }^{\circ} \mathrm{C}, 100$ psig Hydrogen, 3/1 Solvent-to-Coal Ratio and 1 hour....

Table A.12 Reactor Pressures of Hydrogenation Reactions with CBB under conditions of $400{ }^{\circ} \mathrm{C}, 100$ psig Argon, 3/1 Solvent-to-Coal Ratio and 1 hour. 119

Table C.1 Elemental Analysis Results from Select Hydrogenation Reactions 


\section{LIST OF FIGURES}

Figure 2.1 Crystalline Structure of Graphite [10] …...................................................6

Figure 2.2 Optical Textures of A) Isotropic and B) Anisotropic Semicokes...........................7

Figure 2.3 Distribution of Oxygen Functionality in Coals as a Function of Rank [40]............16

Figure 2.4 One Typical Molecular Unit in Coal [43] .......................................................16

Figure 2.5 Alternate routes for Coal Liquefaction [23] ..................................................18

Figure 2.6 Solvent Mediated Hydrogenolysis of a Strong Linkage in Coal [25] ...................21

Figure 2.7 Conceptual Reaction Sequences in Coal Liquefaction [5] .................................22

Figure 2.8 Effect of Carbon Content on Liquid Product Yield [15] ....................................25

Figure 2.9 Variation in the yield of benzene solubles with rank and reaction time [28]..........26

Figure 2.10 Wyodak Coal Conversion vs. Ash Content [40] …..........................................30

Figure 3.1 Vacuum distillation Apparatus for separating RACL into DACL-L and

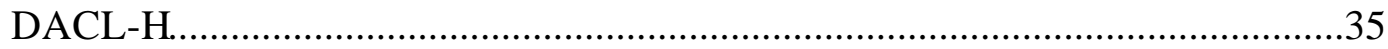

Figure 3.2 Experimental procedure flow sheet for production of carbon product

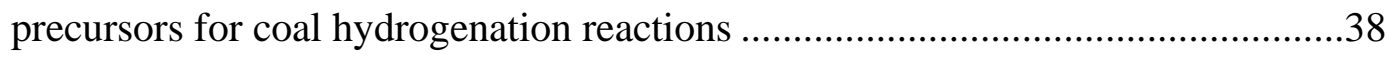

Figure 3.3 Overall view of the $50 \mathrm{~mL}$ tubing bomb microreactor....................................40

Figure 4.1 Comparison of the percent of the reaction feed recovered as THF solubles and

the total mass lost during each trial of hydrogenation run twelve (12)

Figure 4.2 The effect of the hydrogenation solvent on the overall conversion to THF

solubles at the reaction conditions of $400{ }^{\circ} \mathrm{C}, 1000 \mathrm{psig} \mathrm{H}_{2}$ (cold), $3 / 1$

solvent-to-coal ratio, and 1 hour

Figure 4.3 The effect of the hydrogenation solvent on the coal-alone conversion (daf

basis) of coal to THF solubles at the reaction conditions of $400{ }^{\circ} \mathrm{C}, 1000$

psig $\mathrm{H}_{2}$ (cold), 3/1 solvent-to-coal ratio, and 1 hour

Figure 4.4 Reactor pressures during coal hydrogenation reactions with coal-derived

solvents at reaction conditions of $400{ }^{\circ} \mathrm{C}, 1000 \mathrm{psig}_{2}$ (cold), 3/1 solvent-

to-coal ratio, and 1 hour

Figure 4.5 Effect of distillation on the softening point of the pitch resulting from hydrogenation reactions with coal-derived solvents at reaction conditions of $400{ }^{\circ} \mathrm{C}, 1000 \mathrm{psig}_{2}$ (cold), 3/1 solvent-to-coal ratio, and 1 hour. .65 
Figure 4.6 Effect of solvent choice on the hydrogenation product distribution with reaction conditions of $400{ }^{\circ} \mathrm{C}, 1000 \mathrm{psig}_{2}$ (cold), 3/1 solvent-to-coal ratio, and 1 hour.

Figure 4.7 Effect of hydrogenation solvent on the coke yield of the pitches resulting from hydrogenation reactions with the conditions of $400{ }^{\circ} \mathrm{C}, 1000 \mathrm{psig}_{2}$ (cold), 3/1 solvent-to-coal ratio, and 1 hour. Pitch softening point is around $120{ }^{\circ} \mathrm{C} \ldots . . .70$

Figure 4.8 Effect of softening point on the coke yield of pitches made from hydrogenation reactions using the five different coal-derived solvents under reaction conditions of $400{ }^{\circ} \mathrm{C}, 1000 \mathrm{psig}_{2}$ (cold), 3/1 solvent-to-coal ratio, and 1 hour.

Figure 4.9 Optical micrographs of cokes produced from pitches (with softening points around $120^{\circ} \mathrm{C}$ ) using different solvents during hydrogenation reactions with conditions of $400{ }^{\circ} \mathrm{C}, 1000$ psig $\mathrm{H}_{2}$ (cold), 3/1 solvent-to-coal ratio, and 1 hour and solvents A) DACL-L, B) DACL-H, C) RACL, D) HCO, and E) CBB.

Figure 4.10 Effect of initial reactor pressure and gaseous atmosphere on the overall conversion of hydrogenation reactions with $\mathrm{CBB}$ and reaction conditions of $400{ }^{\circ} \mathrm{C}, 3 / 1$ solvent-to-coal ratio, and 1 hour.....

Figure 4.11 Effect of initial reactor pressure and gaseous atmosphere on the coal-alone conversion of hydrogenation reactions with $\mathrm{CBB}$ and reaction conditions of $400{ }^{\circ} \mathrm{C}, 3 / 1$ solvent-to-coal ratio, and 1 hour .....

Figure 4.12 Average reactor pressures over time of hydrogenation reactions using CBB, 1000 psig initial hydrogen or argon pressure, $400{ }^{\circ} \mathrm{C}, 3 / 1$ solvent-to-coal ratio, and 1 hour .82

Figure 4.13 Average reactor pressures over time of hydrogenation reactions using CBB, 500 psig initial hydrogen or argon pressure, $400{ }^{\circ} \mathrm{C}, 3 / 1$ solvent-to-coal ratio, and 1 hour

Figure 4.14 Average reactor pressures over time of hydrogenation reactions using CBB, 100 psig initial hydrogen or argon pressure, $400{ }^{\circ} \mathrm{C}, 3 / 1$ solvent-to-coal ratio, and 1 hour 
Figure 4.15 Effect of initial reactor pressure and atmosphere on the product distribution of reactions run to produce a pitch with a softening point of $120^{\circ} \mathrm{C}$ under reaction conditions of $\mathrm{CBB}$ solvent, $400{ }^{\circ} \mathrm{C}, 3 / 1$ solvent-to-coal ratio, and 1 hour

Figure 4.16 Effect of raising the softening point of pitches produced under different atmospheres and initial reaction pressures on the coke yield with reaction conditions of $\mathrm{CBB}$ solvent, $400^{\circ} \mathrm{C}, 3 / 1$ solvent-to-coal ratio, 1 hour.

Figure 4.17 Optical micrographs of cokes produced from select pitches derived from hydrogenation products from reactions $\left(\mathrm{CBB}\right.$ solvent, $400^{\circ} \mathrm{C}, 3 / 1$ solventto-coal ratio, 1 hour) with varying initial pressures and atmospheres, A) 1000 psig Hydrogen, B) 1000 psig Argon, C) 500 psig Hydrogen, D) 500 psig Argon, E) 100 psig Hydrogen, and F) 100 psig Argon.....

Figure 4.18 Effect of solvent-to-coal ratio on the overall and coal-alone conversions of hydrogenation reactions performed with the HCO solvent under conditions of $400{ }^{\circ} \mathrm{C}, 1000$ psig Hydrogen, and 1 hour.

Figure 4.19 Effect of solvent-to-coal ratio on the amount of distillation required to achieve a specific softening point from hydrogenation reactions with conditions of $\mathrm{HCO}$ solvent, $400{ }^{\circ} \mathrm{C}, 1000$ psig hydrogen, and 1 hour

Figure 4.20 Effect of lowering the solvent-to-coal ratio on the pitch coke yield and various softening points from hydrogenation reactions with conditions of HCO solvent, $400{ }^{\circ} \mathrm{C}, 1000$ psig hydrogen, and 1 hour

Figure 4.21 Effect of pitch softening point on the coke yield for all pitch fractions produced under varying reaction conditions

Figure B.1 Photograph of coke produced from hydrogenation reaction 1A with DACL-L, $400{ }^{\circ} \mathrm{C}, 1000$ psig hydrogen, 3/1 solvent-to-coal ratio, 1 hour. Pitch has softening point of $129^{\circ} \mathrm{C}$.

Figure B.2 Photograph of coke produced from hydrogenation reaction 1D with DACL-L, $400{ }^{\circ} \mathrm{C}, 1000$ psig hydrogen, 3/1 solvent-to-coal ratio, 1 hour. Pitch has softening point of $165^{\circ} \mathrm{C}$. 
Figure B.3 Photograph of coke produced from hydrogenation reaction 2A with DACL$\mathrm{H}, 400{ }^{\circ} \mathrm{C}, 1000$ psig hydrogen, 3/1 solvent-to-coal ratio, 1 hour. Pitch has softening point of $78.3^{\circ} \mathrm{C}$.

Figure B.4 Photograph of coke produced from hydrogenation reaction 2B with DACL-H, $400{ }^{\circ} \mathrm{C}, 1000$ psig hydrogen, 3/1 solvent-to-coal ratio, 1 hour. Pitch has softening point of $87.6^{\circ} \mathrm{C}$.

Figure B.5 Photograph of coke produced from hydrogenation reaction $2 \mathrm{C}$ with DACL-H, $400{ }^{\circ} \mathrm{C}, 1000$ psig hydrogen, 3/1 solvent-to-coal ratio, 1 hour. Pitch has softening point of $126.5^{\circ} \mathrm{C}$.

Figure B.6 Photograph of coke produced from hydrogenation reaction 3A with RACL, $400{ }^{\circ} \mathrm{C}, 1000$ psig hydrogen, 3/1 solvent-to-coal ratio, 1 hour. Pitch has softening point of $135.1^{\circ} \mathrm{C}$.

Figure B.7 Photograph of coke produced from hydrogenation reaction 3B with RACL, $400{ }^{\circ} \mathrm{C}, 1000$ psig hydrogen, 3/1 solvent-to-coal ratio, 1 hour. Pitch has softening point of $120.2^{\circ} \mathrm{C}$. 122

Figure B.8 Photograph of coke produced from hydrogenation reaction 3C with RACL, $400{ }^{\circ} \mathrm{C}, 1000$ psig hydrogen, 3/1 solvent-to-coal ratio, 1 hour. Pitch has softening point of $161.0^{\circ} \mathrm{C}$.

Figure B.9 Photograph of coke produced from hydrogenation reaction 3D with RACL, $400{ }^{\circ} \mathrm{C}, 1000$ psig hydrogen, 3/1 solvent-to-coal ratio, 1 hour. Pitch has softening point of $118.7^{\circ} \mathrm{C}$.

Figure B.10 Photograph of coke produced from hydrogenation reaction 4B with HCO, $400{ }^{\circ} \mathrm{C}, 1000$ psig hydrogen, 3/1 solvent-to-coal ratio, 1 hour. Pitch has softening point of $172.2^{\circ} \mathrm{C}$.

Figure B.11 Photograph of coke produced from hydrogenation reaction $4 \mathrm{C}$ with $\mathrm{HCO}$, $400{ }^{\circ} \mathrm{C}, 1000$ psig hydrogen, 3/1 solvent-to-coal ratio, 1 hour. Pitch has softening point of $119.4^{\circ} \mathrm{C}$.

Figure B.12 Photograph of coke produced from hydrogenation reaction 4D with HCO, $400{ }^{\circ} \mathrm{C}, 1000$ psig hydrogen, 3/1 solvent-to-coal ratio, 1 hour. Pitch has softening point of $153.4^{\circ} \mathrm{C}$. 123 
Figure B.13 Photograph of coke produced from hydrogenation reaction 4E with HCO, $400{ }^{\circ} \mathrm{C}, 1000$ psig hydrogen, 3/1 solvent-to-coal ratio, 1 hour. Pitch has softening point of $129.7^{\circ} \mathrm{C}$.

Figure B.14 Photograph of coke produced from hydrogenation reaction 5A with CBB, $400{ }^{\circ} \mathrm{C}, 1000$ psig hydrogen, 3/1 solvent-to-coal ratio, 1 hour. Pitch has softening point of $109.2^{\circ} \mathrm{C}$.

Figure B.15 Photograph of coke produced from hydrogenation reaction 5B with CBB, $400{ }^{\circ} \mathrm{C}, 1000$ psig hydrogen, 3/1 solvent-to-coal ratio, 1 hour. Pitch has softening point of $126.9^{\circ} \mathrm{C}$.

Figure B.16 Photograph of coke produced from hydrogenation reaction 5C with CBB, $400{ }^{\circ} \mathrm{C}, 1000$ psig hydrogen, 3/1 solvent-to-coal ratio, 1 hour. Pitch has softening point of $153.6^{\circ} \mathrm{C}$.

Figure B.17 Photograph of coke produced from hydrogenation reaction 5D with CBB, $400{ }^{\circ} \mathrm{C}, 1000$ psig hydrogen, $3 / 1$ solvent-to-coal ratio, 1 hour. Pitch has softening point of $106.1^{\circ} \mathrm{C}$. 125

Figure B.18 Photograph of coke produced from hydrogenation reaction 6A with CBB, $400{ }^{\circ} \mathrm{C}, 1000$ psig argon, 3/1 solvent-to-coal ratio, 1 hour. Pitch has softening point of $105.2^{\circ} \mathrm{C}$.

Figure B.19 Photograph of coke produced from hydrogenation reaction 6B with CBB, $400{ }^{\circ} \mathrm{C}, 1000$ psig argon, 3/1 solvent-to-coal ratio, 1 hour. Pitch has softening point of $146.8^{\circ} \mathrm{C}$.

Figure B.20 Photograph of coke produced from hydrogenation reaction 6D with CBB, $400{ }^{\circ} \mathrm{C}, 1000$ psig argon, 3/1 solvent-to-coal ratio, 1 hour. Pitch has softening point of $119.3^{\circ} \mathrm{C}$.

Figure B.21 Photograph of coke produced from hydrogenation reaction 7A with CBB, $400{ }^{\circ} \mathrm{C}, 500$ psig hydrogen, $3 / 1$ solvent-to-coal ratio, 1 hour. Pitch has softening point of $113.2^{\circ} \mathrm{C}$. 126

Figure B.22 Photograph of coke produced from hydrogenation reaction 7B with CBB, $400{ }^{\circ} \mathrm{C}, 500$ psig hydrogen, 3/1 solvent-to-coal ratio, 1 hour. Pitch has softening point of $158.4^{\circ} \mathrm{C}$. 126 
Figure B.23 Photograph of coke produced from hydrogenation reaction 7C with CBB, $400{ }^{\circ} \mathrm{C}, 500$ psig hydrogen, $3 / 1$ solvent-to-coal ratio, 1 hour. Pitch has softening point of $142.4^{\circ} \mathrm{C}$.

Figure B.24 Photograph of coke produced from hydrogenation reaction 7D with CBB, $400{ }^{\circ} \mathrm{C}, 500$ psig hydrogen, $3 / 1$ solvent-to-coal ratio, 1 hour. Pitch has softening point of $97.5^{\circ} \mathrm{C}$.

Figure B.25 Photograph of coke produced from hydrogenation reaction 8A with CBB, $400{ }^{\circ} \mathrm{C}, 500$ psig argon, 3/1 solvent-to-coal ratio, 1 hour. Pitch has softening point of $86.6^{\circ} \mathrm{C}$.

Figure B.26 Photograph of coke produced from hydrogenation reaction 8B with CBB, $400{ }^{\circ} \mathrm{C}, 500$ psig argon, 3/1 solvent-to-coal ratio, 1 hour. Pitch has softening point of $172.9^{\circ} \mathrm{C}$.

Figure B.27 Photograph of coke produced from hydrogenation reaction $8 \mathrm{C}$ with $\mathrm{CBB}$, $400{ }^{\circ} \mathrm{C}, 500$ psig argon, 3/1 solvent-to-coal ratio, 1 hour. Pitch has softening point of $108.9^{\circ} \mathrm{C}$.

Figure B.28 Photograph of coke produced from hydrogenation reaction 8D with CBB, $400{ }^{\circ} \mathrm{C}, 500$ psig argon, 3/1 solvent-to-coal ratio, 1 hour. Pitch has softening point of $132.5^{\circ} \mathrm{C}$.

Figure B.29 Photograph of coke produced from hydrogenation reaction 9A with CBB, $400{ }^{\circ} \mathrm{C}, 100$ psig hydrogen, $3 / 1$ solvent-to-coal ratio, 1 hour. Pitch has softening point of $73.9^{\circ} \mathrm{C}$.

Figure B.30 Photograph of coke produced from hydrogenation reaction 9B with CBB, $400{ }^{\circ} \mathrm{C}, 100$ psig hydrogen, $3 / 1$ solvent-to-coal ratio, 1 hour. Pitch has softening point of $123.6^{\circ} \mathrm{C}$. 128

Figure B.31 Photograph of coke produced from hydrogenation reaction 9C with CBB, $400{ }^{\circ} \mathrm{C}, 100$ psig hydrogen, $3 / 1$ solvent-to-coal ratio, 1 hour. Pitch has softening point of $132.0^{\circ} \mathrm{C}$. 128

Figure B.32 Photograph of coke produced from hydrogenation reaction 10A with CBB, $400{ }^{\circ} \mathrm{C}, 100$ psig argon, 3/1 solvent-to-coal ratio, 1 hour. Pitch has softening point of $81.1^{\circ} \mathrm{C}$. 128 
Figure B.33 Photograph of coke produced from hydrogenation reaction 10B with CBB, $400{ }^{\circ} \mathrm{C}, 100$ psig argon, 3/1 solvent-to-coal ratio, 1 hour. Pitch has softening point of $159.1{ }^{\circ} \mathrm{C}$.

Figure B.34 Photograph of coke produced from hydrogenation reaction 10C with CBB, $400{ }^{\circ} \mathrm{C}, 100$ psig argon, $3 / 1$ solvent-to-coal ratio, 1 hour. Pitch has softening point of $103.9{ }^{\circ} \mathrm{C}$.

Figure B.35 Photograph of coke produced from hydrogenation reaction 10D with CBB, $400{ }^{\circ} \mathrm{C}, 100$ psig argon, 3/1 solvent-to-coal ratio, 1 hour. Pitch has softening point of $120.3^{\circ} \mathrm{C}$.

Figure B.36 Photograph of coke produced from hydrogenation reaction 11A with HCO, $400{ }^{\circ} \mathrm{C}, 1000$ psig hydrogen, $2 / 1$ solvent-to-coal ratio, 1 hour. Pitch has softening point of $140.6^{\circ} \mathrm{C}$.

Figure B.37 Photograph of coke produced from hydrogenation reaction 11B with HCO, $400{ }^{\circ} \mathrm{C}, 1000$ psig hydrogen, 2/1 solvent-to-coal ratio, 1 hour. Pitch has softening point of $127.5^{\circ} \mathrm{C}$.

Figure B.38 Photograph of coke produced from hydrogenation reaction $11 \mathrm{C}$ with $\mathrm{HCO}$, $400{ }^{\circ} \mathrm{C}, 1000$ psig hydrogen, $2 / 1$ solvent-to-coal ratio, 1 hour. Pitch has softening point of $167.5^{\circ} \mathrm{C}$.

Figure B.39 Photograph of coke produced from hydrogenation reaction 11D with HCO, $400{ }^{\circ} \mathrm{C}, 1000$ psig hydrogen, $2 / 1$ solvent-to-coal ratio, 1 hour. Pitch has softening point of $154.2^{\circ} \mathrm{C}$.

Figure B.40 Photograph of coke produced from hydrogenation reaction 12A with HCO, $400{ }^{\circ} \mathrm{C}, 1000$ psig hydrogen, $1 / 1$ solvent-to-coal ratio, 1 hour. Pitch has softening point of $162.1^{\circ} \mathrm{C}$.

Figure B.41 Photograph of coke produced from hydrogenation reaction 12B with HCO, $400{ }^{\circ} \mathrm{C}, 1000$ psig hydrogen, $1 / 1$ solvent-to-coal ratio, 1 hour. Pitch has softening point of $127.3{ }^{\circ} \mathrm{C}$.

Figure B.42 Photograph of coke produced from hydrogenation reaction $12 \mathrm{C}$ with $\mathrm{HCO}$, $400{ }^{\circ} \mathrm{C}, 1000$ psig hydrogen, 1/1 solvent-to-coal ratio, 1 hour. Pitch has softening point of $124.6^{\circ} \mathrm{C}$. 


\section{CHAPTER 1 INTRODUCTION}

The element carbon is used in the production of many materials on which our daily lives depend. Examples of such materials are plastics, pharmaceuticals, iron, steel and aluminum. However, the amount of carbon found on earth represents only $0.04 \%$ of the total mass of the earth [17]. Half of this carbon is in a non-reactive form, such as carbon dioxide and carbonate materials. The remainder of the earth's carbon is concentrated in various fossil fuels, including coal, petroleum, and natural gas [17]. These fossil fuels are the predominant source of energy and feedstock for the production of chemicals in the world today [32].

Although the major use of fossil fuels is the production of energy, these materials are extremely important in their non-fuel uses. Currently, products derived from the petroleum industry dominate the non-fuel uses of fossil fuels [32]. These products include the production of petrochemicals, asphalt and road tar, waxes, liquefied petroleum gases, and petroleum coke. However, petroleum reserves are declining rapidly, and the concentration of impurities such as sulfur, vanadium, and nickel, in the petroleum reserves is on the rise.

One alternative source of carbon for the production of carbon artifacts could come from coal. The known reserves of coal are expected to significantly outlast those of petroleum. Currently, several non-fuel uses of coal include high-temperature carbonization for the production of metallurgical coke, gasification to produce synthesis gases, activated carbons, coal tar, and coal tar pitch. Most carbon product feedstocks from coal are derived from by-products from the metallurgical coke industry. During the process of high temperature carbonization, the volatiles are captured and condensed into coal tar. The recovered coal tar can then be processed by distillation to carbon feedstock such as tar acids, tar bases, naphthalene, creosote oils, and coal tar pitch. 
Coal tar pitch is generally defined as the solid residue remaining after the removal of oils from coal tar by distillation. This pitch has many different uses in industry today. It is used as a binder in the production of carbon electrodes for electric furnaces and anodes for the aluminum industry. Coal tar pitch can be used to impregnate carbon artifacts when high density and strength are necessary. It can also be used as a carbon feedstock for the production of carbon fibers, nuclear graphite, and carbon composites.

One disadvantage to the use of coal tar pitch is that it is derived as a by-product of the carbonization process of coal. The amount of coal tar produced from one ton of coal is on the order of $4 \mathrm{wt} \%$ of the original coal (Table 1.1). Moreover, coal tar pitch accounts for only approximately $50 \mathrm{wt} \%$ of coal tar, or approximately $2 \mathrm{wt} \%$ of the original coal [45]. This disadvantage is magnified by the fact that the production of metallurgical coke by carbonization is declining in the United States by 3-4\% per year due to increased imports, decreasing coke demand, and environmental regulations placed on existing coke ovens [1]. In order to compensate for the decrease in pitch derived from coal tar and the dwindling supply of petroleum, these precursors for carbon products could be produced directly from coal.

Table 1.1 Production Yields from Coal Carbonization [34]

\begin{tabular}{|c|c||}
\hline Yield from 1 ton of coal & Weight \% \\
\hline \hline 1520 lbs coke & 76 \\
\hline 78 lbs tar & 4 \\
\hline 20 lbs light oil & 1 \\
\hline 20 lbs ammonium sulfate & 14 \\
\hline 280 lbs gas & 4 \\
\hline 80 lbs miscellaneous & 1 \\
\hline \hline
\end{tabular}

One avenue to the production of carbon product precursors from coal is through the liquefaction of coal. Liquefaction has two general methods of producing carbon products: direct and indirect liquefaction. Indirect liquefaction converts coal into synthesis gas: carbon monoxide and hydrogen. These gases are then reformed to 
produce various hydrocarbons. In direct liquefaction, or hydrogenation, coal is thermally treated in the presence of hydrogen or a hydrogen-rich donor solvent to produce low molecular-weight organic species.

In previous work at West Virginia University, coal-derived pitches have been obtained by combining coal hydrogenation (liquefaction) and solvent extraction [34]. In these experiments, coal was hydrogenated in the presence of tetralin $(1,2,3,4-$ tetrahydronaphthalene). This solvent has been well studied in the past and proven to be a very effective hydrogen donor in the presence of coal. However, during liquefaction reactions tetralin is converted into naphthalene and cannot be used as a recyclable solvent without external separation and rehydrogenation.

One alternative to using tetralin in the liquefaction reactions is to employ a coalderived liquid as the liquefaction solvent. Making this substitution would have two possible advantages: (1) the possibility of producing a recyclable solvent during the product separation steps thus eliminating the need to supply an external solvent and (2) the process would employ only coal and coal products as starting materials, thus generating a completely coal-derived carbon product precursor. Thus, the evaluation of five coal-derived liquids as liquefaction solvents for the production of carbon product precursors is presented in this thesis report.

\subsection{Research Objectives}

Five different coal-derived liquids have been collected for testing as liquefaction solvents in order to produce precursors for carbon products. The first three of these liquids are fractions of a process-derived coal liquid from Antaeus Technical Services, Inc. in Alloy, West Virginia. This coal liquid is a mid-distillate by-product from the pyrolysis of an Eastern caking-type bituminous coal to produce high quality char. The fourth and fifth coal liquids are heavy creosote oil and carbon black base \#1, obtained from Koppers Industries, Inc. in Pittsburgh, Pennsylvania. Both of these liquids are distillate fractions of coal tar derived from the production of metallurgical coke. 
The products of the liquefaction reactions were separated into three different fractions: unconverted coal, carbon pitch, and a possible recycle solvent. The resultant carbon pitch was tested as a precursor of carbon products. This was done using standard test procedures such as softening point, ash determination, coking value, and optical texture. Using these parameters, the products from the direct liquefaction of coal can be compared to cokes and pitches of commercial value today. 


\section{CHAPTER 2}

\section{BACKGROUND}

This chapter is dedicated to explaining some of the general concepts that are pertinent to the present thesis research. A general description of carbon, its properties, types of carbon artifacts, and their importance to industry is discussed. Also a brief review of coal formation, properties, and classification is presented. Finally, the concepts that govern the production of carbon artifacts from coal by direct liquefaction are discussed.

\subsection{Carbon and Carbon Products}

Carbon is a unique element that is essential in the industrial world today. In its various forms, carbon is used as a feedstock for chemicals and plastics, a transportation fuel, in the production of anodes and electrodes for metal reduction, carbon fibers, and other applications too numerous to list here. The diversity of uses for carbon stems from its ability not only to form bonds with elements such as hydrogen, oxygen, nitrogen, sulfur, and others, but its amazing ability to form a variety of bonds with itself. The ability for carbon to form bonds is so diverse, that it has spawned its own discipline in chemistry, organic chemistry.

Elemental carbon has the ability to take on three different crystalline forms: diamond, graphite, and fullerenes. The carbon in diamond is tetrahedrally bonded while fullerenes are bonded in the shape of a soccer ball, with hexagons and pentagons of carbon atoms. However, the most naturally occurring form of carbon is in the crystalline structure of graphite. In graphite, the carbon atoms are in a $\mathrm{sp}^{2}$ spatial arrangement and trigonally bonded in planar sheets. These planar sheets are normally found in the hexagonal $\mathrm{ABAB}$ sequence but can occur in the rhombohedral $\mathrm{ABCABC}$ sequence (Figure 2.1). 


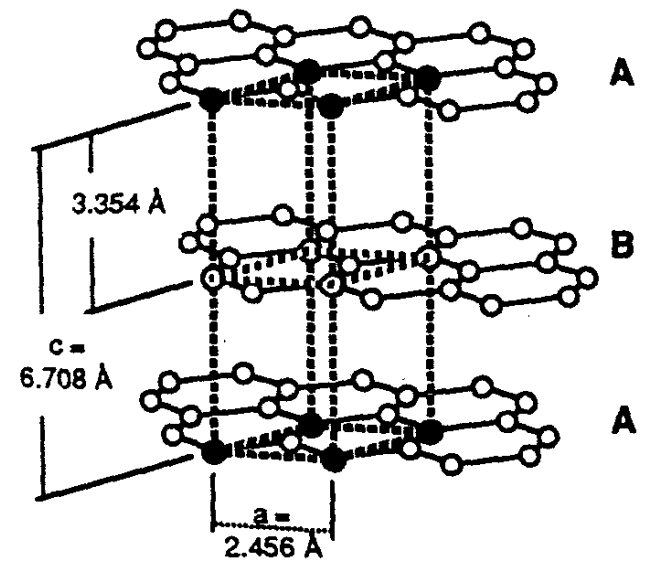

Hexagonal Unit Cell

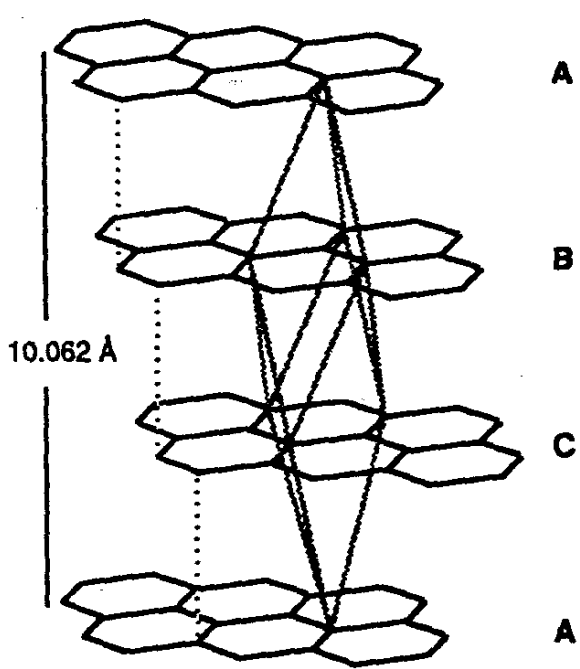

Rhombohedral stacking

Figure 2.1 Crystalline Structure of Graphite [10]

Graphite in its ideal form would have no faults in its layers of carbon planes. The carbon atoms are held together within the planes by covalent bonds, while the planes are held together by much weaker Van der Waal's forces. The diversity of graphitic properties, such as thermal conductivity, hardness, porosity, electrical conductivity, surface effects, and chemical reactivity, can be attributed to the difference in the parallel and perpendicular bond strengths in graphite. The ability to control the crystal structure allows for the production of different carbon products in industry. Usually artificial graphite is formed by the mixture of a highly-ordered material with amorphous or lessordered material. The higher the degree of order, or ideally graphitic, the more anisotropic the carbon artifact will be. At the other end of the spectrum is an isotropic artifact with more deviations from the ideal graphite structure. The anisotropy or isotropy can be observed by optical microscopy and is an important property in determining the end use of the carbon artifact. Figure 2.2 shows photomicrographs representing isotropic and anisotropic textures.

Industrial carbon artifacts are based on the graphite structure. Precursors to carbon materials can be considered as being graphitizable or non-graphitizable. Graphitizable carbons are materials that when subjected to a high temperature treatment 
are converted to graphitic carbons. These materials are usually rich in hydrogen and low in oxygen. Non-graphitizable carbons are those that are not converted to a graphitic structure after heat treatment. These materials are usually low in hydrogen and rich in oxygen and form a rigid disordered structure when heated. Example of such carbons are wood, non-fusing coals, and cross-linked polymers.

\subsection{Pitches}

Currently, the majority of coal-based carbon pitches are derived as by-products from the production of metallurgical coke in the recovery coke oven. The volatile products of the carbonization process are condensed to form coal tar. Pitch is defined as the substance that is left after distillation of the coal tar to remove the heavy creosote and anthracene oils. Pitch is a complex mixture of organic compounds that are predominately polycyclic aromatic hydrocarbons.

Pitches can also be made from petroleum. One type of petroleum pitch is a byproduct obtained from the catalytic cracking process. Petroleum pitch can be produced from these heavy residues by thermal treatment, vacuum or steam stripping, oxidation, or distillation. The types of pitch that are produced depend on the treatment of the residues. Usually, longer treatment times and higher treatment temperatures result in a higher aromatic pitch with a more anisotropic texture.
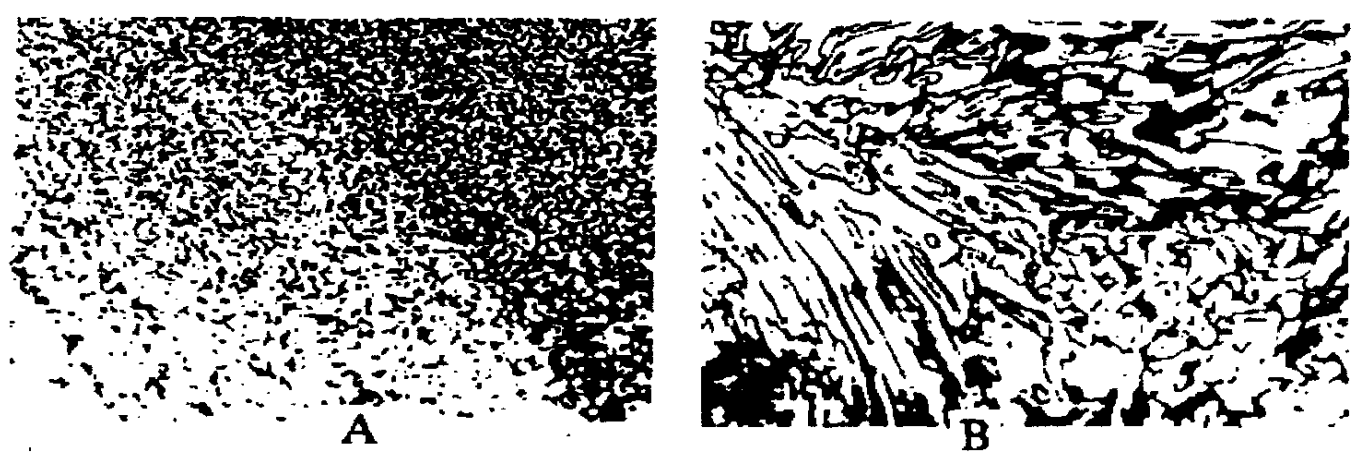

Figure 2.2 Optical Textures of A) Isotropic and B) Anisotropic Semicokes 
Another type of pitch that can be formed is mesophase pitch. This pitch exists in a state where the macromolecular components exhibit both an ordered solid state and a fluid liquid. These pitches are highly oriented and can be used to produce high modulus fibers and carbon composites. Mesophase pitches can form when anisotropic pitch is heated above $350{ }^{\circ} \mathrm{C}$. After melting, the pitch undergoes dehydrogenative condensation to increase the pitch aromaticity. The increase in aromaticity produces larger, more planar molecules, which begin to associate with each other. During the early stages of this association, the molecules come together to form tiny anisotropic spheres of liquid crystalline-like materials. These spheres increase in size as the aromatic molecules of the isotropic pitch are incorporated in the growing mesophase sphere. As these spheres collide, they coalesce to form larger spheres in order to minimize surface energy until the pitch becomes $100 \%$ bulk mesophase.

The physical and chemical properties of pitch determine its end use. Pitch can be used as a binder in the production of anodes and electrodes to hold coke particles together. This type of pitch needs to have a high-carbon yield and not affect the properties of the finished product. Some characteristic properties of binder and impregnating pitch from coal and petroleum are shown in Table 2.1. Pitch can also be used to reduce the porosity of carbon products where high density and strength are required. This type of impregnation pitch should have a low viscosity and low ash content. The production of carbon fibers is another possible use for carbon. This type of pitch requires a low solids content, a low softening point for ease of spinning, and high reactivity toward stabilization.

\subsection{Cokes}

Metallurgical coke is produced by high-temperature carbonization of coal. This requires heating of the coal in the absence of air to produce a solid carbon residue. This process also gives off gaseous and condensable hydrocarbon by-products. The solid residue is metallurgical coke and is used to produce pig iron from iron ore in a blast furnace. 
Table 2.1 Characteristics of Various Commercial Pitches [13]

\begin{tabular}{||c|c|c|c|c|c|c||}
\hline & \multicolumn{3}{|c|}{ Binder Pitch } & \multicolumn{3}{c|}{ Impregnating Pitch } \\
\hline Supplier & Allied & Aristech & Koppers & Ashland & Kawasaki & $\begin{array}{c}\text { Mitsubishi } \\
\text { Kasai }\end{array}$ \\
\hline $\begin{array}{c}\text { Feedstock } \\
\text { Base }\end{array}$ & Coal Tar & Coal Tar & Coal Tar & Petroleum & Coal Tar & Coal \\
\hline $\begin{array}{c}\text { Softening } \\
\text { Point }\left({ }^{\circ} \mathrm{C}\right)\end{array}$ & 109.1 & 109.8 & 110.3 & 121.1 & 99.5 & 95.3 \\
\hline $\begin{array}{c}\text { Coking } \\
\text { Value (\%wt) }\end{array}$ & 58.5 & 57.6 & 58.0 & 49.1 & 50.0 & 44.3 \\
\hline $\begin{array}{c}\text { Ash Content } \\
(\% \mathrm{wt})\end{array}$ & 0.17 & 0.16 & 0.21 & 0.03 & 0.00 & 0.003 \\
\hline $\begin{array}{c}\text { Sulfur (\%wt) } \\
\text { Carbon } \\
(\% \mathrm{wt})\end{array}$ & 0.61 & 0.62 & 0.59 & 3.1 & 0.41 & 0.43 \\
\hline $\begin{array}{c}\text { Hydrogen } \\
(\% \mathrm{wt})\end{array}$ & 3.66 & 4.42 & 3.92 & 5.08 & 4.44 & 4.27 \\
\hline$\% \mathrm{H}_{\text {aromatic }}$ & 85.4 & 85.8 & 86.0 & 55.5 & 86.1 & 82.8 \\
\hline
\end{tabular}

Petroleum coke is produced by upgrading the heavy fractions of crude oil which are formed during petroleum processing. The residue or heavy fractions can be converted to petroleum coke by several coking methods. However, the most common process is the delayed coking process. High-grade coke from petroleum is consumed by the aluminum industry in order to reduce aluminum oxide to aluminum. Petroleum coke can also be used to produce graphite electrodes and some carbon-carbon composites.

The properties of the coke determine its specific end use. There are two different types of coke: anisotropic and isotropic. The anisotropic cokes have large crystallite domain sizes while the isotropic cokes have a fine-grained texture (see Figure 2.2). Anisotropic coke is employed in the manufacture of graphite electrodes, which are capable of carrying large electrical currents at high temperature in the electric-arc furnace. The isotropic cokes are more suited for nuclear graphite. This graphite requires a high chemical purity to avoid the adsorption of low-energy neutrons. Also, because the 
isotropic coke has no preferred bulk orientation, the graphite will have a high dimensional stability especially when heated.

\subsection{Characterization Techniques for Cokes and Pitches}

Because the physical and chemical properties of coke and pitch samples determine the end use of that substance, it is important to present a brief discussion on some of the more common characterization techniques. Some of the different techniques are softening point, ash content, coking value, optical microscopy, and x-ray diffraction. However, not all are used in the present thesis research.

\subsubsection{Softening Point}

Because pitch samples do not exhibit a specific phase transition from a solid to a liquid upon heating, a distinct melting point cannot be ascertained. However, as a pitch is heated, the viscosity of the sample begins to decrease. The softening point is the temperature at which the sample reaches a low enough viscosity to flow a prescribed distance (see Section 3.3.1 for more detail). The measurement gives some insight into the consistency of the sample and can be beneficial in determining its end use. The softening point is a crucial property for pitches, which are used as binders, impregnating agents, and fiber precursors.

\subsubsection{Ash Content}

The ash content determines the amount of impurities present in the pitch sample. These impurities are derived from the inorganic material present in the original coal sample. These inorganic materials are converted to inorganic oxides during the combustion process of the ash content test (Section 3.3.3). The combustion process removes all the organic matter from the pitch sample and leaves behind the inorganic 
matter. Because these inorganic oxides are considered impurities in the final carbon artifacts, it is important for the ash content of the pitch to be low.

\subsubsection{Coking Value}

The determination of a pitch's coking value is extremely important to its possible commercial applications. The coke yield determines the amount of carbon residue remaining after hydrogen and volatile matter are removed by thermal treatment. The heating process (up to $600{ }^{\circ} \mathrm{C}$, see Section 3.3.2) eliminates these volatiles and then the pitch is transformed into a semicoke. The semicoke is then converted to coke when the sample contracts and carbonization is complete. Most commercial applications require a coke yield of 50 to 60 percent by weight.

\subsubsection{Optical Microscopy}

Once a coke sample has been formed, the optical texture can be determined by optical microscopy with a polarized-light microscope. The optical texture gives some insight into the surface and graphitization properties of the coke sample. The texture can range from an isotropic carbon (small, uniform domains) to anistropic carbon (large, elongated domains). The commercial application of the coke sample depends on where it falls in the range of isotropic to anisotropic texture.

\subsubsection{X-ray Diffraction}

X-ray diffraction can be used to determine the bulk structure of carbon materials. This technique can also indicate the amount of ordered material present and the crystallite size of the ordered structures. The x-ray diffraction measurement is determined by placing the sample in powder form in a capillary or spread on a flat sample holder. An xray beam is then aimed at the sample and the diffracted x-rays are recorded on film or 
with a diffractometer. This technique can also estimate the average particle size of the sample and give some insight into the amount of strain or defects in the crystal lattice.

\subsection{Carbon Products from Coal}

In this section, a review of basic concepts defining the art of producing carbon products directly from coal is discussed. In order to accomplish this, one must first have a basic knowledge of coal, including its method of formation, composition, classification, and structure. This section also describes the differences between coal and its major competitor, petroleum. Several different methods of upgrading are discussed, such as pyrolysis, indirect liquefaction, and direct liquefaction.

\subsubsection{Coal - Formation, Composition, and Classification}

Coal can be defined in many different ways. Gibson's definition, that coal "consists of a complex mixture of organic chemical substances containing carbon, hydrogen, and oxygen in chemical combination, together with smaller amounts of nitrogen and sulphur," describes the chemical composition of coal [17]. On the other hand, Francis [16] describes coal by explaining its origin when he states that coal is "a compact stratified mass of mummified plants which have been modified chemically in varying degree, interspersed with smaller amounts of inorganic matter." Both of these definitions can be related by reviewing coal formation, composition, and classification.

The formation of coal entails two different stages, the diagnetic or biochemical stage and the geochemical stage. The diagnetic stage begins with the formation of peat beds as plant material settles in low, swampy areas. At this stage, bacteria and fungi begin to decompose the plant material by removing oxygen and hydrogen by giving off water, carbon dioxide, and methane. The biochemical stage of coal formation ends as more and more sediment begins to cover the peat layer. As the peat is further submerged and the sediment layer reaches a height of approximately 40 centimeters, bacteria and 
fungi cease to exist, thus ending the diagnetic stage [37]. During the first stage of coalification, the carbon content of material is raised from $40-45$ percent to greater than 60 percent [6].

The second stage of coalification is the geochemical stage. During this stage, the peat bed undergoes further metamorphosis due to temperature and pressure from further layers of sediment depositing on top of the peat bed. Oxygen and hydrogen are again eliminated as methane, carbon dioxide, and water. As this occurs, the carbon content is slowly increased, however, all coals are not subjected to the same amount of coalification. This gives rise to a series of coalification (shown below) that ranges from lignite to anthracite.

$$
\text { peat } \rightarrow \text { lignite } \rightarrow \text { sub-bituminous } \rightarrow \text { bituminous } \rightarrow \text { anthracite }
$$

Because coal is made from different types of organic material from plants, the composition of coal can vary widely. There are two different ways that one can describe the composition of coal, physically and chemically. Physical classification of coal is derived from the observation that one piece of coal is made up of different "banded components." These components or lithotypes were classified by Stopes in 1919 as vitrain, clarain, durain, and fusain [35]. Lithotypes can be further broken into smaller microscopic entities called macerals. There are three main groups of macerals, vitrinite, exinite, and inertinite. Vitrinite is derived from woody tissues at various levels of decomposition. Exinite or liptinite comes from spores and pollen coats, cuticles, resins, and other fatty secretions. Inertinites are derived from plant tissues that have been partially carbonized in the peat stage of coalification.

Defining the chemical composition of coal entails the use of an ultimate and proximate analysis. Ultimate or elemental analysis is a quantitative determination of the amount of carbon, nitrogen, hydrogen, sulfur, and oxygen that are present in the coal. The proximate analysis assesses the change in the weight of coal as the sample is heated. Proximate analysis determines the amount of fixed carbon, moisture, ash, and volatile 
matter that is present in the original coal sample. This method of determining chemical composition is significant for its use in classifying coals by rank.

Coal rank varies from anthracite through bituminous and sub bituminous to lignite with anthracite being the highest or most mature rank of coal. The American Society for Testing and Materials (ASTM) classifies coal by the amount of fixed carbon or volatile matter for medium-volatile bituminous through anthracite. The lower ranked coals, lignite through high-volatile A bituminous, are ranked by their heating value. The ASTM classifications can be seen in Table 2.2.

As the amount of carbon decreases with decreasing rank, other elements must fill in the remaining structure. The hydrogen and oxygen content increase with decreasing coal rank, but the nitrogen and sulfur content vary little with rank. Instead, the abundance of these two elements depends on where the coal was formed. The elemental composition of coal of varying rank can be seen in Table 2.3. It can be seen as coal rank decreases that the hydrogen-to-carbon ratio increases. Also, the amount of oxygen compared to carbon decreases with increasing rank. However, the levels of nitrogen and sulfur atoms remain low for all ranks of coal. All of these elements are bonded together to form various aromatic rings, aliphatic chains, and functional groups.

The majority of the functional groups that are present in coal are those that include oxygen. These types of functional groups include phenols, alcohols, ethers, carboxylic acids, and carbonyls. There has been significant study in the literature on correlating the mineral- and ash-free carbon content of coal to the relative amount of each of these functional groups. Whitehurst et al. [40] show the outcome of these correlations in Figure 2.3. Using these correlations along with the relative abundance of each atom, a complex model of a basic coal structure was proposed by Wiser [43]. This model is shown in Figure 2.4. Weak bonds in the coal structure are identified by the arrows in Figure 2.4. Coal liquefaction and dissolution requires breaking the molecular structure of coal into small soluble fragments at these weak bonds. 
Table 2.2 The ASTM System for Classifying Coals by Rank [31]

\begin{tabular}{||c|c|c|c|c||}
\hline Class & Group & Fixed Carbon & Volatile Matter $^{\mathrm{a}}$ & Heating Value $^{\mathrm{b}}$ \\
\hline Anthracite & Metaanthracite & $>98$ & $<2$ & \\
\hline & Anthracite & $92-98$ & $2-8$ & \\
\hline & Semianthracite & $86-92$ & $8-14$ & \\
\hline Bituminous & Low-volatile & $78-86$ & $14-22$ & \\
\hline & Medium-volatile & $69-78$ & $22-31$ & \\
\hline & High-volatile A & $<69$ & $>31$ & $>14,000$ \\
\hline & High-volatile B & & & $13,000-14,000$ \\
\hline & High-volatile C & & & $10,500-13,000$ \\
\hline Sub bituminous & Sub bituminous & & & $10,500-11,500$ \\
\hline & Sub bituminous & & & $9,500-10,500$ \\
\hline & Sub bituminous & & & $6,300-9,500$ \\
\hline & Lignite A & & & $<, 300-8,300$ \\
\hline Lignitic & Lignite B & & & $<6,300$ \\
\hline
\end{tabular}

Note: This classification system is based on ASTM standard D 388-66, which is published annually by ASTM in their compilation of

standards. ${ }^{a}$ The fixed carbon and volatile matter, reported as percentages, are determined on a dry, mineral-free basis. The mineral matter is calculated from the ass content by the Parr formula: mineral matter $=1.08$ [percent ash +0.55 (percent sulfur)] ${ }^{\mathrm{b}}$ The heating value, reported in British thermal units per pound, is expressed on a moist, mineral-free basis. The moisture content is the bed moisture or equilibrium moisture of the coal after equilibration with nominally $100 \%$ relative humidity atmosphere. Some overlap occurs in the heating-value range of sub bituminous $\mathrm{A}$ and high volatile $\mathrm{C}$ coals. Coals with heating values between 10,500 and 11,500 are classified as high volatile $\mathrm{C}$ bituminous if they display caking properties and as sub bituminous $\mathrm{A}$ if they do not.

Table 2.3 Percent Elemental Composition of Various Coal Ranks [11]

\begin{tabular}{||l|c|c|c|c|c||}
\hline & \multicolumn{5}{|c|}{ Element, \%wt (dry ash-free basis) } \\
\hline Sample & $\mathrm{C}$ & $\mathrm{H}$ & $\mathrm{O}$ & $\mathrm{N}$ & $\mathrm{S}$ \\
\hline \hline Meta-anthracite & 97.9 & 0.21 & 1.7 & 0.2 & - \\
\hline Anthracite & 95.9 & 0.89 & 1.8 & 0.3 & 1.8 \\
\hline Anthracite & 92.8 & 2.7 & 2.9 & 1.0 & 0.6 \\
\hline Semianthracite & 90.5 & 3.9 & 3.4 & 1.5 & 0.7 \\
\hline Low volatile bituminous & 90.8 & 4.6 & 3.3 & 0.7 & 0.6 \\
\hline Medium volatile bituminous & 89.1 & 5.0 & 3.6 & 1.7 & 0.6 \\
\hline High volatile A bituminous & 84.9 & 5.6 & 6.9 & 1.6 & 1.0 \\
\hline High volatile B bituminous & 81.9 & 5.1 & 10.5 & 1.9 & 0.6 \\
\hline High volatile C bituminous & 77.3 & 4.9 & 14.3 & 1.2 & 2.3 \\
\hline Subbituminous A & 78.5 & 5.3 & 13.9 & 1.5 & 0.8 \\
\hline Subbituminous B & 72.3 & 4.7 & 21.0 & 1.7 & 0.3 \\
\hline Subbituminous C & 70.6 & 4.8 & 23.3 & 0.7 & 0.6 \\
\hline Lignite & 70.6 & 4.7 & 23.4 & 0.7 & 0.6 \\
\hline \hline
\end{tabular}




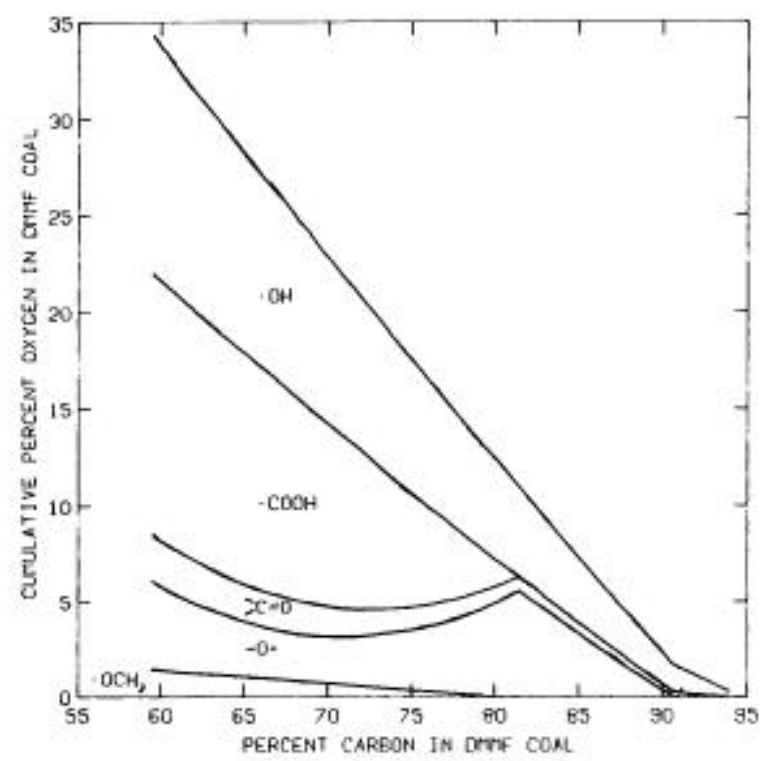

Figure 2.3 Distribution of Oxygen Functionality in Coals as a Function of Rank [40]

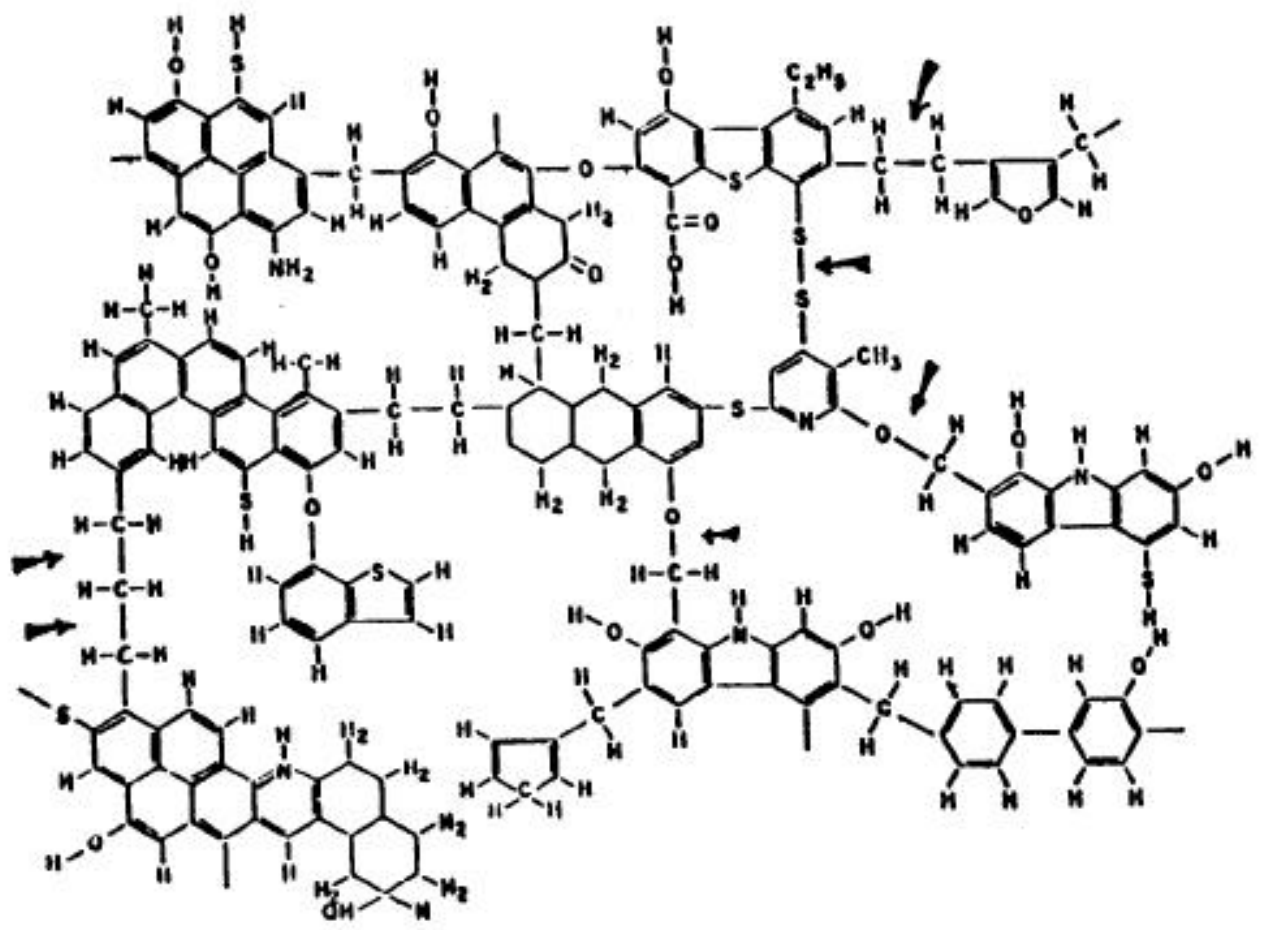

Figure 2.4 One Typical Molecular Unit in Coal [43] 


\subsubsection{Coal vs. Petroleum}

In order for coal to be considered as a possible precursor to high value carbon products, it must be converted so that it has properties similar to that of its main competition, petroleum. For this to happen, one must understand some of the key differences between the structure of coal and oil. The major difference between coal and oil is that the molecular weight of crude oil has a range of 150 to 250 [26], while the average molecular weight of coal usually exceeds 1000. Another major difference between coal and oil is that on average the atomic hydrogen-to-carbon ratio for coal is much lower than that of oil. The typical value for crude oil lies between 1.4 and 1.9, while the average value for coal is only about 0.8 [33]. A list of typical hydrogen-tocarbon atomic ratios for several coals and hydrocarbons, such as asphaltene, toluene, crude petroleum, gasoline, and methane, is given in Table 2.4.

Table 2.4 Typical Compositions of Coals and Liquid Hydrocarbons ${ }^{\mathrm{a}}$ [23]

\begin{tabular}{||c|c|c|c|c|c|c|c|c|c||}
\hline Element & Anthracite & $\begin{array}{c}\text { mv } \\
\text { Bit. }\end{array}$ & $\begin{array}{c}\text { hvb } \\
\text { Bit. }\end{array}$ & Lignite & Asphaltene & Toluene & $\begin{array}{c}\text { Petroleum } \\
\text { Crude }\end{array}$ & Gasoline & Methane \\
\hline $\mathrm{C}$ & 93.7 & 88.4 & 80.3 & 72.7 & 87 & 91.3 & $83.0-87.0$ & 86 & 75 \\
\hline $\mathrm{H}$ & 2.4 & 5 & 5.5 & 4.2 & 6.5 & 8.7 & $11.0-14.0$ & 14 & 25 \\
\hline $\mathrm{O}$ & 2.4 & 4.1 & 11.1 & 21.3 & 3.5 & & & & \\
\hline $\mathrm{N}$ & 0.9 & 1.7 & 1.9 & 1.2 & 2.2 & & 0.2 & & \\
\hline $\mathrm{S}$ & 0.6 & 0.8 & 1.2 & 0.6 & 0.37 & & 1 & & \\
\hline $\begin{array}{c}\text { H/C } \\
\text { Ratio }\end{array}$ & 0.31 & 0.67 & 0.82 & 0.69 & 0.9 & 1.14 & 1.76 & 1.94 & 4 \\
\hline
\end{tabular}

${ }^{\mathrm{a}}$ Coal analysis on moisture- and ash-free basis; ash content of coal 3-15\%

In order for coal to be viable as a carbon feedstock, the original hydrogen-tocarbon ratio must be increased. There are two different ways of performing this task: the addition of hydrogen or the rejection of carbon. These two methods are the basis for most coal conversion processes. There are four chief processes that are included here: pyrolysis, indirect liquefaction or gasification, and direct liquefaction with and without a catalyst [23]. These conversion pathways are illustrated in Figure 2.5. 


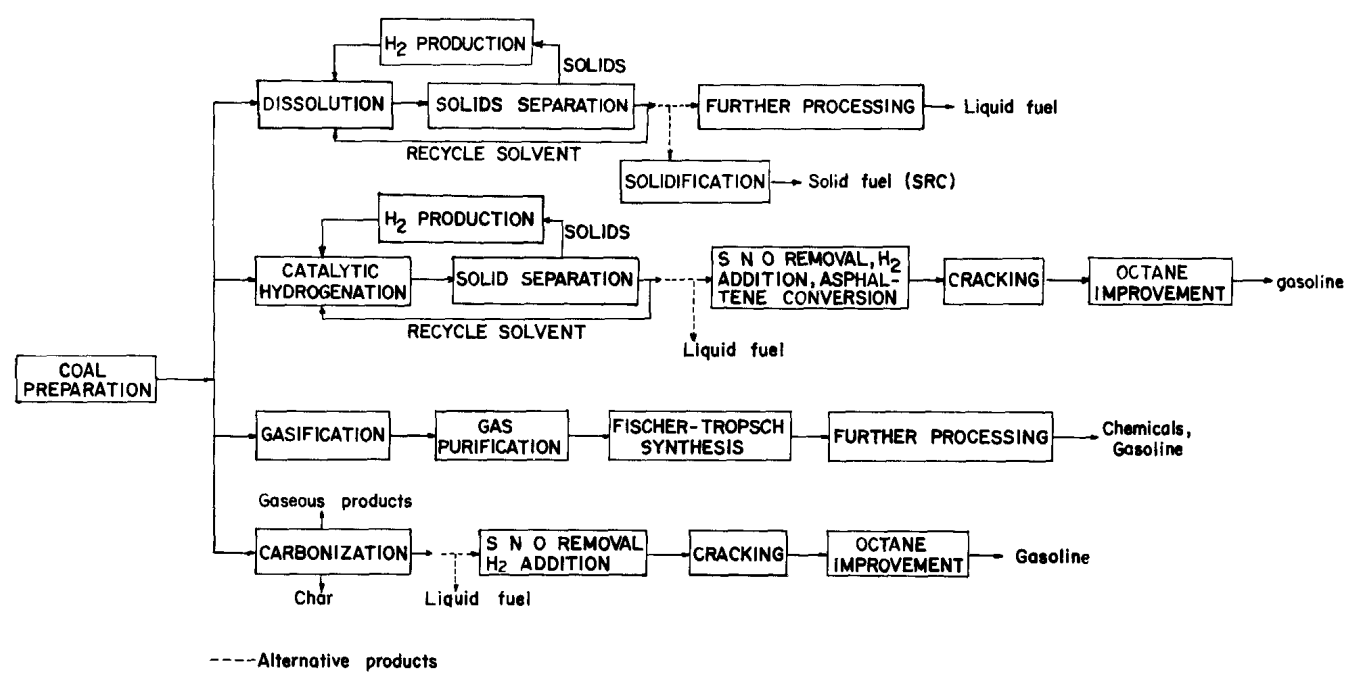

Figure 2.5 Alternate routes for Coal Liquefaction [23]

\subsubsection{Pyrolysis}

Pyrolysis or carbonization employs the approach of rejecting carbon as its method of increasing the hydrogen-to-carbon ratio of raw coal. This path is illustrated as the bottom process in Figure 2.5. Pyrolysis takes place as coal is heated in the absence of oxygen and thermally decomposed into hydrogen rich liquids and gases and a carbon rich residue (char or coke). This is done in the absence of oxygen, so that undesirable combustion reactions do not take place. As the coal is heated $\left(350-400{ }^{\circ} \mathrm{C}\right)$, the bonds or links break between aromatic cluster units. Then the aliphatic side chains, as well as the low molecular weight fragments of coal, break away from the cluster units at $450-$ $500{ }^{\circ} \mathrm{C}$. From these the tars and gases are given off. As the sample reaches higher temperatures, the aromatic clusters repolymerize causing the formation of the coke or char [26]. This char contains the mineral matter that was present in the original coal sample. These minerals often act as catalysts in reactions that take place between the char and the product gas [39]. The liquid products, or coal tar, formed from the condensed volatile matter, are processed further by hydrogenation and desulfurization to create valuable products. It is these materials, which are now rich in hydrogen. The 
yield of these liquids can be optimized by shortening the time that the product is exposed to higher temperatures. This helps minimize the formation of gas as the larger fragments undergo further decomposition [23].

\subsubsection{Indirect Liquefaction}

Indirect liquefaction or gasification takes place when coal is completely broken down into synthesis gases, mainly carbon monoxide and hydrogen. The general process for indirect liquefaction is shown as the third approach in Figure 2.5. The synthesis gases generated from coal can then be combined in the presence of a Fischer-Tropsch catalyst to form various higher hydrocarbons [23].

An advantage of indirect liquefaction is that because the original coal sample is completely destroyed and only the organic matter is gasified, the amount of mineral matter and impurities in the final product can be minimized. Also, depending on the choice of Fisher-Tropsch catalyst, the products can be highly selective to gas, gasoline, kerosene, diesel fuel, and fuel oil. Products such as methanol and acetone can also be produced depending on the specific type of catalyst. Several types of commonly used catalysts are $\mathrm{Fe}, \mathrm{Co}, \mathrm{Ni}, \mathrm{Ru}, \mathrm{ZnO}_{2}$, and $\mathrm{ThO}_{2}$. However, in order for the gasification to take place, coal is usually reacted with steam and oxygen to produce carbon monoxide and hydrogen gas. This process creates many by-products that must be removed before further processing into valuable products, such as fuel. Also, the destruction of the original coal structure can be very expensive in terms of thermal efficiency [23].

\subsubsection{Direct Liquefaction}

Direct liquefaction consists of two different processes, hydrogen-donor solvent reaction and dissolution and catalytic hydrogenation. These two approaches are illustrated as the top two processes in Figure 2.5. In the present research, catalysts are not being used. Therefore, the subsequent discussion of direct liquefaction will only 
include the hydrogen-donor solvent process and is the focus of the remainder of this chapter.

\subsection{Mechanisms of Liquefaction}

Curran et al. [9] and Vernon [38] proposed that the transfer of hydrogen to coal from a solvent follows a free radical mechanism. The free radicals are formed by the thermal degradation of the coal structure and are looking to be capped in the most thermodynamically favorable process. Wiser [44] concluded that during each of these ruptures of the covalent bonds, two free radicals are formed, and that these free radicals are capped in one of three ways: (1) addition of atoms (such as hydrogen) or other radical groups to the free radicals, (2) rearrangement of atoms within the free radical, and (3) polymerization of the free radical.

The first method of capping the free radical is the desired method when performing coal liquefaction with a hydrogen donor solvent. This allows the large coal molecules to be thermally degraded, capped with hydrogen, and stabilized as smaller, more soluble and hydrogen-rich species. These species would typically have a molecular weight ranging from 300 to 1000 [40]. The second and third methods occur when there is not a hydrogen donor solvent available. If the free radical species contains an unstable structure such as a hydroaromatic unit, the free radical species could cap itself. Finally, if the free radical species is stable and in the presence of other free radical species, polymerization or retrograde reactions could take place. This is the basis for the formation of coke, char, and other large and insoluble molecular weight species. Therefore, for the formation of low molecular-weight carbon-product precursors, the first method is preferred.

McMillen and Malhotra [24, 25] proposed a slightly different mechanism for the liquefaction of coal. Their theory states that the free radical mechanism is occurring during coal liquefaction, but it does not account for the total amount of conversion. McMillen and Malhotra point out that if a solvent is used to quench radicals, then its 
ability as a liquefaction solvent should correlate with the weakness of their carbonhydrogen bonds. However, they found that solvents that are equally effective as radical scavengers, i.e. indane, ethylbenzene, and tetralin, were not equally effective as liquefaction solvents [25]. From this observation, they proposed that solvents not only take a passive role in liquefaction by stabilizing radicals but are also actively participating in bond cleavage. The solvent adds a hydrogen atom into the ipso position of the coal molecule. This addition of a hydrogen atom causes the cleavage of strong coal bonds and the formation of additional coal radicals (Figure 2.6).

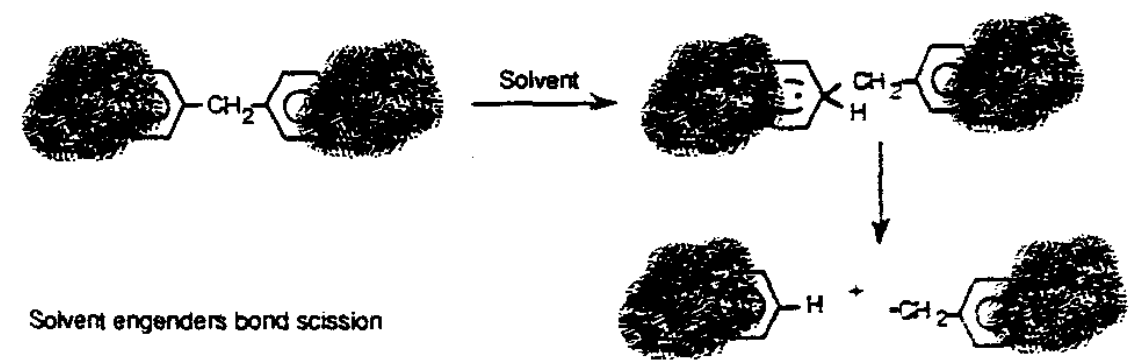

Figure 2.6 Solvent Mediated Hydrogenolysis of a Strong Linkage in Coal [25]

On a macroscopic level, the conversion of coal to liquid hydrocarbons can be visualized as a progressive hydrogenation through a series represented by the following:

$$
\text { Coal } \rightarrow \text { Preasphaltenes } \rightarrow \text { Asphaltenes } \rightarrow \text { Oils (Carbenes }+ \text { Carboids) }
$$

The definition of these liquids is shown in Table 2.5. However, Berkowitz [5] states that the hydrogenation process is much more complicated than the progression illustrated in Equation 2-1 and contains some reversible processes. This schematic is shown in Figure 2.7 and entails two different steps. The first step is "coal solubilization, which depends on the nature and intensity of pyrolytic and H-transfer reactions in the reactant system" [5]. The second occurs when secondary hydrogenation takes place. Secondary hydrogenation depends on the specific reaction conditions and drives the products toward lower molecular weight species [5]. 
Table 2.5 Definition of Primary Liquids from Berkowitz [5]

\begin{tabular}{|l|c|c||}
\hline & Soluble In & Insoluble In \\
\hline \hline Carbenes & Carbon disulfide & n-Pentane \\
\hline Carboids & n-Hexane & Carbon disulfide \\
\hline Asphaltenes & Benzene and toluene & n-Hexane \\
\hline Preasphaltenes & Tetrahydrofuran & Benzene \\
\hline
\end{tabular}

Most of the information that has been obtained concerning the chemistry and kinetics of coal liquefaction has been determined from reactions with coal and a model hydrogen donor such as tetrahydronaphthalene (tetralin). However, these data are still somewhat fragmentary and contradictory.

One hypothesis for the reaction of coal and tetralin is illustrated in Equation 2-2.

$$
\text { coal + tetralin } \Rightarrow \text { coal-derived products }+ \text { naphthalene }
$$

This reaction mechanism gives a way to correlate the solubilization of the coal by hydrogen transfer by quantifying the conversion of tetralin to naphthalene at varying reaction conditions [28]. However, this is not the only possible reason for the formation of naphthalene from tetralin. The tetralin could undergo dehydrogenation that results in the formation of hydrogen gas. Or the tetralin could be converted by isomerization to methylindane as well as hydrogen donation to form naphthalene [12].

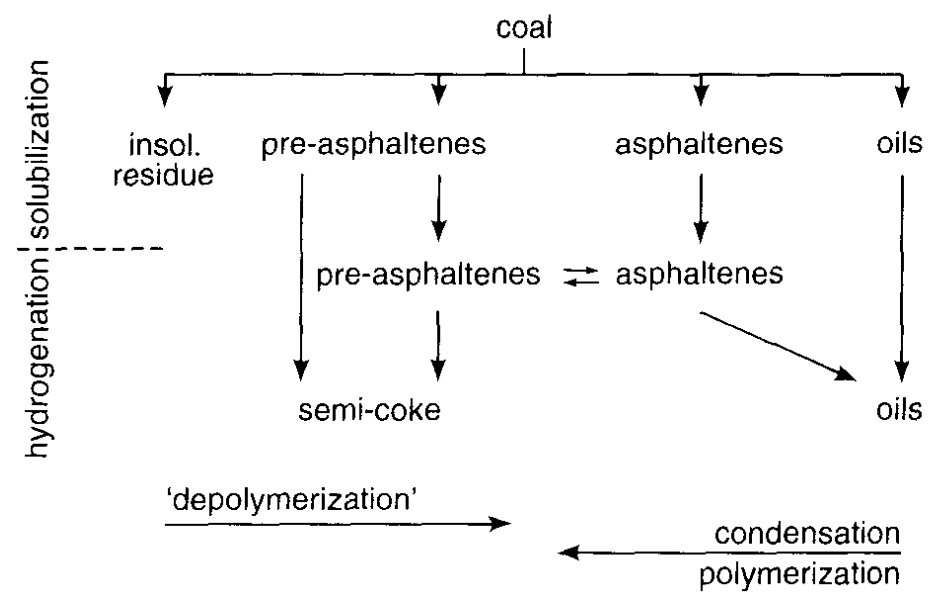

Figure 2.7 Conceptual Reaction Sequences in Coal Liquefaction [5] 
Berkowitz [5] also points out that naphthalene can be formed in other possible liquefaction reactions. Using methylnaphthalene to represent a structure found in the coal macromolecule, naphthalene can be formed from the reaction illustrated in Equation $2-3$.

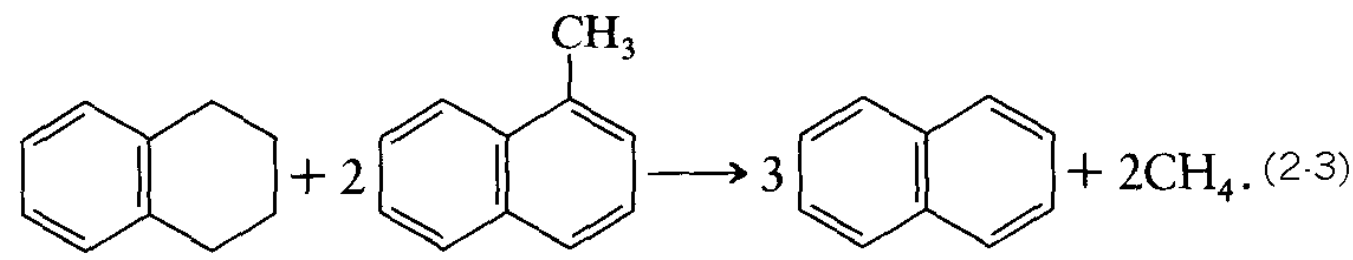

As illustrated above and due to the complexity of the coal macromolecule, the chemistry of coal liquefaction has a significant amount of diversity. However, through laboratory studies and pilot plant operations, properties of coal that affect liquefaction results have been compiled and are summarized below in Table 2.6.

Table 2.6 Fundamental Properties Important in Coal Liquefaction [5]

\begin{tabular}{||c|c|c||}
\hline \hline Property & Influence & Desired level \\
\hline \hline Rank & Liquids vield & Medium \\
\hline Ash content & Operations and handling & Low \\
\hline Moisture content & Thermal efficiency & Low \\
\hline Hydrogen content & Liquids yield and hydrogen & High \\
\hline Oxygen content & Gas make and hydrogen consumption & Low \\
\hline Extractability $^{\mathrm{a}}$ & Liquids yield and quality & High \\
\hline Aliphatic character & Liquids yield and quality & High \\
\hline Reactive macerals & Liquids yield & High \\
\hline Particle size & Operations & Fine/very fine \\
\hline
\end{tabular}

a In effect, "solubility" in potent solvents

${ }^{\mathrm{b}}$ Principally vitrinites and exinites

\subsection{Coal Liquefaction Parameters}

In this section some of the different factors that affect the ability of coal to be processed by direct coal liquefaction will be investigated. These include the coal composition, the type of solvent, the mineral matter in the coal, and the presence or absence of hydrogen gas. 


\subsubsection{Coal Composition}

The effect of coal rank on the process of liquefaction has been extensively studied in the past with very different results. One reason for such discrepancies is the fact that the same rank of coal could be very different according to the geographical region in which it originated and the petrographic composition of the coal. The petrographic composition refers to the vegetation components that go into the process of making coal. These components depend on the types of vegetation present in the area, as well as the amount of biochemical degradation of organic matter before the coalification process of coal formation has started. Several studies that explored this trend are outlined below.

Fisher et al. [15] investigated the influence of coal rank on coal conversion while considering the effects of petrographic composition. They found that coals with more than $89 \%$ carbon content were unsuitable for hydrogenation and give a low liquid yield because of their large, condensed polynuclear structure. High volatile bituminous coals were the best for liquefaction, and low rank coals such as lignite and sub bituminous gave lower liquid yields. Also, the low rank coals were affected more by the reaction conditions. The results of this study can be seen in Figure 2.8. These results were confirmed by Given et al. [18] when they found that high volatile bituminous coals gave the highest yields during direct liquefaction.

Neavel [28] found that coal conversion to benzene solubles (asphaltenes and lighter hydrocarbons) decreased as coal rank increased. This experiment was performed using hydrogenated creosote oil as the hydrogen donor solvent at approximately $400{ }^{\circ} \mathrm{C}$. Neavel's results are shown in Figure 2.9. However, Gorin [19] reports heavily divergent liquefaction yields depending on the original coal rank. These differences were attributed to the geographic region from which the coal was mined. Finally, a study by Yarzab et al. [46] attempted to correlate coal properties of over 100 U.S. coals and conversion. These coals were split into three different populations according to 15 coal characteristics. The result of this study was that a correlation demanded a different set of properties for each population. 


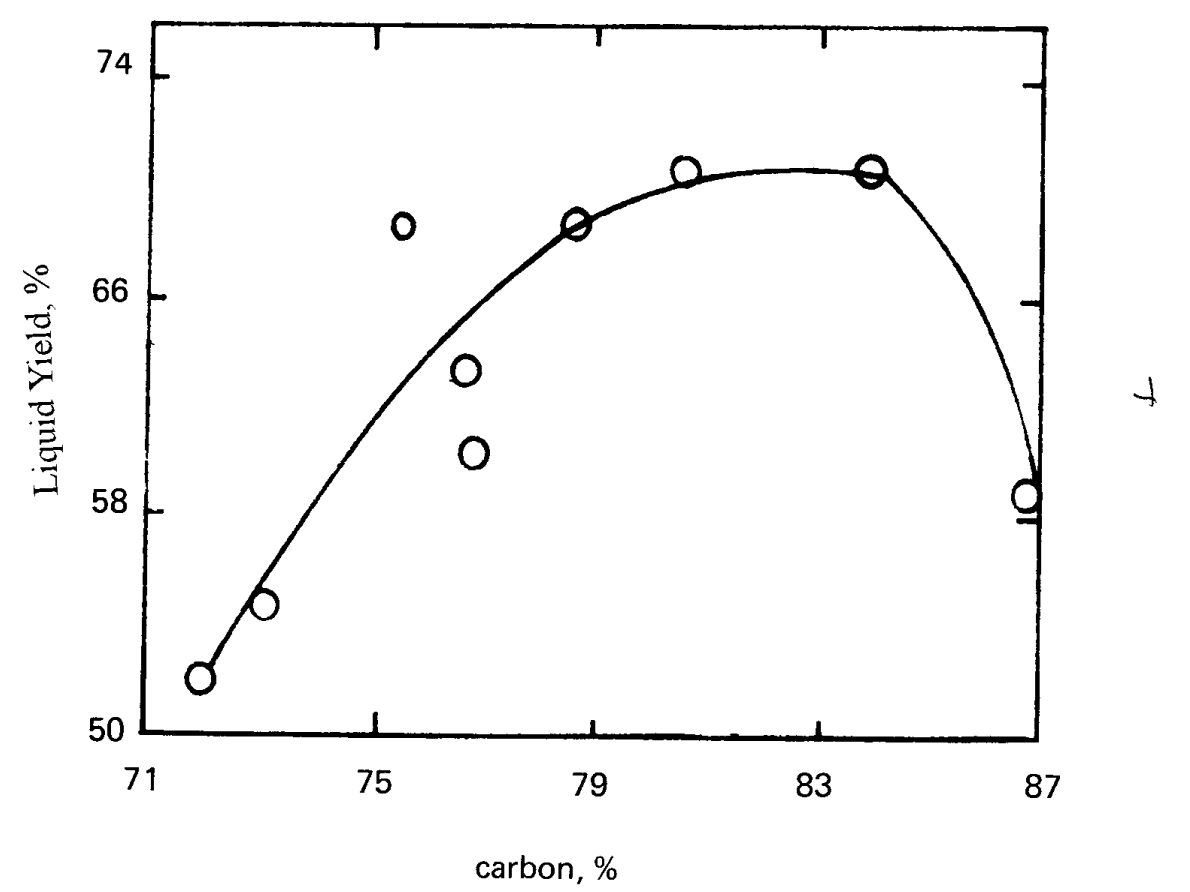

Figure 2.8 Effect of Carbon Content on Liquid Product Yield [15]

Keogh and Davis [21] found that coal rank can also affect the mechanism of coal liquefaction. They found that both bituminous and sub-bituminous coals have two distinct stages of liquefaction. For bituminous coals, during the first stage as conversion increases, the production of asphaltenes and preasphaltenes increases while the production of oils and gases remains stable. In the second stage, as a maximum in conversion is achieved, then the asphaltenes and preashaltenes are converted to oils and gases. For sub-bituminous coals, the first stage includes an increase in conversion, asphaltenes and preasphaltenes, and oils and gases. The second stage is the same as for bituminous coals as the asphaltenes and preashaltenes are converted to oil and gas.

The success of coal liquefaction not only depends on coal rank but also depends on the petrographic composition of the coal. Each type of maceral has a different behavior when subjected to liquefaction conditions. Keogh et al. [22] used density gradient centrifugation to separate and study the behavior of each maceral group from a single parent coal. They found that at lower temperatures $\left(385^{\circ} \mathrm{C}\right)$ conversions are similar. However, as temperature increases, liptinites were converted more than vitrinite 
which was converted more than inertinite. Finally, they showed that the weighted conversion of the individual macerals did not add up to the total amount of conversion of the parent coal, suggesting some synergistic effects of the combined maceral groups.

Cloke and Wang [8] also studied the effect of maceral composition on liquefaction behavior using hydrogenated anthracene oil. They found that most of the vitrinite was hydrogenated by $350{ }^{\circ} \mathrm{C}$. The increase of temperature from $300^{\circ} \mathrm{C}$ to $375{ }^{\circ} \mathrm{C}$ showed little effect on the conversion of liptinite, however, most of the liptinite was converted by $400{ }^{\circ} \mathrm{C}$. Finally, inertinite could be partially hydrogenated above $400{ }^{\circ} \mathrm{C}$. However, this is not always beneficial because the rate of repolymerization outweighs the rate of hydrogenation.

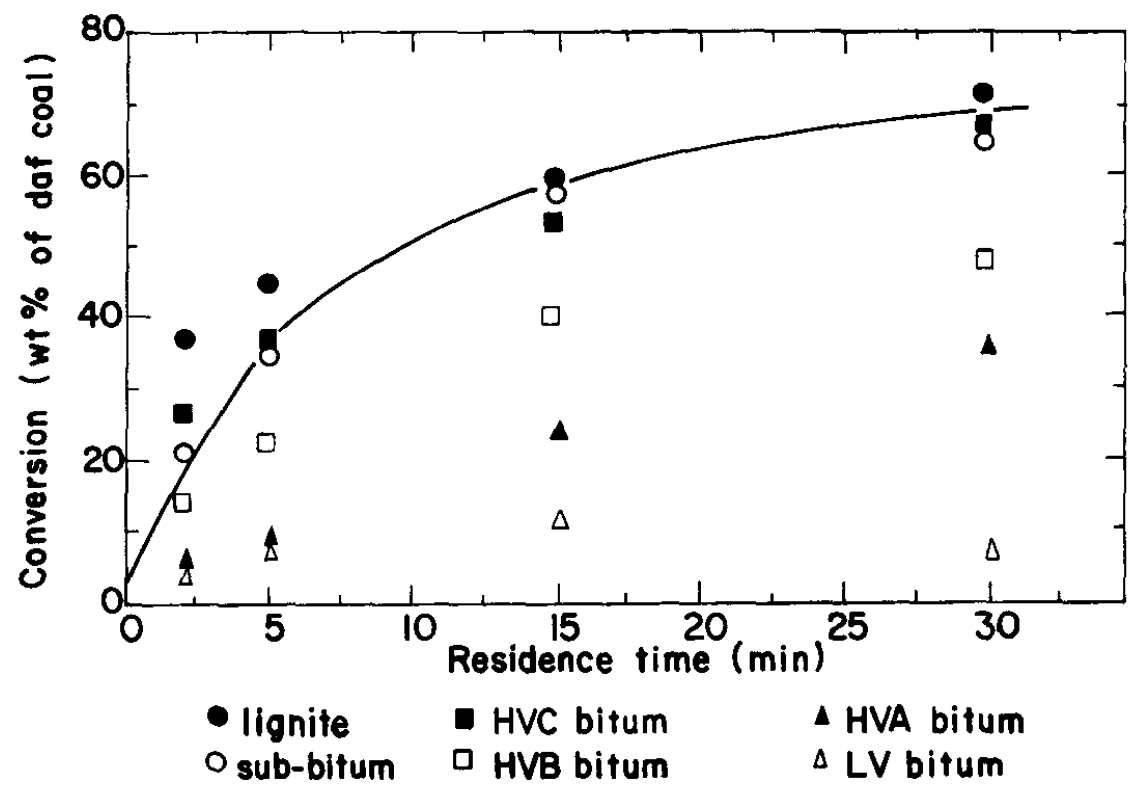

Figure 2.9 Variation in the yield of benzene solubles with rank and reaction time [28]

\subsubsection{Liquefaction Solvents}

The choice of liquefaction solvent can have an enormous effect on the success of direct coal liquefaction. The choice not only affects the conversion, but also the amount 
of hydrogen consumed, the degree and quantity of retrograde reactions, and the quality of liquid products [20]. As stated above, the process of liquefaction thermally decomposes the macromolecules of coal into smaller, free radical units. At this point, if hydrogen is added, the free radicals will be stabilized and the small molecules will become stable and soluble. The liquefaction solvent is chosen so that the most efficient transfer of hydrogen to these free radicals can be achieved.

Whitehurst et al. [40] lists four chemical properties that influence the ability for a solvent to be used in coal liquefaction. These are: (1) the hydrogen donor capacity of the solvent, (2) the physical solubilization of coal products, (3) hydrogen transfer capability (the ability to shuttle hydrogen from the coal molecule itself to cap the free radical), and (4) the presence of species that promote the production of char.

Oele et al. [29] defined four different types of solvents based on their effects on coal: non-specific solvents, specific solvents, degrading solvents, and reactive solvents. Of these four types, only specific and reactive solvents are of interest to direct liquefaction. Specific solvents dissolve $20-40 \%$ of the original coal at temperatures about or below $200^{\circ} \mathrm{C}$. These solvents are electron donors and the process is a physical solution. Some solvents that fall into this group are N-methylpyrolidone (NMP) and pyridine.

A reactive solvent actually undergoes a chemical reaction with the species that is being dissolved. This is the common solvent used in high temperature direct liquefaction reactions. The solvent reacts with coal by donating hydrogen to the free radicals that are formed. Tetralin is one such solvent.

Orchin and Storch [30] performed some liquefaction experiments in order to determine the ability of several reactive solvents to convert coal to benzene solubles. These reactions were carried out at $400{ }^{\circ} \mathrm{C}$ under a hydrogen atmosphere that was initially at atmospheric pressure. The results are shown in Table 2.7. The least effective solvent was a high boiling aromatic compound or a hydroaromatic compound that 
dehydrogenates slowly at the reaction temperature and low pressure. The most effective solvents contained an aromatic hydroxyl group as well as a hydroaromatic ring.

Table 2.7 Effectiveness of Some Solvents for Hydrogenation [30]

\begin{tabular}{|c|c||}
\hline Solvent & $\begin{array}{c}\text { Benzene Soluble } \\
(\%, \text { maf coal basis })\end{array}$ \\
\hline \hline o-Cyclohexylphenol & 81.6 \\
\hline 1,2,3,4-Tetrahydro-5-hydroxynaphthalene & 85.3 \\
\hline Tetralin & 49.4 \\
\hline Cresol & 32.1 \\
\hline Dicyclohexyl & 27.2 \\
\hline Naphthalene & 22.2 \\
\hline o-Phenylphenol & 19.6 \\
\hline Diphenyl & 19.4 \\
\hline
\end{tabular}

${ }^{\mathrm{a}}$ With $1 \mathrm{~atm}$ initial (cold) hydrogen pressure without catalyst. The reaction time is $0.5 \mathrm{hr}$ at $400^{\circ} \mathrm{C}$ with a $4: 1$ solvent/coal ratio.

\subsubsection{Mineral Matter in Coal}

There have been many studies performed on the catalytic effect that mineral matter in coal may produce during liquefaction. Most of the catalytic activity has been ascribed to the presence of pyrite $\left(\mathrm{FeS}_{2}\right)$ or the reduced form of pyrite, pyrrhotite $(\mathrm{FeS}$, $\mathrm{x}=1.0$ to 1.14$)[40]$.

Mukherjee and Chowdhury [27] characterized the ash content of a high-vitrinite coal in order to study the catalytic effect of the mineral matter in liquefaction. The hydrogenation reaction took place in the absence of a donor solvent, but specific minerals were added to coal. The results showed that the best correlation of catalytic activity was obtained using added sulfur (organic plus pyritic). Other minerals that showed a correlation with benzene solubles were iron, titanium, and kaolinite. 
Whitehurst et al. [40] studied the effect of iron pyrite on the solvent-solvent interactions that occur during the liquefaction of coal. These results showed that the rate of solvent-solvent hydrogen transfer reactions occurred at a higher rate in the presence of coal (containing pyrite) than in solvent-solvent reactions alone.

Another way to study the effect of mineral matter in coal is to remove the mineral matter content without altering the organic composition of the coal before reaction [40]. The mineral matter present in coal can be selectively removed depending on the type of pretreatment. Two kinds of coals were pretreated so that in one experiment all mineral matter was removed except pyrites, and the other set was pretreated to remove all pyrites. In order to remove all mineral matter except pyrite, the coal was treated with $\mathrm{HCl}$ followed by $\mathrm{HF}$ and then treated again with $\mathrm{HCl}$. The pyrite can be removed by using the Meyers Process. This process uses an aqueous ferric sulfate solution as a leachant to remove the pyrite [41]. After the pretreatment of these coals to remove the ash content, the coal conversion dropped with lower ash content (see Figure 2.10) and the hydrogen consumption dropped with lower ash content signifying that some catalytic activity can be attributed to the presence of pyrite [40].

\subsubsection{Hydrogen Pressure}

The exact role of a hydrogen atmosphere is not specifically known, however, the presence can greatly benefit the production of soluble coal. The hydrogen at high pressure could donate hydrogen and stabilize the coal free radicals in one of two ways: (1) directly donate hydrogen to the free radical or (2) transfer hydrogen to the donor solvent, which can then be transferred to the coal particle. Yen et al. [47] showed that when tetralin was used as a donor solvent, the yield of benzene insolubles was $25.3 \%$ when a nitrogen atmosphere was employed. When the atmosphere was changed to hydrogen, a positive effect on coal conversion was observed as the yield of benzene insolubles decreased to $13.8 \%$ indicating more conversion to benzene solubles. Tomic and Schobert [36] also observed an increase in the amount of conversion when a hydrogen atmosphere was used instead of an inert atmosphere during liquefaction 
without solvents or catalysts. This increase in conversion was believed to occur as hydrogen reduced the amount of retrograde reactions at high temperature [36]. Finally, Artok [2] states that without a catalyst, but with a solvent present, the efficient use of hydrogen during liquefaction is difficult.

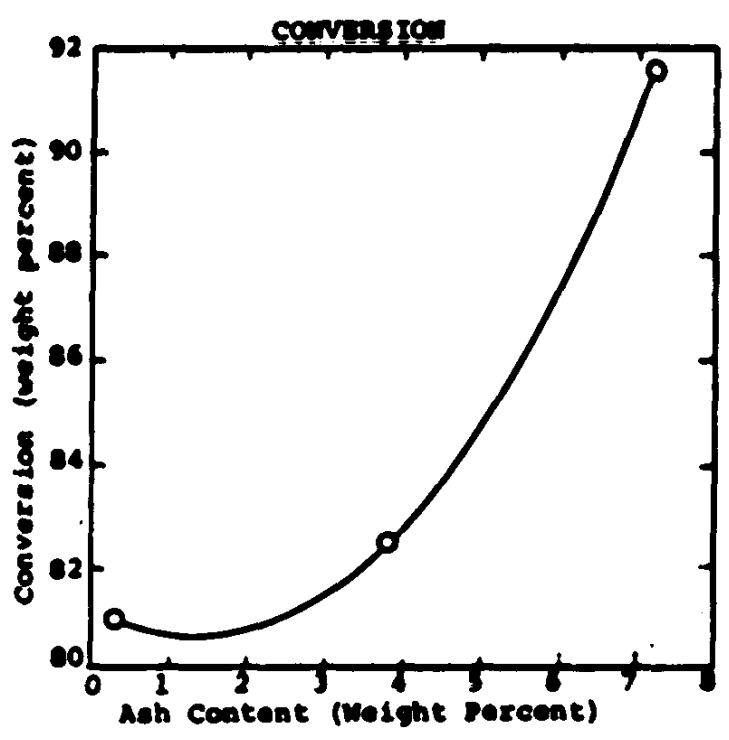

Figure 2.10 Wyodak Coal Conversion vs. Ash Content [40]

The presence of a hydrogen atmosphere on conversion is not the only subject of importance. Another major issue is the exact mechanism that hydrogen undergoes in liquefaction. Finseth et al. [14] state that the bulk of the hydrogen consumed from an uncatalyzed solvent liquefaction above $400{ }^{\circ} \mathrm{C}$ is consumed by gas generation, heteroatom removal, and hydrogenolysis of the coal matrix. Wilson et al. [42] report that hydrogen is consumed by alkyl fission and hydrogenolysis, not with hydrogenating aromatic rings. Chawla et al. [7] state that at long times (greater than 15 minutes) hydrogen is consumed by secondary reactions of as asphaltenes and preasphaltenes are converted to oil and gas.

\subsection{Summary of Background Remarks}

The above discussion has focused on elemental carbon, carbon artifacts, the production of carbon artifacts from coal, and the principles and parameters governing the 
effectiveness of direct coal liquefaction. By changing the liquefaction reaction parameters, a different set of reaction products could be isolated. Each of these could potentially exhibit different properties when tested as carbon product precursors. It is the goal of this thesis report to understand the effect that several of the discussed reaction parameters (solvent, pressure, and gaseous atmosphere) would have on the quantity and properties of the resultant pitch fraction and its subsequent use as a carbon-product precursor. 


\section{CHAPTER 3 EXPERIMENTAL}

In this chapter, all of the materials and equipment in the experiments are discussed along with the process of performing the hydrogenation reactions, extracting the products, and testing the final products.

\subsection{Materials}

Various chemicals and gases were used during the course of this investigation. The supplier and purity are listed below for each of the chemicals and gases.

Tetrahydrofuran (THF) was used as a solvent during the product separation steps of the experiments. THF was obtained from Fisher Scientific and was the histological grade with purity listed as $99 \%$ or greater. It was used during all experiments as delivered.

Argon and hydrogen were used as the gaseous atmosphere for the hydrogenation experiments. Nitrogen was used as an inert purge gas during vacuum drying. They were obtained as standard laboratory grade from AirGas of West Virginia.

A medium-volatile bituminous coal (WVGS 13421) was obtained from the West Virginia Geological Survey. A proximate analysis was performed to determine its amount of moisture, fixed carbon, volatile matter, and ash. The results of this analysis along with some other characteristics of WVGS 13421 are shown in Table 3.1. An ultimate analysis was performed to determine the elemental composition of the coal and this can be seen in Table 3.2. The coal was ground to -20 mesh and dried overnight in a vacuum oven. The vacuum oven was set at $110^{\circ} \mathrm{C}$ with a nitrogen purge $(100 \mathrm{cc} / \mathrm{min})$ and a vacuum of 25-30 in $\mathrm{Hg}$. 
Three coal-derived solvents were obtained for testing as hydrogenation solvents. The first is a mid-distillate coal liquid obtained from Antaeus Technical Services, Inc. This coal liquid was produced as a by-product from the production of a high quality char and is referred to in this thesis as the Raw Antaeus Coal Liquid (RACL). This coal liquid was a very viscous fluid at ambient temperatures. The second is a heavy creosote oil ( $\mathrm{HCO})$, and the third is a carbon black base (CBB). The latter two samples were obtained from Koppers Industries, Inc and are considered to be similar but were obtained from Koppers at different times. However, the elemental composition was slightly different for the two Koppers' samples, and so they were treated as separate solvents. The elemental composition of each raw material is

Table 3.1 Characteristics of WVGS 13421

\begin{tabular}{||l|c||}
\hline Coal Bed & Powellton \\
\hline County & Raleigh \\
\hline ASTM rank & mvb \\
\hline Mean-maximum reflectance of vitrinite & 1.11 \\
\hline Proximate analysis (as received) & 0.98 \\
\hline Moisture & 67.87 \\
\hline Fixed carbon & 27.96 \\
\hline Volatile matter & 3.19 \\
\hline Ash & 63.3 \\
\hline Petrographic composition (\% volume) & 5.7 \\
\hline Vitrinite & 30.0 \\
\hline Exinite & \\
\hline Inertinite & \\
\hline
\end{tabular}

Table 3.2 Elemental Compositions ${ }^{\mathrm{a}}$ of WVGS 13421 and Coal-Derived Solvents

\begin{tabular}{||c|c|c|c|c|c|c||}
\hline \hline & $\begin{array}{c}\text { WVGS } \\
13421\end{array}$ & RACL & DACL-L & DACL-H & HCO & CBB \\
\hline \hline $\mathrm{C}$ & $81.59 \%$ & $86.67 \%$ & $80.51 \%$ & $88.51 \%$ & $93.41 \%$ & $91.85 \%$ \\
\hline $\mathrm{H}$ & $4.56 \%$ & $6.76 \%$ & $7.74 \%$ & $5.72 \%$ & $5.14 \%$ & $5.51 \%$ \\
\hline $\mathrm{N}$ & $1.10 \%$ & $1.22 \%$ & $0.94 \%$ & $1.25 \%$ & $0.88 \%$ & $0.81 \%$ \\
\hline $\mathrm{S}$ & $0.73 \%$ & $0.72 \%$ & $0.61 \%$ & $0.76 \%$ & $0.55 \%$ & $0.67 \%$ \\
\hline $\mathrm{O}^{\mathrm{b}}$ & $4.82 \%$ & $4.54 \%$ & $10.19 \%$ & $3.62 \%$ & $0.02 \%$ & $1.11 \%$ \\
\hline $\begin{array}{c}\mathrm{H} / \mathrm{C} \text { Atomic } \\
\text { Ratio }\end{array}$ & 0.67 & 0.94 & 1.15 & 0.78 & 0.66 & 0.72 \\
\hline
\end{tabular}

${ }^{\mathrm{a}}$ Elemental compositions are not on an ash free basis

${ }^{\mathrm{b}}$ Determined by difference 
shown in Table 3.2. HCO was a pasty material that needed to be heated in order to process easily. CBB was fluid at ambient temperatures but contained some solid like matter entrained in the fluid. Therefore, it was also heated before processing.

The Antaeus coal liquids were further split into two fractions before use as donor solvents. The raw liquids were vacuum distilled (apparatus shown in Figure 3.1) to approximately $50 \%$ by weight. The temperature was kept below $270^{\circ} \mathrm{C}$ so that pyrolysis reactions do not occur. The light distillate (DACL-L, b.p. $<270{ }^{\circ} \mathrm{C}, 25-30 \mathrm{in} . \mathrm{Hg}$ ) and residue (DACL-H, b.p. $>270{ }^{\circ} \mathrm{C}, 25-30 \mathrm{in}$. Hg) were collected and stored in the cold room until time for use. DACL-L was fluid at ambient temperature and used without further preparation. DACL-H was a pitch-like solid material that was ground to -8 mesh. This material exhibited a softening point of $120{ }^{\circ} \mathrm{C}$ and a coke yield of $46 \%$ by weight. The heavy creosote oil and carbon black base were used without further treatment. The elemental compositions of these reactants are shown in Table 3.2.

\subsection{Experimental Procedure for Hydrogenation Reactions}

\subsubsection{Overview of Hydrogenation Reaction}

The effectiveness of five coal-derived liquids as hydrogenation solvents in the direct hydrogenation of a medium-volatile bituminous coal was investigated. Initially, the reaction conditions for each solvent-coal mixture were kept identical. The temperature was $400{ }^{\circ} \mathrm{C}$, and the initial pressure was $1000 \mathrm{psig}$ of hydrogen in the cold reactor. The solvent-to-coal ratio was 3 to 1 by weight, and the reaction time was one hour. These are standard conditions that have been used before in the literature for reactions of coal and model hydrogen donor solvents, such as tetralin. The products of the hydrogenation reactions were extracted using THF in order to calculate the overall conversion (as THF solubles) for the solvent-coal mixture. Finally, the effects of changing the gas-phase pressure and atmosphere (runs five through ten), and solvent-tocoal ratio (runs four, eleven, and twelve) were investigated. A list of conditions for all 


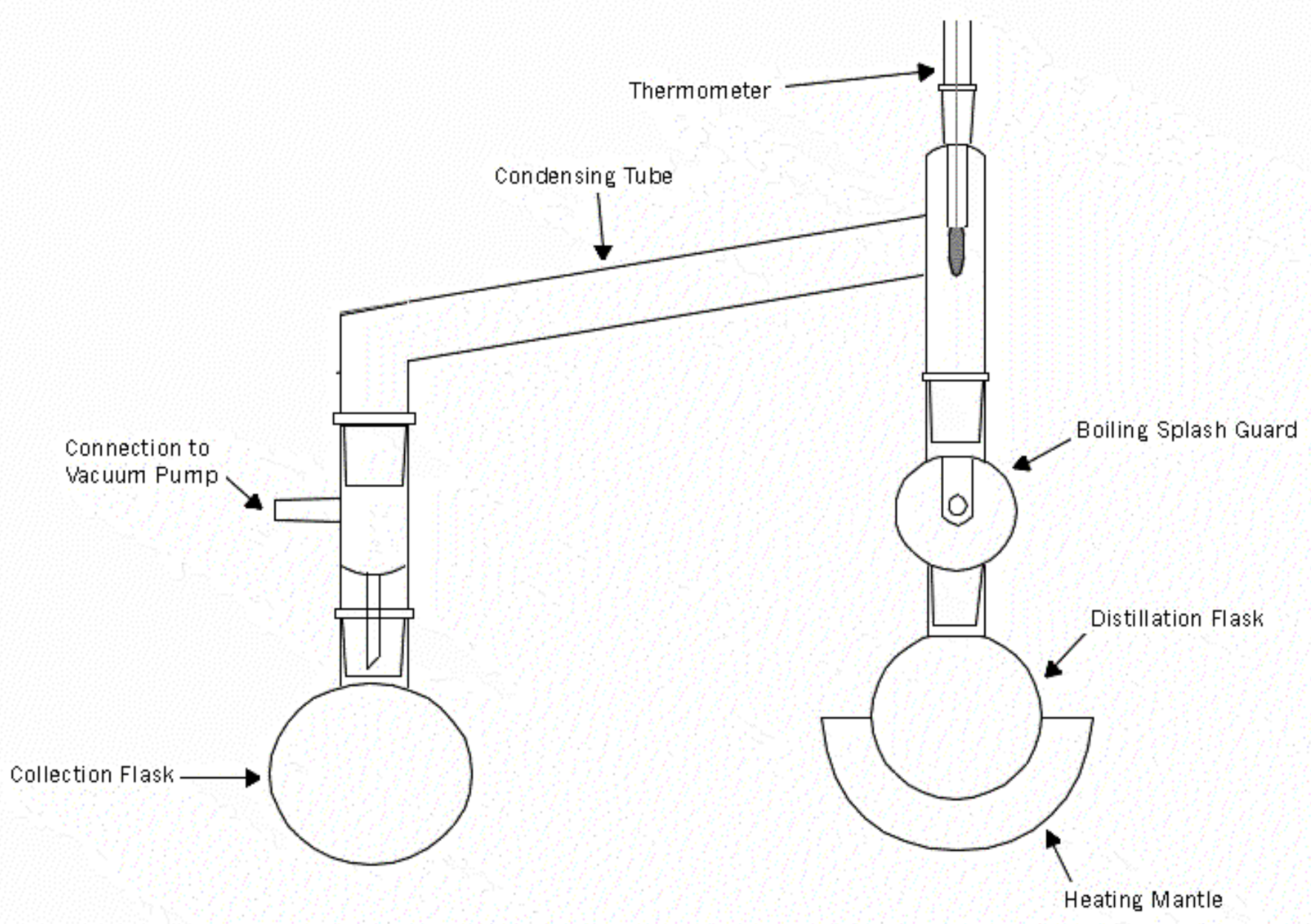

Figure 3.1 Vacuum distillation Apparatus for separating RACL into DACL-L and DACH-H 
the reactions is shown in Table 3.3. For each set of reaction conditions given in Table 3.3 (identified by the run number $1-12$ ), four repeated trials were performed. These trials are identified by the letters A, B, C, and D. Thus each individual run is identified by a number followed by a letter. The number corresponds to the reaction conditions given in Table 3.3. The letter refers to a specific trial (A, B, C, or D) of the same reaction conditions. A complete list of data from all the reactions is shown in Table A.1 in the appendix.

The extract (THF soluble fraction) was then vacuum distilled to recover a possible recycle solvent and a distillation residue. The heavy distillation residue (termed "pitch" hereafter) was tested as a possible precursor for carbon-products. The effect of the distillation on the pitch characteristics was investigated. Several distillations were performed to remove different amounts of the light fraction (termed "recycle solvent" hereafter). The light distillate is given the name "recycle solvent" because in many similar processes this fraction is recycled to the reactor for further hydrogenation reactions. However, testing the effectiveness of the isolated recycle solvents as subsequent hydrogenation solvents is outside the scope of this research and is not performed. The softening point of the resultant pitch from each distillation was determined. The data from these distillations and softening points allowed the correlation of the amount of recycle solvent removed and the softening point of the resultant pitch. This correlation was used to produce a pitch by vacuum distillation with a target softening point of $120{ }^{\circ} \mathrm{C}$. A process flow diagram for the overall experimental procedure is shown in Figure 3.2. 
Table 3.3 Hydrogenation Reaction Conditions

\begin{tabular}{|c|c|c|c|c|c|c||}
\hline $\begin{array}{c}\text { Run } \\
\#\end{array}$ & Solvent & $\begin{array}{c}\text { Temperature } \\
\left({ }^{\circ} \mathrm{C}\right)\end{array}$ & Atmosphere & $\begin{array}{c}\text { Pressure } \\
(\text { psig Cold })\end{array}$ & $\begin{array}{c}\text { Solvent/Coal } \\
\text { Ratio }\end{array}$ & $\begin{array}{c}\text { Time } \\
(\mathrm{hr})\end{array}$ \\
\hline \hline 1 & DACL-L & 400 & $\mathrm{H}_{2}$ & 1000 & $3 / 1$ & 1 \\
\hline 2 & DACL-H & 400 & $\mathrm{H}_{2}$ & 1000 & $3 / 1$ & 1 \\
\hline 3 & RACL & 400 & $\mathrm{H}_{2}$ & 1000 & $3 / 1$ & 1 \\
\hline 4 & $\mathrm{HCO}$ & 400 & $\mathrm{H}_{2}$ & 1000 & $3 / 1$ & 1 \\
\hline 5 & $\mathrm{CBB}$ & 400 & $\mathrm{H}_{2}$ & 1000 & $3 / 1$ & 1 \\
\hline 6 & $\mathrm{CBB}$ & 400 & $\mathrm{Argon}$ & 1000 & $3 / 1$ & 1 \\
\hline 7 & $\mathrm{CBB}$ & 400 & $\mathrm{H}_{2}$ & 500 & $3 / 1$ & 1 \\
\hline 8 & $\mathrm{CBB}$ & 400 & $\mathrm{Argon}$ & 500 & $3 / 1$ & 1 \\
\hline 9 & $\mathrm{CBB}$ & 400 & $\mathrm{H}_{2}$ & 100 & $3 / 1$ & 1 \\
\hline 10 & $\mathrm{CBB}$ & 400 & $\mathrm{Argon}$ & 100 & $3 / 1$ & 1 \\
\hline 11 & $\mathrm{HCO}$ & 400 & $\mathrm{H}_{2}$ & 1000 & $2 / 1$ & 1 \\
\hline 12 & $\mathrm{HCO}$ & 400 & $\mathrm{H}_{2}$ & 1000 & $1 / 1$ & 1 \\
\hline
\end{tabular}

\subsubsection{Fluidized Sand Bath Preparation}

A Techne SBL-2 fluidized sand bath was used to heat the reactors during hydrogenation runs. A TECHNE TL-8D temperature controller regulated the sand bath temperature. The sand bath was filled three-quarters full with a -100 mesh aluminum oxide powder (sand). The sand bath was preheated to $25{ }^{\circ} \mathrm{C}$ above the desired reaction temperature. The extra temperature accounted for the rapid loss in temperature that occurred when the cold reactors were plunged into the sand bath. The inlet airflow to the bath was adjusted so that light bubbling occurs in the sand. If the airflow was too low, the heat would not be evenly distributed. If the airflow was too high, sand would be propelled out of the overflow tray. 


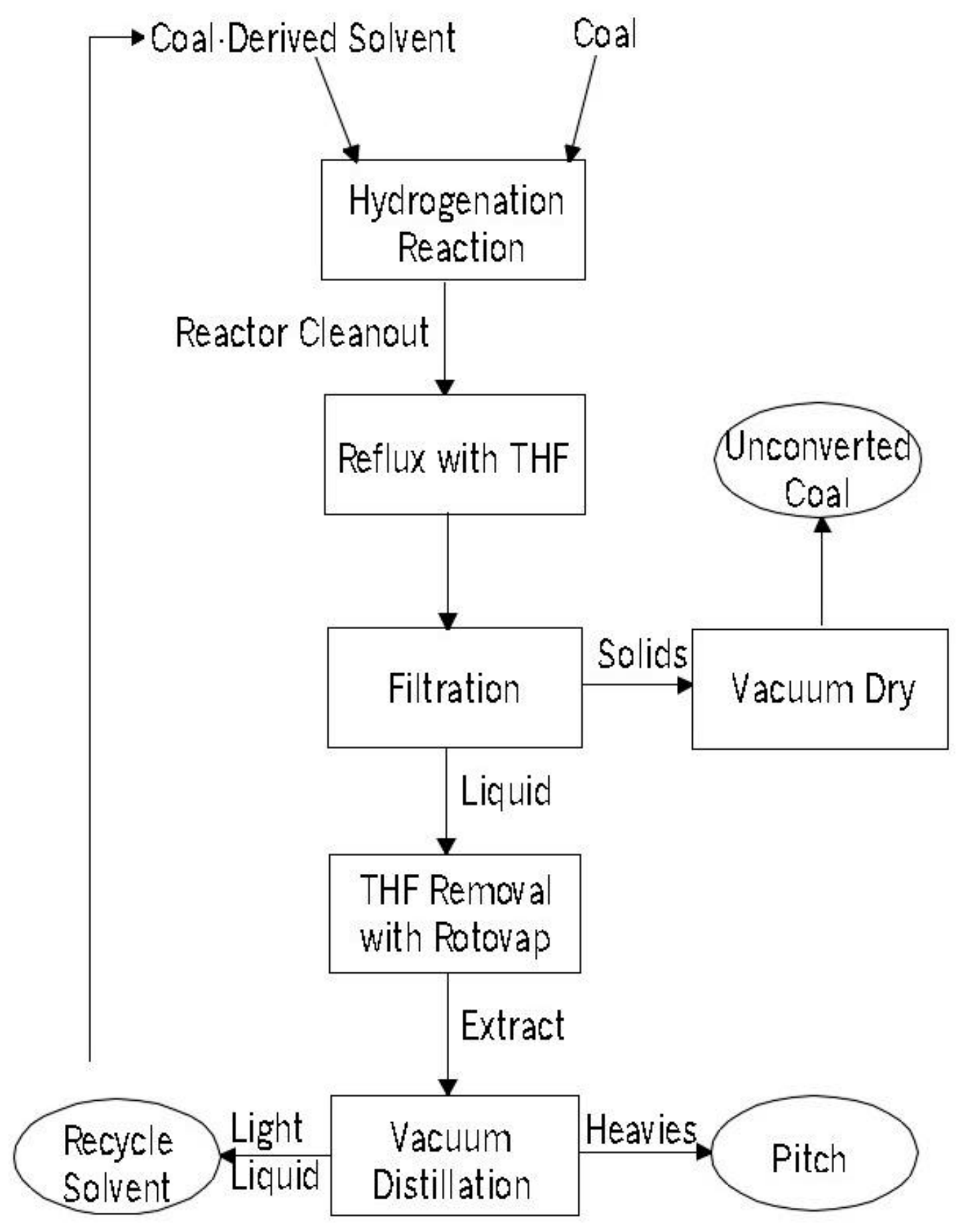

Figure 3.2 Experimental procedure flow sheet for production of carbon product precursors for coal hydrogenation reactions 


\subsubsection{Reactor Preparation}

Two tubing bomb microreactors (TBMR) were prepared for each hydrogenation run (see Figure 3.3). The reactors were cleaned thoroughly before each use. The inside of the reactors was scoured using an appropriately sized cylindrical wire brush. The threads of the end caps were wiped clean using steel wool. Air was then blown down the reactor stem to remove any particulates from the stem.

Once cleaned, one end of the reactor was sealed according to the following procedure. The TBMR was placed in a vise, and a small amount of copper anti-seize lubricant was applied to the threads. The lubricant helped to secure the Swagelok caps and prevented the caps from seizing to the reactor body under the high-temperature reaction conditions. The Swagelok cap was placed on the reactor and tightened until hand tight. An extra quarter turn was added using a wrench to seal the cap fully.

\subsubsection{Reactor Charging}

Reactants were weighed on an analytical balance (Denver Instruments Model A-200DS) to the nearest $0.1 \mathrm{mg}$ and then added to the reactor. The coal-derived solvent was placed in the reactor first. Since the coal liquids are viscous liquids, their mass was measured by difference. Once their mass was determined, the appropriate amount of coal was added to the reactor. The solvent-to-coal ratio was kept constant at 3 to 1 . Finally, some ball bearings (usually five) were weighed and added to the reactor. These were introduced to help stir the contents of the reactor during reaction. Once all the reactants had been charged, the open end of the TBMR was sealed according to step 3.2.3. 


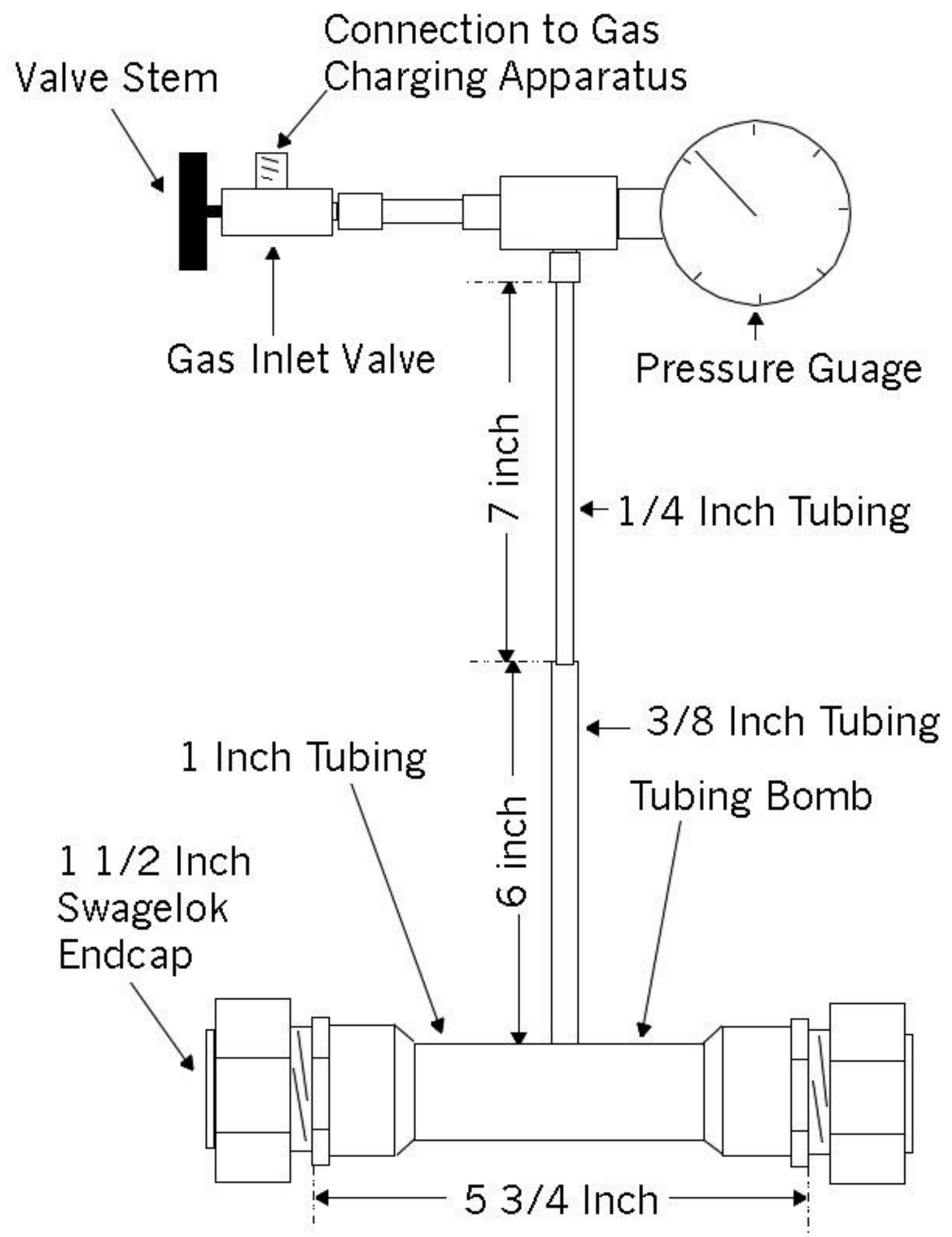

Figure 3.3 Overall view of the $50 \mathrm{~mL}$ tubing bomb microreactor 


\subsubsection{Gas Charging}

The hydrogenation reactions were run under either an argon or hydrogen atmosphere. This insured that oxygen would not react with the coal, promoting polymerization and the production of large insoluble coal fragments. Air was removed from the reactors by using a pressure purge cycle. The reactors were pressurized to 1000 psig initially with hydrogen or argon (depending on the specific hydrogenation run, see Table 3.3) and checked for leaks with a soap-water solution. The purge valve was then slowly opened to allow the reactor to reach atmospheric pressure again. Opening the purge valve slowly was essential so that none of the small particulates were lost during depressurization. This pressurization and release process was repeated two more times. Finally, the reactor was pressurized to the desired cold reaction pressure (see Table 3.3). The gas inlet valve of the tubular reactor was then closed, and the port on the gas inlet valve was sealed by screwing on a $1 / 4$-inch Swagelok plug.

\subsubsection{Reaction Procedure}

Once the reactors were charged with reactants and gas, they were placed in the reactor holder above the fluidized sand bath. The reactor holder was attached to a shaking mechanism used during the reaction. Once the reactors were secure in the holder, the shaking mechanism was turned on, and the speed was adjusted so that the reactors were vertically agitated at approximately $400 \mathrm{rpm}$ with a stroke of approximately 1.5 inches.

The reactors were then heated by immersion into the sand bath by raising the sand bath using a winch-and-pulley system. The sand bath was raised until the hot sand completely covered the reactor bodies. The temperature of the bath was then adjusted to the desired reaction temperature. Finally, a stopwatch was started to count down from 58 
minutes. The extra two minutes (total reaction time was to be $1 \mathrm{hr}$ ) allowed time to remove the reactors from the sand bath and quench the reaction.

Once the reaction time had elapsed (58 minutes), the sand bath was lowered by means of the winch-and-pulley system. The agitator was slowed down and then turned off. The reactors were removed from the holders and placed in a water bath. This served to cool the reactors quickly and quench the hydrogenation reactions.

\subsubsection{Product Collection}

The products of all the reactions except those using DACL-H or a solvent-to-coal ratio of $1 / 1$ were viscous fluids interlaced with some solid particles. The other two were more solid at ambient temperature and required a separate procedure for collecting the products of the reaction.

For all reactions except those with DACL-H or a solvent-to-coal ratio of $1 / 1$, the reactor was placed in a vise and the Swagelok plug was removed from the gas inlet valve. Then one end cap was slowly removed (so that the pressure could be released). The reactor was not vented through the gas inlet valve in order to keep the hydrogenation products in the main body (not the stem or pressure gauge) for ease of cleaning out the reactor. A small brush was used to clean any sand away from the reactor threads. The end cap was then replaced and only hand tightened. The reactor was flipped in the vice and the same procedure was used to loosen the other end cap.

A 500-mL flat-bottom boiling flask was placed in a clamp in a fume hood and fitted with a glass funnel. One end cap of the reactor was removed and the reactor was clamped over the funnel allowing its contents to drain into the funnel (when creosote oil, carbon black base, or raw antaeus coal liquids were used as the hydrogenation solvent, a heat gun was used to help promote this process). Once the products stop dripping, the reactor was filled with THF. A stainless steel spatula was used to scrape the sides of the reactor while it contained THF. The THF was then drained into the boiling flask. This 
process was repeated several times until all the reaction mass was washed from the reactor. The transfer of the reaction mass from the reactor must be quantitative since the subsequent mass balance and processing steps depend on this procedure.

The end cap was then placed on the open end of the reactor, and the reactor was turned upside down over the funnel. The opposite end cap was now removed and the reactor was again washed with THF several times. Next, both end caps were removed and the final particulates left in the reactor were washed into the flask. The gas inlet valve was opened and THF was used to flush any matter from the reactor stem. The end caps were then scraped and washed out with THF. Finally, the funnel was washed with THF and removed from the flask.

For reactions using DACL-H or the lowest solvent-to-coal ratio, the reactor was chilled in dry ice for approximately 15 minutes before being opened. The end caps were removed by the procedure described above. The contents of the reactor were then chipped out using a metal spatula into a large metal pan. Once the contents of the reactor were removed to the pan, the products were then poured from the pan into a $500-\mathrm{mL}$ flatbottom flask through a funnel. The pan, reactor, and funnel were finally washed with THF into the flask.

\subsubsection{THF Extraction}

The 500-mL round bottom flask containing the coal/solvent/THF solution was filled (if needed) with fresh THF until it was approximately $3 / 4$ full. The flask was placed in a heating mantle and fitted with a simple water-cooled condenser. The cooling water was turned on and the heating mantle temperature was adjusted using a variac. The power was set so that a rolling boil $\left(\cong 75^{\circ} \mathrm{C}\right)$ was obtained. The contents of the flask were allowed to boil overnight (usually 12-16 hours).

The flask was then cooled to room temperature. The contents of the flask were centrifuged for 30 minutes at 2000 rotations-per-minute. The liquid portion of the 
centrifuged product was poured into a Buchner-type filtering funnel that was under vacuum suction. The filtering funnel was fitted with a pre-weighed piece of filter paper. Following filtration, the solid product (residue) was washed with THF while in the filter funnel. The residues produced by centrifugation and vacuum filtration were finally combined to form the THF insoluble fraction.

The filtrate was poured into a clean, weighed $250-\mathrm{mL}$ flat bottom flask. The THF in the filtrate was removed by rotary evaporation and collected for later use. The soluble product (extract) was set aside for further processing.

The THF insoluble residue was then placed in a vacuum oven $\left(80{ }^{\circ} \mathrm{C}\right.$ and $25-30$ $\mathrm{mm} \mathrm{Hg}$ ) and allowed to dry overnight (16-20 hours) under a nitrogen purge (100 cc/min). The dried residue was then weighed and the amount of THF insoluble product was calculated. This weight was used to calculate the overall conversion using Equation 3-1. The coal-alone conversion was also calculated using Equation 3-2 [13]. It should be noted that for purposes of calculating the coal-alone conversion, all the THF insoluble matter was assumed to come from the coal only and not from the added solvent.

$$
\% \text { Overall Conversion }=\frac{[(\text { Mass of Reactants })-(\text { Mass of THF Insolubles })]}{\text { Mass of Reactants }}
$$

$\%$ Coal Conversion $(\mathrm{daf})=\frac{[(\text { Mass of Dry Coal })-(\text { Mass of THF Insolubles })]}{\text { Mass of Coal }(\text { daf })}$

It is important to note why THF was used in this process rather than NMP, which has been extensively used at West Virginia University as a solvent. Several preliminary reactions were performed using NMP as the extraction solvent, but a large mass loss was observed for the process. The majority of this mass loss occurred during the removal of NMP from the soluble products. Since NMP has a boiling point $\left(202{ }^{\circ} \mathrm{C}\right)$ in the range of many of the light products (particularly those to be collected as the recycle solvent), during the rotoevaporation of NMP, many of the reaction products were lost. Because 
one of the goals of this research was to isolate a possible recycle solvent, a solvent with a lower boiling point (THF) has been employed.

\subsubsection{Product Isolation}

Once the THF was removed from the extract, the THF-soluble hydrogenation products were separated using vacuum distillation. This was performed using the same procedure as described for separating the Antaeus coal tar into two fractions with one exception. The distillate was collected in a graduated cylinder in order to quantify the amount collected. The residue from the vacuum distillation was considered to be the soluble coal product (pitch). The distillate was the recycle solvent. The distillation was carried out several times (usually four) for each hydrogenation reaction. Each of these distillations collected a different amount of recycle solvent. The pitch and recycle solvent masses were calculated from each of these fractional distillations to determine the effect that the mass distilled had on the softening point of the pitch.

\subsection{Coal Extract Testing}

The properties of the coal extract pitches (i.e. high boiling distillate residues) collected from the hydrogenation reactions were evaluated as possible precursors for value-added carbon materials. These evaluation tests included softening point, coke yield, ash content, optical examination, and elemental analysis.

\subsubsection{Softening Point}

The softening point is required for the characterization of binder pitch, impregnation pitch, and pitch for fiber spinning. The softening point is a measure of the ability of the sample to flow and gives an indication of the rheological consistency of the sample. 
The softening point was determined in duplicate using a Mettler FP80HT central processor and a Mettler FP83HT dropping cell following the ASTM D3104 procedure [4]. The sample holder was filled with a sample and heated until melting occurs. The sample was then cooled and allowed to solidify into the sample holder. Additional sample was added and melted into the holder until full. The sample holder was then placed into the dropping cell, where it was heated at a rate of $2{ }^{\circ} \mathrm{C} / \mathrm{min}$ over a range of about $70-200{ }^{\circ} \mathrm{C}$.

The softening point was determined to be the temperature at which the sample, suspended in a cylindrical cup with a $1 / 4$ inch hole in the bottom, flowed downward for a distance of 0.8 inches to interfere with a light beam. The softening point was displayed automatically when the beam of light was interrupted.

\subsubsection{Coking Value}

The coking value provides some insight into the amount of non-volatile matter in the sample. It also gives some indication of the sample's relative coke forming propensity. A desired value for coke yield is between 50 and 60 percent by weight.

The coking value was determined using the West Virginia University (WVU) method. The sample (approximately $0.4-0.8$ grams) was placed in a pre-weighed porcelain crucible and immersed in coke breeze inside a larger crucible. The coke breeze allowed for the coking process to take place in the absence of oxygen. The sample was

$$
\text { Coking Value, } \%=100\left(\frac{\text { Mass of Residue After Heating }}{\text { Mass of Original Sample }}\right)
$$

then heated to $600{ }^{\circ} \mathrm{C}$ at a rate of $5{ }^{\circ} \mathrm{C} / \mathrm{min}$ in a Fisher Scientific Isotemp Programmable Furnace Model 497. The sample was held at $600{ }^{\circ} \mathrm{C}$ for two hours and then cooled 10 ${ }^{\circ} \mathrm{C} /$ min until reaching room temperature. The crucible was then removed from the coke breeze and weighed. The coking value was determined using Equation 3-3. This 
procedure was chosen for obtaining the coke yield so that the resultant coke sample's optical texture could be investigated. The long heating time allowed the characteristic domains of the sample to develop more fully.

\subsubsection{Ash Content}

After the carbon content of a sample has been burned in air, the ash is the remaining residue. The ash is the inorganic oxides of the mineral matter that were present in the original coal. For most carbon products, the ash or inorganic portion of the sample is considered an impurity.

The ash content determination was carried out in a Fisher Scientific Isotemp Programmable Furnace Model 497. The ash content was determined according to the procedure specified by ASTM D2415 [3]. The sample was placed in a pre-weighed, partially covered crucible, set in the furnace, and heated at a rate of $8{ }^{\circ} \mathrm{C} / \mathrm{min}$ until the furnace reaches $500{ }^{\circ} \mathrm{C}$ in air. The heating rate was then changed to $4{ }^{\circ} \mathrm{C} / \mathrm{min}$ until the temperature reaches $750{ }^{\circ} \mathrm{C}$. The sample was held here for three hours in air and then cooled at a rate of $10{ }^{\circ} \mathrm{C} / \mathrm{min}$ to ambient temperature. The final weight of the crucible and sample was determined, and the ash content was calculated from Equation 3-4.

$$
\text { Ash Content, } \%=100\left(\frac{\text { Mass of Residual Ash }}{\text { Mass of Original Sample }}\right) \quad 3-4
$$

\subsubsection{Optical Texture}

Once the pitch sample has been converted to coke, the optical texture can be determined. The texture of a coke can be isotropic, anisotropic, or in between. The degree of optical texture can give some insight into the possible end uses for the carbon sample. It also indicates the surface and graphitization properties of each of the samples. 
The optical texture of the sample was determined under a polarized-light optical microscope (Zeiss Axiostop, West Germany). The coke sample from the WVU method of coking was used to determine optical texture. The sample was embedded in epoxy resin and its cross section was polished on a Buchler Ltd. Metallurgical Apparatus with different textured abrasives. The sample was then observed under the Zeiss polarizedlight microscope and optical texture (isotropic or anisotropic) was determined. A camera was mounted on the polarized-light microscope to photograph the optical textures.

\subsubsection{Elemental Analysis}

An elemental analysis was performed on several representative pitches, residues, and recycle solvents. By combining this information with the elemental composition of the original hydrogenation reactants, an elemental balance could be performed for several different reaction conditions.

A Flash EA 1112 series elemental analyzer from ThermoQuest was used for this analysis. A small amount of sample (1-3 mg) was weighed and placed in a small tin container. Vanadium pentoxide $(3-5 \mathrm{mg})$ was added to the tin container for use as an oxidizing agent to insure complete combustion of the sample. The tin container was closed and crushed to evacuate all the air in the sample container. The sample was placed in the autosampler and the mass and sample name were recorded. The instrument then dropped the sample container into combustion reactor were the sample was converted into carbon dioxide, water, nitrogen oxides, and sulfur trioxide. The nitrogen oxides and sulfur trioxide were converted to elemental nitrogen and sulfur dioxide, respectively by reduction. These gases then passed into a gas chromatographic column, where they were separated. The eluted gases were detected by a thermal conductivity detector and processed to give the percentages of nitrogen, carbon, hydrogen, and sulfur in the sample with oxygen being determined by difference.

Several parameters could be adjusted to give the best results, such as carrier gas flow, oxygen flow rate, oxygen injection duration, cycle time, and sampling delay. The 
carrier gas was helium and was set at a flow rate of $130 \mathrm{ml} / \mathrm{min}$. Oxygen was used in the combustion reactor and was set at a flow rate of $240 \mathrm{ml} / \mathrm{min}$ for an injection time of 7 seconds. The cycle time for each sample was set at 600 seconds and the sample delay was 12 seconds. Each sample was analyzed in triplicate, and any erroneous values were discarded before averaging the results.

\subsection{Error Calculation}

In order to determine the accuracy and consistency of the experimental procedures presented herein, a percent relative error was calculated for the different quantitative characterization techniques. Unless otherwise noted in this report, all error is reported as a relative error. The relative error is a percent deviation from the average value of the number reported. For example, an error of $\pm 2 \%$ in a value of 90.00 means that the range of error of 88.2 to $91.8 \%$. The relative error was used to determine the error in two different values evaluated at the same conditions according to Equation 3-5.

$$
\% \text { Relative Error }=\left(\frac{\mid \text { Value 1 }- \text { Value 2 } \mid}{\left(\frac{\text { Value } 1+\text { Value 2 }}{2}\right)}\right) \times 100
$$




\section{CHAPTER 4}

\section{RESULTS AND DISCUSSION}

In this chapter, the results of the production of carbon product precursors from the direct hydrogenation of coal are presented. Hydrogenation reactions were performed with various coal-derived solvents under similar conditions in order to determine the most effective solvent. Several of the reaction conditions (pressure, gas-phase composition, and solvent-to-coal ratio) were then varied so that their role in producing carbon-product precursors could be assessed. The results focus on the effect of gas pressure, gas-phase composition, solvent, and solvent-to-coal ratio on the conversion of coal to pitch-like materials and the properties of the pitch. The resultant materials were characterized by softening point, ash content, coking value, and optical texture. Products from several of the hydrogenation runs were also characterized by elemental analysis. Overall mass and ash balances were also performed for each run and are presented here. By evaluating the results, an optimum set of reaction conditions for the production of carbon-product precursors from coal can be established.

\subsection{Mass Balances}

A mass balance was performed for each hydrogenation reaction trial. The components of the mass balance were the amount of coal and solvent charged into the reactor and the amount of pitch, THF insolubles (residue), and recycle solvent collected after processing the hydrogenation products. The results of the mass balances can be seen in Table 4.1. The conditions for each hydrogenation run are given in Table 3.3.

For every reaction, a negative mass balance was observed, indicating a net loss of mass during the reaction and product separation steps. There are several different explanations for the negative mass balances. First, any product gas that may have formed during the reactions was not collected and quantified and thus is absent from the mass balance calculation. Typically the mass loss due to gas production could be between 2 $5 \%$ by weight. Second, any light material that was produced during the hydrogenation 
Table 4.1 Overall Mass Balances of the Coal Hydrogenation Reactions

\begin{tabular}{|c|c|c|c|c|c|c|c|c|c|c|}
\hline Run & Trial & $\begin{array}{c}\text { In } \\
\text { Coal }(g)\end{array}$ & $\begin{array}{c}\text { In } \\
\text { Solvent (g) }\end{array}$ & $\begin{array}{l}\text { Total } \\
\text { In }(g)\end{array}$ & $\begin{array}{c}\text { Out } \\
\text { Pitch }(g)\end{array}$ & \begin{tabular}{|c|} 
Out \\
THF Ins. (g)
\end{tabular} & $\begin{array}{c}\text { Out } \\
\text { Rec. Solv. } \\
\text { (g) }\end{array}$ & $\begin{array}{l}\text { Total } \\
\text { Out }(\mathrm{g})\end{array}$ & $\begin{array}{l}\text { Out - In } \\
\text { (g) }\end{array}$ & $\begin{array}{c}(\text { Out-In)/In } \\
(\%)\end{array}$ \\
\hline 1 & $A$ & 8.3812 & 25.1046 & 33.4858 & 8.5037 & 4.6171 & 16.6769 & 29.7977 & -3.6881 & -11.0 \\
\hline 1 & $B$ & 8.4897 & 25.4679 & 33.9576 & 12.3280 & 4.7903 & 14.4829 & 31.6012 & -2.3564 & -6.9 \\
\hline 1 & C & 8.3809 & 25.1423 & 33.5232 & 9.6637 & 4.8612 & 15.3188 & 29.8437 & -3.6795 & -11.0 \\
\hline 1 & D & 8.4776 & 25.4351 & 33.9127 & 6.9489 & 4.8407 & 17.4629 & 29.2525 & -4.6602 & -13.7 \\
\hline 2 & A & 5.9996 & 17.9994 & 23.999 & 17.2400 & 6.6085 & 0.0000 & 23.8485 & -0.1505 & -0.6 \\
\hline 2 & $B$ & 5.9988 & 17.9999 & 23.9987 & 16.2053 & 6.6643 & 0.0000 & 22.8696 & -1.1291 & -4.7 \\
\hline 2 & C & 6.0008 & 18.0008 & 24.0016 & 12.7595 & 6.8085 & 1.9900 & 21.558 & -2.4436 & -10.2 \\
\hline 2 & $D$ & 6.0009 & 17.9990 & 23.9999 & 9.5452 & 7.2738 & 3.9600 & 20.779 & -3.2209 & -13.4 \\
\hline 3 & A & 7.6118 & 22.8324 & 30.4442 & 9.9431 & 6.9708 & 10.2900 & 27.2039 & -3.2403 & -10.6 \\
\hline 3 & $B$ & 7.6541 & 22.9600 & 30.6141 & 11.5130 & 7.1990 & 9.7100 & 28.422 & -2.1921 & -7.2 \\
\hline 3 & C & 7.6744 & 23.0200 & 30.6944 & 8.8603 & 7.2135 & 11.2000 & 27.2738 & -3.4206 & -11.1 \\
\hline 3 & D & 8.2833 & 24.8500 & 33.1333 & 12.2342 & 8.6765 & 9.0800 & 29.9907 & -3.1426 & -9.5 \\
\hline 4 & A & 8.7873 & 26.3643 & 35.1516 & 11.0642 & 6.0297 & 14.6300 & 31.7239 & -3.4277 & -9.8 \\
\hline 4 & $B$ & 8.8595 & 26.5785 & 35.438 & 5.4141 & 6.4669 & 21.2400 & 33.121 & -2.317 & -6.5 \\
\hline 4 & C & 8.8076 & 26.4215 & 35.2291 & 7.5975 & 6.2503 & 17.1900 & 31.0378 & -4.1913 & -11.9 \\
\hline 4 & $D$ & 8.9488 & 26.8472 & 35.796 & 6.4161 & 6.5263 & 17.4800 & 30.4224 & -5.3736 & -15.0 \\
\hline 4 & $E$ & 8.7055 & 26.1183 & 34.8238 & 7.1096 & 6.9566 & 20.2183 & 34.2845 & -0.5393 & -1.5 \\
\hline 5 & A & 9.0940 & 27.2847 & 36.3787 & 8.6773 & 6.9411 & 19.1700 & 34.7884 & -1.5903 & -4.4 \\
\hline 5 & $B$ & 8.9570 & 26.8698 & 35.8268 & 7.1536 & 7.0941 & 20.6700 & 34.9177 & -0.9091 & -2.5 \\
\hline 5 & C & 8.8303 & 26.4937 & 35.324 & 5.6086 & 6.9512 & 21.2800 & 33.8398 & -1.4842 & -4.2 \\
\hline 5 & $D$ & 8.8314 & 26.4938 & 35.3252 & 8.5937 & 7.0349 & 19.2400 & 34.8686 & -0.4566 & -1.3 \\
\hline 6 & A & 8.6048 & 25.8137 & 34.4185 & 6.0769 & 7.2494 & 16.9400 & 30.2663 & -4.1522 & -12.1 \\
\hline 6 & $B$ & 9.0270 & 27.0806 & 36.1076 & 4.7830 & 8.1360 & 20.5800 & 33.499 & -2.6086 & -7.2 \\
\hline 6 & C & 8.5940 & 25.7836 & 34.3776 & 3.4138 & 7.9002 & 21.8700 & 33.184 & -1.1936 & -3.5 \\
\hline 6 & $D$ & 8.9388 & 26.8162 & 35.755 & 6.5164 & 7.8078 & 19.1700 & 33.4942 & -2.2608 & -6.3 \\
\hline 7 & $A$ & 8.5583 & 25.6744 & 34.2327 & 6.4744 & 7.0102 & 17.7300 & 31.2146 & -3.0181 & -8.8 \\
\hline 7 & $B$ & 8.9103 & 26.7293 & 35.6396 & 5.3671 & 7.2512 & 21.4800 & 34.0983 & -1.5413 & -4.3 \\
\hline 7 & C & 8.6285 & 25.8895 & 34.518 & 5.4428 & 7.7470 & 18.8400 & 32.0298 & -2.4882 & -7.2 \\
\hline 7 & D & 8.8169 & 26.4519 & 35.2688 & 7.7059 & 7.7566 & 17.9700 & 33.4325 & -1.8363 & -5.2 \\
\hline
\end{tabular}


Table 4.1 (Continued) Overall Mass Balances of the Coal Hydrogenation Reactions

\begin{tabular}{|c|c|c|c|c|c|c|c|c|c|c|}
\hline Run & Trial & $\begin{array}{c}\text { In } \\
\text { Coal (g) }\end{array}$ & $\begin{array}{c}\text { In } \\
\text { Solvent }(\mathrm{g})\end{array}$ & $\begin{array}{l}\text { Total } \\
\text { In (g) }\end{array}$ & $\begin{array}{c}\text { Out } \\
\text { Pitch (g) }\end{array}$ & $\begin{array}{c}\text { Out } \\
\text { THF Ins. (g) }\end{array}$ & $\begin{array}{c}\text { Out } \\
\text { Rec. Solv. } \\
\text { (g) }\end{array}$ & $\begin{array}{l}\text { Total } \\
\text { Out (g) }\end{array}$ & $\begin{array}{l}\text { Out - In } \\
\text { (g) }\end{array}$ & $\begin{array}{c}(\text { Out-In)/ln } \\
(\%)\end{array}$ \\
\hline 8 & A & 8.9144 & 26.7416 & 35.656 & 7.3802 & 8.0749 & 17.6100 & 33.0651 & -2.5909 & -7.3 \\
\hline 8 & B & 8.5729 & 25.7200 & 34.2929 & 3.9747 & 7.6985 & 20.1200 & 31.7932 & -2.4997 & -7.3 \\
\hline 8 & C & 8.8134 & 26.4439 & 35.2573 & 6.1858 & 8.3588 & 18.5200 & 33.0646 & -2.1927 & -6.2 \\
\hline 8 & D & 8.6033 & 25.8076 & 34.4109 & 4.9405 & 7.8483 & 19.6000 & 32.3888 & -2.0221 & -5.9 \\
\hline 9 & $A$ & 8.9656 & 26.8936 & 35.8592 & 8.7617 & 8.2419 & 17.1200 & 34.1236 & -1.7356 & -4.8 \\
\hline 9 & $B$ & 8.6900 & 26.0717 & 34.7617 & 5.4339 & 8.1171 & 19.1000 & 32.651 & -2.1107 & -6.1 \\
\hline 9 & C & 9.1626 & 27.4904 & 36.653 & 5.6319 & 8.4754 & 18.9100 & 33.0173 & -3.6357 & -9.9 \\
\hline 10 & A & 8.5836 & 25.7540 & 34.3376 & 7.3670 & 8.5019 & 15.8400 & 31.7089 & -2.6287 & -7.7 \\
\hline 10 & B & 9.0234 & 27.0691 & 36.0925 & 4.7132 & 8.9974 & 18.9400 & 32.6506 & -3.4419 & -9.5 \\
\hline 10 & C & 8.6621 & 25.9863 & 34.6484 & 6.4714 & 7.9306 & 17.1300 & 31.532 & -3.1164 & -9.0 \\
\hline 10 & D & 8.8383 & 26.5110 & 35.3493 & 6.1156 & 7.9726 & 17.4600 & 31.5482 & -3.8011 & -10.8 \\
\hline 11 & A & 11.7463 & 23.4898 & 35.2361 & 7.2230 & 8.5762 & 14.3000 & 30.0992 & -5.1369 & -14.6 \\
\hline 11 & $B$ & 11.5104 & 23.0186 & 34.529 & 8.0716 & 8.7815 & 15.2900 & 32.1431 & $\mid-2.3859$ & -6.9 \\
\hline 11 & C & 11.6680 & 23.3358 & 35.0038 & 6.8942 & 9.1683 & 15.8000 & 31.8625 & -3.1413 & -9.0 \\
\hline 11 & D & 11.5366 & 23.0717 & 34.6083 & 6.9836 & 8.6664 & 17.2200 & 32.87 & -1.7383 & -5.0 \\
\hline 12 & A & 14.9673 & 14.9673 & 29.9346 & 8.1438 & 10.7303 & 8.5800 & 27.4541 & -2.4805 & -8.3 \\
\hline 12 & $B$ & 15.1486 & 15.1480 & 30.2966 & 7.5261 & 11.1392 & 9.5600 & 28.2253 & -2.0713 & -6.8 \\
\hline 12 & C & 15.7095 & 15.7103 & 31.4198 & 6.2607 & 11.1933 & 9.7100 & 27.164 & -4.2558 & -13.5 \\
\hline 12 & D & 15.4615 & 15.4618 & 30.9233 & 8.1711 & 11.1289 & 9.2400 & 28.54 & -2.3833 & -7.7 \\
\hline
\end{tabular}


reaction that condensed upon quenching of the reaction could have been lost during the THF extraction process. During THF removal by rotary evaporation, some of this lighter material could have become volatile and collected with the removed THF causing a negative mass balance. These types of materials would also be lost during the initial period of vacuum distillation. Any very light material would not condense in the graduated cylinder with the other recycle solvent but would rather be collected in the cold trap of the vacuum pump. This was confirmed by periodically checking the cold trap of the vacuum pump for the presence of collected liquid (small amounts of liquid were usually present). Finally, the process of separating the hydrogenation products into different fractions (pitch, residue, and recycle solvent) required a significant amount of experimental transfers and procedures. Each of these procedures resulted in some amount of mass loss.

For the majority of the reaction runs listed in Table 4.1, the amount of mass loss was around $10 \%$ by weight or less. This is a reasonable result considering the procedures that were used in obtaining the product fractions. Several of the runs did, however, have a mass loss of greater than $10 \%$. This is most likely due to mass loss that occurred during the vacuum distillation step of product separation. The majority of the distillate (recycle solvent) needed to be heated in the condensing tube in order to make it flow into the graduated cylinder for collection. During these runs of greater lost mass, some recycle solvent could have been left in the condensing tube and therefore, not accounted for in the mass balance calculation. An example of this effect can be seen by evaluating the product distribution of the different trials of run twelve (12). Since, the only difference in processing from trial to trial was the amount of recycle solvent removed during vacuum distillation (as seen in the column labeled "Out Rec. Solv."), the percent of THF solubles (the sum of the pitch and recycle solvent fractions) of the feed should be equivalent for each run. Also, since the hydrogenation reaction and product isolation procedures are the same, the amount of mass loss from gas production and experimental error should be equivalent for each trial. Figure 4.1 shows that this assumption was accurate for three of the four trials. Trial $\mathrm{C}$ had a dip in the amount of THF solubles recovered, which explains the spike in the loss of mass data. This dip in 


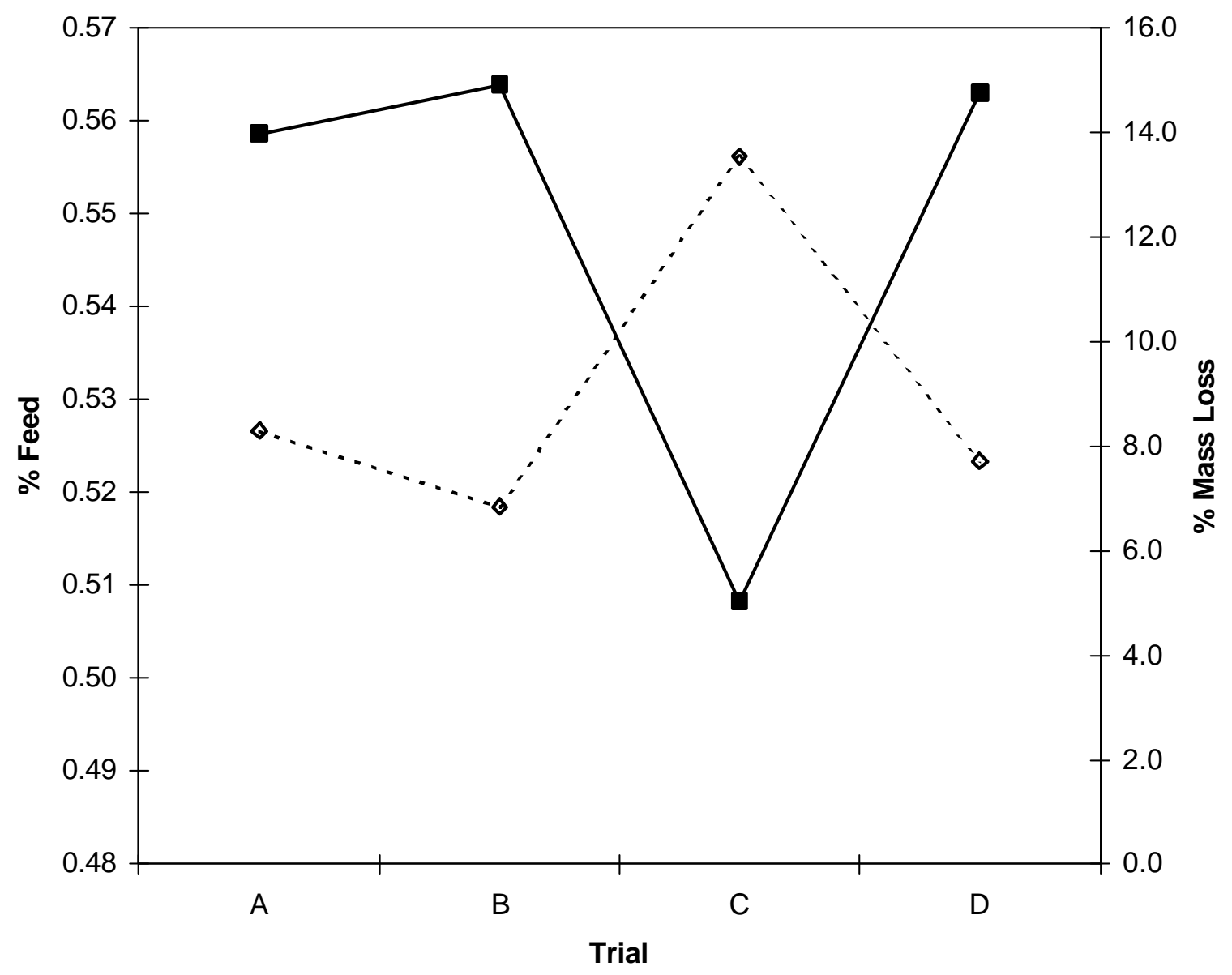

$\longrightarrow$ - Feed Converted to Pitch and Rec. Solv. - - - - . \% Total Mass Loss of Run

Figure 4.1 Comparison of the percent of the reaction feed recovered as THF solubles and the total mass lost during each trial of hydrogenation run twelve (12) 
the THF solubles recovered corresponds to mass lost by some distillate accumulating in the condensation tube of the distillation apparatus.

The presence of a negative mass balance will have some effects on further calculations and results below. The error from the mass balance is carried over into any calculation that depends on the data from the mass balance such as an ash balance or elemental balance. However, the accuracy of the mass balance (within 10\%) is good for this type of reaction system.

\subsection{Ash Balance}

An ash balance was performed on the products for all hydrogenation reactions and is presented in Table 4.2 with the various run conditions presented in Table 3.3. The ash content for each sample was determined according to the procedure outlined in Section 3.3.3 and on average had a relative error of less than $\pm 2 \%$. The ash content was determined for the reactants (coal and solvent) and for the pitch and THF insoluble portion of the products. Several samples of the recovered recycle solvent (the distillate) were tested for ash, but as expected the values were negligible. Therefore, the recycle solvent portion of the products was eliminated from the ash balance calculations. The weight of ash in each fraction was determined by multiplying the amount of each fraction (from the mass balance) by the ash percentage of that particular sample.

The results of the ash balance in Table 4.2 show a relatively random distribution of gain and loss of ash during the pitch production process. Since the ash balance depends on the mass of each fraction for calculation, any error in the mass balance will effect the ash balance results. Two figures, the ash present in the coal and the ash present in the THF insoluble residue, dominate the ash balance. The positive ash balance corresponds to the negative values of the mass balance calculations. If organic material is lost, the percentage of ash is elevated in the products, thus producing a positive ash balance. A negative ash balance could be attributed to incomplete separation of THF solubles and insolubles. A small amount of THF solubles mixed with insolubles would cause a 
Table 4.2 Ash Balance of Hydrogenation Reactants and Products for All Runs

\begin{tabular}{|c|c|c|c|c|c|c|c|c|c|}
\hline Run & Trial & $\begin{array}{l}\text { Ash In } \\
\text { Coal (g) }\end{array}$ & $\begin{array}{l}\text { Ash In } \\
\text { Solv. (g) }\end{array}$ & $\begin{array}{c}\text { Total Ash } \\
\text { In (g) }\end{array}$ & $\begin{array}{l}\text { Ash Out } \\
\text { Pitch (g) }\end{array}$ & $\begin{array}{c}\text { Ash Out THF } \\
\text { Ins. (g) }\end{array}$ & $\begin{array}{l}\text { Total Ash } \\
\text { Out (g) }\end{array}$ & $\begin{array}{l}\text { Out - In } \\
\text { (g) }\end{array}$ & $\begin{array}{c}\text { (Out-In)/In } \\
(\%)\end{array}$ \\
\hline 1 & A & 0.6030 & 0.0000 & 0.6030 & 0.0094 & 0.5333 & 0.5426 & -0.0604 & -10.0 \\
\hline 1 & B & 0.6108 & 0.0000 & 0.6108 & 0.0100 & 0.5207 & 0.5308 & -0.0801 & -13.1 \\
\hline 1 & $C$ & 0.6030 & 0.0000 & 0.6030 & 0.0100 & 0.5882 & 0.5982 & -0.0048 & -0.8 \\
\hline 1 & $\mathrm{D}$ & 0.6100 & 0.0000 & 0.6100 & 0.0025 & 0.5228 & 0.5253 & -0.0846 & -13.9 \\
\hline 2 & $\bar{A}$ & 0.4317 & 0.0243 & 0.4560 & 0.0000 & 0.4011 & 0.4011 & -0.0548 & -12.0 \\
\hline 2 & B & 0.4316 & 0.0243 & 0.4559 & 0.0045 & 0.4538 & 0.4584 & 0.0025 & 0.5 \\
\hline 2 & $\mathrm{C}$ & 0.4318 & 0.0243 & 0.4561 & 0.0031 & 0.4837 & 0.4869 & 0.0308 & 6.8 \\
\hline 2 & $\mathrm{D}$ & 0.4318 & 0.0243 & 0.4561 & 0.0029 & 0.5110 & 0.5139 & 0.0578 & 12.7 \\
\hline 3 & $A$ & 0.5477 & 0.0215 & 0.5691 & 0.0026 & 0.6012 & 0.6039 & 0.0347 & 6.1 \\
\hline 3 & B & 0.5507 & 0.0216 & 0.5723 & 0.1036 & 0.5604 & 0.6641 & 0.0918 & 16.0 \\
\hline 3 & C & 0.5522 & 0.0216 & 0.5738 & 0.0020 & 0.5558 & 0.5578 & -0.0160 & -2.8 \\
\hline 3 & $\mathrm{D}$ & 0.5960 & 0.0234 & 0.6193 & 0.0032 & 0.5809 & 0.5841 & -0.0353 & -5.7 \\
\hline 4 & $A$ & 0.6322 & 0.0000 & 0.6322 & 0.0023 & 0.7169 & 0.7193 & 0.0870 & 13.8 \\
\hline 4 & $B$ & 0.6374 & 0.0000 & 0.6374 & 0.0004 & 0.7146 & 0.7150 & 0.0776 & 12.2 \\
\hline 4 & $C$ & 0.6337 & 0.0000 & 0.6337 & 0.0014 & 0.6644 & 0.6658 & 0.0321 & 5.1 \\
\hline 4 & $\mathrm{D}$ & 0.6439 & 0.0000 & 0.6439 & 0.0015 & 0.8452 & 0.8467 & 0.2028 & 31.5 \\
\hline 4 & $E$ & 0.6264 & 0.0000 & 0.6264 & 0.0036 & 0.8035 & 0.8071 & 0.1807 & 28.9 \\
\hline 5 & $A$ & 0.6543 & 0.0132 & 0.6675 & 0.0039 & 0.7101 & 0.7140 & 0.0465 & 7.0 \\
\hline 5 & $B$ & 0.6445 & 0.0130 & 0.6575 & 0.0066 & 0.7874 & 0.7941 & 0.1366 & 20.8 \\
\hline 5 & $\mathrm{C}$ & 0.6353 & 0.0128 & 0.6482 & 0.0018 & 0.7229 & 0.7247 & 0.0766 & 11.8 \\
\hline 5 & $\bar{D}$ & 0.6354 & 0.0128 & 0.6483 & 0.0020 & 0.6979 & 0.6998 & 0.0516 & 8.0 \\
\hline 6 & $A$ & 0.6191 & 0.0125 & 0.6316 & 0.0042 & 0.5919 & 0.5961 & -0.0355 & -5.6 \\
\hline 6 & B & 0.6495 & 0.0131 & 0.6626 & 0.0093 & 0.6379 & 0.6472 & -0.0154 & -2.3 \\
\hline 6 & $C$ & 0.6183 & 0.0125 & 0.6308 & 0.0000 & 0.0000 & 0.0000 & -0.6308 & -100.0 \\
\hline 6 & $\mathrm{D}$ & 0.6431 & 0.0130 & 0.6562 & 0.0027 & 0.6207 & 0.6234 & -0.0328 & -5.0 \\
\hline 7 & $A$ & 0.6158 & 0.0125 & 0.6282 & 0.0024 & 0.7115 & 0.7139 & 0.0857 & 13.6 \\
\hline 7 & $B$ & 0.6411 & 0.0130 & 0.6541 & 0.0027 & 0.6910 & 0.6937 & 0.0396 & 6.1 \\
\hline 7 & $C$ & 0.6208 & 0.0126 & 0.6334 & 0.0009 & 0.7402 & 0.7411 & 0.1077 & 17.0 \\
\hline 7 & $\mathrm{D}$ & 0.6344 & 0.0128 & 0.6472 & 0.0014 & 0.8044 & 0.8057 & 0.1585 & 24.5 \\
\hline
\end{tabular}


Table 4.2 (Continued) Ash Balance of Hydrogenation Reactants and Products for All Runs

\begin{tabular}{|c|c|c|c|c|c|c|c|c|c||}
\hline \hline Run & Trial & Coal (g) & Solv. (g) & $\begin{array}{c}\text { Ash In } \\
\text { In }\end{array}$ & $\begin{array}{c}\text { Ash Out } \\
\text { Pitch (g) }\end{array}$ & $\begin{array}{c}\text { Ash Out THF } \\
\text { Ins. (g) }\end{array}$ & $\begin{array}{c}\text { Total Ash } \\
\text { Out (g) }\end{array}$ & $\begin{array}{c}\text { Out - In } \\
\text { (g) }\end{array}$ & $\begin{array}{c}\text { (Out-In)/In } \\
(\%)\end{array}$ \\
\hline \hline 8 & A & 0.6414 & 0.0130 & 0.6544 & 0.0020 & 0.6952 & 0.6973 & 0.0429 & 6.6 \\
\hline 8 & B & 0.6168 & 0.0125 & 0.6293 & 0.0028 & 0.6671 & 0.6699 & 0.0406 & 6.4 \\
\hline 8 & C & 0.6341 & 0.0128 & 0.6469 & 0.0010 & 0.6503 & 0.6513 & 0.0043 & 0.7 \\
\hline 8 & D & 0.6190 & 0.0125 & 0.6315 & 0.0008 & 0.6169 & 0.6177 & -0.0138 & -2.2 \\
\hline 9 & A & 0.6451 & 0.0130 & 0.6581 & 0.0032 & 0.7030 & 0.7062 & 0.0481 & 7.3 \\
\hline 9 & B & 0.6252 & 0.0126 & 0.6379 & 0.0019 & 0.6871 & 0.6890 & 0.0511 & 8.0 \\
\hline 9 & C & 0.6592 & 0.0133 & 0.6726 & 0.0058 & 0.6539 & 0.6596 & -0.0129 & -1.9 \\
\hline 10 & A & 0.6176 & 0.0125 & 0.6301 & 0.0056 & 0.6780 & 0.6836 & 0.0535 & 8.5 \\
\hline 10 & B & 0.6492 & 0.0131 & 0.6624 & 0.0101 & 0.7355 & 0.7456 & 0.0833 & 12.6 \\
\hline 10 & C & 0.6232 & 0.0126 & 0.6358 & 0.0055 & 0.6491 & 0.6546 & 0.0188 & 3.0 \\
\hline 10 & D & 0.6359 & 0.0129 & 0.6488 & 0.0066 & 0.6306 & 0.6372 & -0.0115 & -1.8 \\
\hline 11 & A & 0.8451 & 0.0000 & 0.8451 & 0.0077 & 0.9177 & 0.9254 & 0.0802 & 9.5 \\
\hline 11 & B & 0.8282 & 0.0000 & 0.8282 & 0.0068 & 0.9484 & 0.9552 & 0.1270 & 15.3 \\
\hline 11 & C & 0.8395 & 0.0000 & 0.8395 & 0.0022 & 0.9627 & 0.9649 & 0.1254 & 14.9 \\
\hline 11 & D & 0.8301 & 0.0000 & 0.8301 & 0.0171 & 0.8926 & 0.9097 & 0.0797 & 9.6 \\
\hline 12 & A & 1.0769 & 0.0000 & 1.0769 & 0.0016 & 1.0999 & 1.1015 & 0.0246 & 2.3 \\
\hline 12 & B & 1.0899 & 0.0000 & 1.0899 & 0.0047 & 1.0359 & 1.0406 & -0.0493 & -4.5 \\
\hline 12 & C & 1.1303 & 0.0000 & 1.1303 & 0.0015 & 1.1361 & 1.1376 & 0.0073 & 0.6 \\
\hline 12 & D & 1.1125 & 0.0000 & 1.1125 & 0.0033 & 1.1079 & 1.1112 & -0.0013 & -0.1 \\
\hline \hline
\end{tabular}


negative deviation in the ash content of the THF insolubles. Incomplete separation of the THF fractions could be attributed to the swelling of the filter paper and a large filter cake being formed during vacuum filtration. When the filtration slowed for these reasons, THF was removed by evaporation into the fume hood, depositing some THF solubles on the residue fraction, thus decreasing the ash content in the THF insoluble fraction and causing a negative ash balance.

\subsection{Solvent Evaluation}

The first goal of this research was to determine the effectiveness of five coalderived liquids as hydrogen-donor solvents for coal. Each of the five coal liquids was used as a hydrogenation solvent under the same conditions. These reactions are run numbers one (1) through five (5) from Table 3.3. Initially, these liquids were characterized according to their ability to convert coal to THF soluble material. Two different methods of measuring their effectiveness were used: (1) the overall conversion based on the total feed (i.e. coal plus solvent) and (2) the coal-alone conversion based on the weight of coal only. The definition of these conversions is given by Equations 3-1 and 3-2, respectively in Section 3.2.8.

The overall conversion for each of the solvents is given in Figure 4.2. These results show that the most effective solvent for conversion to THF solubles was DACL-L at $85.8 \pm 0.3 \%$. The least effective solvent was DACL-H at $71.5 \pm 1.3 \%$ overall conversion. As expected, the overall conversion achieved using RACL falls between the above two values at $76.0 \pm 1.5 \%$. The two liquids from Koppers Industries, Inc., HCO and $\mathrm{CBB}$ were also very effective according to Figure 4.2 with overall conversion values of $82.2 \pm 1.1 \%$ and $80.4 \pm 0.4 \%$, respectively.

The conversion results are quite different, however, when the coal-alone conversion is used. Figure 4.3 illustrates the effectiveness of the coal liquids as hydrogenation solvents on a coal-only basis. The order of conversion for each solvent 


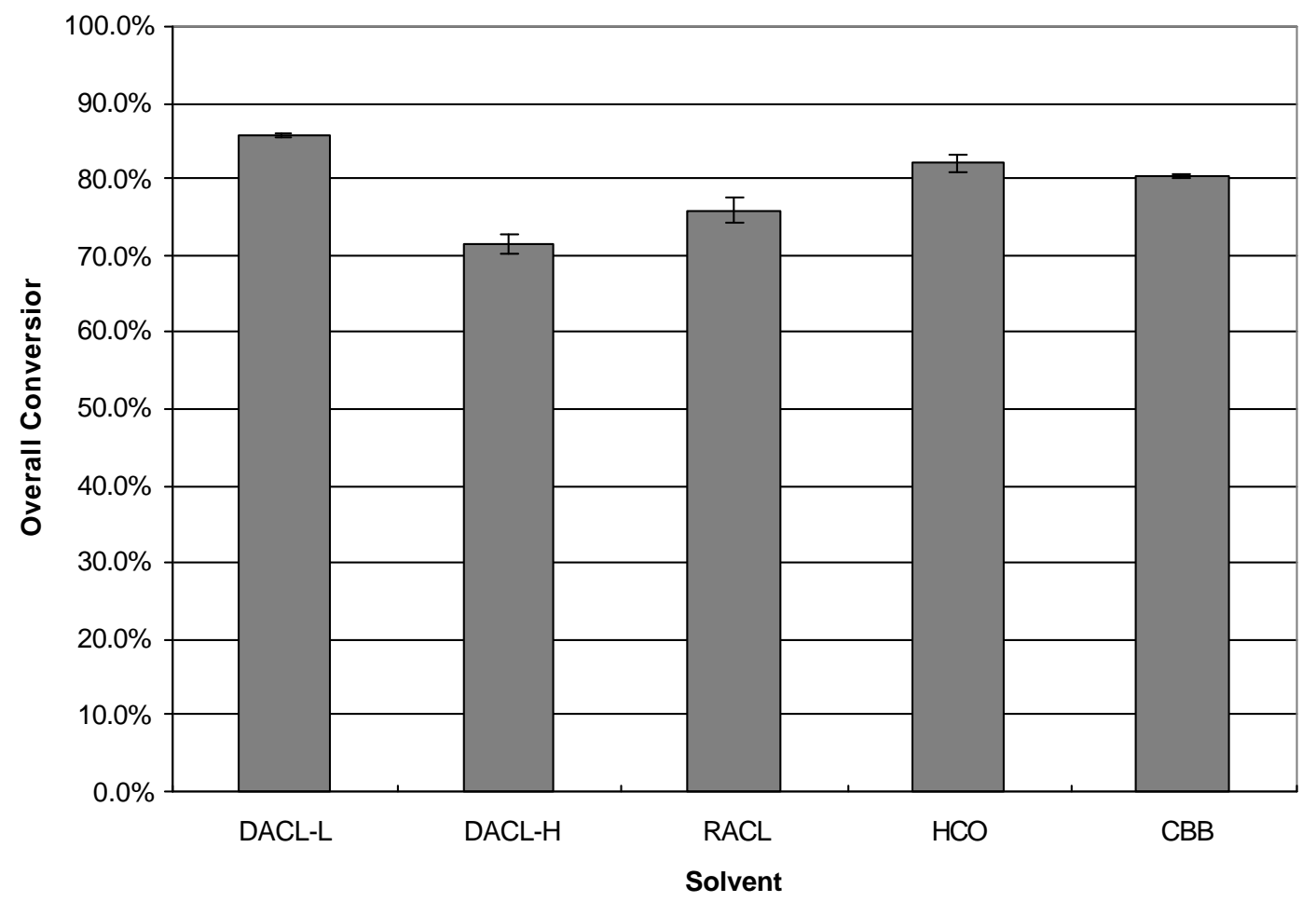

Figure 4.2 The effect of the hydrogenation solvent on the overall conversion to THF solubles at the reaction conditions of $400{ }^{\circ} \mathrm{C}, 1000 \mathrm{psig} \mathrm{H}_{2}$ (cold), 3/1 solventto-coal ratio, and 1 hour 


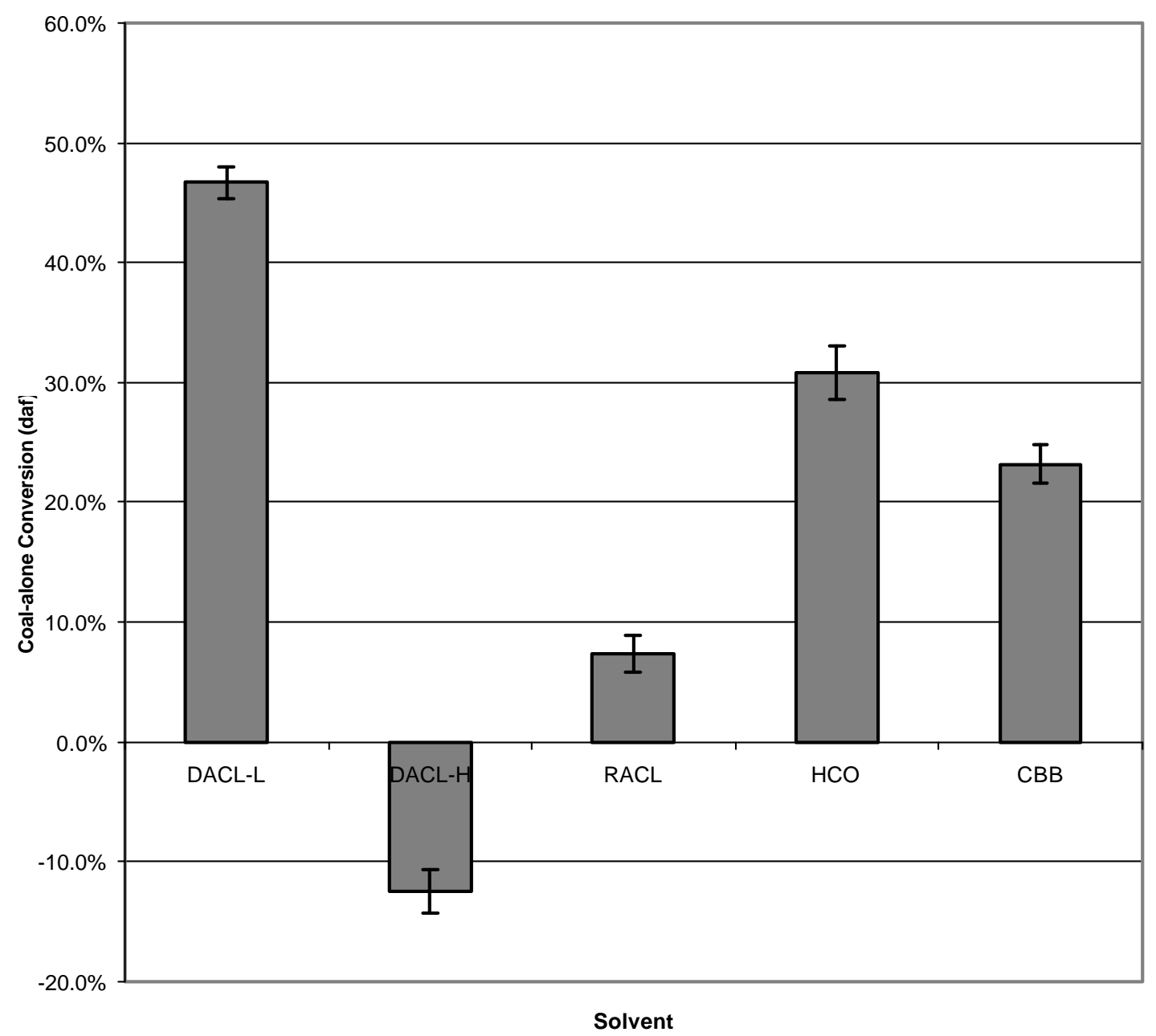

Figure 4.3 The effect of the hydrogenation solvent on the coal-alone conversion (daf basis) of coal to THF solubles at the reaction conditions of $400{ }^{\circ} \mathrm{C}, 1000$ psig $\mathrm{H}_{2}$ (cold), 3/1 solvent-to-coal ratio, and 1 hour 
when compared to the other solvents did not change by going to a coal-only basis. However, the absolute value of the conversion changed drastically for each solvent. The coal-alone conversion for reactions using DACL-L was $46.7 \pm 1.3 \%$ while a conversion of $-12.5 \pm 1.8 \%$ was calculated for DACL-H reactions. The negative conversion signified that not only was very little of the coal converted to THF solubles, but also some of the hydrogenation solvent (DACL-H) was insoluble in THF due to possible coking reactions. The coal-alone conversion for the hydrogenation reactions using RACL, HCO, and CBB were $7.3 \pm 1.5 \%, 30.8 \pm 2.2 \%$, and $23.2 \pm 1.6 \%$, respectively.

The reason for the large difference between the values of the two methods of calculating the conversions is that the overall conversion includes the solvent in its calculation, while the coal-alone conversion does not. Because the coal liquids (solvents)

exhibited a high solubility in THF to begin with and the use of high solvent-to-coal ratio (3/1 by weight), the majority of the THF soluble fraction of the hydrogenation products was derived from the solvent itself. Therefore, the effect of changing solvents on coal conversion was masked by the large amount of solvent that was being included in the overall conversion calculation. But nonetheless, the DACL-L did a reasonable job by converting about $47 \%$ of the coal to THF-soluble products.

\subsection{Reaction Pressure}

The reactor pressures were recorded throughout all hydrogenation reactions in order to gain some insight into the role that the hydrogen atmosphere might play in the coal conversion. An empty reactor charged with hydrogen gas (1000 psig cold) only was also heated to the reaction temperature, and the pressure was recorded throughout the time scale of other hydrogenation reactions. The average reaction pressure recorded over time for each solvent is illustrated in Figure 4.4. The most glaring observation from Figure 4.4 is that after the pressure reached a maximum (between 1950 and 2150 psig depending on the solvent) due to the rapid heating, the pressure decreased with time for each run except for the empty reactor. There are two possible reasons for the observed 


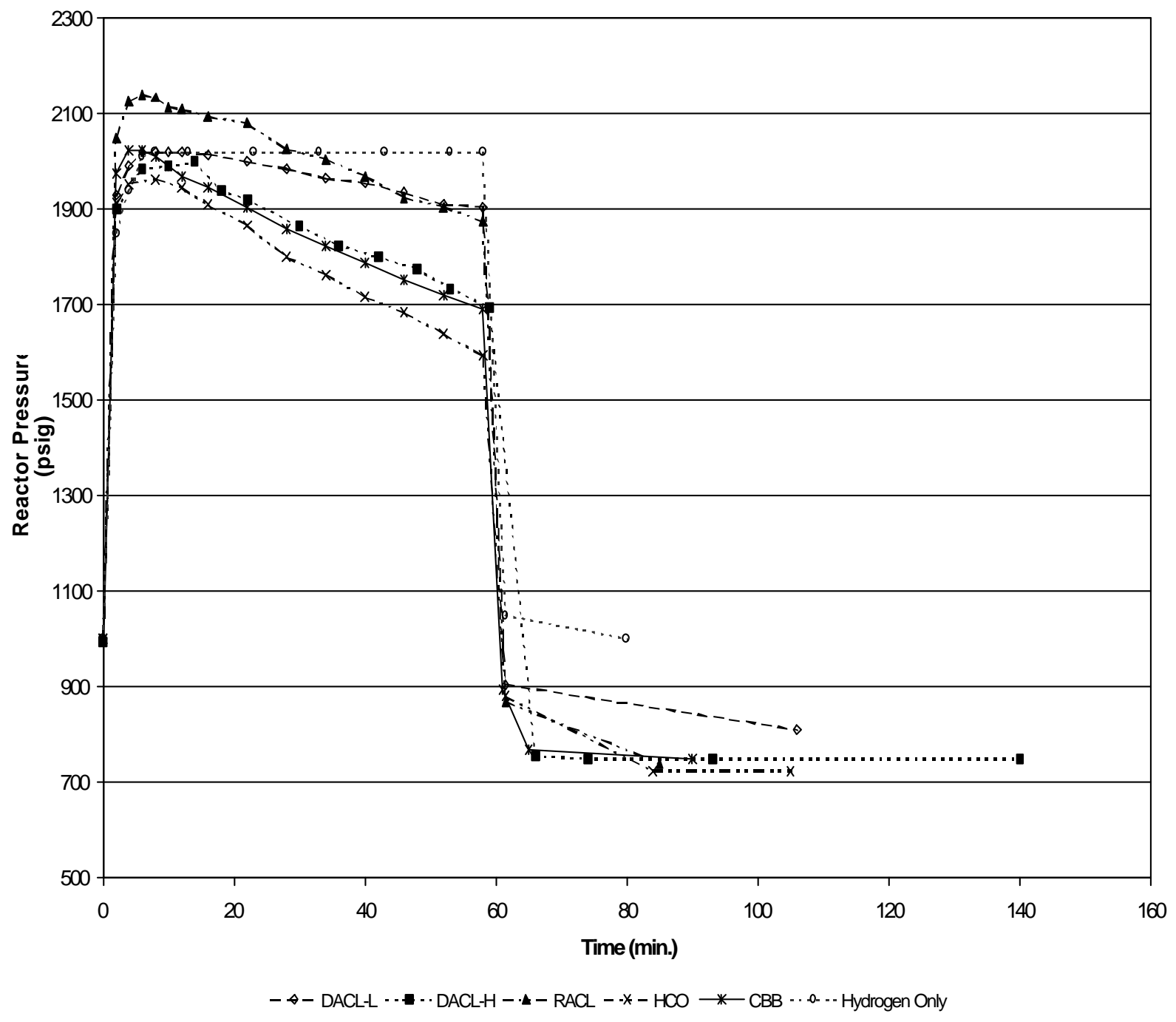

Figure 4.4 Reactor pressures during coal hydrogenation reactions with coal-derived solvents at reaction conditions of $400{ }^{\circ} \mathrm{C}, 1000 \mathrm{psig}_{2}$ (cold), 3/1 solventto-coal ratio, and 1 hour 
effect. First, the reactors could have been leaking. However, the reactors were thoroughly checked and sealed before immersion in the sand bath. The reactors were also allowed to sit overnight following each reaction in order to insure that no slow leaks could be detected. If any reactors showed a decline in pressure after this period, the sample was discarded and thus not presented here. Therefore, leaks in the reactors were not the cause for such an effect. The second possible explanation was that the hydrogen gas was being consumed by the reactants. This being the most likely interpretation, the hydrogen could be transferred to two different components of the reaction. The hydrogen could have been consumed by hydrogenation of the solvent or by adding hydrogen to the coal such as described by the free radical mechanism of hydrogenation. At this time the exact mechanism of hydrogen consumption for these conditions cannot be determined. The decrease in pressure during the hydrogenation reaction also indicates that the hydrogen gas is being consumed faster than gaseous products are being evolved.

The second important observation from Figure 4.4 is the relative maximum pressure that each solvent achieved during the reactions. With the exception of RACL solvent, the relative height of the pressure curves decreases as the carbon content of the solvent increases. This was expected since as the carbon content of the solvent increases so does the concentration of higher molecular weight species in the solvent. These higher molecular weight species would not be as volatile under the present reaction conditions, thus corresponding to lower reactor pressures.

Finally, it is important to notice the pressure of the reactor system once the reaction has been quenched by immersion in a water bath. The sharp decrease in pressure that occurred at sixty minutes is due to this quenching process. Once the pressure drop ceased (usually by the 90 minute mark) the reactor could be considered at room temperature. It is significant to note that for each reaction system illustrated in Figure 4.4, the final pressure of the system (720 to 850 psig depending on the solvent) was less than that of the initial pressure (1000 psig $\mathrm{H}_{2}$ cold). This again may indicate the consumption of hydrogen during the hydrogenation reaction. 


\subsection{Product Distillation}

Once the hydrogenation reaction products were separated into THF soluble and insoluble fractions and the THF was removed from the soluble fraction, the soluble fraction was further split into two fractions, the light distillate (or recycle solvent) and the heavy distillation residue (or pitch). This separation was achieved by the vacuum distillation described in Section 3.2.9. Each trial of every run was distilled to a different extent in order to collect a different amount of recycle solvent. This was done to gain some insight into the effect that the distillation process would have on the resultant pitch softening point and other characteristics such as coking value, ash content, and optical texture.

Figure 4.5 shows the effect that the extent of distillation has on the softening point of the pitch resulting from the hydrogenation reactions. This figure shows a linear relationship between the amount of feed recovered as pitch and the softening point of the resultant pitch. Using this relationship, a pitch can be tailored to a specific softening point by controlling the distillation step of production. The relative amounts of pitch recovered for the products made from the three Antaeus coal liquids show a predictable relationship. The light material (DACL-L) required the most distillation to achieve a softening point of $120^{\circ} \mathrm{C}$ or higher. The heavy fraction (DACL-H) required the least amount of distillation while the original coal liquid (RACL) fell in between and nearly in the middle of these two lines. This was not unexpected since the split of DACL-L and DACL-H from RACL was approximately $50 \%$ by weight.

The two interesting trends shown in Figure 4.5 are those for $\mathrm{HCO}$ and $\mathrm{CBB}$. According to the trends shown by the Antaeus coal liquids, the heavier materials should be shifted to the right of this graph. The starting materials for these two sets of reactions were clearly higher in heavy material than that of DACL-L. However, both of the Koppers Industries, Inc. liquids fell to the left (required more distillation) than that of DACL-L. This phenomenon can be explained by examining the coal-alone conversion exhibited when each of these solvents was employed. DACL-L had a significantly higher 


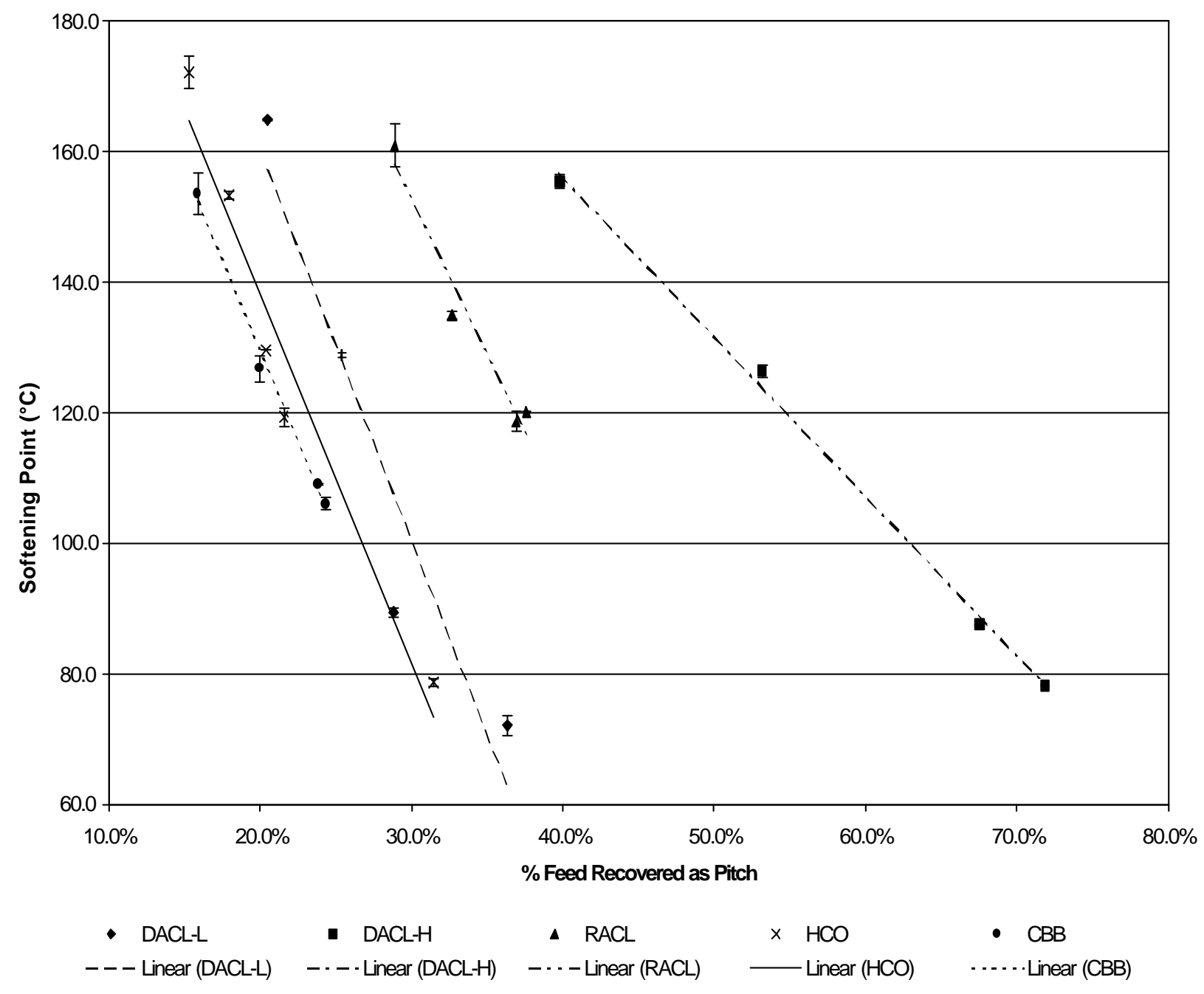

Figure 4.5 Effect of distillation on the softening point of the pitch resulting from hydrogenation reactions with coal-derived solvents at reaction conditions of $400{ }^{\circ} \mathrm{C}, 1000 \mathrm{psig}_{2}$ (cold), 3/1 solvent-to-coal ratio, and 1 hour 
coal-alone conversion (approximately $47 \%$ ) than that of $\mathrm{HCO}$ and $\mathrm{CBB}$ (approximately $31 \%$ and $23 \%$ respectively). Therefore, the products recovered from reactions performed with DACL-L should have more heavy components (converted from coal) than those reactions using $\mathrm{HCO}$ and $\mathrm{CBB}$. This would lead to the phenomenon of the $\mathrm{HCO}$ and $\mathrm{CBB}$ distillation trends shown in Figure 4.5 being to the left of the DACL-L linear representation.

\subsection{Hydrogenation Products}

Once the distillation step has occurred, the hydrogenation products have now been partitioned into three different fractions: (1) THF insolubles, (2) pitch, and (3) recycle solvent. The THF insolubles and recycle solvents were considered to be by-products of pitch production and, hence, were not thoroughly characterized. The ash content of the THF insolubles was determined so that an ash balance (Section 4.2) could be calculated, and an elemental analysis was performed on several of the insoluble and recycle solvent fractions. The remainder of this section is focused on characterizing and comparing the pitch produced by hydrogenation with the different coal-derived solvents. In order to compare the pitches produced from the separate solvents, pitches of approximately the same softening point $\left(\mathrm{T}_{\mathrm{sp}} \approx 120^{\circ} \mathrm{C}\right)$ were derived and characterized.

The product distribution of the hydrogenation products with a softening point of about $120{ }^{\circ} \mathrm{C}$ depends on the particular solvent. Figure 4.6 illustrates the product distribution for the hydrogenation reactions using the five coal-derived solvents. The product distribution from the reactions using DACL-L, HCO, and CBB all appear rather similar. The dominant fraction for each reaction was the recycle solvent, with the pitch fraction being the next highest. DACL-H reactions exhibit a very different profile in Figure 4.6. The majority of the product was converted to pitch, however, the coal conversion for these reactions was the lowest (even negative for the coal only conversion). This phenomenon is created by the physical properties of the original solvent. DACL-H at room temperature is solid pitch-like material with a softening point greater than $100{ }^{\circ} \mathrm{C}$. Therefore, after reaction, only the light material created during 


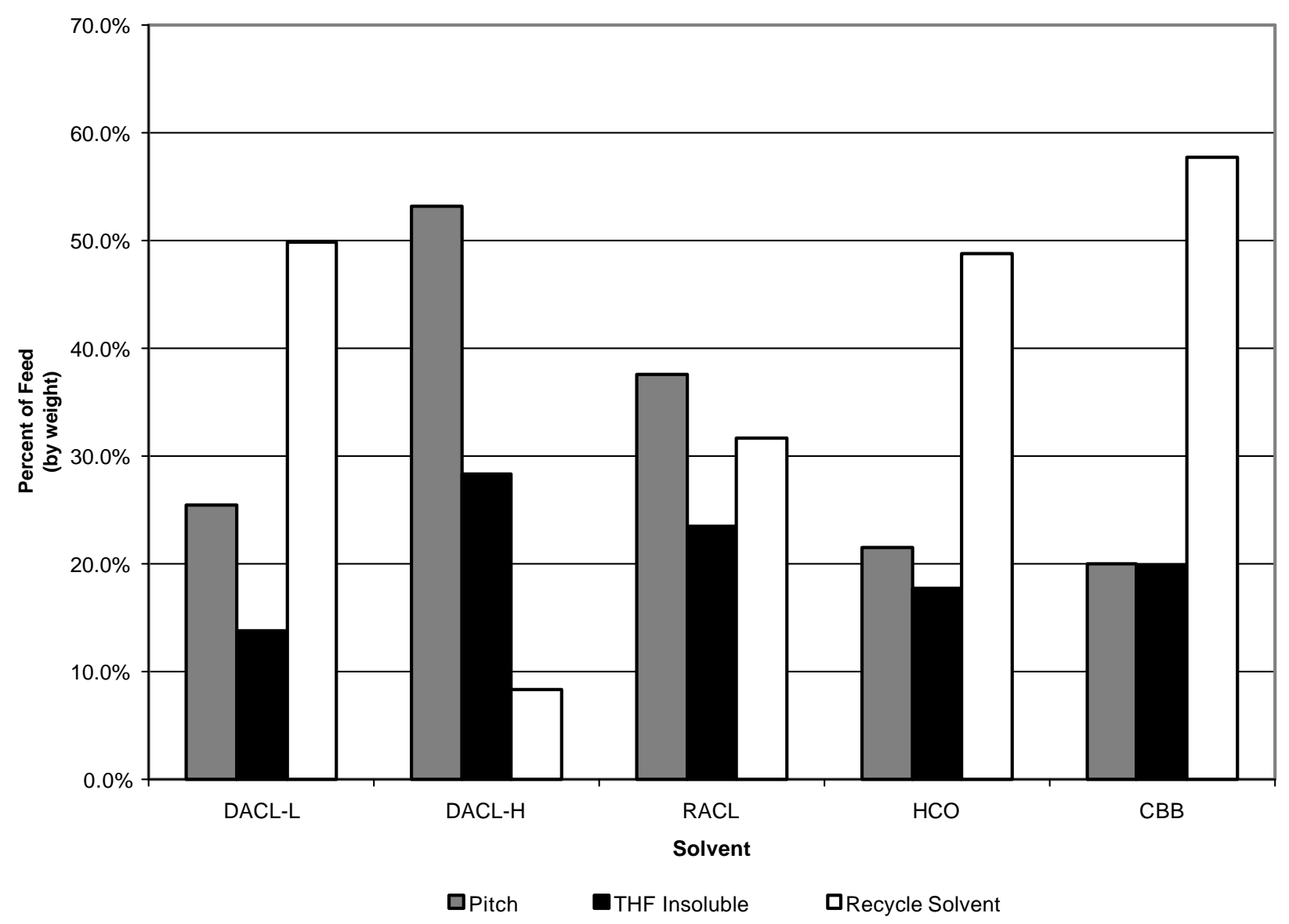

Figure 4.6 Effect of solvent choice on the hydrogenation product distribution with reaction conditions of $400{ }^{\circ} \mathrm{C}, 1000 \mathrm{psig}_{2}$ (cold), 3/1 solvent-to-coal ratio, and 1 hour for a pitch with approximately $120^{\circ} \mathrm{C}$ softening point 
hydrogenation needs to be removed to get the softening point to $120{ }^{\circ} \mathrm{C}$, and since the conversion is so low, very little light material was produced causing the high pitch production with low recycle solvent production.

It is also interesting to note that according to the above discussion and Figure 4.6 it is apparent that there is a trade-off between the amount of pitch produced and the amount of recycle solvent recovered depending on the solvent employed for hydrogenation. A large amount of pitch means more final pitch product, however, a low amount of recycle solvent means that the process may not be able to sustain itself. Therefore, a balance between the amount of pitch and recycle solvent produced needs to be struck. However, this balance may not be an equal one depending on the amount of recycle solvent required to perform subsequent reactions. This would depend on the optimum solvent-to-coal ratio which is discussed in a later section.

\subsubsection{Ash Content}

The ash content of the pitch and THF insoluble fractions was determined according to the ASTM method outlined in Section 3.3.3. For most carbon-product precursors, ash is considered to be an impurity and as such low values are required for the product pitches. The amount of relative error in determining the ash content for the insoluble fractions, which contain most of the ash, is small, $\pm 2 \%$. However, the pitch fractions contain a very small amount of ash (usually less than $0.1 \%$ by weight) leading to a much higher relative error of $\pm 18 \%$ for the ash determinations. Several of the recycle solvents were tested for ash, and each was found to contain no ash. This is expected since the recycle solvent is the distillate portion of the hydrogenation products. Therefore, any ash that may have been transferred into the THF soluble portion of the hydrogenation products would be concentrated in the pitch sample.

The ash contents of the pitch and insoluble fractions of the hydrogenation products are presented in Table 4.3 for each different solvent. The percent ash in all of the pitch products is at or less than $0.1 \%$ signifying that they are all very pure products. 
The ash content of the insoluble fraction has a wide range depending on the type of solvent that was used. This can be related to the solvent's ability to convert the organic material of the coal into soluble material. The solvents showing the higher coal conversions (Figure 4.3) also have the highest ash contents for the THF insolubles. As more coal is converted to soluble material the percentage of ash in the unconverted material (THF insoluble) would rise since it is based on the total organic material in the residue and not the coal. Reactions performed with DACL-L also produced the pitch with the highest ash content, but this could be due to the error in the ash analysis.

Table 4.3 Softening Point of Pitch and Ash Content of Pitch and THF Insoluble Fractions of Hydrogenation Products

\begin{tabular}{||l|l|l|l||}
\hline Solvent & $\begin{array}{c}\text { Pitch } \\
\text { Softening } \\
\text { Point }\left({ }^{\circ} \mathrm{C}\right)\end{array}$ & $\begin{array}{c}\text { \% Ash in } \\
\text { Pitch }\end{array}$ & $\begin{array}{c}\text { \% Ash in } \\
\text { THF Insol. }\end{array}$ \\
\hline DACL-L & 129.0 & $0.110 \%$ & $11.55 \%$ \\
\hline DACL-H & 126.5 & $0.025 \%$ & $7.11 \%$ \\
\hline RACL & 120.2 & $0.009 \%$ & $7.79 \%$ \\
\hline HCO & 119.4 & $0.019 \%$ & $10.63 \%$ \\
\hline CBB & 126.9 & $0.093 \%$ & $11.10 \%$ \\
\hline
\end{tabular}

\subsubsection{Coke Yield}

The coking value gives an indication of the amount of non-volatile matter in the pitch sample. The coke yield was determined according to the procedure described in Section 3.3.2. This characterization technique typically has a relative error of $\pm 2 \%$ so it is an accurate measurement. The coke yields of the pitches with a softening point of approximately $120^{\circ} \mathrm{C}$ for each solvent-coal reaction are detailed in Figure 4.7. Each of these coke yields are in the range of 43.5 to $48 \%$ by weight, which is slightly below the 


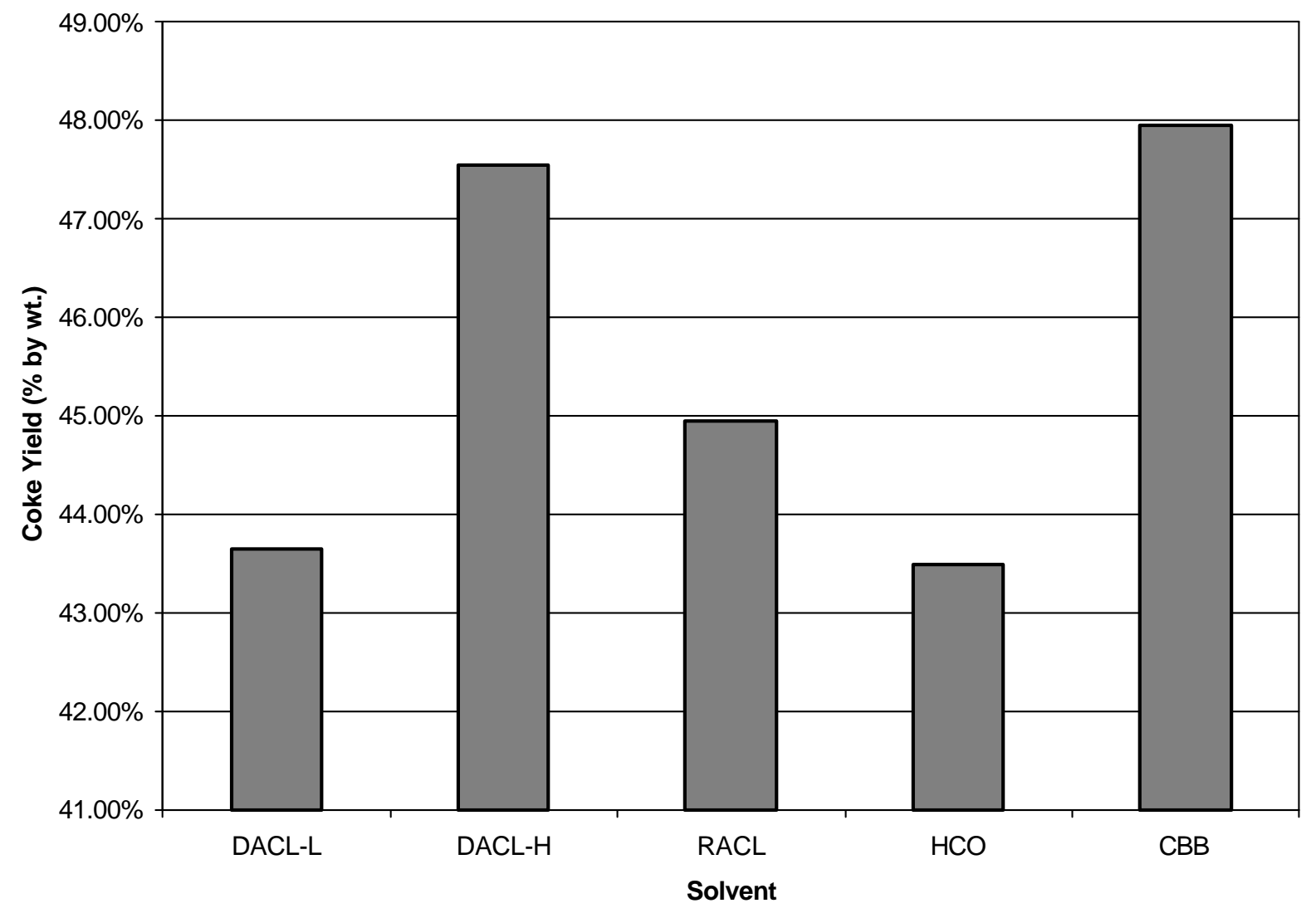

Figure 4.7 Effect of hydrogenation solvent on the coke yield of the pitches resulting from hydrogenation reactions with the conditions of $400{ }^{\circ} \mathrm{C}, 1000 \mathrm{psig} \mathrm{H}_{2}$ (cold), $3 / 1$ solvent-to-coal ratio, and 1 hour. Pitch softening point is around $120^{\circ} \mathrm{C}$. 
desired value of commercial pitches $(50-60 \%)$. However, the difference in coke yields when compared by the various solvents is insignificant when factoring in the relative error of the test.

There are two possible ways of increasing the coke yield of the hydrogenation pitches. First, the desired softening point of the pitch could be increased. This would eliminate more of the light volatile compounds that are relinquished during the coking. The second possible way of increasing the coke yield of the pitch is to lower the solventto-coal ratio of the hydrogenation reactions assuming the coal conversion is the same at a lower solvent-to-coal ratio. This would reduce the amount of solvent in the final pitch product, thus increasing the coking value. The results of lowering the solvent-to-coal ratio are discussed in a later section. The effect of raising the softening point on the coke yield of the resultant pitch is illustrated by Figure 4.8. For all of the pitches shown, there is a linear dependence of coke yield on the pitch softening point. Furthermore, all of the pitches are in the same basic range on the graph except DACL-L derived pitches, which are shifted slightly to the right. This suggests that the pitch made from coal and DACL-L contains on average more volatile components, thus requiring greater distillation (leading to an increase in softening point) to increase the coke yield. In order to achieve a pitch with a coke yield of greater than $50 \%$ by weight, Figure 4.8 shows that the softening point of the pitch needs to be at or above approximately $140{ }^{\circ} \mathrm{C}$.

\subsubsection{Optical Texture}

Once the coke samples were weighed and the coke yield was calculated, the coke sample was embedded in epoxy and polished for observation under the polarized-light microscope. This technique allowed for determination of the optical texture of the coke, which is extremely important in determining the end use of the carbon product precursor. The optical texture was determined according the procedure described in Section 3.3.4, and photographs were taken of all coke samples. A comprehensive collection of these pictures is given in Appendix B. Figure 4.9 shows cokes produced from the various pitches; the softening point of the pitches was approximately $120{ }^{\circ} \mathrm{C}$. All reaction conditions for these pitches were the same except for the choice of solvent. 


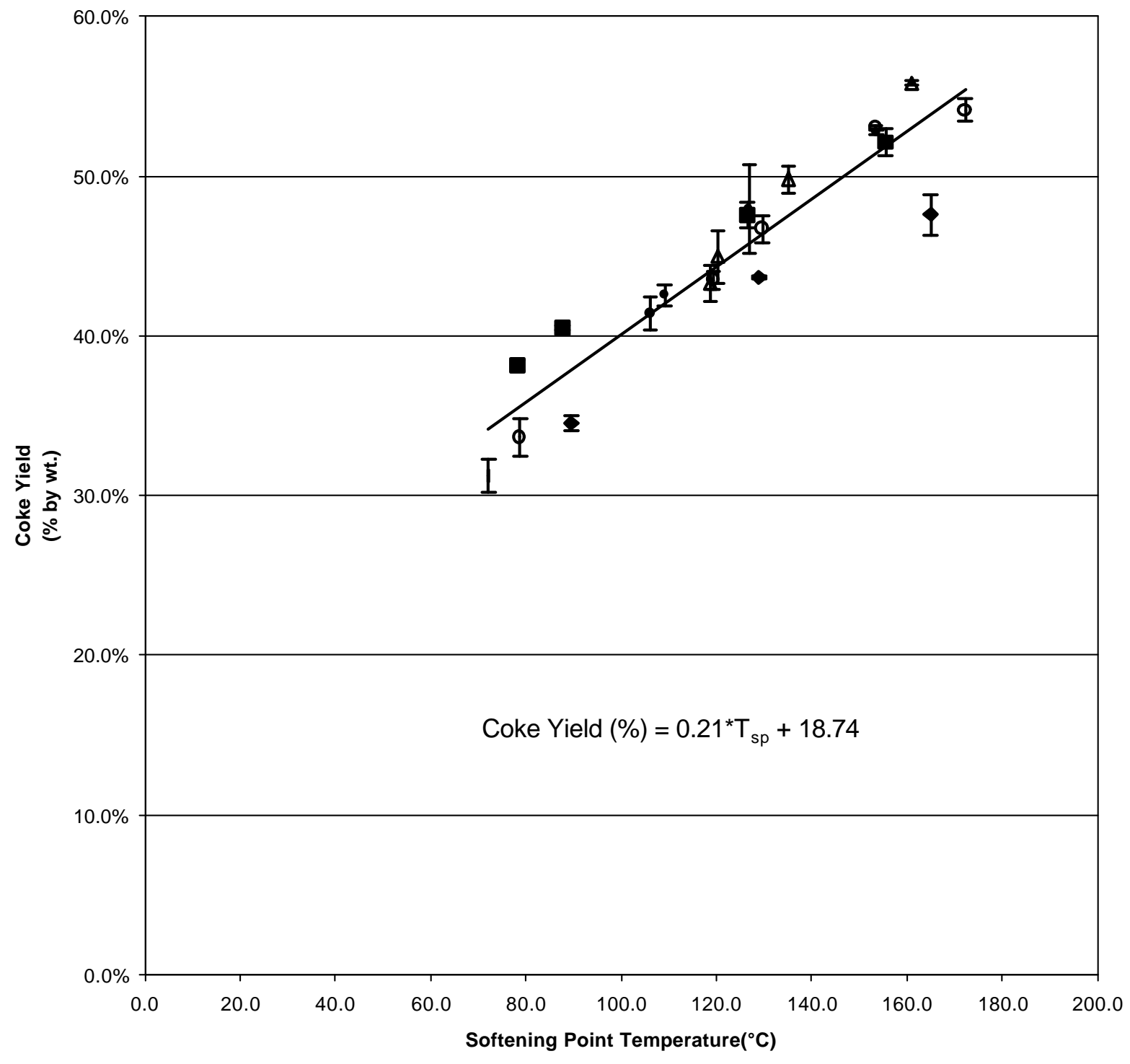

I DACL-L DDACL-H $\triangle$ RACL OHCO • CBB

Figure 4.8 Effect of softening point on the coke yield of pitches made from hydrogenation reactions using the five different coal-derived solvents under reaction conditions of $400{ }^{\circ} \mathrm{C}, 1000 \mathrm{psig}_{2}$ (cold), 3/1 solvent-to-coal ratio, and 1 hour 


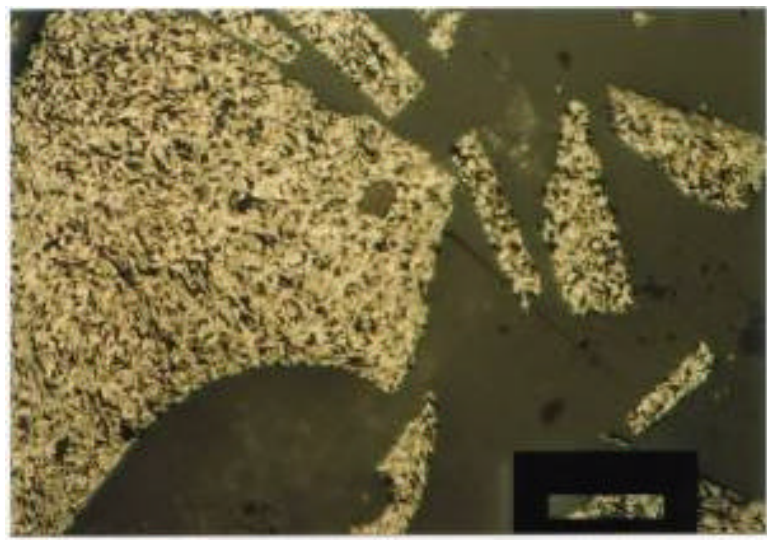

A

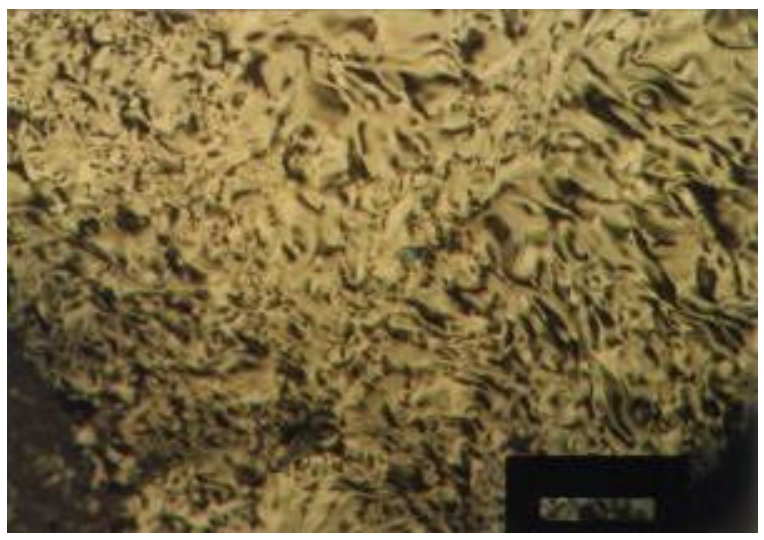

$\mathrm{C}$

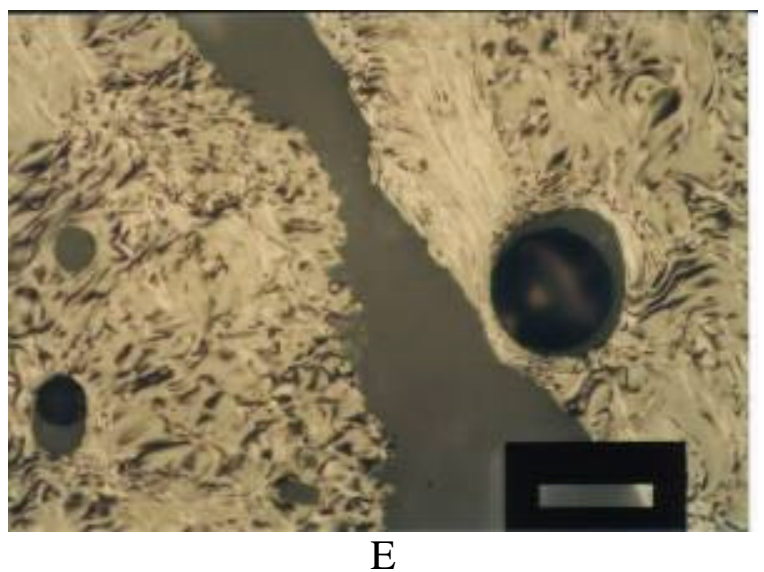

Figure 4.9 Optical micrographs of cokes produced from pitches (with softening points around $120^{\circ} \mathrm{C}$ ) using different solvents during hydrogenation reactions with conditions of $400{ }^{\circ} \mathrm{C}, 1000 \mathrm{psig}_{2}$ (cold), 3/1 solvent-to-coal ratio, and 1 hour and solvents A) DACL-L, B) DACL-H, C) RACL, D) HCO, and E) CBB 
Figure 4.9 shows that the optical texture for each of the cokes produced from hydrogenation reactions of coal and a coal-derived solvent were anisotropic. The major difference observed when comparing the solvents is in the domain size of the anisotropic cokes. The domains produced by using DACL-H and RACL (Figure 4.9 B and C, respectively) seem to be similar in size and are also fairly uniform throughout the sample. The cokes produced from $\mathrm{HCO}$ and $\mathrm{CBB}$ solvents (Figure 4.9 D and E, respectively) have areas of very large domains interspersed with areas of slightly smaller domains, similar to that of the cokes produced with DACL-H and RACL. The type of texture determines the possible end uses for the carbon product precursors. As mentioned previously in Section 2.3, the anisotropic coke is good for the production of graphite electrodes, while the isotropic coke is more suited to the production of nuclear graphite which requires a high purity and uniform dimensional stability.

\subsubsection{Elemental Analysis}

An elemental analysis was performed on a select group of pitches and their corresponding THF insoluble and recycle solvent fractions. The select pitches were again ones with a softening point of approximately $120{ }^{\circ} \mathrm{C}$ and from each different solvent. The elemental analysis was used to determine the amount of carbon, hydrogen, nitrogen, and sulfur in the sample according to the procedure outline in Section 3.3.5. The results of the elemental analysis for the carbon and hydrogen percentage in the samples are very accurate with relative errors of $\pm 2 \%$ for carbon and $\pm 5 \%$ for the hydrogen content. The error involved in determining the nitrogen and sulfur content in the samples is significantly larger due to the fact that the samples contain smaller amounts of these two elements compared to the carbon content. The relative error involved in determining the nitrogen and sulfur content is on the order of $\pm 20 \%$. Therefore, further discussion on the elemental content of the hydrogenation reactants and products will only concern the carbon and hydrogen content.

The elemental composition and hydrogen-to-carbon atomic ratios of the selected hydrogenation products are shown in Table 4.4. The reaction conditions for each run can 
be seen in Table 3.3. For each set of hydrogenation products, some general trends can be observed. The hydrogen-to-carbon ratio increases for each hydrogenation run from the THF insolubles to the pitch fraction up to the recycle solvent. This is the expected result since the recycle solvent is the lightest component of the hydrogenation products corresponding to the highest hydrogen-to-carbon ratio. Also, the hydrogen-to-carbon atomic ratios for the recycle solvents have a higher value than that of the original solvent employed in the reaction. This indicates that some lighter material was being produced during the hydrogenation reaction. The carbon content of the product pitches are similar at a value of about $90 \%$ by weight. The THF insoluble fraction also does not show a significant difference in carbon $(\approx 81 \%)$ and hydrogen $(\approx 4 \%)$ content when comparing the different solvents used. However, the recovered recycle solvent does show a significant difference from one sample to another. The carbon content of the recycle solvents recovered from the reactions using $\mathrm{HCO}$ and $\mathrm{CBB}$ (93.9\% and $90.7 \%$, respectively) are higher than those produced using the other solvents (less than 85\%). This can be attributed to the fact that the original solvents, $\mathrm{HCO}$ and $\mathrm{CBB}$, have a higher carbon content than the other hydrogenation solvents.

The elemental analysis was also used to perform a carbon and hydrogen balance for each of the selected hydrogenation reactions. The results of the elemental balances can be seen in Table 4.5 and Table 4.6 for carbon and hydrogen, respectively. The carbon balance shows a negative balance for all of the selected runs. This is consistent with the negative mass balance that was observed during each of these runs. Since carbon is by far the most abundant element in all of the reaction species, any loss of mass would correspond to a significant loss in elemental carbon causing the observed negative carbon balances. The hydrogen balances shown in Table 4.6 also show a negative hydrogen balance for each of the selected runs. This also corresponds to a negative mass balance. However, a positive hydrogen balance could have been expected from examining the transient reactor pressure for each reaction (see Figure 4.4). It showed that hydrogen was being consumed by the hydrogenation reactants throughout the thermal 
Table 4.4 Elemental Composition of Select Hydrogenation Products

\begin{tabular}{|c|c|c|c|c|c|}
\hline \multirow[b]{2}{*}{ Run } & \multirow[b]{2}{*}{ Element } & \multirow[b]{2}{*}{$\begin{array}{l}\text { Original } \\
\text { Solvent }\end{array}$} & \multicolumn{3}{|c|}{ Product Fraction } \\
\hline & & & Pitch & $\begin{array}{c}\text { THF } \\
\text { Insoluble } \\
\end{array}$ & $\begin{array}{l}\text { Recycle } \\
\text { Solvent }\end{array}$ \\
\hline \multirow{5}{*}{$1 \mathrm{~A}$} & $\mathrm{C}$ & $80.51 \%$ & $86.80 \%$ & $82.52 \%$ & $82.62 \%$ \\
\hline & $\mathrm{H}$ & $7.74 \%$ & $6.16 \%$ & $4.18 \%$ & $8.21 \%$ \\
\hline & $\mathrm{N}$ & $0.94 \%$ & $1.22 \%$ & $1.53 \%$ & $0.87 \%$ \\
\hline & $S$ & $0.61 \%$ & $0.67 \%$ & $0.91 \%$ & $0.19 \%$ \\
\hline & $\begin{array}{c}\mathrm{H} / \mathrm{C} \text { Atomic } \\
\text { Ratio }\end{array}$ & 1.15 & 0.85 & 0.61 & 1.19 \\
\hline \multirow{5}{*}{$2 \mathrm{C}$} & $\mathrm{C}$ & $88.51 \%$ & $89.70 \%$ & $83.08 \%$ & $85.60 \%$ \\
\hline & $\mathrm{H}$ & $5.72 \%$ & $5.62 \%$ & $4.15 \%$ & $7.25 \%$ \\
\hline & $\mathrm{N}$ & $1.25 \%$ & $1.68 \%$ & $2.02 \%$ & $1.48 \%$ \\
\hline & $S$ & $0.76 \%$ & $0.66 \%$ & $0.85 \%$ & $0.57 \%$ \\
\hline & $\begin{array}{c}\mathrm{H} / \mathrm{C} \text { Atomic } \\
\text { Ratio }\end{array}$ & 0.78 & 0.75 & 0.60 & 1.02 \\
\hline \multirow{5}{*}{ 3B } & $\mathrm{C}$ & $86.67 \%$ & $90.53 \%$ & $80.72 \%$ & $81.86 \%$ \\
\hline & $\mathrm{H}$ & $6.76 \%$ & $5.83 \%$ & $4.55 \%$ & $8.44 \%$ \\
\hline & $\mathrm{N}$ & $1.22 \%$ & $1.29 \%$ & $2.19 \%$ & $1.87 \%$ \\
\hline & $S$ & $0.72 \%$ & $0.73 \%$ & $0.92 \%$ & $0.67 \%$ \\
\hline & $\begin{array}{c}\mathrm{H} / \mathrm{C} \text { Atomic } \\
\text { Ratio }\end{array}$ & 0.94 & 0.77 & 0.68 & 1.24 \\
\hline \multirow{5}{*}{$4 \mathrm{C}$} & $\mathrm{C}$ & $93.41 \%$ & $91.16 \%$ & $79.02 \%$ & $93.90 \%$ \\
\hline & $\mathrm{H}$ & $5.14 \%$ & $5.31 \%$ & $3.96 \%$ & $5.23 \%$ \\
\hline & $\mathrm{N}$ & $0.88 \%$ & $1.45 \%$ & $1.42 \%$ & $0.93 \%$ \\
\hline & $S$ & $0.55 \%$ & $0.71 \%$ & $0.96 \%$ & $0.48 \%$ \\
\hline & $\begin{array}{c}\mathrm{H} / \mathrm{C} \text { Atomic } \\
\text { Ratio }\end{array}$ & 0.66 & 0.70 & 0.60 & 0.67 \\
\hline \multirow{5}{*}{$5 B$} & $\mathrm{C}$ & $91.85 \%$ & $89.75 \%$ & $79.17 \%$ & $90.73 \%$ \\
\hline & $\mathrm{H}$ & $5.51 \%$ & $5.14 \%$ & $3.97 \%$ & $5.79 \%$ \\
\hline & $\mathrm{N}$ & $0.81 \%$ & $1.15 \%$ & $0.86 \%$ & $0.89 \%$ \\
\hline & $S$ & $0.67 \%$ & $0.63 \%$ & $0.94 \%$ & $0.69 \%$ \\
\hline & $\begin{array}{c}\mathrm{H} / \mathrm{C} \text { Atomic } \\
\text { Ratio }\end{array}$ & 0.72 & 0.69 & 0.60 & 0.77 \\
\hline
\end{tabular}


Table 4.5 Elemental Carbon Balance for Hydrogenation Reactants and Products for Selected Runs

\begin{tabular}{|c|c|c|c|c|c|c|c|c|c|c||}
\hline \hline Run & Trial & $\begin{array}{c}\text { Carbon } \\
\text { In Coal } \\
(\mathrm{g})\end{array}$ & $\begin{array}{l}\text { Carbon In } \\
\text { Solv. }(\mathrm{g})\end{array}$ & $\begin{array}{c}\text { Total } \\
\text { Carbon In } \\
(\mathrm{g})\end{array}$ & $\begin{array}{c}\text { Carbon } \\
\text { Out Pitch } \\
(\mathrm{g})\end{array}$ & $\begin{array}{c}\text { Carbon } \\
\text { Out THF } \\
\text { Ins. }(\mathrm{g})\end{array}$ & $\begin{array}{c}\text { Carbon } \\
\text { Out Rec. } \\
\text { Solv. }(\mathrm{g})\end{array}$ & $\begin{array}{c}\text { Total } \\
\text { Carbon } \\
\text { Out }(\mathrm{g})\end{array}$ & $\begin{array}{c}\text { Out - In } \\
(\mathrm{g})\end{array}$ & $\begin{array}{c}\text { (Out- } \\
\text { In)//n } \\
(\%)\end{array}$ \\
\hline \hline 1 & A & 6.8381 & 20.2105 & 27.0486 & 7.3812 & 3.8101 & 13.7776 & 24.9690 & -2.0796 & -7.7 \\
\hline 2 & C & 4.8960 & 15.9325 & 20.8285 & 11.4446 & 5.6568 & 1.7034 & 18.8048 & -2.0237 & -9.7 \\
\hline 3 & B & 6.2449 & 19.8992 & 26.1441 & 10.4227 & 5.8113 & 7.9482 & 24.1822 & -1.9619 & -7.5 \\
\hline 4 & C & 7.1860 & 24.7083 & 31.8944 & 6.9261 & 4.9389 & 16.1406 & 28.0056 & -3.8888 & -12.2 \\
\hline 5 & B & 7.3079 & 24.6799 & 31.9878 & 6.4201 & 5.6164 & 18.7533 & 30.7898 & -1.1980 & -3.7 \\
\hline \hline
\end{tabular}

Table 4.6 Elemental Hydrogen Balance for Hydrogenation Reactants and Products for Selected Runs

\begin{tabular}{||c|c|c|c|c|c|c|c|c|c|c||}
\hline \hline Run & Trial & $\begin{array}{c}\text { Hydrogen in } \\
\text { Coal (g) }\end{array}$ & $\begin{array}{c}\text { Hydrogen } \\
\text { in Solv. } \\
(\mathrm{g})\end{array}$ & $\begin{array}{c}\text { Total } \\
\text { Hydrogen } \\
\text { In (g) }\end{array}$ & $\begin{array}{c}\text { Hydrogen } \\
\text { Out Pitch } \\
(\mathrm{g})\end{array}$ & $\begin{array}{c}\text { Hydrogen } \\
\text { Out THF } \\
\text { Ins. }(\mathrm{g})\end{array}$ & $\begin{array}{c}\text { Hydrogen } \\
\text { Out Rec. } \\
\text { Solv. }(\mathrm{g})\end{array}$ & $\begin{array}{c}\text { Total } \\
\text { Hydrogen } \\
\text { Out }(\mathrm{g})\end{array}$ & $\begin{array}{c}\text { Out }- \text { In } \\
(\mathrm{g})\end{array}$ & $\begin{array}{c}\text { (Out- } \\
\text { In)In } \\
(\%)\end{array}$ \\
\hline 1 & $\mathrm{A}$ & 0.3825 & 1.9426 & 2.3251 & 0.5236 & 0.1928 & 1.3695 & 2.0859 & -0.2391 & -10.3 \\
\hline 2 & $\mathrm{C}$ & 0.2739 & 1.0299 & 1.3038 & 0.7168 & 0.2826 & 0.1442 & 1.1436 & -0.1602 & -12.3 \\
\hline 3 & $\mathrm{B}$ & 0.3493 & 1.5525 & 1.9019 & 0.6717 & 0.3274 & 0.8198 & 1.8190 & -0.0829 & -4.4 \\
\hline 4 & $\mathrm{C}$ & 0.4020 & 1.3614 & 1.7633 & 0.4031 & 0.2477 & 0.9109 & 1.5617 & -0.2017 & -11.4 \\
\hline 5 & $\mathrm{~B}$ & 0.4088 & 1.4804 & 1.8892 & 0.3676 & 0.2817 & 1.1972 & 1.8464 & -0.0428 & -2.3 \\
\hline \hline
\end{tabular}


treatment process. Since hydrogen was being consumed, one might expect an increase in the total hydrogen out of the hydrogenation reactions. However, by examining the different causes for error in the mass balance calculation, the explanation of a negative hydrogen balance becomes apparent. The two major causes for loss of mass throughout these reactions were the fact that the product gas was not quantified and the loss of light material during THF removal and vacuum distillation. Both of these mass losses involve the loss of the lightest products which are produced by the hydrogenation reactions. These light materials would have been the significantly more hydrogen-rich products of the reactions. Because these materials are the ones that are unaccounted for in the mass balance calculation and elemental analysis, a negative hydrogen balance unfortunately occurs.

\subsection{Variation of Hydrogenation Parameters}

In order to understand further how the hydrogenation conditions would affect the final products, three of the reaction conditions were altered. The pressure, gaseous atmosphere, and solvent-to-coal ratio were all varied in reactions six (6) through twelve (12). The initial hydrogen pressure was lowered from 1000 psig to 500 psig and finally to 100 psig in runs five (5), seven (7), nine (9). Hydrogenation reactions with these same pressures but under an argon atmosphere were performed in runs six (6), eight (8), and ten (10). Finally, the solvent-to-coal ratio was lowered from $3 / 1$ to $2 / 1$ down to $1 / 1$ by weight in reactions four (4), eleven (11), and twelve (12). All other conditions for these reactions were kept constant and can be seen in Table 3.3.

\subsubsection{Effect of Pressure and Atmosphere}

Reactions five (5) through ten (10) were performed to determine the effect of lowering the initial pressure and employing an inert atmosphere instead of hydrogen on the conversion, product distribution, and pitch characteristics. Each reaction was performed with the $\mathrm{CBB}$ solvent, at a temperature of $400{ }^{\circ} \mathrm{C}$, a solvent-to-coal ratio of 3/1, and run for one hour. The CBB solvent was used for these experiments rather than 
DACL-L, which showed a higher conversion (both types), because it is a commerciallyavailable material and could be used as is. The Antaeus liquid is not currently available commercially. Each set of reaction conditions was run four times and separated into different softening point pitches by vacuum distillation. Again, a target softening point of $120{ }^{\circ} \mathrm{C}$ was desired though not always achieved.

Figure 4.10 shows the effect of increasing the reaction pressure and changing the atmosphere on the overall conversion, while Figure 4.11 depicts the same effect on the coal-alone conversion of the hydrogenation reactions. As the pressure is increased, regardless of the gaseous atmosphere, both the overall and coal-alone conversions increase. However, the overall conversion actually only increases $3 \%$ from pressures of 100 psig to 1000 psig hydrogen and only $2 \%$ for the same increase in argon pressure. This is an insignificant increase when considering a ten fold increase in pressure was required. The effect of increasing the gas pressure on the overall conversion is masked due to the low amount of coal compared to solvent charged to the reactors. This becomes evident when the effect of gas pressure on the coal-alone conversion is investigated in Figure 4.11. When hydrogen gas is employed the coal-alone conversion increases from $7 \%$ to $23 \%$ when the pressure is raised from 100 psig to 1000 psig. This is a much more significant increase than that shown in Figure 4.10 for the overall conversion. The coalalone conversion also increases (6\% to $12 \%$ ) when argon pressure is raised from 100 to 1000 psig, however, not as significantly. This shows that when hydrogen gas is being used in the hydrogenation reaction, it is beneficial to the reaction of coal to soluble products.

Another way of illustrating the use of gaseous hydrogen in the hydrogenation reactions is to compare the reactor pressures during the thermal treatment when the same initial pressures are employed with hydrogen and argon atmospheres. These results are depicted in Figures 4.12, 4.13 and 4.14 for the initial reaction pressures of 1000, 500, and $100 \mathrm{psig}$, respectively. It is interesting to note that when the initial pressures were either 1000 or 500 psig (Figures 4.12 and 4.13), the hydrogen charged reactors decreased in 


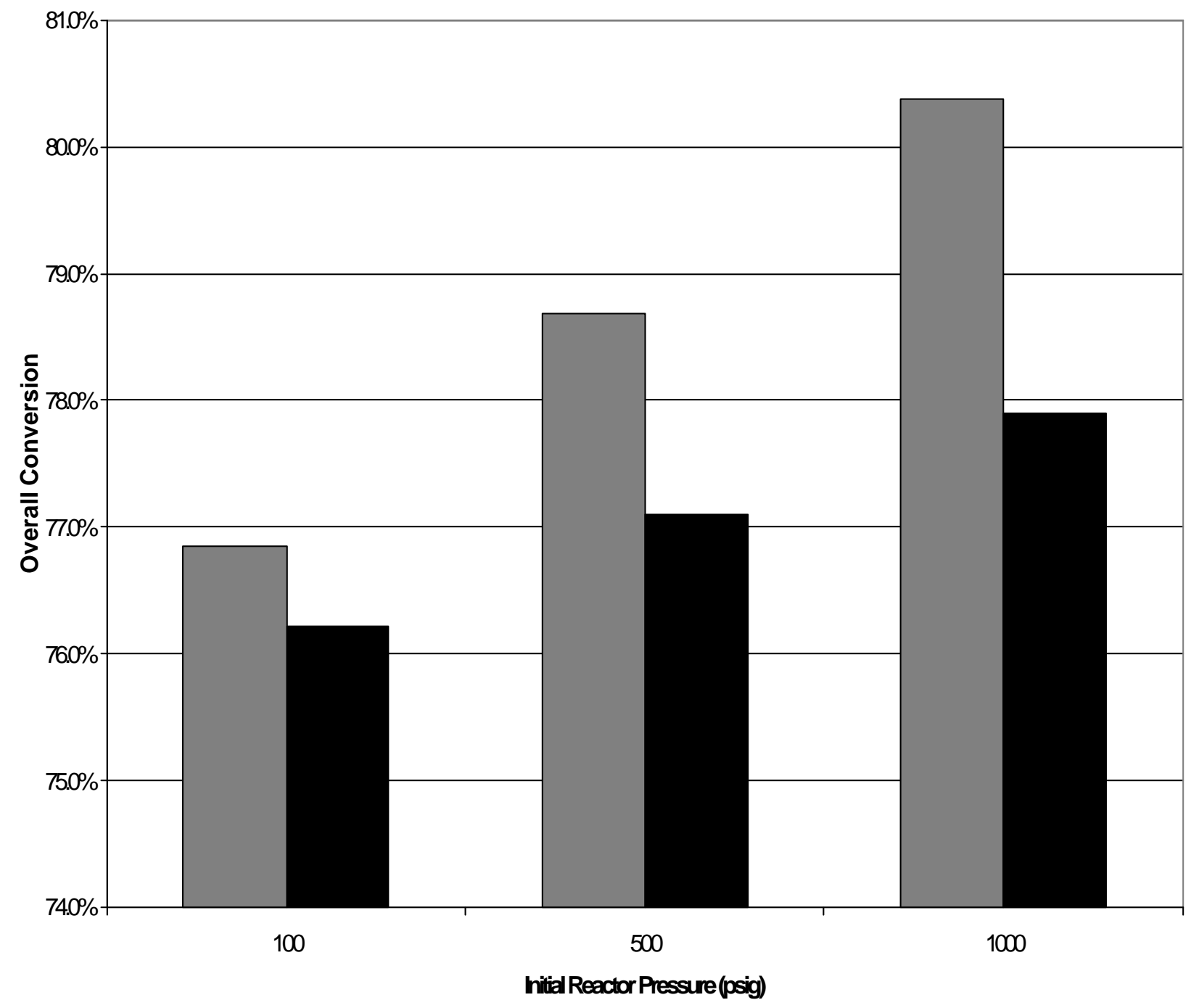

DHydrogen argon

Figure 4.10 Effect of initial reactor pressure and gaseous atmosphere on the overall conversion of hydrogenation reactions with $\mathrm{CBB}$ and reaction conditions of $400{ }^{\circ} \mathrm{C}, 3 / 1$ solvent-to-coal ratio, and 1 hour 


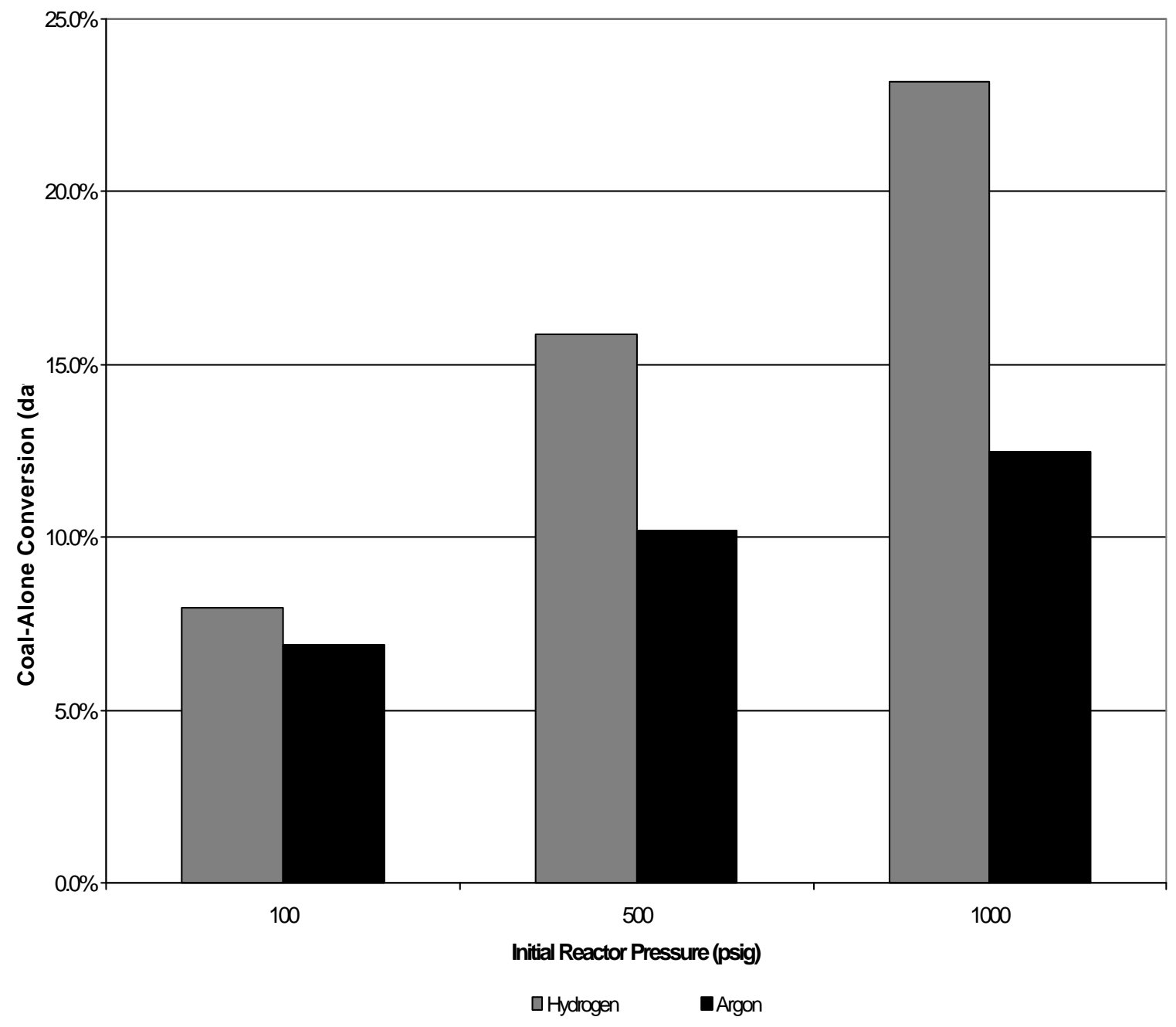

Figure 4.11 Effect of initial reactor pressure and gaseous atmosphere on the coal-alone conversion of hydrogenation reactions with $\mathrm{CBB}$ and reaction conditions of $400{ }^{\circ} \mathrm{C}, 3 / 1$ solvent-to-coal ratio, and 1 hour 


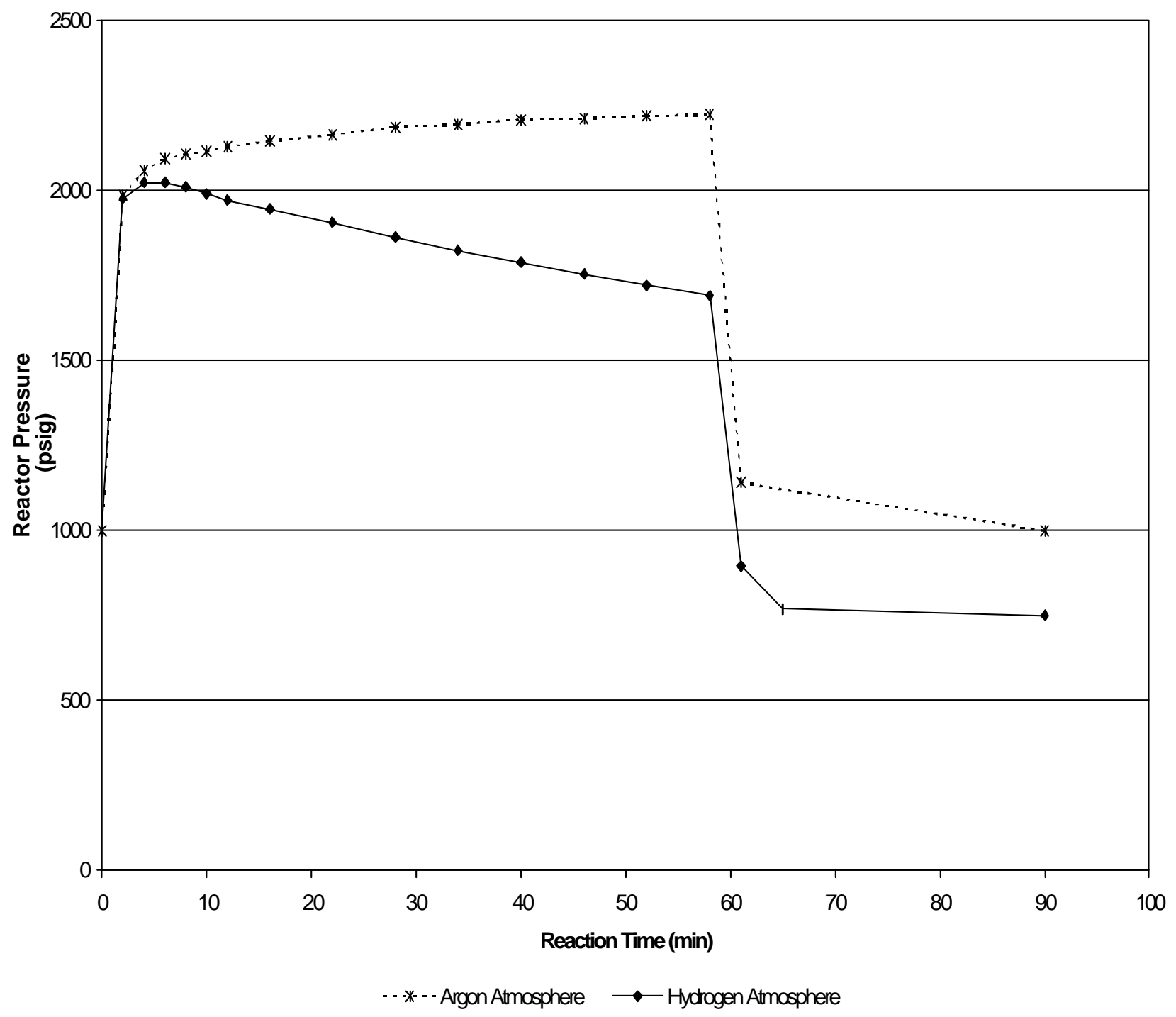

Figure 4.12 Average reactor pressures over time of hydrogenation reactions using CBB, 1000 psig initial hydrogen or argon pressure, $400{ }^{\circ} \mathrm{C}, 3 / 1$ solvent-to-coal ratio, and 1 hour 


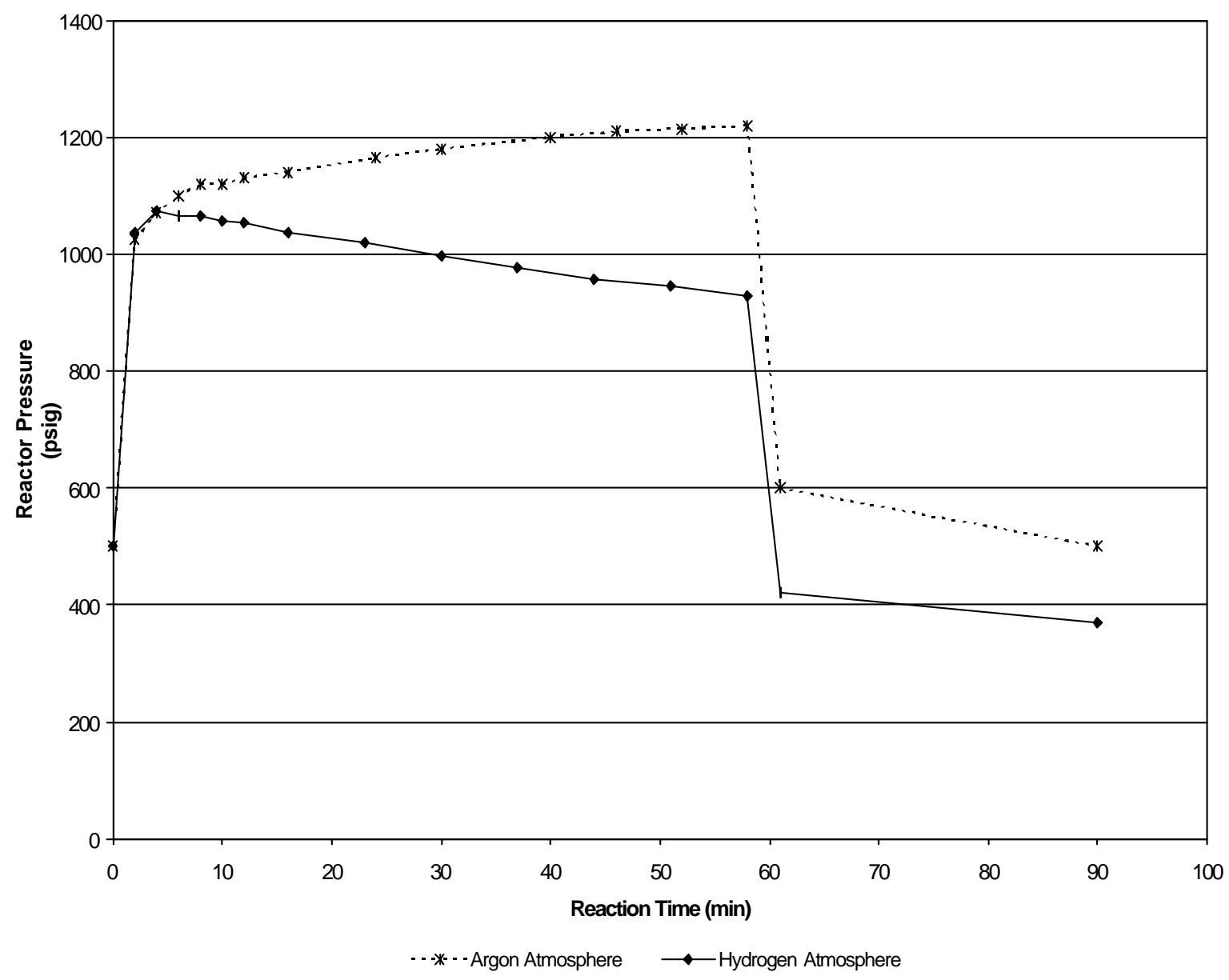

Figure 4.13 Average reactor pressures over time of hydrogenation reactions using CBB, 500 psig initial hydrogen or argon pressure, $400{ }^{\circ} \mathrm{C}, 3 / 1$ solvent-to-coal ratio, and 1 hour 


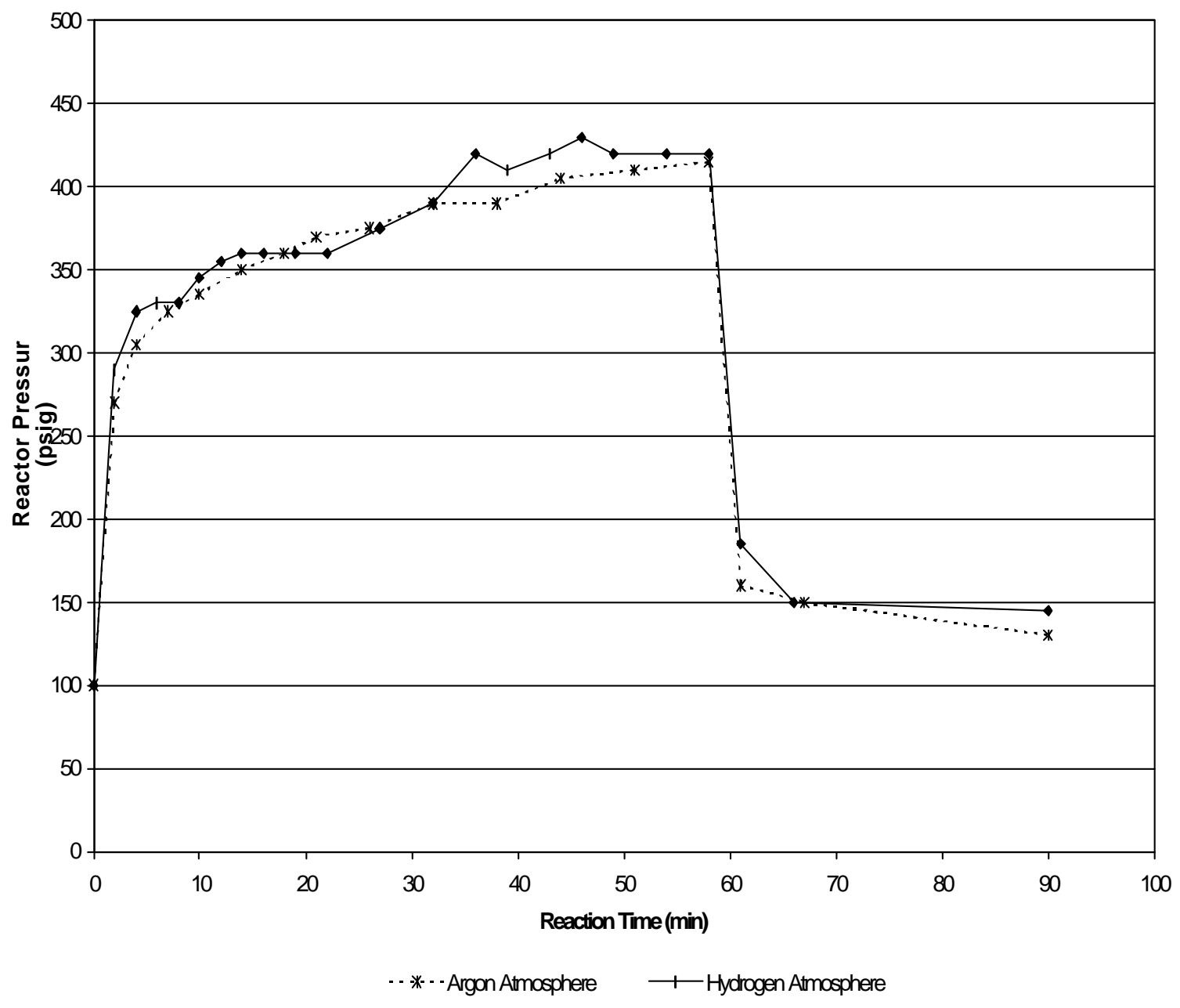

Figure 4.14 Average reactor pressures over time of hydrogenation reactions using CBB, 100 psig initial hydrogen or argon pressure, $400{ }^{\circ} \mathrm{C}, 3 / 1$ solvent-to-coal ratio, and 1 hour 
pressure over time, while the argon charged reactors continued to increase in pressure throughout the reaction time. The decrease in pressure in the hydrogen charged reactions was again due to the fact that the hydrogen was consumed by hydrogenating either transient coal radicals and/or the solvent. By comparing the initial and final pressures of the reactions performed under a hydrogen atmosphere, an estimation of the amount of hydrogen consumed can be made. The hydrogen consumed for the reactions with 1000 psig initial hydrogen pressure was approximately 0.04 moles of hydrogen or $0.2 \%$ of the reaction feed mass. The hydrogen consumed for the reactions with 500 psig initial hydrogen pressure was approximately 0.02 moles of hydrogen or $0.1 \%$ of the reaction feed mass. The increase in pressure during the argon charged reactions is from the production of gas. However, this gas most likely condensed when the reaction was quenched and cooled, as evidenced by the fact that the final reactor pressure was equal to the initial reactor pressure. This does not mean, however, that no product gases were formed during the hydrogen charged reactions -- only that the amount of gas production inside the reactor was less than the amount of hydrogen consumption. This would lead to the net decrease in reactor pressure observed when hydrogen was used in both Figures 4.12 and 4.13 .

Figure 4.14 shows a different trend with the lower initial pressure of 100 psig. Both the hydrogen and argon charged reactors increase in pressure over time. Therefore, gas was being produced throughout both sets of reactions. This time in the hydrogen charged reactor, however, the rate of gas production was greater than the rate of hydrogen gas consumption. This explanation is further justified by comparing the initial and final pressures in the reactors. For both systems, the final pressure is greater than the initial pressure, signifying a net production in gas and less hydrogen reacted at 100 psig.

The effect of changing the initial reactor pressure and atmosphere on the product distribution is illustrated in Figure 4.15. The distributions shown represent the products thus formed when a pitch with a softening point in the proximity of $120{ }^{\circ} \mathrm{C}$ was obtained. For both the argon and hydrogen charged reactions, as the pressure is increased the amount of THF insolubles decreased slightly from $23 \%$ to $21 \%$ for argon reactions and 


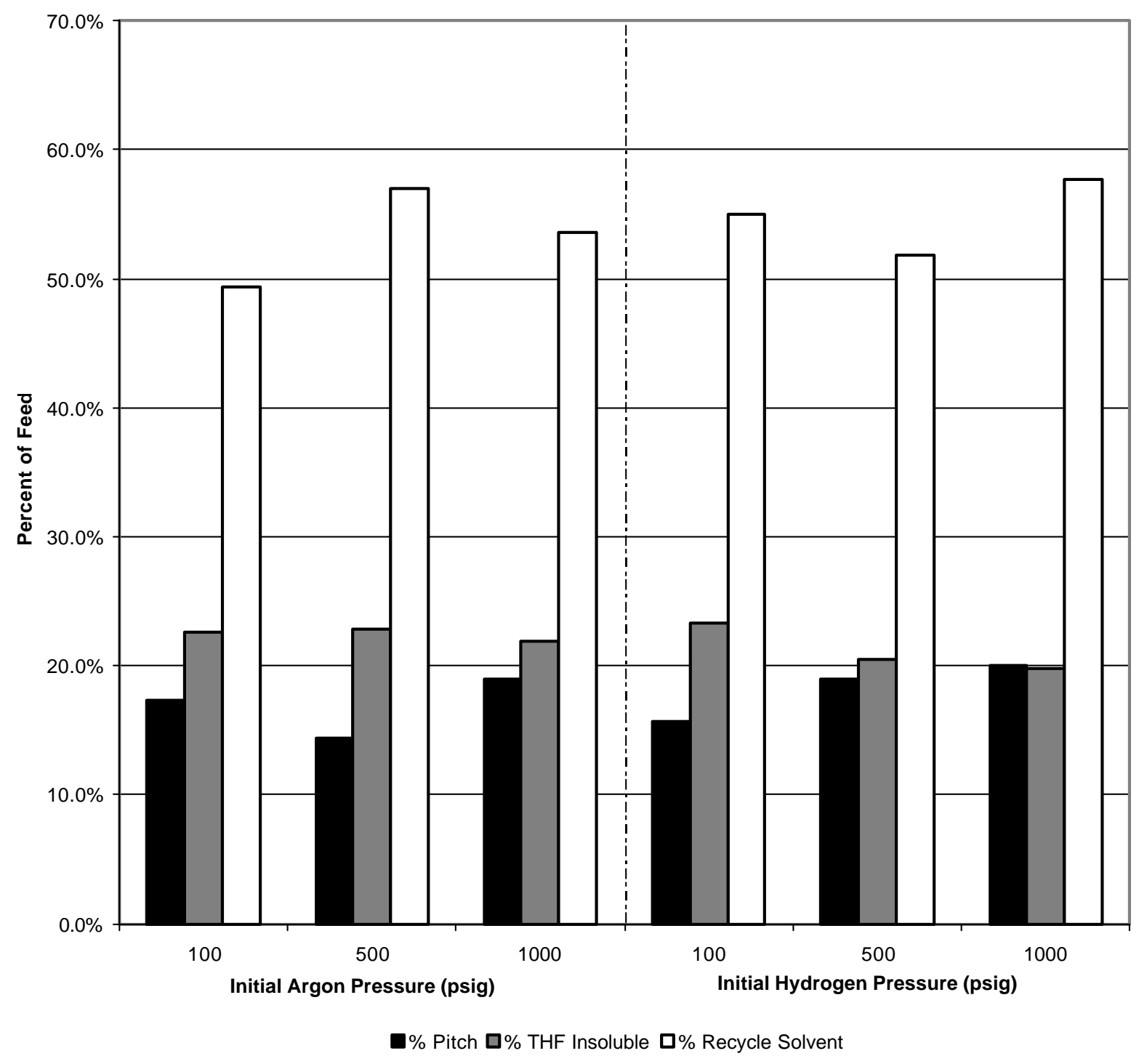

Figure 4.15 Effect of initial reactor pressure and atmosphere on the product distribution of reactions run to produce a pitch with a softening point of $120^{\circ} \mathrm{C}$ under reaction conditions of $\mathrm{CBB}$ solvent, $400{ }^{\circ} \mathrm{C}, 3 / 1$ solvent-to-coal ratio, and 1 hour 
23.5 to $20 \%$ for hydrogen reactions. This is directly responsible for the increase in both the overall and coal-alone conversions as more coal is reacted. The percent of pitch and recycle solvent recovered from the feed seems to be fairly constant when experimental error is considered. The percent of pitch obtained with a hydrogen atmosphere increased slightly (from $16 \%$ to $20 \%$ ) as the initial reactor pressure increased. This could be attributed to the increase of coal conversion when the hydrogen pressure was increased. The percent of pitch obtained from the feed when using an argon atmosphere does not show such a trend. The percent of feed going to pitch did increase from 100 psig initial argon pressure to $1000 \mathrm{psig}$ initial argon pressure, but a dip was observed when $500 \mathrm{psig}$ initial argon pressure was employed. This dip can be attributed to overshooting the desired softening point of $120^{\circ} \mathrm{C}$. The pitches obtained when using 100 and 1000 psig initial argon pressure had average softening points of 120.3 and $119.3{ }^{\circ} \mathrm{C}$, respectively. The pitch obtained from the reaction charged with 500 psig initial argon pressure was distilled to an average softening point of $132.5^{\circ} \mathrm{C}$ (due to an error in distillation). This increase in softening point corresponds to a smaller amount of pitch produced due to more recycle solvent being removed during distillation. This could explain the dip in the pitch production shown at 500 psig initial argon pressure in Figure 4.15.

After separating the hydrogenation products into the fractions shown in Figure 4.15 , the effect of the pressure and atmosphere on the pitch characteristics was studied. The selected pitches with a softening point in the area of $120^{\circ} \mathrm{C}$ (from 119.3 to $132.5^{\circ} \mathrm{C}$ ) were characterized by ash content, coke yield, optical microscopy, and elemental analysis (the corresponding insoluble and recycle solvent fractions were also characterized by elemental analysis). The results of the ash test for the selected pitches and THF insoluble fraction are shown in Table 4.7. As described previously in Section 4.6.1, the ash content of the THF insoluble fraction varies with the conversion of hydrogenation reactants to soluble products. The highest ash content corresponds to the highest conversion (1000 psig Hydrogen initially) due to the decreased amount of organic material left in the THF insoluble fraction. The ash varies randomly from pitch to pitch but is always at a very low value (below 0.1\%). This is important because the ash content is considered an impurity in the development of carbon products. 
Table 4.7 Ash content of pitch and THF insoluble fractions of pitch produced while varying the initial reactor pressure and gaseous atmosphere

\begin{tabular}{||c|c|c|c|c|c|c|c||}
\hline \hline Run & Trial & $\begin{array}{c}\text { Initial } \\
\text { Reactor } \\
\text { Pressure } \\
\text { (psig) }\end{array}$ & Gas & $\begin{array}{c}\text { Pitch } \\
\text { Average } \\
\text { Softening } \\
\text { Point }\left({ }^{\circ} \mathrm{C}\right)\end{array}$ & $\begin{array}{c}\text { \% Ash in } \\
\text { Pitch }\end{array}$ & $\begin{array}{c}\text { \% Ash in } \\
\text { THF } \\
\text { Insoluble }\end{array}$ & $\begin{array}{c}\text { \% Pitch } \\
\text { Recovered }\end{array}$ \\
\hline \hline 5 & B & 1000 & Hydrogen & 126.9 & $0.093 \%$ & $11.10 \%$ & $20.0 \%$ \\
\hline 6 & D & 1000 & Argon & 119.3 & $0.041 \%$ & $7.95 \%$ & $18.9 \%$ \\
\hline 7 & A & 500 & Hydrogen & 113.2 & $0.037 \%$ & $10.15 \%$ & $18.9 \%$ \\
\hline 8 & D & 500 & Argon & 132.5 & $0.017 \%$ & $7.86 \%$ & $14.4 \%$ \\
\hline 9 & B & 100 & Hydrogen & 123.6 & $0.035 \%$ & $8.47 \%$ & $15.6 \%$ \\
\hline 10 & D & 100 & Argon & 120.3 & $0.108 \%$ & $7.91 \%$ & $17.3 \%$ \\
\hline
\end{tabular}

The coke yield of the selected pitches was also determined. However, because the coke yield is very dependent on the softening point of the pitch (as shown earlier by Figure 4.8) and some of the selected pitches (7A and 8D) have softening points that deviate greatly from the target of $120^{\circ} \mathrm{C}$, a plot of coke yield versus softening point is used to evaluate the effect of pressure and atmosphere on the pitches' coke yield. This plot is shown in Figure 4.16. The coke yield shows little dependence on the hydrogenation reaction conditions of gas composition and pressure. However, it does depend significantly on the softening point of the pitch. From this plot, it can be determined that a pitch with a softening point of $120{ }^{\circ} \mathrm{C}$ would have a coke yield of approximately $45 \%$ by weight. In order to achieve a coke yield of $50 \%$ by weight, the softening point would have to be increased to approximately $145^{\circ} \mathrm{C}$, and to reach a coke yield of $60 \%$ by weight, a softening point of greater than $180^{\circ} \mathrm{C}$ would be required.

Once the coke samples have been formed, the optical texture can be investigated by optical microscopy. Photographs were taken of every coke that was formed to produce the data shown in Figure 4.16 and can be seen in Appendix B. The micrographs 


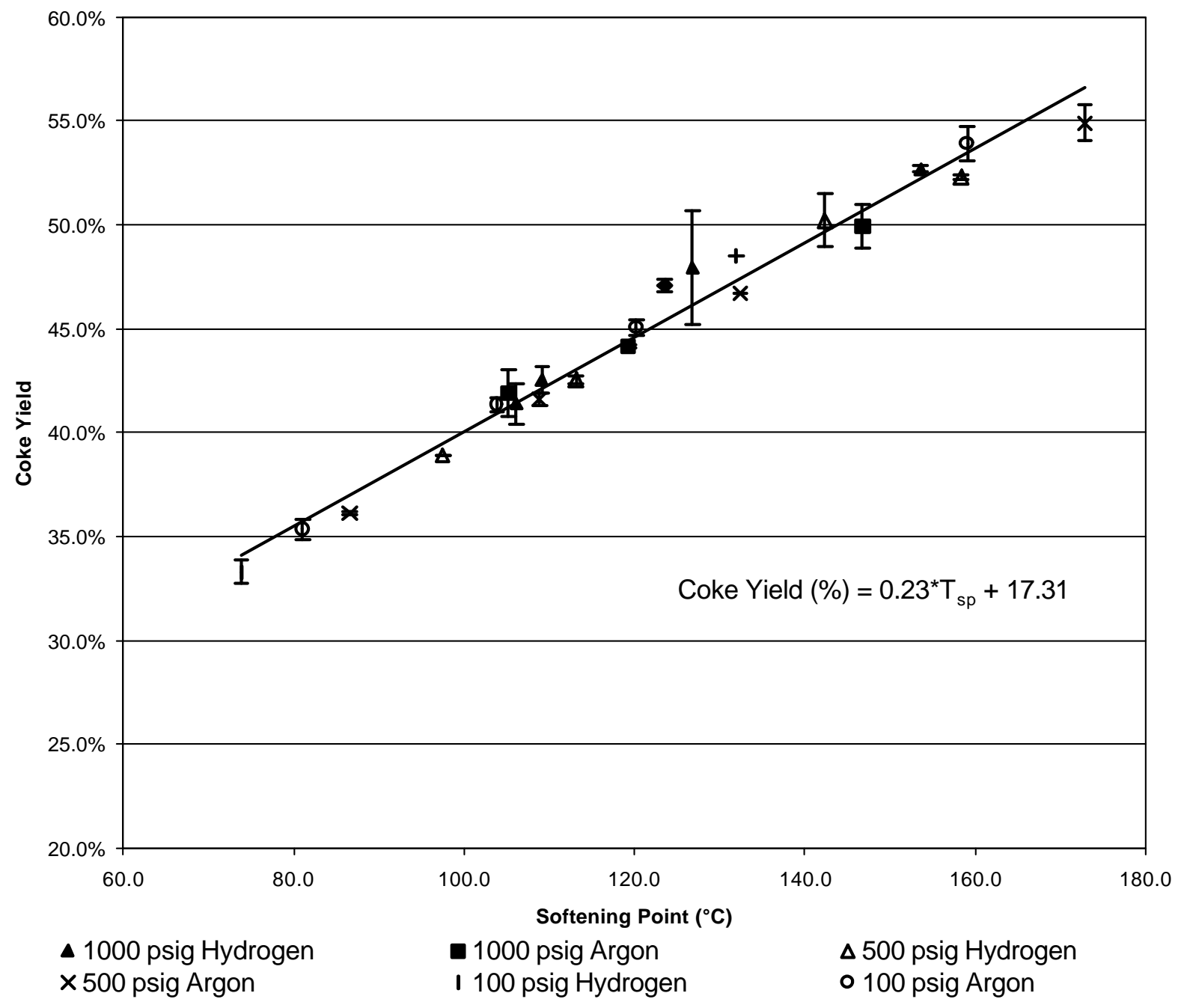

Figure 4.16 Effect of raising the softening point of pitches produced under different atmospheres and initial reaction pressures on the coke yield with reaction conditions of $\mathrm{CBB}$ solvent, $400{ }^{\circ} \mathrm{C}, 3 / 1$ solvent-to-coal ratio, 1 hour 


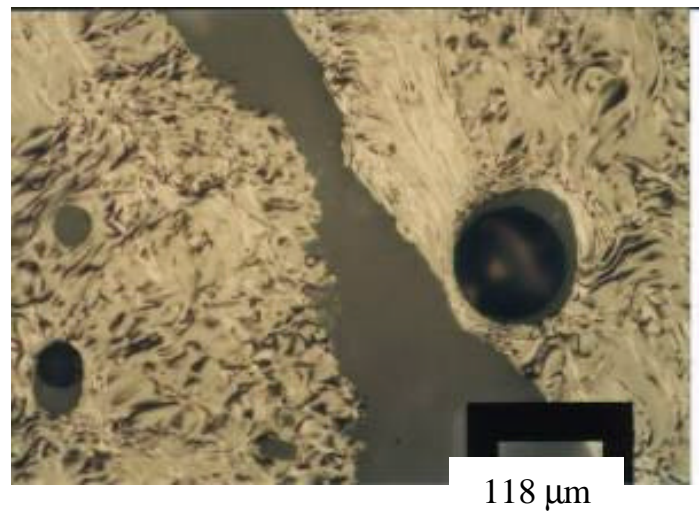

A

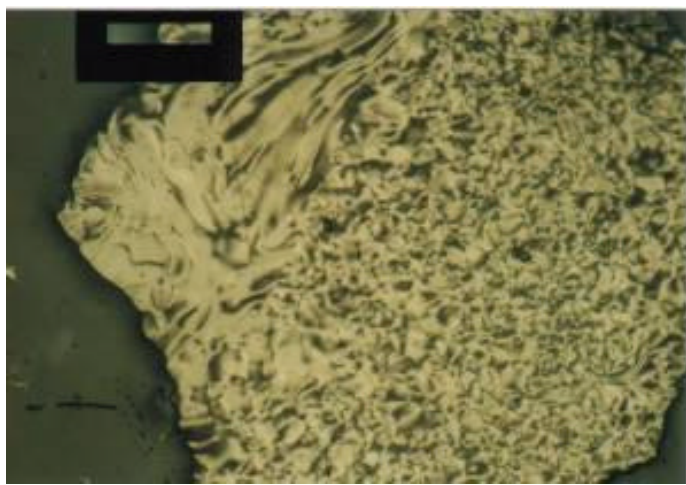

$\mathrm{C}$

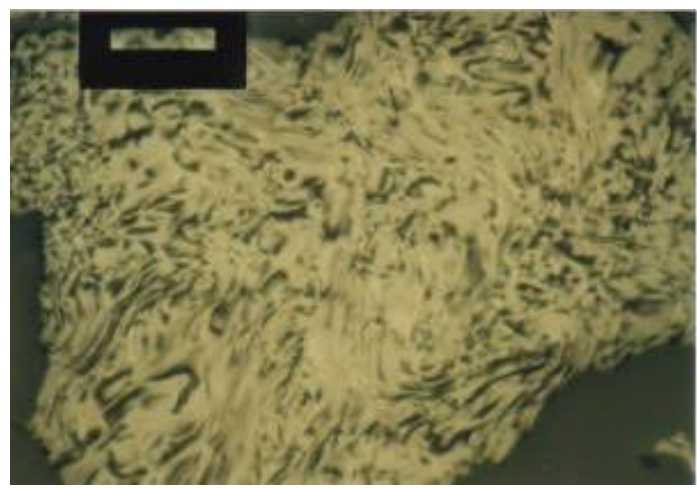

$\mathrm{E}$

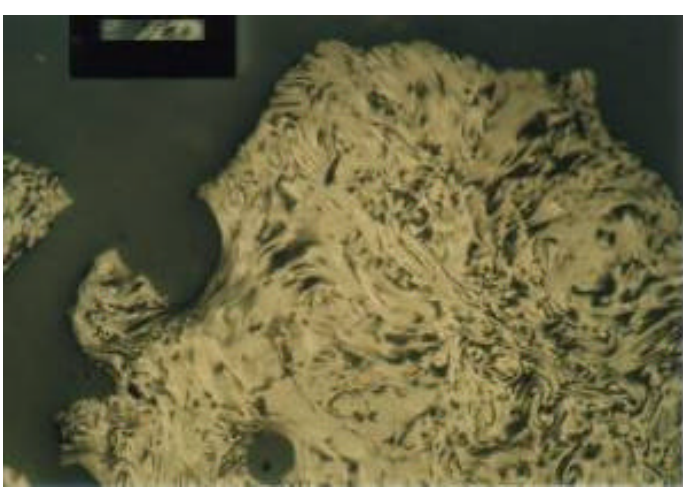

B

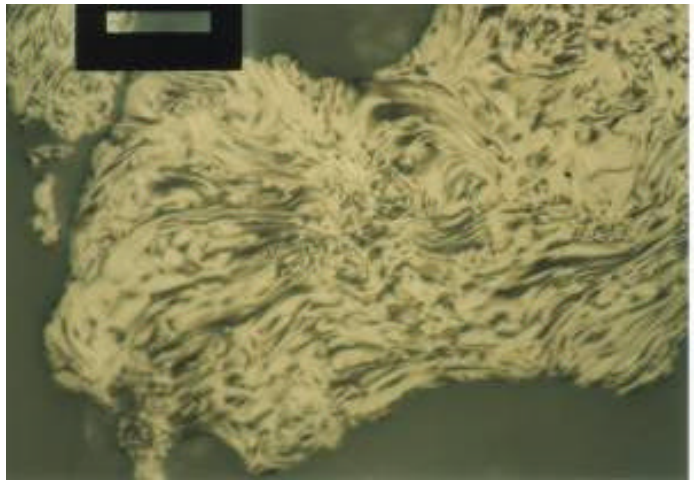

$\mathrm{D}$

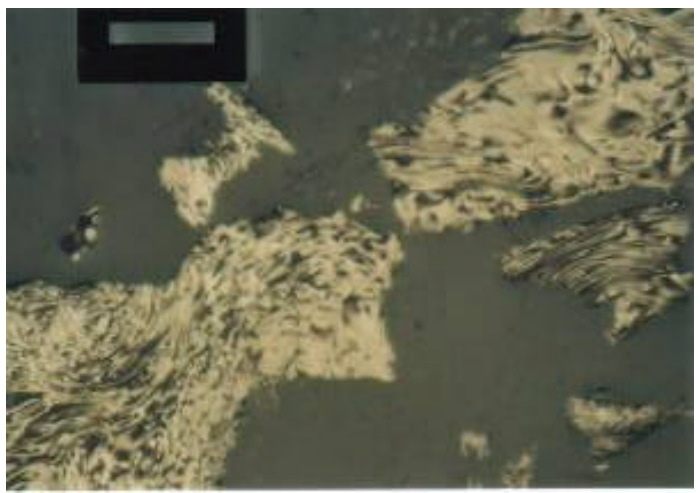

$\mathrm{F}$

Figure 4.17 Optical micrographs of cokes produced from select pitches derived from hydrogenation products from reactions (CBB solvent, $400{ }^{\circ} \mathrm{C}, 3 / 1$ solventto-coal ratio, 1 hour) with varying initial pressures and atmospheres, A) 1000 psig Hydrogen, B) 1000 psig Argon, C) 500 psig Hydrogen, D) 500 psig Argon, E) 100 psig Hydrogen, and F) 100 psig Argon 
of cokes produced from the pitches with a softening point close to $120^{\circ} \mathrm{C}$ (the same ones shown in Table 4.7) are shown in Figure 4.17. Each of these represents a different hydrogenation pressure and atmosphere. Each coke sample has an anisotropic texture with the domain sizes differing depending on the reaction condition used. However, there does not seem to be a direct correlation between the domain sizes in the cokes and the hydrogenation pressure or atmosphere. Therefore, high hydrogen pressures are not required to make anisotropic coke. This is an important result since high pressures and hydrogen incur higher operational costs and hazards.

The final characterization that was carried out on these hydrogenation products was an elemental analysis. This was done according to the procedure described in Section 3.3.5. The results of the elemental analysis for the three product fractions are shown in Table 4.8 and were also used to calculate a carbon and hydrogen balance (shown in Tables 4.9 and 4.10, respectively). Table 4.8 shows that the elemental composition of each product fraction is approximately equal (within experimental error) for each hydrogenation run, regardless of the initial pressure and atmosphere. This could be due to the low conversions achieved which lead to a significant amount of original solvent left in the pitch fraction. Table 4.9 and Table 4.10 reveal a negative carbon and hydrogen balance for the selected hydrogenation reactions. This deviation can be attributed to depending on the mass balance to calculate the carbon and hydrogen balances. The reason for these errors is similar to that described for the previous carbon and hydrogen balances in Section 4.6.4. However, it is important to note that the hydrogen balance is more accurate for the runs with added hydrogen pressure than those with argon. This indicates that more hydrogen was being added when hydrogen was employed as the gas phase.

\subsubsection{Effect of Solvent-to-Coal Ratio}

Thus far, the carbon product precursors (pitches) have had a very desirable ash content and optical texture, but the coke yield for the pitches with a softening point in an acceptable range of the target has been below desired levels. The effect of raising the 
Table 4.8 Elemental composition of select pitches produced from hydrogenation reactions (CBB solvent, $400{ }^{\circ} \mathrm{C}, 3 / 1$ solvent-to-coal ratio, 1 hour) with different initial pressures and atmospheres: 5B) 1000 psig Hydrogen, 6D) 1000 psig Argon, 7A) 500 psig Hydrogen, 8D) 500 psig Argon, 9B) 100 psig Hydrogen, and 10D) 100 psig Argon

\begin{tabular}{|c|c|c|c|c|c|}
\hline \multirow{2}{*}{$\begin{array}{c}\text { Run } \\
\text { (Initial } \\
\text { Pressure } \\
\text { psig) }\end{array}$} & \multirow[b]{2}{*}{ Element } & \multirow[b]{2}{*}{$\begin{array}{c}\text { Original } \\
\text { Solvent CBB } \\
\end{array}$} & \multicolumn{3}{|c|}{ Product Fraction } \\
\hline & & & Pitch & $\begin{array}{c}\text { THF } \\
\text { Insoluble }\end{array}$ & $\begin{array}{l}\text { Recycle } \\
\text { Solvent } \\
\end{array}$ \\
\hline \multirow{5}{*}{$\begin{array}{c}5 \mathrm{~B} \\
\left(1000 \mathrm{H}_{2}\right)\end{array}$} & C & $91.85 \%$ & $89.75 \%$ & $79.17 \%$ & $90.73 \%$ \\
\hline & $\mathrm{H}$ & $5.14 \%$ & $5.14 \%$ & $3.97 \%$ & $5.79 \%$ \\
\hline & $\mathrm{N}$ & $0.88 \%$ & $1.15 \%$ & $0.86 \%$ & $0.89 \%$ \\
\hline & $\mathrm{S}$ & $0.55 \%$ & $0.63 \%$ & $0.94 \%$ & $0.69 \%$ \\
\hline & $\begin{array}{c}\mathrm{H} / \mathrm{C} \text { Atomic } \\
\text { Ratio }\end{array}$ & 0.66 & 0.69 & 0.60 & 0.77 \\
\hline \multirow{5}{*}{$\begin{array}{c}6 \mathrm{D} \\
(1000 \mathrm{Ar})\end{array}$} & $\mathrm{C}$ & $91.85 \%$ & $91.42 \%$ & $82.60 \%$ & $92.89 \%$ \\
\hline & $\mathrm{H}$ & $5.14 \%$ & $5.31 \%$ & $3.91 \%$ & $5.51 \%$ \\
\hline & $\mathrm{N}$ & $0.88 \%$ & $1.29 \%$ & $1.08 \%$ & $0.45 \%$ \\
\hline & $\mathrm{s}$ & $0.55 \%$ & $0.84 \%$ & $0.78 \%$ & $0.78 \%$ \\
\hline & $\begin{array}{c}\mathrm{H} / \mathrm{C} \text { Atomic } \\
\text { Ratio }\end{array}$ & 0.66 & 0.70 & 0.57 & 0.71 \\
\hline \multirow{5}{*}{$\begin{array}{c}7 \mathrm{~A} \\
\left(500 \mathrm{H}_{2}\right)\end{array}$} & $\mathrm{C}$ & $91.85 \%$ & $91.51 \%$ & $82.49 \%$ & $91.26 \%$ \\
\hline & $\mathrm{H}$ & $5.14 \%$ & $5.27 \%$ & $4.09 \%$ & $5.75 \%$ \\
\hline & $\mathrm{N}$ & $0.88 \%$ & $1.68 \%$ & $1.24 \%$ & $0.01 \%$ \\
\hline & $\mathrm{s}$ & $0.55 \%$ & $0.77 \%$ & $0.88 \%$ & $0.63 \%$ \\
\hline & $\begin{array}{c}\mathrm{H} / \mathrm{C} \text { Atomic } \\
\text { Ratio } \\
\end{array}$ & 0.66 & 0.69 & 0.59 & 0.76 \\
\hline \multirow{5}{*}{$\begin{array}{c}8 \mathrm{D} \\
(500 \mathrm{Ar})\end{array}$} & C & $91.85 \%$ & $92.50 \%$ & $81.41 \%$ & $89.59 \%$ \\
\hline & $\mathrm{H}$ & $5.14 \%$ & $5.04 \%$ & $4.21 \%$ & $5.27 \%$ \\
\hline & $\mathrm{N}$ & $0.88 \%$ & $1.73 \%$ & $1.92 \%$ & $0.59 \%$ \\
\hline & $\mathrm{S}$ & $0.55 \%$ & $0.79 \%$ & $0.81 \%$ & $0.76 \%$ \\
\hline & $\begin{array}{c}\text { H/C Atomic } \\
\text { Ratio }\end{array}$ & 0.66 & 0.65 & 0.62 & 0.71 \\
\hline \multirow{5}{*}{$\begin{array}{c}9 \mathrm{~B} \\
\left(100 \mathrm{H}_{2}\right)\end{array}$} & $\mathrm{C}$ & $91.85 \%$ & $91.55 \%$ & $82.22 \%$ & $92.09 \%$ \\
\hline & $\mathrm{H}$ & $5.14 \%$ & $5.19 \%$ & $4.08 \%$ & $5.80 \%$ \\
\hline & $\mathrm{N}$ & $0.88 \%$ & $1.12 \%$ & $1.30 \%$ & $0.87 \%$ \\
\hline & $\mathrm{s}$ & $0.55 \%$ & $0.69 \%$ & $0.84 \%$ & $0.61 \%$ \\
\hline & $\begin{array}{c}\mathrm{H} / \mathrm{C} \text { Atomic } \\
\text { Ratio }\end{array}$ & 0.66 & 0.68 & 0.60 & 0.76 \\
\hline \multirow{5}{*}{$\begin{array}{c}10 \mathrm{D} \\
(100 \mathrm{Ar})\end{array}$} & C & $91.85 \%$ & $89.04 \%$ & $82.02 \%$ & $89.58 \%$ \\
\hline & $\mathrm{H}$ & $5.14 \%$ & $5.07 \%$ & $4.19 \%$ & $5.47 \%$ \\
\hline & $\mathrm{N}$ & $0.88 \%$ & $1.51 \%$ & $1.20 \%$ & $0.77 \%$ \\
\hline & $\mathrm{s}$ & $0.55 \%$ & $0.80 \%$ & $0.64 \%$ & $0.46 \%$ \\
\hline & $\begin{array}{c}\mathrm{H} / \mathrm{C} \text { Atomic } \\
\text { Ratio }\end{array}$ & 0.66 & 0.68 & 0.61 & 0.73 \\
\hline
\end{tabular}


Table 4.9 Carbon balance of select pitches produced from hydrogenation reactions with different initial pressures and atmospheres: 5B) 1000 psig Hydrogen, 6D) 1000 psig Argon, 7A) 500 psig Hydrogen, 8D) 500 psig Argon, 9B) 100 psig Hydrogen, and 10D) 100 psig Argon

\begin{tabular}{||c|c|c|c|c|c|c|c|c|c|c||}
\hline \hline Run & Trial & $\begin{array}{c}\text { In Coal } \\
(\mathrm{g})\end{array}$ & $\begin{array}{c}\text { Carbon } \\
\text { In Solv. } \\
(\mathrm{g})\end{array}$ & $\begin{array}{c}\text { Total } \\
\text { Carbon In } \\
(\mathrm{g})\end{array}$ & $\begin{array}{c}\text { Carbon } \\
\text { Out Pitch } \\
(\mathrm{g})\end{array}$ & $\begin{array}{c}\text { Carbon } \\
\text { Out THF } \\
\text { Ins. }(\mathrm{g})\end{array}$ & $\begin{array}{c}\text { Carbon Out } \\
\text { Rec. Solv. } \\
(\mathrm{g})\end{array}$ & $\begin{array}{c}\text { Total } \\
\text { Carbon } \\
\text { Out }(\mathrm{g})\end{array}$ & $\begin{array}{c}\text { Out }- \text { In } \\
(\mathrm{g})\end{array}$ & $\begin{array}{c}(\text { Out-In)/In } \\
(\%)\end{array}$ \\
\hline \hline 5 & B & 7.3079 & 24.6799 & 31.9878 & 6.4201 & 5.6164 & 18.7533 & 30.7898 & -1.1980 & -3.7 \\
\hline 6 & D & 7.2931 & 24.6307 & 31.9238 & 5.9574 & 6.4492 & 17.8073 & 30.2139 & -1.7099 & -5.4 \\
\hline 7 & A & 6.9826 & 23.5819 & 30.5646 & 5.9244 & 5.7824 & 16.1809 & 27.8877 & -2.6768 & -8.8 \\
\hline 8 & D & 7.0193 & 23.7043 & 30.7236 & 4.5702 & 6.3890 & 17.5604 & 28.5195 & -2.2041 & -7.2 \\
\hline 9 & B & 7.0901 & 23.9469 & 31.0369 & 4.9749 & 6.6739 & 17.5893 & 29.2381 & -1.7989 & -5.8 \\
\hline 10 & D & 7.2111 & 24.3504 & 31.5614 & 5.4455 & 6.5388 & 15.6412 & 27.6255 & -3.9359 & -12.5 \\
\hline
\end{tabular}

Table 4.10 Hydrogen balance of select pitches produced from hydrogenation reactions with different initial pressures and atmospheres: 5B) 1000 psig Hydrogen, 6D) 1000 psig Argon, 7A) 500 psig Hydrogen, 8D) 500 psig Argon, 9B) 100 psig Hydrogen, and 10D) 100 psig Argon

\begin{tabular}{||c|c|c|c|c|c|c|c|c|c|c||}
\hline \hline Run & Trial & $\begin{array}{c}\text { Hydrogen } \\
\text { in Coal }(\mathrm{g})\end{array}$ & $\begin{array}{c}\text { Hydrogen } \\
\text { in Solv. } \\
(\mathrm{g})\end{array}$ & $\begin{array}{c}\text { Total } \\
\text { Hydrogen } \\
\text { In }(\mathrm{g})\end{array}$ & $\begin{array}{c}\text { Hydrogen } \\
\text { Out Pitch } \\
(\mathrm{g})\end{array}$ & $\begin{array}{c}\text { Hydrogen } \\
\text { Out THF } \\
\text { Ins. }(\mathrm{g})\end{array}$ & $\begin{array}{c}\text { Hydrogen } \\
\text { Out Rec. } \\
\text { Solv. }(\mathrm{g})\end{array}$ & $\begin{array}{c}\text { Total } \\
\text { Hydrogen } \\
\text { Out }(\mathrm{g})\end{array}$ & $\begin{array}{c}\text { Out }- \text { In } \\
(\mathrm{g})\end{array}$ & $\begin{array}{c}(\text { Out-In) In } \\
(\%)\end{array}$ \\
\hline 5 & B & 0.4088 & 1.4804 & 1.8892 & 0.3676 & 0.2817 & 1.1972 & 1.8464 & -0.0428 & -2.3 \\
\hline 6 & D & 0.4080 & 1.4775 & 1.8854 & 0.3461 & 0.3056 & 1.0562 & 1.7080 & -0.1775 & -9.4 \\
\hline 7 & A & 0.3906 & 1.4146 & 1.8052 & 0.3415 & 0.2866 & 1.0201 & 1.6482 & -0.1570 & -8.7 \\
\hline 8 & D & 0.3927 & 1.4219 & 1.8146 & 0.2691 & 0.3302 & 1.0323 & 1.6317 & -0.1829 & -10.1 \\
\hline 9 & B & 0.3966 & 1.4364 & 1.8331 & 0.2822 & 0.3310 & 1.1074 & 1.7206 & -0.1124 & -6.1 \\
\hline 10 & D & 0.4034 & 1.4607 & 1.8640 & 0.3099 & 0.3341 & 0.9551 & 1.5991 & -0.2650 & -14.2 \\
\hline
\end{tabular}


softening point in order to achieve a higher coke yield has been thoroughly discussed in Section 4.6.2 and the middle of Section 4.7.1. However, there could be another alternative to raising the softening point to increase the coke yield. By lowering the solvent-to-coal ratio, less solvent would be retained by the produced pitch. Since the retained solvent would generally be volatilized during the coking process, decreasing the amount of solvent retained by the pitch could increase the coke yield by increasing the proportion of heavier coal-derived species, again assuming lowering the solvent-to-coal ratio does not affect the coal conversion. Hydrogenation runs four (4), eleven (11) and twelve (12) explore this option. For the three sets of reactions, HCO was employed as the solvent (again because it is more commercially available than DACL-L, however because of limited quantities of $\mathrm{HCO}$, it was only used for this test and not in the previous section), and the reactions were carried out at $400{ }^{\circ} \mathrm{C}, 1000 \mathrm{psig}$ initial hydrogen pressure, 1 hour, and a decreasing solvent-to-coal ratio (by weight) of 3/1 for run four (4), $2 / 1$ for run eleven (11), and 1/1 for run twelve (12). The effect of lowering the solventto-coal ratio on the overall and coal-alone conversions, ash content, coking value, and elemental analysis is discussed below.

The overall and coal-alone conversions for runs four (4), eleven (11), and twelve (12) are depicted in Figure 4.18. It is interesting to note that the overall conversion decreases as the solvent-to-coal ratio decreases, but the coal-alone conversion remains relatively constant (within experimental error). This shows that the coal-alone conversion does not depend significantly on the amount of solvent, only on the reaction conditions. The loss in overall conversion depicted in Figure 4.18 can be attributed to less solvent being carried into the THF soluble fraction. This is expected since there is less solvent in the original reaction feed as the solvent-to-coal ratio is decreased. The result of the coal-alone conversion section of Figure 4.18 is that the coal conversion is independent of the solvent-to-coal ratio. Therefore, the least amount of solvent that allows adequate processing of the reactants and products could be employed. From a coal-alone conversion standpoint, the optimum solvent-to-coal ratio is $2 / 1$ because the $1 / 1$ ratio would not flow when heated, leading to significant processing problems. 


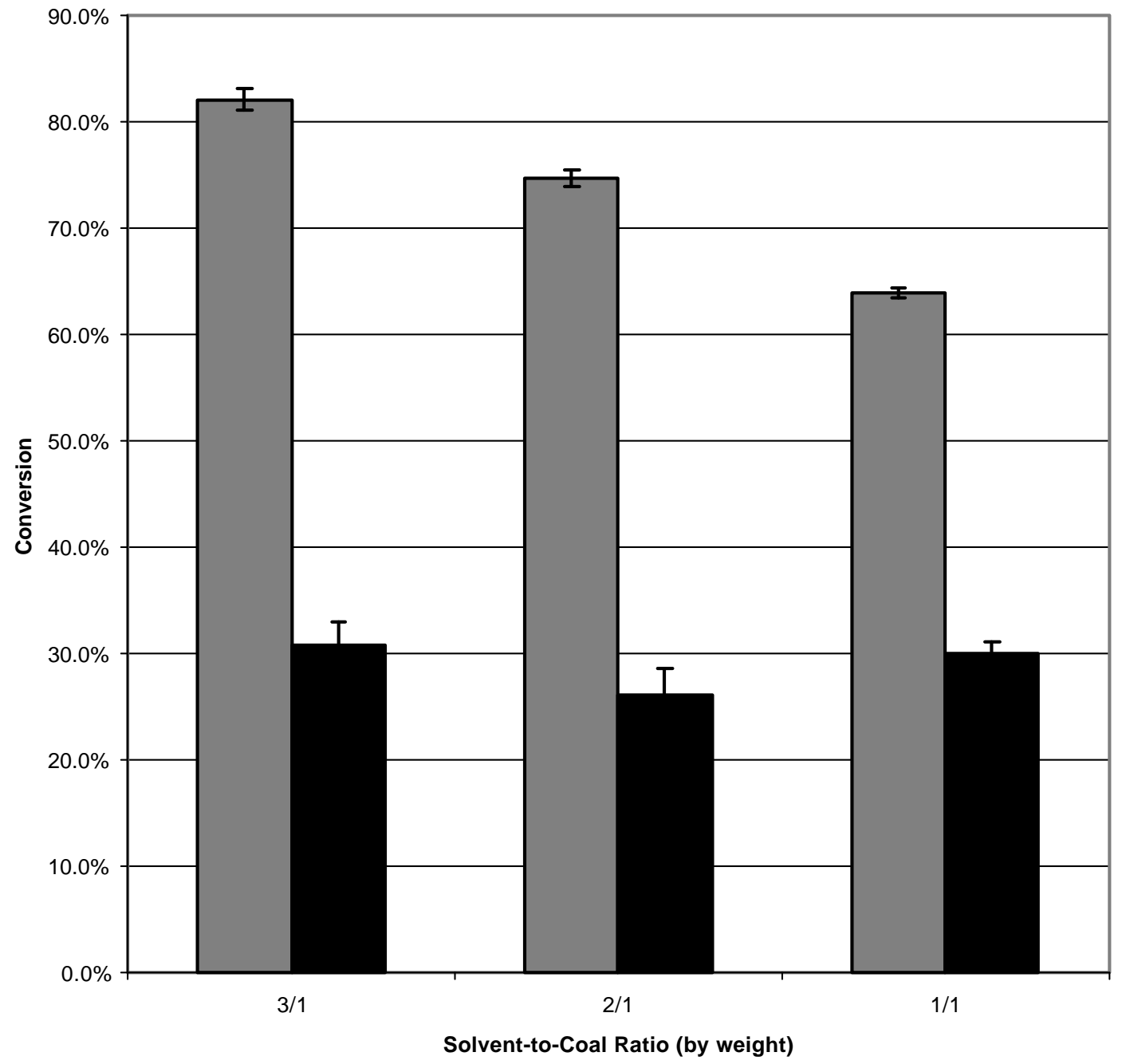

口Overall Conversion $\quad$ Coal-Alone Conversion

Figure 4.18 Effect of solvent-to-coal ratio on the overall and coal-alone conversions of hydrogenation reactions performed with the $\mathrm{HCO}$ solvent under conditions of $400{ }^{\circ} \mathrm{C}, 1000$ psig Hydrogen, and 1 hour 


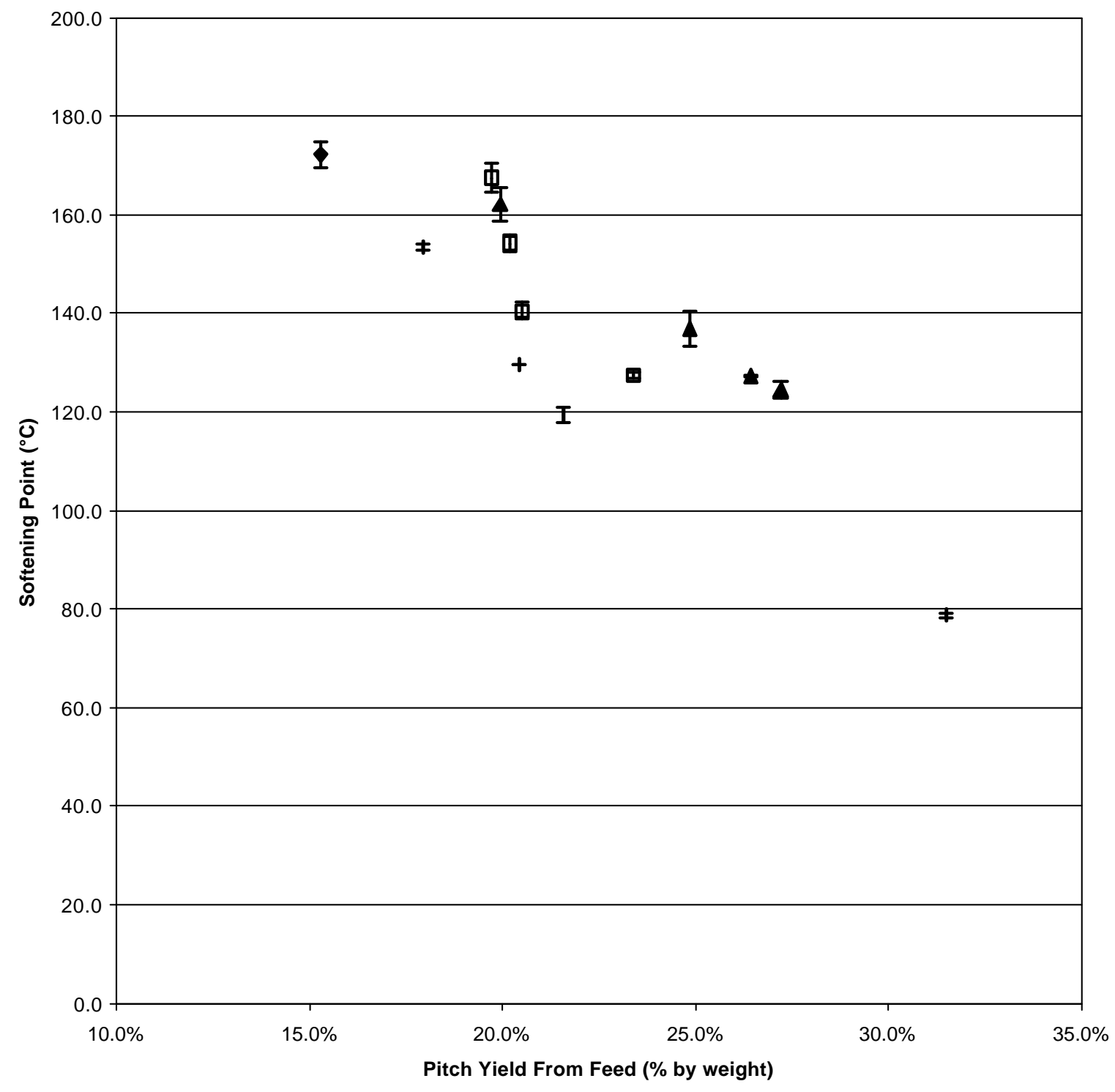

$\bullet 3 / 1 \quad \square 2 / 1 \quad \Delta 1 / 1$

Figure 4.19 Effect of solvent-to-coal ratio on the amount of distillation required to achieve a specific softening point from hydrogenation reactions with conditions of $\mathrm{HCO}$ solvent, $400{ }^{\circ} \mathrm{C}, 1000$ psig hydrogen, and 1 hour 
Once the THF extraction was completed, the THF soluble fraction was separated by vacuum distillation into the pitch and recycle solvent fractions. This was done in such a way that pitches of several different softening points were obtained, including a sample from each run close to the target value of $120^{\circ} \mathrm{C}$. Figure 4.19 shows a nearly linear dependence of the final softening point of the pitch with the percentage of pitch recovered from the original reaction feed. It is interesting to note that as the solvent-tocoal ratio is decreased, the linear representation of softening point versus percent pitch yield shifts to the right in Figure 4.19. This shift corresponds to less distillation required to achieve a similar softening point as the solvent-to-coal ratio is decreased. This phenomenon is expected since a lower solvent content in the feed suggests that less recycle solvent will be recovered and less solvent needs to be distilled from the pitch to achieve the same softening point. This has some advantages and disadvantages. The advantages are that it produces a higher pitch yield and good coal conversion, but the disadvantages are that the products will be harder to process and less recycle solvent will be generated.

After the distillation was performed, three pitches were isolated (one from each run) with a softening point at or near the $120^{\circ} \mathrm{C}$. These runs were $4 \mathrm{C}, 11 \mathrm{~B}$ and $12 \mathrm{~A}$ and had a softening point of $119.4,127.5$ and $124.6^{\circ} \mathrm{C}$, respectively. These three samples were used to evaluate the ash and elemental content of the resultant products.

The ash content of the pitch and THF insoluble fraction of these three trials are shown in Table 4.11. For each of the selected samples, the ash content of the pitch and insoluble fractions are very similar. This is consistent with the fact that the coal-alone conversion remains constant as the solvent-to-coal ratio is lowered.

As with the previous experiments, an elemental analysis was conducted on the hydrogenation products for the selected trials as the solvent-to-coal ratio was lowered and the results of these analyses are shown in Table 4.12. These results indicate that in general the carbon content of each of the pitch fractions decreases (from $91.16 \%$ to $87.29 \%$ ) as the solvent-to-coal ratio decreases. However, the hydrogen content remains 
constant at approximately 5.3\%. The carbon and hydrogen contents of the THF insoluble and recycle solvent fractions are all within experimental error of each other, thus showing no dependence on the solvent-to-coal ratio of the hydrogenation reactions. The elemental compositions of the pitch fractions in Table 4.12 are also similar to those of the pitch fractions shown in Tables 4.4 and 4.8. Each pitch fraction has a carbon content of approximately $90 \%$ and a hydrogen content between 5 and $6 \%$ regardless of reaction conditions or the solvent employed.

Table 4.11 Ash content of pitch and THF insoluble fractions of selected hydrogenation runs with decreasing solvent-to-coal ratio with reaction conditions of $\mathrm{HCO}$ solvent, $400{ }^{\circ} \mathrm{C}, 1000$ psig hydrogen, and 1 hour

\begin{tabular}{||l|l|l|l|l|l||}
\hline Run & Trial & $\begin{array}{l}\text { Solvent-to- } \\
\text { Coal Ratio }\end{array}$ & $\begin{array}{l}\text { Average } \\
\text { Point }\left({ }^{\circ} \mathrm{C}\right)\end{array}$ & $\begin{array}{l}\% \text { Ash in } \\
\text { Softening Ash inTH } \\
\text { Pitch } \\
\text { Insoluble }\end{array}$ \\
\hline \hline 4 & $\mathrm{C}$ & $3 / 1$ & 119.4 & $0.019 \%$ & $10.63 \%$ \\
\hline 11 & $\mathrm{~B}$ & $2 / 1$ & 127.5 & $0.084 \%$ & $10.80 \%$ \\
\hline 12 & $\mathrm{~A}$ & $1 / 1$ & 124.6 & $0.024 \%$ & $10.15 \%$ \\
\hline
\end{tabular}

Finally, the effect of lowering the solvent-to-coal ratio on the coke yield of the resultant pitch was investigated. It was hypothesized that by lowering the solvent-to-coal ratio, the amount of solvent remaining in the pitch fraction after distillation would decrease. This decrease in solvent content would cause an increase in the coke yield. Again, because of the dependence of the coke yield on the softening point, a plot of coke yield versus softening point was produced as Figure 4.20 in order to illustrate this effect. However, as Figure 4.20 illustrates, lowering the solvent-to-coal ratio has little or no effect on the coke yield thus proving the previous hypothesis invalid. All three solventto-coal ratios seem to fall along a similar linear representation of coke yield versus softening point. It is interesting to note that in order to achieve a coke yield of 50 percent by weight, according to Figure 4.20, a softening point of approximately $145^{\circ} \mathrm{C}$ would be required. 
This linear representation is also similar to that shown in both Figure 4.8 and Figure 4.16. The equations of the linear representations for each graph are very similar. The slopes of the lines for Figures 4.8, 4.16, and 4.20 are 0.21, 0.23, and 0.24, respectively. The y-intercept for each figure is 19, 17, and 15 for Figures 4.8, 4.16, and 4.20. This similarity in equations leads to producing a plot (Figure 4.21) of coke yield versus softening point for all pitches produced. Figure 4.21 shows that the linear trends from the three previous figures $(4.8,4,16$, and 4.20) are virtually all on the same line. This illustrates that once the pitch is formed, the relationship between coke yield and softening point is the same regardless of the reaction conditions. It is important to note that for these solvents and this type of coal, a coke yield can be predicted from the pitch softening point and is not changed by the reaction conditions of gas composition, gas pressure, solvent-to-coal ratio, and solvent choice. It is not known from this study if the particular linear relationship is dependent on the characteristics of the coal. Further study is warranted in this area. 
Table 4.12 Elemental analysis of selected hydrogenation trials as the solvent-to-coal ratio was lowered but all other reaction conditions were kept constant at HCO solvent, $400{ }^{\circ} \mathrm{C}, 1000$ psig hydrogen, and 1 hour

\begin{tabular}{|c|c|c|c|c|}
\hline \multirow{2}{*}{$\begin{array}{c}\text { Run } \\
\text { (Solvent- } \\
\text { to-Coal } \\
\text { Ratio) }\end{array}$} & \multirow[b]{2}{*}{ Element } & \multicolumn{3}{|c|}{ Product Fraction } \\
\hline & & Pitch & $\begin{array}{c}\text { THF } \\
\text { Insoluble } \\
\end{array}$ & $\begin{array}{l}\text { Recycle } \\
\text { Solvent }\end{array}$ \\
\hline \multirow{5}{*}{$\begin{array}{c}4 \mathrm{C} \\
(3 / 1)\end{array}$} & $C$ & $91.16 \%$ & $79.02 \%$ & $93.90 \%$ \\
\hline & $\mathrm{H}$ & $5.31 \%$ & $3.96 \%$ & $5.53 \%$ \\
\hline & $\mathrm{N}$ & $1.45 \%$ & $1.42 \%$ & $0.93 \%$ \\
\hline & $S$ & $0.71 \%$ & $0.96 \%$ & $0.48 \%$ \\
\hline & $\begin{array}{c}\mathrm{H} / \mathrm{C} \text { Atomic } \\
\text { Ratio }\end{array}$ & 0.70 & 0.60 & 0.71 \\
\hline \multirow{5}{*}{$\begin{array}{l}11 \mathrm{~B} \\
(2 / 1)\end{array}$} & $\mathrm{C}$ & $89.59 \%$ & $77.53 \%$ & $90.32 \%$ \\
\hline & $\mathrm{H}$ & $5.18 \%$ & $3.95 \%$ & $5.44 \%$ \\
\hline & $\mathrm{N}$ & $1.47 \%$ & $1.70 \%$ & $0.85 \%$ \\
\hline & $S$ & $0.64 \%$ & $0.71 \%$ & $0.39 \%$ \\
\hline & $\begin{array}{c}\mathrm{H} / \mathrm{C} \text { Atomic } \\
\text { Ratio }\end{array}$ & 0.69 & 0.61 & 0.72 \\
\hline \multirow{5}{*}{$\begin{array}{r}12 \mathrm{~A} \\
(1 / 1)\end{array}$} & $\mathrm{C}$ & $87.29 \%$ & $76.81 \%$ & $90.46 \%$ \\
\hline & $\mathrm{H}$ & $5.34 \%$ & $4.11 \%$ & $5.74 \%$ \\
\hline & $\mathrm{N}$ & $1.09 \%$ & $1.36 \%$ & $0.66 \%$ \\
\hline & $S$ & $0.64 \%$ & $0.72 \%$ & $0.42 \%$ \\
\hline & $\begin{array}{c}\mathrm{H} / \mathrm{C} \text { Atomic } \\
\text { Ratio }\end{array}$ & 0.73 & 0.64 & 0.76 \\
\hline
\end{tabular}




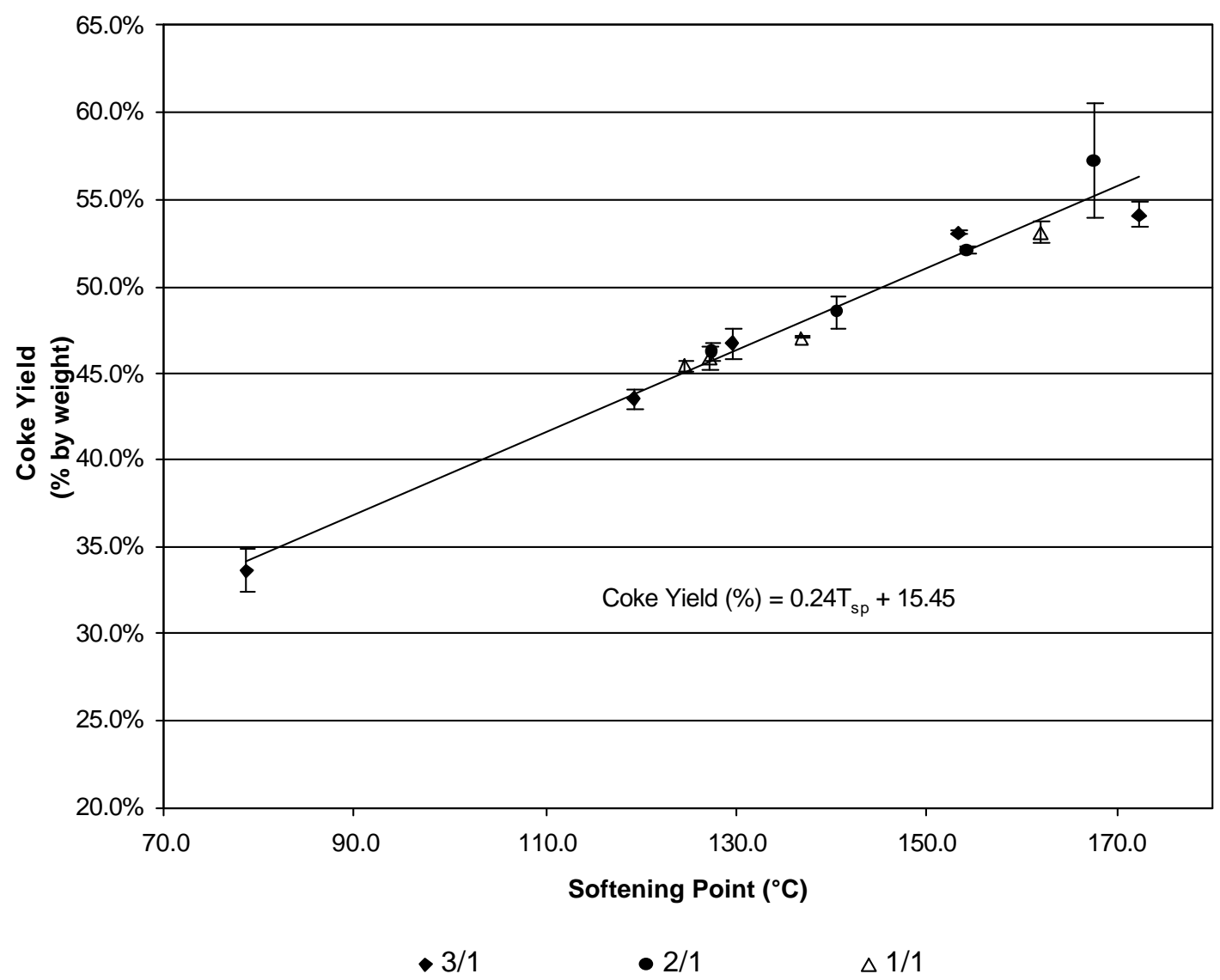

Figure 4.20 Effect of lowering the solvent-to-coal ratio on the pitch coke yield and various softening points from hydrogenation reactions with conditions of $\mathrm{HCO}$ solvent, $400^{\circ} \mathrm{C}, 1000$ psig hydrogen, and 1 hour 


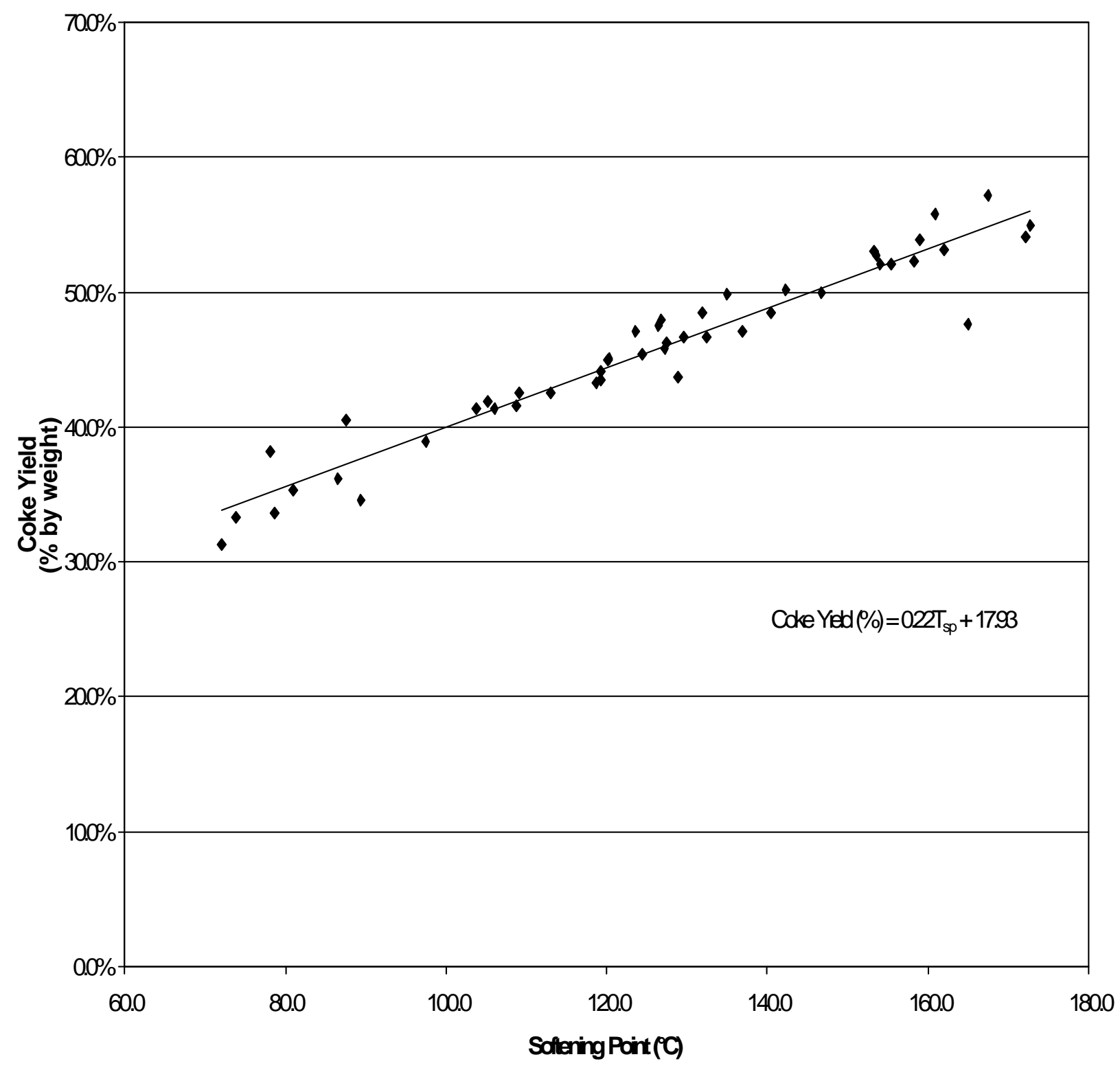

Figure 4.21 Effect of pitch softening point on the coke yield for all pitch fractions produced under varying reaction conditions 


\section{CHAPTER 5 CONCLUSIONS AND RECOMMENDATIONS}

The purpose of this thesis project was to evaluate the effectiveness of five coalderived liquids as possible hydrogenation solvents for the production of carbon-product precursors from coal. Each of these solvents was employed as a hydrogen donor under constant reaction conditions. The hydrogenation products were then separated into three fractions, pitch, THF insolubles, and recycle solvent. The pitch fraction was then characterized by standard methods to compare its properties to those of commercially available pitches. Finally, some of the reaction conditions were varied (pressure, gas composition, and solvent-to-coal ratio) in order to understand their effect on the products of the hydrogenation reactions. From these experiments several conclusions can be drawn.

1) The overall conversion seems to mask the effect of changing reaction conditions on coal reactivity because of the high amounts of solvent compared to the amount of coal included in the calculation. The coal-alone conversion, on the other hand, gives a relatively clear picture of the effect of changing the reaction conditions.

2) By using the coal-alone conversion, the most effective solvent for creating soluble species from coal was DACL-L (46.7\%) followed by HCO (30.8\%) and CBB $(23.2 \%)$.

3) The coal-alone conversion was also dependent on the initial reaction pressure and gas composition. As the pressure increased, the coal-alone conversion increased for both hydrogen and argon atmospheres but not as significantly for the argon. This leads to the conclusion that the gaseous hydrogen does play an active role in converting the coal to soluble species.

4) The coal-alone conversion did not show a dependence on the solvent-to-coal ratio in the hydrogenation reactions. This is a valuable result in that the least amount 
of solvent can be employed that physically allows for practical processing. It was found that a solvent-to-coal ratio of $1 / 1$ was too low for adequate processing in these experiments because of the resistance to flow of the reaction products. Therefore, a 2/1 solvent-to-coal ratio is recommended for any subsequent reactions.

5) Once the hydrogenation reactions took place, the products were separated into the THF insolubles, recycle solvent, and the primary product of pitch. This pitch fraction was tested as a possible precursor for carbon products by standard characterization techniques, such as softening point, ash content, coke yield, optical texture, and elemental analysis. The softening point of each pitch could be tailored to a specific need by changing the extent of distillation. Pitches were produced with a softening point as low as $70^{\circ} \mathrm{C}$ up to $180{ }^{\circ} \mathrm{C}$ regardless of the reaction conditions utilized.

6) The ash content of all of the product pitches was at an acceptably low value of less than $0.1 \%$. This ash value is lower than that for pitches currently used as binders and is approaching the ash value of impregnation pitches.

7) The effect of the processing conditions on the coke yield of the product pitches was also investigated. The coke yield was nearly linearly dependent on the softening point of the pitch (controlled by extent of distillation) for all reaction conditions. The coke yield of pitches with a softening point near the commercial target value of $120{ }^{\circ} \mathrm{C}$, however, was somewhat lower than that desired for commercial applications ( $45 \%$ compared to $50-60 \%$ ). Although the coke yield was dependent on the extent of distillation, it showed no other dependence on the reaction conditions. Changing the reaction pressure, gas composition, solvent-to-coal ratio, and even solvent did not have a significant effect on the coking value. 
8) Anisotropic pitch was produced regardless of the solvent choice. Anisotropic pitch could also be produced at low pressures (100 psig) and without hydrogen. This discovery could significantly reduce the operational costs of pitch production.

9) Two important observations were derived from the elemental analysis of the pitch and recycle solvent fractions. First, the pitch fraction showed a carbon content

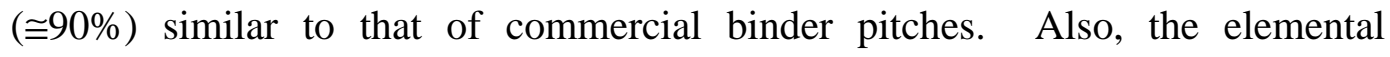
composition of the recycle solvent is similar to that of the original solvent. This could lead to a process that generates its own process solvent, thus alleviating the need for adding more solvent.

The above conclusions lead to the recommendation of an optimum process for the production of pitch from coal and coal-derived liquids. The solvent of choice would be HCO since it exhibited the highest coal-alone conversion while being commerciallyavailable and produced a pitch which yielded an anisotropic carbon. The solvent-to-coal ratio would be $2 / 1$ for ease of processing, and the pressure and gas composition would be 1000 psig hydrogen to maximize conversion. However, the pressure and gas composition could be changed if the processing costs outweigh that of maximizing the conversion.

\subsection{Recommendations for Future Work}

The outcome of this thesis research leads to several recommendations for future work. First, the hydrogenation reaction and process of pitch production should be scaled up somewhat. This would allow for more pitch and recycle solvent to be made. With a greater supply of pitch, a more thorough analysis of the pitch characteristics could be instituted to include measurements of viscosity, aromaticity, density, and solubility in characterization solvents such as toluene and quinoline. By increasing the amount of recycle solvent produced, there would be enough to test it as hydrogenation solvent. 
Also, the solvent-to-coal ratio could be varied between $1 / 1$ and $2 / 1$ to establish the minimum amount needed for adequate processing.

A second study could be performed aiming to increase the conversion of coal to soluble species by the selected solvents. The effect of changing the reaction temperature, time, or addition of a catalyst could be quantified. It would be beneficial to perform a gas-phase analysis on the product gas produced from the hydrogenation reactions. The reaction temperature inside the reactor should be recorded by adding a thermocouple. Finally, the effect of using a different coal sample for the hydrogenation reactions on a similar representation of Figure 4.21 should be investigated. 


\section{REFERENCES}

1. A University, Industry, Government Cooperative Research Partnership. "Non-Fuel Use of Coal: Coal-Derived Carbon Materials”. Nov. 12, 1993. The National Research Center for Coal and Energy (NRCCE), West Virginia University, P. O. Box 6064, Morgantown, WV 26505-6064.

2. Artok, L., Schobert, H.H., and Erbator, O., Fuel Process. Technol., 37, 221, 1994.

3. ASTM D 2415 Standard Test Method for Ash in Coal Tar and Pitch.

4. ASTM D 3104 Standard Test Method for Softening Point of Pitches (Mettler Softening Point Method).

5. Berkowitz, N. An Introduction to Coal Technology. Academic Press, Inc., San Diego, 1994.

6. Chaudhuri, P.D., The Production of Ultra-Pure Coke Precursors for the Manufacture of Value-Added Carbon Products. Thesis, Department of Chemical Engineering, West Virginia University, Morgantown, WV, 1994.

7. Chawla, B., Keogh, R., and Davis, B.H., Energy \& Fuels, 3, 236, 1989.

8. Cloke, M. and Wang, C., Energy \& Fuels, 9, 560, 1995.

9. Curran, G. P., Struck, R. T., and Gorin, E., Ind. Eng. Chem. Process Des. Dev., 6, $166,1967$.

10. Edwards, I.A.S., "Structure in Carbons and Carbon Forms." Introduction to Carbon Science. Ed. H. Marsh, Butterworths, 1989.

11. Ergun, S., "Coal Classification and Characterization," Coal Conversion Technology. Ed. C.Y. Wen and E.S. Lee, Addison-Wesley Publishing Company, Reading, Mass., 1979.

12. Farcasiu, M., Mitchell, T. O., and Whitehurst, D. D., ACS Div. Fuel Chem., Prepr. 27(7), 11, 1976.

13. "Final Technical Report" Coal Based Nuclear Graphites for the New Production Gas Cooled Reactor. Task 1: Development of Coal-Derived Isotropic Coke and Nuclear Graphite. West Virginia University, 1994.

14. Finseth, D.H., Cillo, D.L., Sprecher, R.F., Retcofsky, H.L., and Lett, R.G., Fuel, 64, $1718,1985$. 
15. Fisher, C. H., Sprunk, G. C., Eisner, A., O’Dennell, H. J., Clarke, L., and Storch, H. H., "Hydrogenation and Liquefaction of Coal," Part 2: "Effect of Petrographic Composition and Rank of Coal," U. S. Bur. Mines Tech. Paper, 642, 1942.

16. Francis, W., Coal - Its Formation and Composition. Edward Arnold (Publishers) Ltd., 1954.

17. Gibson, J., Coal: an Introduction to its Formation and Properties. In Coal and Modern Coal Processing: An Introduction, ed. G. J. Pitt and G. R Millward. Academic Press, New York, 1979.

18. Given, P. H., Cronauer, D. C., Spackman, W., Lovell, H. L., Davis, A., and Biswas, B., "Dependence of Coal Liquefaction Behavior on Coal Characteristics," Parts I and II, Fuel, 54, 34 and 40, 1975.

19. Gorin, E., "Fundamentals of Coal Liquefaction." Chemistry of Coal Utilization, ed. M.A. Elliott. John Wiley and Sons, New York, 1981, pp. 1845-1918.

20. Huang, H., Wang, K., Wang, S., Klein, M.T., and Calkins, W.H., Energy \& Fuels, 12, $95,1998$.

21. Keogh, R.A. and Davis, B.H., Energy \& Fuels, 8, 289, 1994.

22. Keogh, R.A., Taulbee, D.N., Hower, J.C., Chawla, B., and Davis, B.H., Energy \& Fuels, 6, 614, 1992.

23. Lee, E.S., "Coal Liquefaction." Coal Conversion Technology. Ed. C.Y. Wen and E.S. Lee, Addison-Wesley Publishing Company, Reading, Mass., 1979.

24. Malhotra, R. and McMillen, D.F., Energy \& Fuels, 4, 184, 1990.

25. Malhotra, R. and McMillen, D.F., Energy \& Fuels, 7, 227, 1993.

26. Merrick, D. Coal Combustion and Conversion Technology. Elsevier: New York, 1984.

27. Mukherjee, D. K., and Chowdry, P. B., Fuel, 55, 4, 1976.

28. Neavel, R. C., Fuel, 55, 237, 1976.

29. Oele, A. P., Waterman, H. I., Goedkoop, M. L., and Van Krevelen, D. W., Fuel, 30, 169, 1951.

30. Orchin, M. and Storch, H. H., Ind. Eng. Chem., 40, 1385, 1948. 
31. Schobert, H. Coal: The Energy Source of the Past and Future. American Chemical Society, USA, 1987.

32. Song, C. and Schobert, H. H., Fuel, 1996, 75(6), 724-736.

33. Speight, J.G. The Chemisty and Technology of Coal. Marcel Dekker: New York, 1983.

34. Stansberry, P.G., Zondlo, J.W., and Stiller, A.H., "Coal-Derived Carbons." Carbon for Advanced Technologies. Ed. T.D. Burchell, Pergamon, Amsterdam, 1999.

35. Stopes, M.C., Proc. R. Soc. London, 90B, 470, 1919.

36. Tomic, J. and Schobert, H.H., Energy \& Fuels, 10, 709, 1996.

37. Van Krevelen, D.W., Coal, Typology-Chemistry-Physics-Constitution. Elsevier Scientific Publishing Company, Amsterdam, 1981.

38. Vernon, L.W., Fuel, 59, 102, 1980.

39. Wen, C.Y. and Dutta, S., "Rates of Coal Pyrolysis and Gasification Reactions." Coal Conversion Technology. Ed. C. Y. Wen and E.S. Lee. Addison-Wesley: Reading, Mass., 1979, pp. 57-170.

40. Whitehurst, D.D., Mitchell, T. O., and Farcasiu, M., Coal Liquefaction: The Chemistry and Technology of Thermal Processes, Mobil Research and Development Corporation, Central Research Division, Princeton, New Jersey, 1980.

41. Williams, D.G. "Coal Cleaning." Coal Handbook. Ed. R.A. Meyers. Marcel Dekker, Inc., New York, 1981, pp. 209-302.

42. Wilson, M.A., Pugmire, R.J., Vasallo, A.M., Grant, D.M., Collin, P.J., and Zilm, K.W., Ind. Eng. Chem. Prod. Res. Dev., 21, 477, 1982.

43. Wiser, W. Preprints Fuel Division ACS Meeting, 20 (2), 122, 1975.

44. Wiser, W. H., Fuel, 47, 475, 1968.

45. Yang, J., A Study on the Carbonization of Coal-Derived Pitches. Thesis, Department of Chemical Engineering, West Virginia University, Morgantown, WV, 1994.

46. Yarzab, R. F., Given, P.H., Davis, A., and Spackman, W., Fuel, 59, 81, 1980.

47. Yen, Y. K., Furlani, D. E., and Weller, S. W., Ind. Eng. Chem. Prod. Res. Dev., 15, 24, 1976. 
APPENDIX A

Experimental Raw Data 
Table A.1 Hydrogenation Reactants and Subsequent Product Masses

\begin{tabular}{|c|c|c|c|c|c|c|}
\hline Run & Trial & In Coal $(\mathrm{g})$ & $\begin{array}{c}\text { In Solvent } \\
(\mathrm{g})\end{array}$ & $\begin{array}{c}\text { Out } \\
\text { Pitch }(\mathrm{g}) \\
\end{array}$ & \begin{tabular}{|c|} 
Out THF \\
Ins. (g)
\end{tabular} & $\begin{array}{c}\text { Out } \\
\text { Rec. Solv. } \\
(\mathrm{g}) \\
\end{array}$ \\
\hline 1 & A & 8.3812 & 25.1046 & 8.5037 & 4.6171 & 16.6769 \\
\hline 1 & $B$ & 8.4897 & 25.4679 & 12.3280 & 4.7903 & 14.4829 \\
\hline 1 & $\mathrm{C}$ & 8.3809 & 25.1423 & 9.6637 & 4.8612 & 15.3188 \\
\hline 1 & $D$ & 8.4776 & 25.4351 & 6.9489 & 4.8407 & 17.4629 \\
\hline 2 & A & 5.9996 & 17.9994 & 17.2400 & 6.6085 & 0.0000 \\
\hline 2 & $B$ & 5.9988 & 17.9999 & 16.2053 & 6.6643 & 0.0000 \\
\hline 2 & C & 6.0008 & 18.0008 & 12.7595 & 6.8085 & 1.9900 \\
\hline 2 & D & 6.0009 & 17.9990 & 9.5452 & 7.2738 & 3.9600 \\
\hline 3 & A & 7.6118 & 22.8324 & 9.9431 & 6.9708 & 10.2900 \\
\hline 3 & $B$ & 7.6541 & 22.9600 & 11.5130 & 7.1990 & 9.7100 \\
\hline 3 & $\mathrm{C}$ & 7.6744 & 23.0200 & 8.8603 & 7.2135 & 11.2000 \\
\hline 3 & D & 8.2833 & 24.8500 & 12.2342 & 8.6765 & 9.0800 \\
\hline 4 & A & 8.7873 & 26.3643 & 11.0642 & 6.0297 & 14.6300 \\
\hline 4 & $B$ & 8.8595 & 26.5785 & 5.4141 & 6.4669 & 21.2400 \\
\hline 4 & C & 8.8076 & 26.4215 & 7.5975 & 6.2503 & 17.1900 \\
\hline 4 & $D$ & 8.9488 & 26.8472 & 6.4161 & 6.5263 & 17.4800 \\
\hline 4 & $E$ & 8.7055 & 26.1183 & 7.1096 & 6.9566 & 20.2183 \\
\hline 5 & A & 9.0940 & 27.2847 & 8.6773 & 6.9411 & 19.1700 \\
\hline 5 & $B$ & 8.9570 & 26.8698 & 7.1536 & 7.0941 & 20.6700 \\
\hline 5 & $\mathrm{C}$ & 8.8303 & 26.4937 & 5.6086 & 6.9512 & 21.2800 \\
\hline 5 & D & 8.8314 & 26.4938 & 8.5937 & 7.0349 & 19.2400 \\
\hline 6 & A & 8.6048 & 25.8137 & 6.0769 & 7.2494 & 16.9400 \\
\hline 6 & $\mathrm{~B}$ & 9.0270 & 27.0806 & 4.7830 & 8.1360 & 20.5800 \\
\hline 6 & $\mathrm{C}$ & 8.5940 & 25.7836 & 3.4138 & 7.9002 & 21.8700 \\
\hline 6 & $D$ & 8.9388 & 26.8162 & 6.5164 & 7.8078 & 19.1700 \\
\hline 7 & A & 8.5583 & 25.6744 & 6.4744 & 7.0102 & 17.7300 \\
\hline 7 & B & 8.9103 & 26.7293 & 5.3671 & 7.2512 & 21.4800 \\
\hline 7 & $\mathrm{C}$ & 8.6285 & 25.8895 & 5.4428 & 7.7470 & 18.8400 \\
\hline 7 & D & 8.8169 & 26.4519 & 7.7059 & 7.7566 & 17.9700 \\
\hline
\end{tabular}


Table A.1(Continued) Hydrogenation Reactants and Subsequent Product Masses

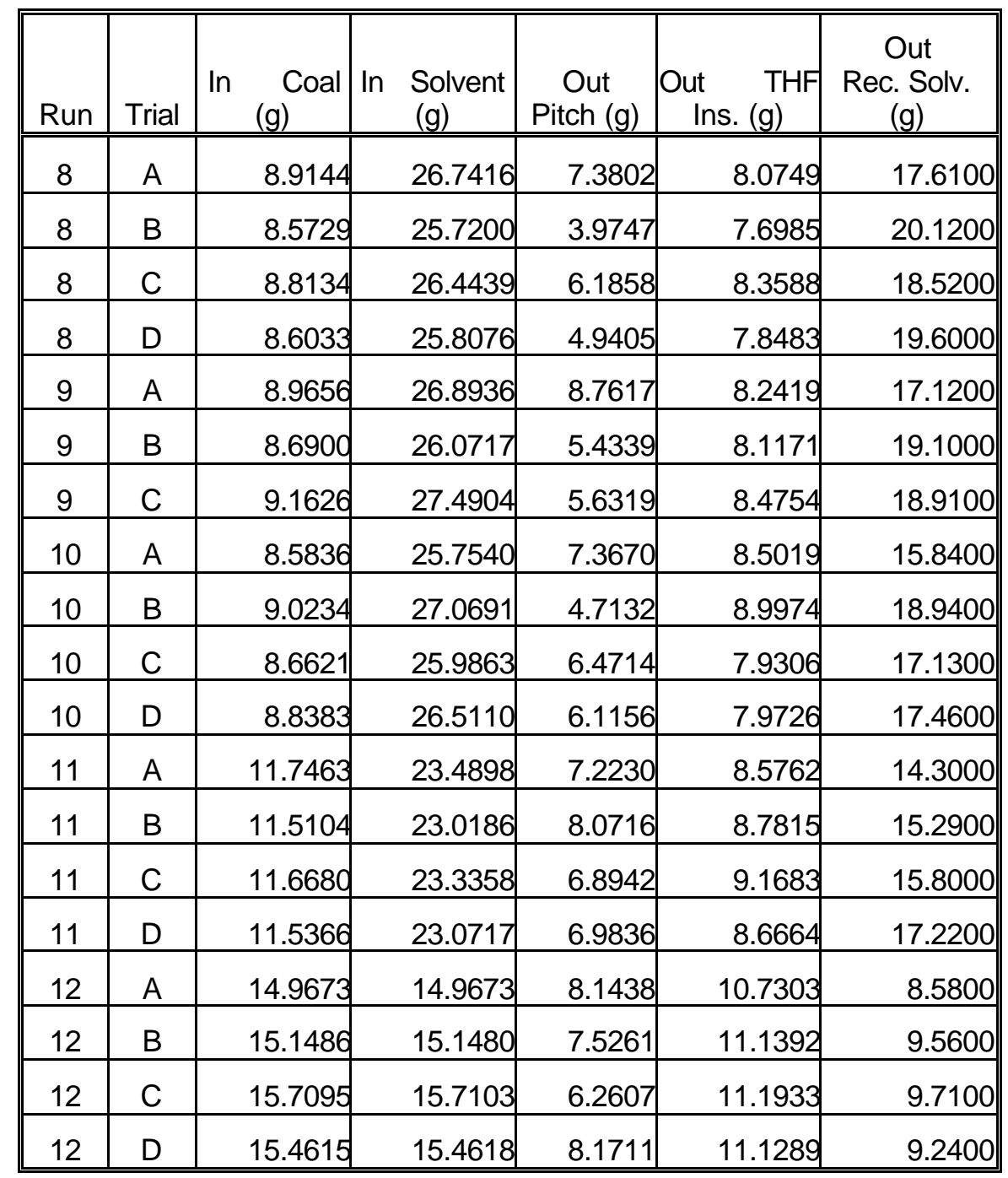


Table A.2 Hydrogenation Pitch Softening Point (Tsp $\left.{ }^{\circ} \mathrm{C}\right)$ and Coke Yield and Ash Content of Pitch and Insoluble Fraction

\begin{tabular}{|c|c|c|c|c|c|c|c|c|c|}
\hline \multirow[b]{2}{*}{ Run } & \multirow[b]{2}{*}{ Trial } & \multicolumn{2}{|c|}{ Pitch } & \multicolumn{2}{|c|}{ Pitch } & \multicolumn{2}{|c|}{ THF Insolubles } & \multicolumn{2}{|c|}{ Pitch } \\
\hline & & Tsp & Tsp & $\%$ Ash & $\%$ Ash & $\%$ Ash & $\%$ Ash & $\%$ Coke & $\%$ Coke \\
\hline 1 & $\mathrm{~A}$ & 129.2 & 128.7 & $0.100 \%$ & $0.120 \%$ & $10.44 \%$ & $12.66 \%$ & $43.6 \%$ & $43.7 \%$ \\
\hline 1 & $\mathrm{~B}$ & 71.0 & 73.3 & $0.088 \%$ & $0.075 \%$ & $10.75 \%$ & $10.99 \%$ & $30.5 \%$ & $32.0 \%$ \\
\hline 1 & $\mathrm{C}$ & 90.0 & 89.0 & $0.106 \%$ & $0.101 \%$ & $12.50 \%$ & $11.70 \%$ & $34.2 \%$ & $34.9 \%$ \\
\hline 1 & D & 165.1 & 164.9 & $0.036 \%$ & $0.037 \%$ & $10.50 \%$ & $11.10 \%$ & $46.7 \%$ & $48.5 \%$ \\
\hline 2 & A & 78.1 & 78.4 & $0.000 \%$ & $0.000 \%$ & $6.11 \%$ & $6.03 \%$ & $37.9 \%$ & $38.4 \%$ \\
\hline 2 & $\mathrm{~B}$ & 87.6 & 87.6 & $0.019 \%$ & $0.037 \%$ & $6.84 \%$ & $6.78 \%$ & $40.4 \%$ & $40.6 \%$ \\
\hline 2 & C & 125.8 & 127.1 & $0.030 \%$ & $0.019 \%$ & $7.18 \%$ & $7.03 \%$ & $47.0 \%$ & $48.1 \%$ \\
\hline 2 & $\mathrm{D}$ & 154.8 & 156.2 & $0.042 \%$ & $0.019 \%$ & $6.94 \%$ & $7.11 \%$ & $51.5 \%$ & $52.7 \%$ \\
\hline 3 & $\mathrm{~A}$ & 134.6 & 135.5 & $0.016 \%$ & $0.037 \%$ & $8.63 \%$ & $8.62 \%$ & $50.4 \%$ & $49.2 \%$ \\
\hline 3 & $B$ & 120.1 & 120.3 & $0.018 \%$ & $0.000 \%$ & $7.79 \%$ & $7.78 \%$ & $43.8 \%$ & $46.1 \%$ \\
\hline 3 & C & 163.3 & 158.6 & $0.022 \%$ & $0.024 \%$ & $7.80 \%$ & $7.61 \%$ & $55.9 \%$ & $55.7 \%$ \\
\hline 3 & D & 119.7 & 117.6 & $0.028 \%$ & $0.024 \%$ & $6.61 \%$ & $6.78 \%$ & $44.1 \%$ & $42.5 \%$ \\
\hline 4 & A & 79.1 & 78.4 & $0.018 \%$ & $0.024 \%$ & $11.83 \%$ & $11.95 \%$ & $34.5 \%$ & $32.8 \%$ \\
\hline 4 & $\mathrm{~B}$ & 174.0 & 170.4 & $0.000 \%$ & $0.015 \%$ & $11.00 \%$ & $11.10 \%$ & $54.6 \%$ & $53.6 \%$ \\
\hline 4 & C & 118.3 & 120.4 & $0.019 \%$ & $0.018 \%$ & $10.63 \%$ & $10.63 \%$ & $43.1 \%$ & $43.9 \%$ \\
\hline 4 & D & 152.9 & 153.8 & $0.023 \%$ & $0.024 \%$ & $12.90 \%$ & $13.00 \%$ & $53.0 \%$ & $53.1 \%$ \\
\hline 4 & $\mathrm{E}$ & 129.7 & 129.6 & $0.023 \%$ & $0.078 \%$ & $11.50 \%$ & $11.60 \%$ & $46.1 \%$ & $47.3 \%$ \\
\hline 5 & A & 109.2 & 109.1 & $0.048 \%$ & $0.043 \%$ & $9.96 \%$ & $10.50 \%$ & $42.1 \%$ & $43.0 \%$ \\
\hline 5 & B & 128.3 & 125.4 & $0.062 \%$ & $0.123 \%$ & $11.10 \%$ & $11.10 \%$ & $49.9 \%$ & $46.0 \%$ \\
\hline 5 & $\mathrm{C}$ & 151.4 & 155.8 & $0.026 \%$ & $0.039 \%$ & $10.40 \%$ & $10.40 \%$ & $52.6 \%$ & $52.8 \%$ \\
\hline 5 & D & 105.4 & 106.8 & $0.024 \%$ & $0.022 \%$ & $9.86 \%$ & $9.98 \%$ & $40.7 \%$ & $42.1 \%$ \\
\hline 6 & A & 105.5 & 104.9 & $0.068 \%$ & $0.071 \%$ & $8.13 \%$ & $8.20 \%$ & $41.1 \%$ & $42.7 \%$ \\
\hline 6 & B & 147.8 & 145.8 & $0.230 \%$ & $0.160 \%$ & $7.86 \%$ & $7.82 \%$ & $49.2 \%$ & $50.7 \%$ \\
\hline 6 & $\mathrm{C}$ & $>200$ & $>200$ & & mole coke & $d$ during $d$ & stillation -- & discarded. & \\
\hline 6 & D & 117.5 & 121.1 & $0.041 \%$ & $0.041 \%$ & $7.93 \%$ & $7.97 \%$ & $44.2 \%$ & $44.1 \%$ \\
\hline 7 & A & 114.1 & 112.2 & $0.036 \%$ & $0.037 \%$ & $10.10 \%$ & $10.20 \%$ & $42.4 \%$ & $42.7 \%$ \\
\hline 7 & $\mathrm{~B}$ & 158.6 & 158.1 & $0.037 \%$ & $0.062 \%$ & $9.49 \%$ & $9.57 \%$ & $52.4 \%$ & $52.2 \%$ \\
\hline 7 & C & 141.8 & 143.0 & $0.016 \%$ & $0.017 \%$ & $9.55 \%$ & $9.56 \%$ & $51.1 \%$ & $49.3 \%$ \\
\hline 7 & $D$ & 97.3 & 97.7 & $0.017 \%$ & $0.019 \%$ & $10.40 \%$ & $10.34 \%$ & $38.9 \%$ & $38.9 \%$ \\
\hline
\end{tabular}


Table A.2 (Continued) Hydrogenation Pitch Softening Point (Tsp $\left.{ }^{\circ} \mathrm{C}\right)$ and Coke Yield and Ash Content of Pitch and Insoluble Fraction

\begin{tabular}{|c|c|c|c|c|c|c|c|c|c|}
\hline \multirow[b]{2}{*}{ Run } & \multirow[b]{2}{*}{ Trial } & \multicolumn{2}{|c|}{ Pitch } & \multicolumn{2}{|c|}{ Pitch } & \multicolumn{2}{|c|}{ THF Insolubles } & \multicolumn{2}{|c|}{ Pitch } \\
\hline & & Tsp & Tsp & $\%$ Ash & $\%$ Ash & $\%$ Ash & $\%$ Ash & $\%$ Coke & $\%$ Coke \\
\hline 8 & A & 87.3 & 85.9 & $0.035 \%$ & $0.020 \%$ & $8.72 \%$ & $8.50 \%$ & $36.2 \%$ & $36.1 \%$ \\
\hline 8 & $B$ & 172.4 & 173.3 & $0.048 \%$ & $0.093 \%$ & $8.58 \%$ & $8.75 \%$ & $54.3 \%$ & $55.5 \%$ \\
\hline 8 & $\mathrm{C}$ & 108.1 & 109.6 & $0.018 \%$ & $0.013 \%$ & $7.70 \%$ & $7.86 \%$ & $41.4 \%$ & $41.8 \%$ \\
\hline 8 & $\mathrm{D}$ & 131.5 & 133.4 & $0.016 \%$ & $0.018 \%$ & $7.70 \%$ & $8.02 \%$ & $46.7 \%$ & $46.7 \%$ \\
\hline 9 & A & 73.9 & 73.9 & $0.041 \%$ & $0.032 \%$ & $8.59 \%$ & $8.47 \%$ & $33.7 \%$ & $32.9 \%$ \\
\hline 9 & $\mathrm{~B}$ & 124.0 & 123.2 & $0.039 \%$ & $0.030 \%$ & $8.39 \%$ & $8.54 \%$ & $47.3 \%$ & $46.9 \%$ \\
\hline 9 & $\mathrm{C}$ & 132.1 & 131.8 & $0.130 \%$ & $0.075 \%$ & $7.61 \%$ & $7.82 \%$ & $48.5 \%$ & $48.5 \%$ \\
\hline 10 & $\mathrm{~A}$ & 80.5 & 81.6 & $0.028 \%$ & $0.123 \%$ & $8.03 \%$ & $7.92 \%$ & $35.7 \%$ & $35.0 \%$ \\
\hline 10 & $\mathrm{~B}$ & 157.0 & 161.2 & $0.202 \%$ & $0.227 \%$ & $8.19 \%$ & $8.16 \%$ & $53.3 \%$ & $54.5 \%$ \\
\hline 10 & $\mathrm{C}$ & 103.5 & 104.2 & $0.101 \%$ & $0.069 \%$ & $8.26 \%$ & $8.11 \%$ & $41.6 \%$ & $41.1 \%$ \\
\hline 10 & D & 119.4 & 121.1 & $0.102 \%$ & $0.114 \%$ & $8.03 \%$ & $7.79 \%$ & $45.3 \%$ & $44.8 \%$ \\
\hline 11 & A & 139.3 & 141.8 & $0.044 \%$ & $0.170 \%$ & $10.90 \%$ & $10.50 \%$ & $49.2 \%$ & $47.8 \%$ \\
\hline 11 & $\mathrm{~B}$ & 127.1 & 127.8 & $0.120 \%$ & $0.048 \%$ & $10.70 \%$ & $10.90 \%$ & $45.9 \%$ & $46.6 \%$ \\
\hline 11 & C & 165.4 & 169.6 & $0.023 \%$ & $0.042 \%$ & $10.30 \%$ & $10.70 \%$ & $54.9 \%$ & $59.5 \%$ \\
\hline 11 & D & 153.0 & 155.3 & $0.240 \%$ & $0.250 \%$ & $10.30 \%$ & $10.30 \%$ & $51.9 \%$ & $52.2 \%$ \\
\hline 12 & A & 123.4 & 125.7 & $0.048 \%$ & $0.000 \%$ & $10.20 \%$ & $10.10 \%$ & $45.6 \%$ & $45.2 \%$ \\
\hline 12 & $\mathrm{~B}$ & 134.4 & 139.3 & $0.026 \%$ & $0.054 \%$ & $9.91 \%$ & $10.00 \%$ & $47.0 \%$ & $47.1 \%$ \\
\hline 12 & C & 159.6 & 164.5 & $0.019 \%$ & $0.021 \%$ & $10.30 \%$ & $10.20 \%$ & $53.5 \%$ & $52.7 \%$ \\
\hline 12 & $\mathrm{D}$ & 127.2 & 127.4 & $0.043 \%$ & $0.082 \%$ & $9.30 \%$ & $9.30 \%$ & $46.3 \%$ & $45.4 \%$ \\
\hline
\end{tabular}


Table A.3 Reactor Pressures of Hydrogenation Reactions with DACL-L under conditions of $400{ }^{\circ} \mathrm{C}, 1000 \mathrm{psig}$ Hydrogen, 3/1 Solvent-to-Coal Ratio and 1 hour
Table A.4 Reactor Pressures of Hydrogenation Reactions with DACL-H under conditions of $400{ }^{\circ} \mathrm{C}, 1000 \mathrm{psig}$ Hydrogen, 3/1 Solvent-to-Coal Ratio and 1 hour

\begin{tabular}{|c|c|c|}
\hline Time & Pressure & \\
\hline (min) & Run 1 & Run 2 \\
\hline 0 & 1000 & 1000 \\
\hline 2 & 1960 & 1900 \\
\hline 4 & 2010 & 1970 \\
\hline 6 & 2040 & 2000 \\
\hline 8 & 2040 & 2000 \\
\hline 10 & 2040 & 2000 \\
\hline 12 & 2040 & 2000 \\
\hline 16 & 2040 & 1990 \\
\hline 22 & 2020 & 1980 \\
\hline 28 & 2010 & 1960 \\
\hline 34 & 1990 & 1940 \\
\hline 40 & 1980 & 1930 \\
\hline 46 & 1960 & 1910 \\
\hline 52 & 1930 & 1890 \\
\hline 58 & 1920 & 1890 \\
\hline 61.5 & 910 & 900 \\
\hline 106 & 800 & 820 \\
\hline 1230 & 800 & 820 \\
\hline
\end{tabular}

\begin{tabular}{|r|r|r|}
\hline \multicolumn{1}{|r|}{ Time } & Pressure & \\
\hline \multicolumn{1}{|r|}{ (min) } & Run 1 & \multicolumn{1}{|r|}{ Run 2 } \\
\hline \hline 0 & 1000 & 990 \\
\hline 2 & 1900 & 1900 \\
\hline 6 & 2020 & 1950 \\
\hline 10 & 2020 & 1960 \\
\hline 14 & 2020 & 1980 \\
\hline 18 & 1980 & 1900 \\
\hline 22 & 1960 & 1880 \\
\hline 30 & 1880 & 1850 \\
\hline 36 & 1840 & 1810 \\
\hline 42 & 1820 & 1780 \\
\hline 48 & 1780 & 1770 \\
\hline 53 & 1740 & 1730 \\
\hline 59 & 1700 & 1690 \\
\hline 66 & 750 & 760 \\
\hline 74 & 750 & 750 \\
\hline 93 & 750 & 750 \\
\hline 140 & 750 & 750 \\
\hline 600 & 750 & 750 \\
\hline
\end{tabular}


Table A.5 Reactor Pressures of Hydrogenation Reactions with RACL under conditions of $400{ }^{\circ} \mathrm{C}, 1000 \mathrm{psig}$ Hydrogen, 3/1 Solvent-to-Coal Ratio and 1 hour

\begin{tabular}{|r|r|r|}
\hline \multicolumn{1}{|r|}{ Time } & Pressure & \\
\hline \multicolumn{1}{|r|}{ (min) } & Run 1 & Run 2 \\
\hline \hline 0 & 1000 & 1000 \\
\hline 2 & 2060 & 2040 \\
\hline 4 & 2130 & 2120 \\
\hline 6 & 2150 & 2130 \\
\hline 8 & 2140 & 2130 \\
\hline 10 & 2120 & 2110 \\
\hline 12 & 2120 & 2100 \\
\hline 16 & 2100 & 2090 \\
\hline 22 & 2090 & 2070 \\
\hline 28 & 2040 & 2010 \\
\hline 34 & 2020 & 1990 \\
\hline 40 & 1980 & 1960 \\
\hline 46 & 1930 & 1920 \\
\hline 52 & 1910 & 1900 \\
\hline 58 & 1890 & 1860 \\
\hline 61.5 & 880 & 860 \\
\hline 85 & 750 & 730 \\
\hline 1140 & 750 & 730 \\
\hline
\end{tabular}

Table A.6 Reactor Pressures of Hydrogenation Reactions with $\mathrm{HCO}$ under conditions of $400{ }^{\circ} \mathrm{C}, 1000 \mathrm{psig}$ Hydrogen, 3/1 Solvent-to-Coal Ratio and 1 hour

\begin{tabular}{|r|r|r|r|}
\hline \multicolumn{1}{|r|}{ Time } & Pressure & & \\
\hline (min) & Run 1 & Run 2 & \multicolumn{1}{|c|}{ Run 3 } \\
\hline \hline 0 & 1000 & 1000 & 1000 \\
\hline 2 & 1980 & 1880 & 1880 \\
\hline 4 & 2030 & 1920 & 1910 \\
\hline 8 & 2060 & 1920 & 1910 \\
\hline 12 & 2060 & 1920 & 1860 \\
\hline 16 & 2030 & 1880 & 1820 \\
\hline 22 & 1980 & 1840 & 1780 \\
\hline 28 & 1920 & 1800 & 1680 \\
\hline 34 & 1880 & 1740 & 1670 \\
\hline 40 & 1830 & 1700 & 1620 \\
\hline 46 & 1790 & 1660 & 1600 \\
\hline 52 & 1740 & 1620 & 1560 \\
\hline 58 & 1700 & 1590 & 1490 \\
\hline 61.5 & 980 & 860 & 800 \\
\hline 84 & 800 & 710 & 660 \\
\hline 105 & 800 & 710 & 660 \\
\hline 490 & 800 & 710 & 660 \\
\hline \hline \multicolumn{3}{|c}{} \\
\hline
\end{tabular}


Table A.7 Reactor Pressures of Hydrogenation Reactions with CBB under conditions of $400{ }^{\circ} \mathrm{C}, 1000 \mathrm{psig}$ Hydrogen, 3/1 Solvent-to-Coal Ratio and 1 hour

\begin{tabular}{|r|r|r|r|r||}
\hline Time & Pressure & & & \\
\hline (min) & Run 1 & \multicolumn{1}{l|}{ Run2 } & Run 3 & Run 4 \\
\hline \hline 0 & 1000 & 1000 & 1000 & 1000 \\
\hline 2 & 1970 & 1960 & 1980 & 1990 \\
\hline 4 & 2020 & 2010 & 2020 & 2040 \\
\hline 6 & 2020 & 2020 & 2020 & 2030 \\
\hline 8 & 2010 & 2010 & 2000 & 2020 \\
\hline 10 & 1980 & 1980 & 1990 & 2010 \\
\hline 12 & 1960 & 1970 & 1970 & 1980 \\
\hline 16 & 1940 & 1940 & 1940 & 1960 \\
\hline 22 & 1900 & 1900 & 1900 & 1920 \\
\hline 28 & 1850 & 1860 & 1860 & 1870 \\
\hline 34 & 1820 & 1820 & 1820 & 1830 \\
\hline 40 & 1780 & 1790 & 1780 & 1800 \\
\hline 46 & 1750 & 1760 & 1750 & 1750 \\
\hline 52 & 1720 & 1730 & 1710 & 1720 \\
\hline 58 & 1690 & 1700 & 1680 & 1690 \\
\hline 61 & 900 & 900 & 910 & 870 \\
\hline 65 & 760 & 800 & 760 & 760 \\
\hline 90 & 740 & 780 & 750 & 730 \\
\hline \hline
\end{tabular}

Table A.8 Reactor Pressures of Hydrogenation Reactions with CBB under conditions of $400{ }^{\circ} \mathrm{C}, 1000 \mathrm{psig}$ Argon, 3/1 Solvent-to-Coal Ratio and 1 hour

\begin{tabular}{||r|r|r|r|r||}
\hline Time & \multicolumn{1}{l|}{ Pressure } & & & \\
\hline (min) & \multicolumn{1}{|l|}{ Run 1 } & \multicolumn{1}{l|}{ Run2 } & Run 3 & run 4 \\
\hline \hline 0 & 1000 & 1000 & 1000 & 1000 \\
\hline 2 & 2000 & 1900 & 2030 & 2000 \\
\hline 4 & 2060 & 1980 & 2120 & 2070 \\
\hline 6 & 2100 & 2020 & 2140 & 2110 \\
\hline 8 & 2120 & 2040 & 2150 & 2120 \\
\hline 10 & 2130 & 2040 & 2160 & 2130 \\
\hline 12 & 2140 & 2060 & 2170 & 2140 \\
\hline 16 & 2170 & 2070 & 2180 & 2160 \\
\hline 22 & 2190 & 2100 & 2190 & 2170 \\
\hline 28 & 2210 & 2110 & 2220 & 2200 \\
\hline 34 & 2220 & 2120 & 2220 & 2210 \\
\hline 40 & 2230 & 2140 & 2240 & 2220 \\
\hline 46 & 2240 & 2140 & 2240 & 2220 \\
\hline 52 & 2240 & 2140 & 2260 & 2230 \\
\hline 58 & 2250 & 2150 & 2260 & 2230 \\
\hline 61 & 1150 & 1140 & 1140 & 1130 \\
\hline 90 & 1000 & 1000 & 1000 & 1000 \\
\hline \hline
\end{tabular}


Table A.9 Reactor Pressures of Hydrogenation Reactions with CBB under conditions of $400{ }^{\circ} \mathrm{C}, 500 \mathrm{psig}$ Hydrogen, 3/1 Solvent-to-Coal Ratio and 1 hour

\begin{tabular}{||r|r|r|r|r||}
\hline Time & Pressure & & & \\
\hline (min) & Run 1 & \multicolumn{1}{|l|}{ Run2 } & \multicolumn{1}{l|}{ Run 3 } & Run 4 \\
\hline \hline 0 & 500 & 500 & 500 & 500 \\
\hline 2 & 1020 & 1020 & 1040 & 1070 \\
\hline 4 & 1060 & 1060 & 1070 & 1100 \\
\hline 6 & 1060 & 1060 & 1050 & 1090 \\
\hline 8 & 1060 & 1060 & 1050 & 1090 \\
\hline 10 & 1060 & 1050 & 1040 & 1080 \\
\hline 12 & 1050 & 1050 & 1040 & 1080 \\
\hline 16 & 1040 & 1030 & 1020 & 1060 \\
\hline 23 & 1020 & 1020 & 1000 & 1040 \\
\hline 30 & 1000 & 1000 & 980 & 1010 \\
\hline 37 & 980 & 980 & 960 & 990 \\
\hline 44 & 960 & 970 & 940 & 960 \\
\hline 51 & 950 & 950 & 930 & 950 \\
\hline 58 & 940 & 940 & 910 & 920 \\
\hline 61 & 430 & 420 & 420 & 410 \\
\hline 90 & 380 & 380 & 360 & 360 \\
\hline \hline
\end{tabular}

Table A.10 Reactor Pressures of Hydrogenation Reactions with CBB under conditions of $400{ }^{\circ} \mathrm{C}, 500 \mathrm{psig}$ Argon, 3/1 Solvent-to-Coal Ratio and 1 hour

\begin{tabular}{|r|r|r|}
\hline Time & Pressure & \multicolumn{1}{l|}{} \\
\hline \hline (min) & \multicolumn{1}{|l|}{ Run 1 } & \multicolumn{1}{l|}{ Run2 } \\
\hline 0 & 500 & 500 \\
\hline 2 & 1020 & 1030 \\
\hline 4 & 1070 & 1070 \\
\hline 6 & 1100 & 1100 \\
\hline 8 & 1120 & 1120 \\
\hline 10 & 1120 & 1120 \\
\hline 12 & 1130 & 1130 \\
\hline 16 & 1140 & 1140 \\
\hline 24 & 1160 & 1170 \\
\hline 30 & 1180 & 1180 \\
\hline 40 & 1200 & 1200 \\
\hline 46 & 1210 & 1210 \\
\hline 52 & 1220 & 1210 \\
\hline 58 & 1220 & 1220 \\
\hline 61 & 600 & 600 \\
\hline 90 & 500 & 500 \\
\hline
\end{tabular}


Table A.11 Reactor Pressures of Hydrogenation Reactions with CBB under conditions of $400{ }^{\circ} \mathrm{C}, 100 \mathrm{psig}$ Hydrogen, 3/1 Solvent-to-Coal Ratio and 1 hour

\begin{tabular}{|c|c|c|}
\hline Time & Pressure & \\
\hline$(\min )$ & Run 1 & Run2 \\
\hline 0 & 100 & 100 \\
\hline 2 & 300 & 280 \\
\hline 4 & 330 & 320 \\
\hline 6 & 340 & 320 \\
\hline 8 & 340 & 320 \\
\hline 10 & 350 & 340 \\
\hline 12 & 360 & 350 \\
\hline 14 & 360 & 360 \\
\hline 16 & 360 & 360 \\
\hline 19 & 360 & 360 \\
\hline 22 & 360 & 360 \\
\hline 27 & 380 & 370 \\
\hline 32 & 390 & 390 \\
\hline 36 & 440 & 400 \\
\hline 39 & 440 & 380 \\
\hline 43 & 440 & 400 \\
\hline 46 & 450 & 410 \\
\hline 49 & 440 & 400 \\
\hline 54 & 440 & 400 \\
\hline 58 & 440 & 400 \\
\hline 61 & 200 & 170 \\
\hline 66 & 170 & 130 \\
\hline 90 & 160 & 130 \\
\hline
\end{tabular}

Table A.12 Reactor Pressures of Hydrogenation Reactions with CBB under conditions of $400{ }^{\circ} \mathrm{C}, 100 \mathrm{psig}$ Argon, 3/1 Solvent-to-Coal Ratio and 1 hour

\begin{tabular}{|c|c|c|c|c|}
\hline Time & & & & \\
\hline$(\mathrm{min})$ & & & Run2 & \\
\hline & 0 & 100 & & 100 \\
\hline & 2 & 240 & & 300 \\
\hline & 4 & 280 & & 330 \\
\hline & 7 & 300 & & 350 \\
\hline & 10 & 310 & & 360 \\
\hline & 14 & 320 & & 380 \\
\hline & 18 & 330 & & 390 \\
\hline & 21 & 340 & & 400 \\
\hline & 26 & 350 & & 400 \\
\hline & 32 & 360 & & 420 \\
\hline & 38 & 360 & & 420 \\
\hline & 44 & 380 & & 430 \\
\hline & 51 & 380 & & 440 \\
\hline & 58 & 390 & & 440 \\
\hline & 61 & 160 & & 160 \\
\hline & 67 & 150 & & 150 \\
\hline & 90 & 130 & & 130 \\
\hline
\end{tabular}


APPENDIX B

Micrographs of Cokes

(All scale factors are $118 \mu \mathrm{m}$ ) 

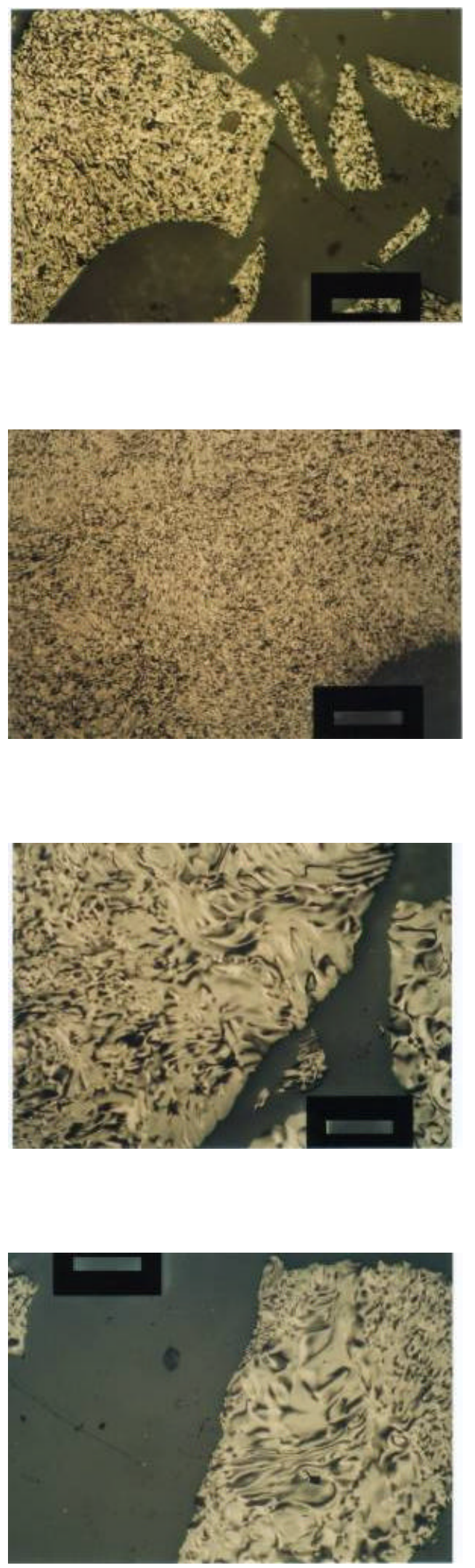

Figure B.1 Photograph of coke produced from hydrogenation reaction 1A with DACL-L, $400{ }^{\circ} \mathrm{C}, 1000$ psig hydrogen, 3/1 solvent-to-coal ratio, 1 hour. Pitch has softening point of 129 ${ }^{\circ} \mathrm{C}$.

Figure B.2 Photograph of coke produced from hydrogenation reaction $1 \mathrm{D}$ with DACL-L, $400{ }^{\circ} \mathrm{C}, 1000 \mathrm{psig}$ hydrogen, $3 / 1$ solvent-to-coal ratio, 1 hour. Pitch has softening point of 165 ${ }^{\circ} \mathrm{C}$.

Figure B.3 Photograph of coke produced from hydrogenation reaction $2 \mathrm{~A}$ with DACL-H, $400{ }^{\circ} \mathrm{C}$, 1000 psig hydrogen, 3/1 solvent-tocoal ratio, 1 hour. Pitch has softening point of $78.3{ }^{\circ} \mathrm{C}$.

Figure B.4 Photograph of coke produced from hydrogenation reaction $2 \mathrm{~B}$ with DACL-H, $400{ }^{\circ} \mathrm{C}$, 1000 psig hydrogen, 3/1 solvent-tocoal ratio, 1 hour. Pitch has softening point of $87.6^{\circ} \mathrm{C}$. 

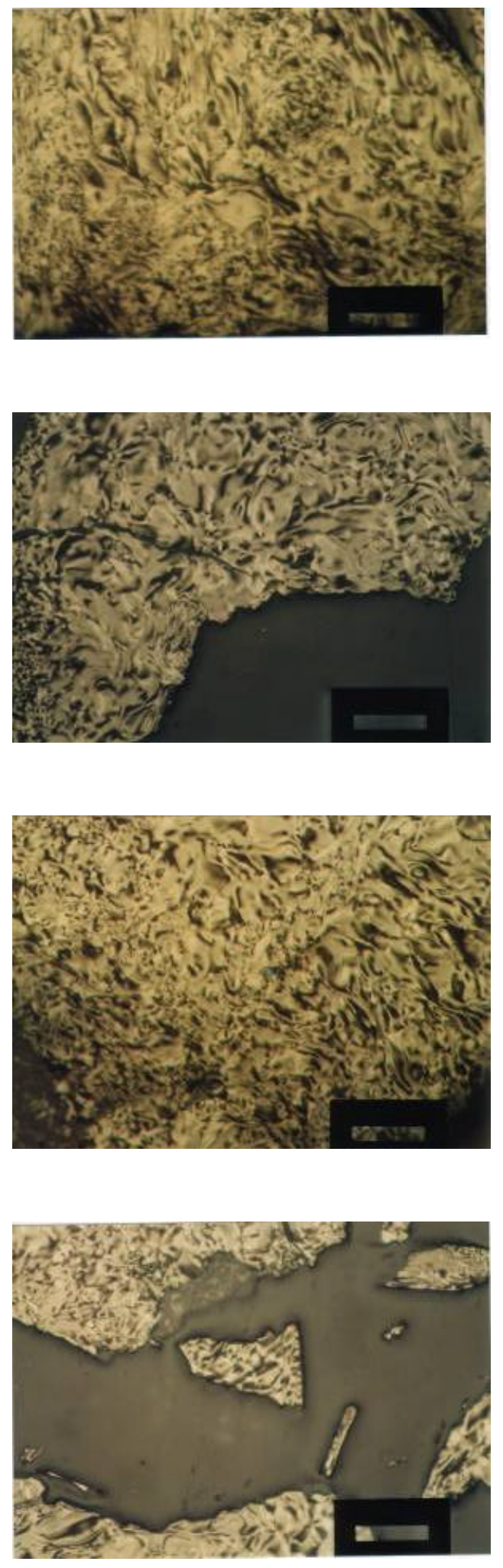

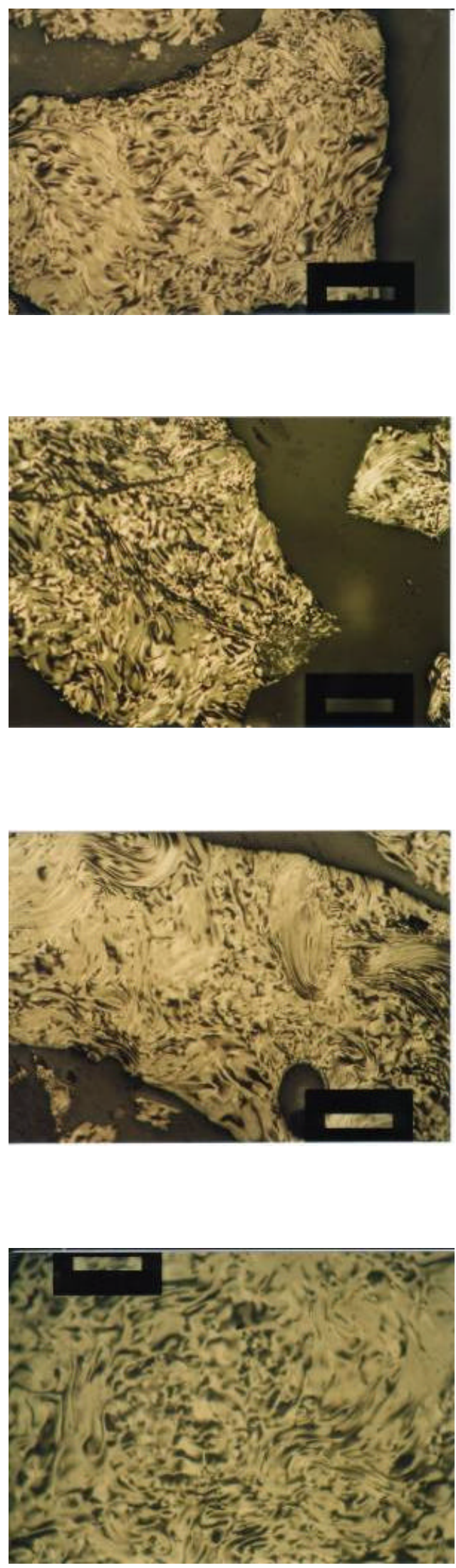

Figure B.9 Photograph of coke produced from hydrogenation reaction $3 \mathrm{D}$ with RACL, $400{ }^{\circ} \mathrm{C}, 1000 \mathrm{psig}$ hydrogen, 3/1 solvent-to-coal ratio, 1 hour. Pitch has softening point of 118.7 ${ }^{\circ} \mathrm{C}$.

Figure B.10 Photograph of coke produced from hydrogenation reaction 4B with $\mathrm{HCO}, 400{ }^{\circ} \mathrm{C}, 1000$ psig hydrogen, $3 / 1$ solvent-to-coal ratio, 1 hour. Pitch has softening point of $\mathbf{1 7 2 . 2}$ ${ }^{\circ} \mathrm{C}$.

Figure B.11 Photograph of coke produced from hydrogenation reaction $4 \mathrm{C}$ with $\mathrm{HCO}, 400{ }^{\circ} \mathrm{C}, 1000$ psig hydrogen, $3 / 1$ solvent-to-coal ratio, 1 hour. Pitch has softening point of 119.4 ${ }^{\circ} \mathrm{C}$.

Figure B.12 Photograph of coke produced from hydrogenation reaction 4D with $\mathrm{HCO}, 400{ }^{\circ} \mathrm{C}, 1000$ psig hydrogen, 3/1 solvent-to-coal ratio, 1 hour. Pitch has softening point of 153.4 ${ }^{\circ} \mathrm{C}$. 

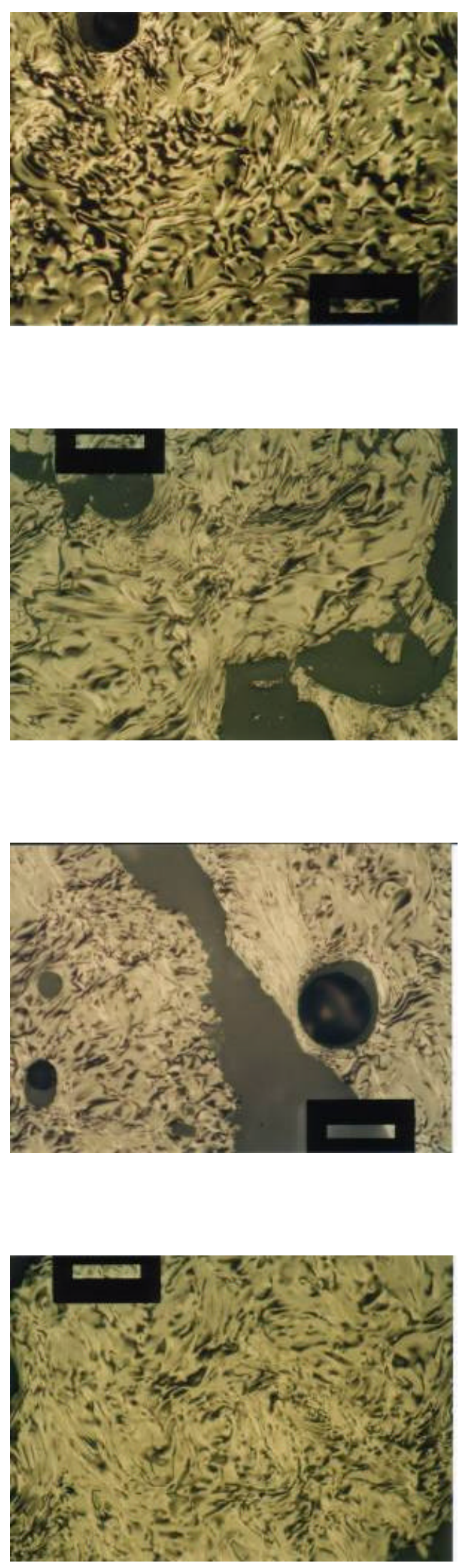

Figure B.13 Photograph of coke produced from hydrogenation reaction $4 \mathrm{E}$ with $\mathrm{HCO}, 400{ }^{\circ} \mathrm{C}, 1000$ psig hydrogen, 3/1 solvent-to-coal ratio, 1 hour. Pitch has softening point of 129.7 ${ }^{\circ} \mathrm{C}$.

Figure B.14 Photograph of coke produced from hydrogenation reaction $5 \mathrm{~A}$ with $\mathrm{CBB}, 400{ }^{\circ} \mathrm{C}, 1000 \mathrm{psig}$ hydrogen, 3/1 solvent-to-coal ratio, 1 hour. Pitch has softening point of 109.2 ${ }^{\circ} \mathrm{C}$.

Figure B.15 Photograph of coke produced from hydrogenation reaction $5 \mathrm{~B}$ with $\mathrm{CBB}, 400{ }^{\circ} \mathrm{C}, 1000$ psig hydrogen, 3/1 solvent-to-coal ratio, 1 hour. Pitch has softening point of 126.9 ${ }^{\circ} \mathrm{C}$.

Figure B.16 Photograph of coke produced from hydrogenation reaction $5 \mathrm{C}$ with $\mathrm{CBB}, 400{ }^{\circ} \mathrm{C}, 1000$ psig hydrogen, 3/1 solvent-to-coal ratio, 1 hour. Pitch has softening point of 153.6 ${ }^{\circ} \mathrm{C}$. 

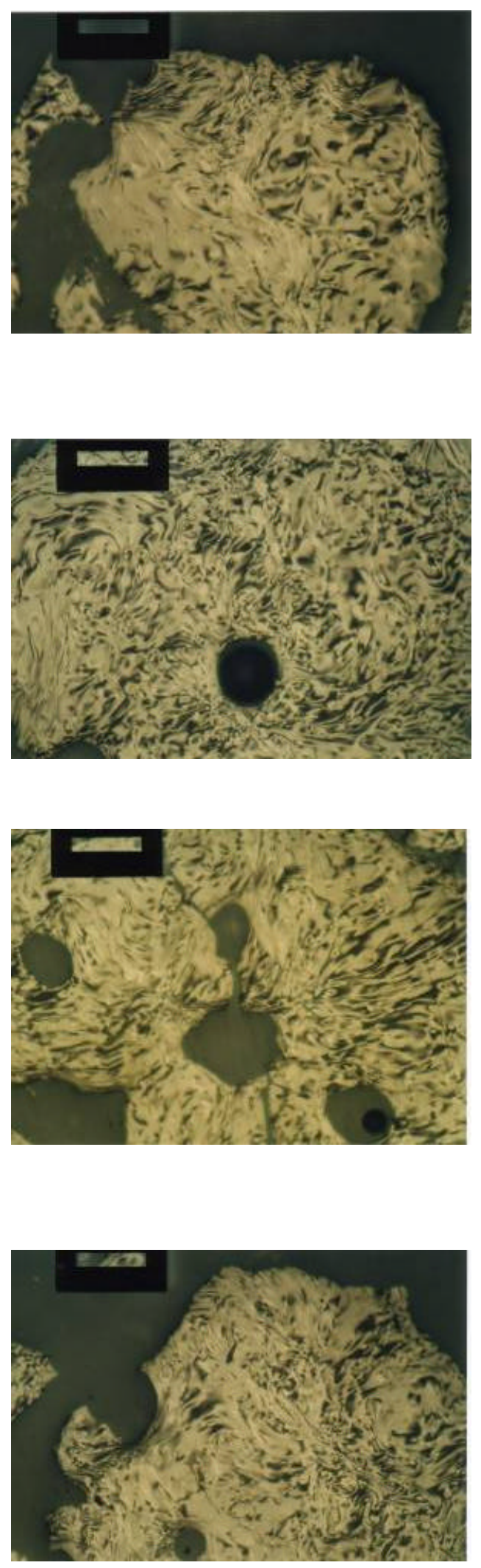

Figure B.17 Photograph of coke produced from hydrogenation reaction 5D with $\mathrm{CBB}, 400{ }^{\circ} \mathrm{C}, 1000 \mathrm{psig}$ hydrogen, 3/1 solvent-to-coal ratio, 1 hour. Pitch has softening point of 106.1 ${ }^{\circ} \mathrm{C}$.

Figure B.18 Photograph of coke produced from hydrogenation reaction $6 \mathrm{~A}$ with $\mathrm{CBB}, 400{ }^{\circ} \mathrm{C}, 1000$ psig argon, 3/1 solvent-to-coal ratio, 1 hour. Pitch has softening point of $105.2{ }^{\circ} \mathrm{C}$.

Figure B.19 Photograph of coke produced from hydrogenation reaction $6 \mathrm{~B}$ with $\mathrm{CBB}, 400{ }^{\circ} \mathrm{C}, 1000$ psig argon, 3/1 solvent-to-coal ratio, 1 hour. Pitch has softening point of $146.8^{\circ} \mathrm{C}$.

Figure B.20 Photograph of coke produced from hydrogenation reaction $6 \mathrm{D}$ with $\mathrm{CBB}, 400{ }^{\circ} \mathrm{C}, 1000$ psig argon, 3/1 solvent-to-coal ratio, 1 hour. Pitch has softening point of $119.3{ }^{\circ} \mathrm{C}$. 

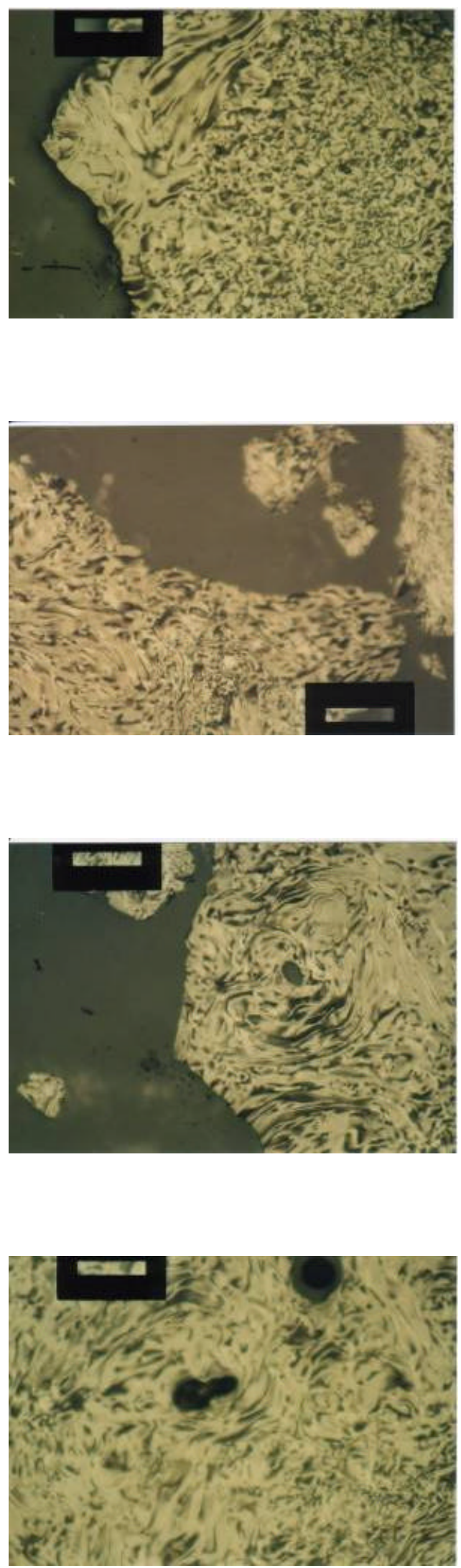

Figure B.21 Photograph of coke produced from hydrogenation reaction 7A with $\mathrm{CBB}, 400{ }^{\circ} \mathrm{C}, 500 \mathrm{psig}$ hydrogen, 3/1 solvent-to-coal ratio, 1 hour. Pitch has softening point of 113.2 ${ }^{\circ} \mathrm{C}$.

Figure B.22 Photograph of coke produced from hydrogenation reaction 7B with $\mathrm{CBB}, 400{ }^{\circ} \mathrm{C}, 500 \mathrm{psig}$ hydrogen, 3/1 solvent-to-coal ratio, 1 hour. Pitch has softening point of 158.4 ${ }^{\circ} \mathrm{C}$.

Figure B.23 Photograph of coke produced from hydrogenation reaction $7 \mathrm{C}$ with $\mathrm{CBB}, 400{ }^{\circ} \mathrm{C}, 500 \mathrm{psig}$ hydrogen, $3 / 1$ solvent-to-coal ratio, 1 hour. Pitch has softening point of 142.4 ${ }^{\circ} \mathrm{C}$.

Figure B.24 Photograph of coke produced from hydrogenation reaction $7 \mathrm{D}$ with $\mathrm{CBB}, 400{ }^{\circ} \mathrm{C}, 500 \mathrm{psig}$ hydrogen, 3/1 solvent-to-coal ratio, 1 hour. Pitch has softening point of 97.5 ${ }^{\circ} \mathrm{C}$. 

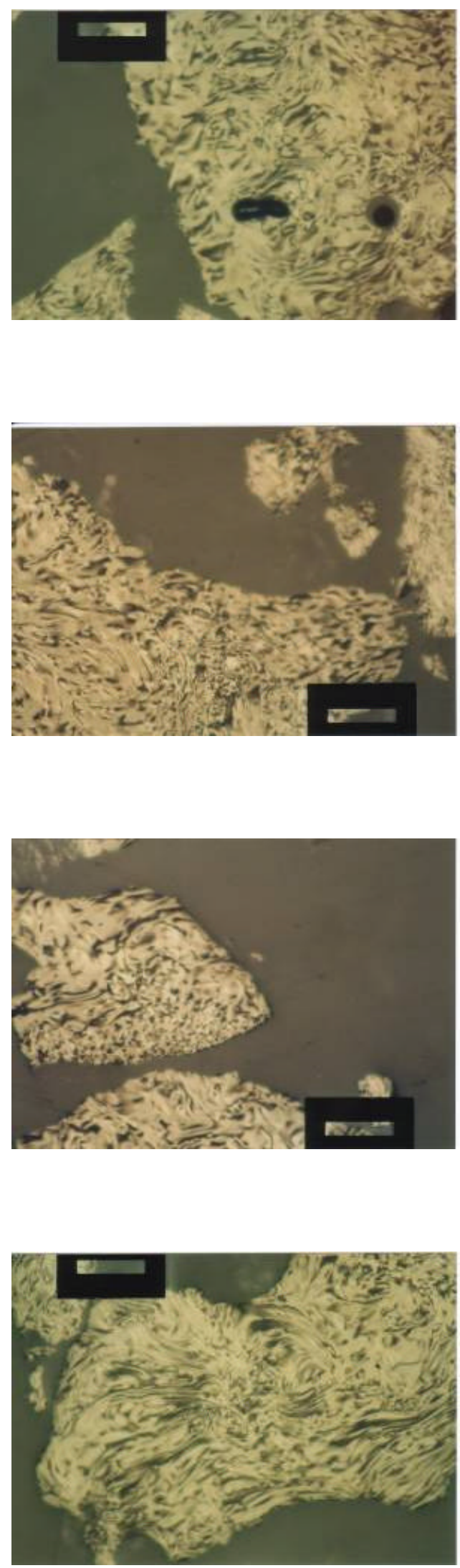

Figure B.25 Photograph of coke produced from hydrogenation reaction $8 \mathrm{~A}$ with $\mathrm{CBB}, 400{ }^{\circ} \mathrm{C}, 500$ psig argon, 3/1 solvent-to-coal ratio, 1 hour. Pitch has softening point of $86.6^{\circ} \mathrm{C}$.

Figure B.26 Photograph of coke produced from hydrogenation reaction $8 \mathrm{~B}$ with $\mathrm{CBB}, 400{ }^{\circ} \mathrm{C}, 500$ psig argon, $3 / 1$ solvent-to-coal ratio, 1 hour. Pitch has softening point of $172.9{ }^{\circ} \mathrm{C}$.

Figure B.27 Photograph of coke produced from hydrogenation reaction $8 \mathrm{C}$ with $\mathrm{CBB}, 400{ }^{\circ} \mathrm{C}, 500$ psig argon, 3/1 solvent-to-coal ratio, 1 hour. Pitch has softening point of $108.9^{\circ} \mathrm{C}$.

Figure B.28 Photograph of coke produced from hydrogenation reaction $8 \mathrm{D}$ with $\mathrm{CBB}, 400{ }^{\circ} \mathrm{C}, 500$ psig argon, 3/1 solvent-to-coal ratio, 1 hour. Pitch has softening point of $132.5^{\circ} \mathrm{C}$. 

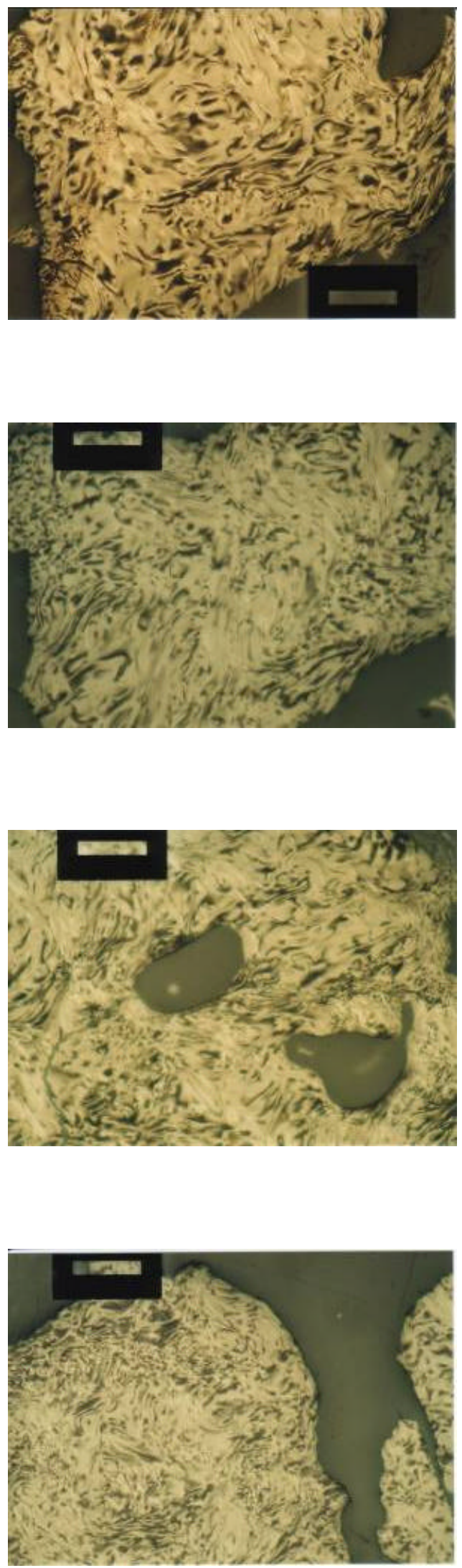

Figure B.29 Photograph of coke produced from hydrogenation reaction 9A with $\mathrm{CBB}, 400{ }^{\circ} \mathrm{C}, 100 \mathrm{psig}$ hydrogen, 3/1 solvent-to-coal ratio, 1 hour. Pitch has softening point of 73.9 ${ }^{\circ} \mathrm{C}$.

Figure B.30 Photograph of coke produced from hydrogenation reaction 9B with $\mathrm{CBB}, 400{ }^{\circ} \mathrm{C}, 100 \mathrm{psig}$ hydrogen, $3 / 1$ solvent-to-coal ratio, 1 hour. Pitch has softening point of 123.6 ${ }^{\circ} \mathrm{C}$.

Figure B.31 Photograph of coke produced from hydrogenation reaction 9C with $\mathrm{CBB}, 400{ }^{\circ} \mathrm{C}, 100 \mathrm{psig}$ hydrogen, $3 / 1$ solvent-to-coal ratio, 1 hour. Pitch has softening point of 132.0 ${ }^{\circ} \mathrm{C}$.

Figure B.32 Photograph of coke produced from hydrogenation reaction $10 \mathrm{~A}$ with $\mathrm{CBB}, 400{ }^{\circ} \mathrm{C}, 100$ psig argon, 3/1 solvent-to-coal ratio, 1 hour. Pitch has softening point of $81.1^{\circ} \mathrm{C}$. 

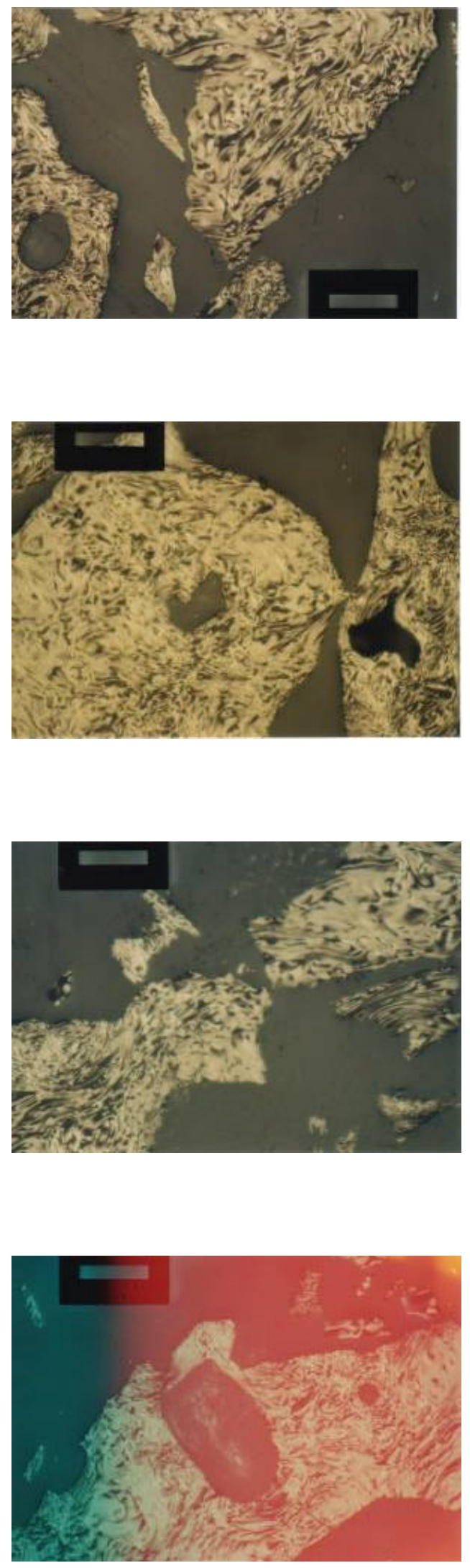

Figure B.33 Photograph of coke produced from hydrogenation reaction $10 \mathrm{~B}$ with $\mathrm{CBB}, 400{ }^{\circ} \mathrm{C}, 100$ psig argon, 3/1 solvent-to-coal ratio, 1 hour. Pitch has softening point of $159.1^{\circ} \mathrm{C}$.

Figure B.34 Photograph of coke produced from hydrogenation reaction $10 \mathrm{C}$ with $\mathrm{CBB}, 400^{\circ} \mathrm{C}, 100$ psig argon, 3/1 solvent-to-coal ratio, 1 hour. Pitch has softening point of $103.9^{\circ} \mathrm{C}$.

Figure B.35 Photograph of coke produced from hydrogenation reaction $10 \mathrm{D}$ with $\mathrm{CBB}, 400^{\circ} \mathrm{C}, 100$ psig argon, 3/1 solvent-to-coal ratio, 1 hour. Pitch has softening point of $120.3^{\circ} \mathrm{C}$.

Figure B.36 Photograph of coke produced from hydrogenation reaction 11A with $\mathrm{HCO}, 400{ }^{\circ} \mathrm{C}, 1000$ psig hydrogen, 2/1 solvent-to-coal ratio, 1 hour. Pitch has softening point of $140.6^{\circ} \mathrm{C}$. 

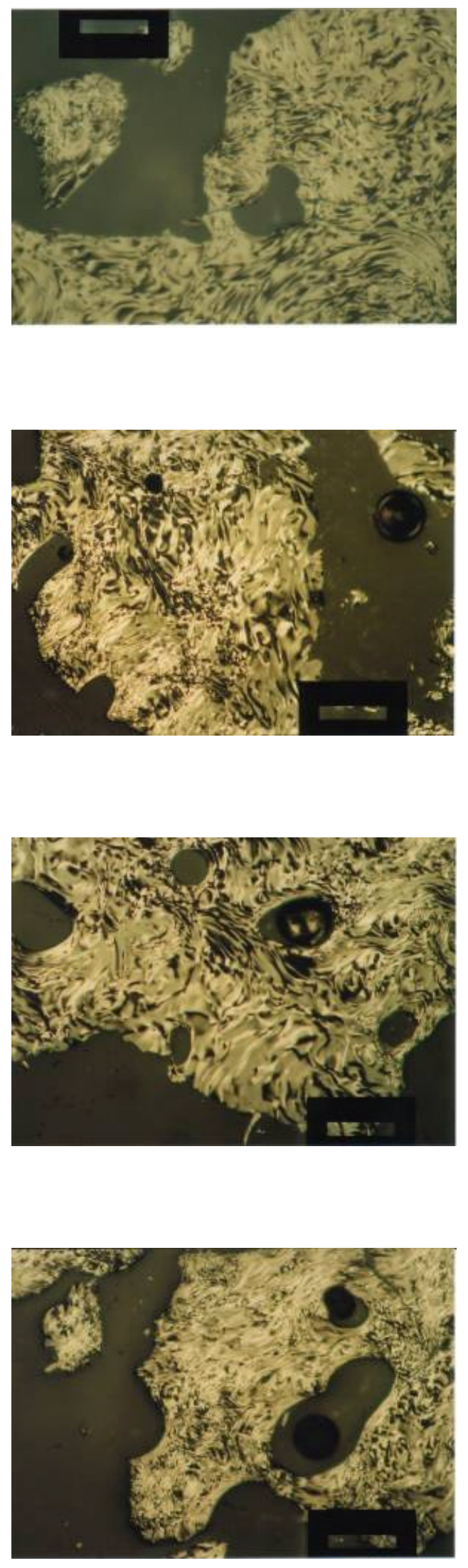

Figure B.37 Photograph of coke produced from hydrogenation reaction $11 \mathrm{~B}$ with $\mathrm{HCO}, 400{ }^{\circ} \mathrm{C}, 1000$ psig hydrogen, 2/1 solvent-to-coal ratio, 1 hour. Pitch has softening point of $127.5^{\circ} \mathrm{C}$.

Figure B.38 Photograph of coke produced from hydrogenation reaction $11 \mathrm{C}$ with $\mathrm{HCO}, 400{ }^{\circ} \mathrm{C}, 1000$ psig hydrogen, 2/1 solvent-to-coal ratio, 1 hour. Pitch has softening point of $167.5^{\circ} \mathrm{C}$.

Figure B.39 Photograph of coke produced from hydrogenation reaction $11 \mathrm{D}$ with $\mathrm{HCO}, 400{ }^{\circ} \mathrm{C}, 1000$ psig hydrogen, $2 / 1$ solvent-to-coal ratio, 1 hour. Pitch has softening point of $154.2^{\circ} \mathrm{C}$.

Figure B.40 Photograph of coke produced from hydrogenation reaction $12 \mathrm{~A}$ with $\mathrm{HCO}, 400{ }^{\circ} \mathrm{C}, 1000$ psig hydrogen, $1 / 1$ solvent-to-coal ratio, 1 hour. Pitch has softening point of $162.1^{\circ} \mathrm{C}$. 

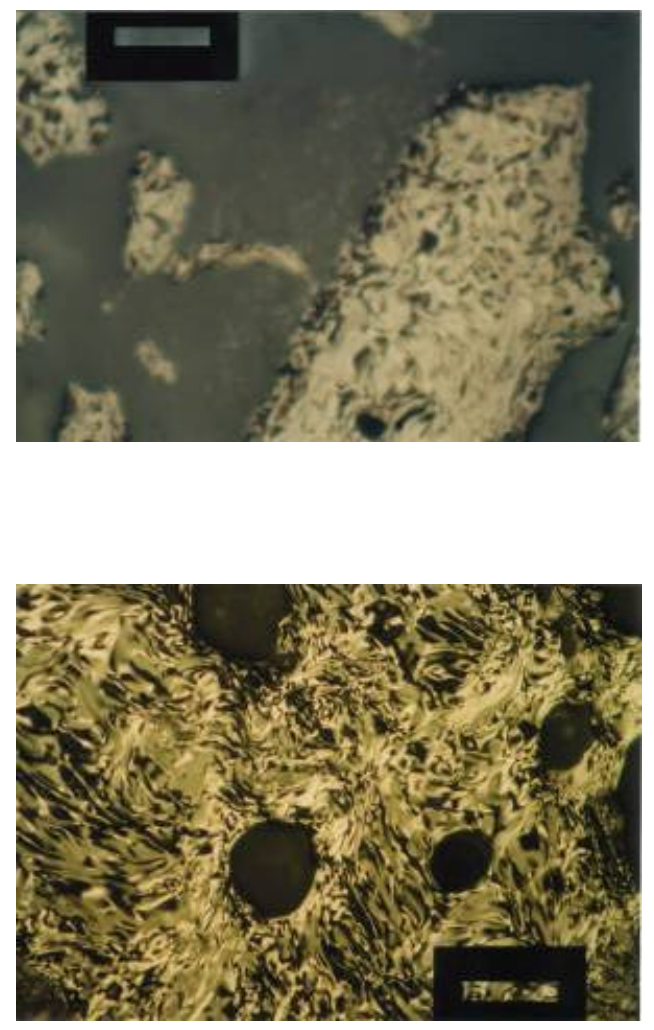

Figure B.41 Photograph of coke produced from hydrogenation reaction 12B with $\mathrm{HCO}, 400{ }^{\circ} \mathrm{C}, 1000$ psig hydrogen, 1/1 solvent-to-coal ratio, 1 hour. Pitch has softening point of $127.3^{\circ} \mathrm{C}$.

Figure B.42 Photograph of coke produced from hydrogenation reaction $12 \mathrm{C}$ with $\mathrm{HCO}, 400{ }^{\circ} \mathrm{C}, 1000$ psig hydrogen, 1/1 solvent-to-coal ratio, 1 hour. Pitch has softening point of $124.6^{\circ} \mathrm{C}$. 
APPENDIX C

Elemental Analysis Data 
Table C.1 Elemental Analysis Results from Select Hydrogenation Reactions

\begin{tabular}{|c|c|c|c|c|}
\hline Sample Name & Nitrogen \% & Carbon \% & Hydrogen \% & Sulfur \% \\
\hline$\overline{\mathrm{COAL}}$ & (0.800726593 & 82.03022003 & 4.413304329 & $\overline{0.735073}$ \\
\hline COAL & 1.393814802 & 81.14820099 & 4.715521336 & 0.7173310 \\
\hline DACL-L & 1.032134652 & 80.14930725 & 7.481013775 & 0.579850316 \\
\hline DACL-L & 0.862452507 & 80.86106873 & 7.994864464 & 0.644888937 \\
\hline 1A Pitch & 1.289442658 & 86.89827728 & 6.020725727 & 0.5555236 \\
\hline 1A Pitch & 1.146941423 & 86.70263672 & 6.294783115 & 0.7779966 \\
\hline 1A THF Insoluble & 0.973333001 & 83.5721817 & 4.165088654 & 0.930670857 \\
\hline 1A THF Insoluble & 2.090841293 & 81.47145081 & 4.185832977 & 0.8849851 \\
\hline 1A Recycle Solvent & 0.725984573 & 81.89357758 & 8.269141197 & -0.1877946 \\
\hline TARecycle Solvent & 1.008112788 & 83.33693695 & 8.15523243 & 0.559279799 \\
\hline DACL-H & 0.906315863 & 88.18888092 & 5.546836376 & 0.797720015 \\
\hline DACL-H & 1.585921168 & 88.83122253 & 5.896028996 & 0.731309056 \\
\hline 2C Pitch & 1.652619839 & 89.20326233 & 5.505034924 & 0.599318624 \\
\hline 2C Pitch & 1.708004594 & 90.18683624 & 5.730174065 & 0.7126492 \\
\hline 2C THF Insoluble & 2.166527987 & 83.86855316 & 4.133490562 & 0.742859304 \\
\hline 2C THF Insoluble & 1.865050554 & 82.3000412 & 4.167425632 & 0.956396997 \\
\hline 2C Recylce Solvent & 1.917423368 & 85.35504913 & 7.15696907 & 0.555400014 \\
\hline 2C Recylce Solvent & 1.046489358 & 85.84366608 & 7.338793755 & 0.587919772 \\
\hline 3B Pitch & 1.497819662 & 90.98829651 & 5.667295933 & 0.824364841 \\
\hline 3B Pitch & 1.079764724 & 90.07225037 & 6.002172947 & 0.6290766 \\
\hline 3B THF Insoluble & 2.174021721 & 79.99674225 & 4.448624134 & 0.908544421 \\
\hline 3B THF Insoluble & 2.215703249 & 81.45055389 & 4.648269653 & 0.934747279 \\
\hline 3B Recycle Solvent & 1.771402955 & 82.48386383 & 8.351308823 & 0.737286687 \\
\hline 3B Recycle Solvent & 1.974727035 & 81.22819519 & 8.534269333 & 0.60970342 \\
\hline RACL & 0.874046028 & 86.2507019 & 6.809337139 & 0.668987215 \\
\hline RACL & 1.559338689 & 87.0880661 & 6.714583397 & 0.777099848 \\
\hline 4C Pitch & 1.617382884 & 91.69573212 & $5.39631366 才$ & 0.761683703 \\
\hline 4C Pitch & 1.28988862 & 90.63007355 & 5.214667797 & 0.660184264 \\
\hline 4C THF Insoluble & 1.346327186 & 79.64372253 & 4.090205193 & 0.956537008 \\
\hline
\end{tabular}


Table C.1 (Continued) Elemental Analysis Results from Select Hydrogenation Reactions

\begin{tabular}{|c|c|c|c|c|}
\hline Sample Name & Nitrogen \% & Carbon \% & Hydrogen \% & Sulfur \% \\
\hline 4C THF Insoluble & 1.498970151 & 78.39524078 & 3.837160587 & (0.960397959 \\
\hline 4C Recycle Solvent & 0.724746406 & 93.58480835 & 5.362288475 & 0.444027484 \\
\hline 4C Recyce Solvent & 1.129940271 & 94.20589447 & 5.697498322 & 0.512170851 \\
\hline $\mathrm{HCO}$ & 0.968861938 & 93.08518219 & 4.987132549 & 0.557442606 \\
\hline $\mathrm{HCO}$ & 1.007636428 & 93.94626617 & 5.31794548 & 0.542826772 \\
\hline 5B Pitch & 0.756639302 & 89.6841507 & 4.952497482 & 0.683298409 \\
\hline 5B Pitch & 1.546139002 & 89.81164551 & 5.324268341 & 0.584444702 \\
\hline 5B THF Insoluble & 0.853470564 & 79.47361755 & 3.838719606 & 0.943519771 \\
\hline 5B THF Insoluble & 0.859390855 & 78.86706543 & 4.102155685 & 0.943781793 \\
\hline 5B Recycle Solvent & 0.891899347 & 91.45198059 & 5.842988014 & 0.729324162 \\
\hline 5B Recycle Solvent & 0.886314631 & 90.00209045 & 5.740687847 & 0.644795418 \\
\hline CBB & 0.982173145 & 91.86216736 & 5.572559834 & 0.718307495 \\
\hline CBB & 0.635398149 & 91.83862305 & 5.446722507 & 0.62724328 \\
\hline 6D Pitch & 1.281929374 & 91.20168304 & 5.251701832 & 0.885590434 \\
\hline 6D Pitch & 1.303733945 & 91.64124298 & 5.369911671 & 0.792035282 \\
\hline 6D THF Insoluble & 0.854979277 & 81.79877472 & 3.842562437 & 0.653879762 \\
\hline 6D THF Insoluble & 1.296254277 & 83.40203094 & 3.986491203 & 0.911690235 \\
\hline 7A Pitch & 1.9395684 & 92.09086609 & 5.295227051 & 0.808043718 \\
\hline 7A Pitch & 1.426768184 & 90.92002106 & 5.252641201 & 0.735275447 \\
\hline 7A THF Insoluble & 0.660272121 & 81.20497894 & 4.100767612 & 0.900794447 \\
\hline 7A THF Insoluble & 1.825739503 & 83.76688385 & 4.077264786 & 0.85759294 \\
\hline 6D Recycle Solvent & -0.204879567 & 94.5942688 & 5.649143219 & 0.910861075 \\
\hline 6D Recycle Solvent & -0.698981762 & 91.18883514 & 5.370734215 & 0.652718902 \\
\hline 7A Recycle Solvent & 0.877761841 & 90.97460175 & 5.855251789 & 0.598276138 \\
\hline 7A Recycle Solvent & 0.586638629 & 91.55131531 & 5.651697636 & 0.659404576 \\
\hline 8D Pitch & 1.751173615 & 92.32575226 & 5.134294987 & 0.675103962 \\
\hline 8D Pitch & 1.724418998 & 92.68335724 & 4.955196381 & 0.907358825 \\
\hline 8D THF Insoluble & 1.571769238 & 81.08649445 & 4.167609692 & 0.838398814 \\
\hline
\end{tabular}


Table C.1 (Continued) Elemental Analysis Results from Select Hydrogenation Reactions

\begin{tabular}{|c|c|c|c|c|}
\hline Sample Name & Nitrogen \% & Carbon \% & Hydrogen \% & Sulfur \% \\
\hline$\overline{8 D}$ THF Insoluble & 2.260994196 & 81.7248764 & 4.246864319 & 0.782370448 \\
\hline 9B Pitch & 1.078383446 & 91.92891693 & 5.153922081 & 0.698048353 \\
\hline 9B Pitch & 1.15290308 & 91.17565918 & 5.233355045 & 0.687234581 \\
\hline 9B THF Insoluble & 1.202765226 & 82.38817596 & 4.087132454 & 0.809182346 \\
\hline 9B THF Insoluble & 1.401732683 & 82.05186462 & 4.069063663 & 0.865704477 \\
\hline 8D Recycle Solvent & 0.624038637 & 88.60739899 & 4.976284981 & 0.860951901 \\
\hline 8D Recycle Solvent & 0.561470747 & 90.58050537 & 5.55779314 & 0.662091851 \\
\hline 9B Recycle Solvent & 0.940030575 & 90.99137115 & 5.815058708 & 0.613212407 \\
\hline 9B Recycle Solvent & 0.798502684 & 93.19036865 & 5.780529976 & 0.598441362 \\
\hline 10D Pitch & 1.523295164 & 88.74085236 & 4.861751556 & 0.863550842 \\
\hline 10D Pitch & 1.500685215 & 89.34506226 & 5.272848129 & 0.739778459 \\
\hline 10D THF Insoluble & 1.478106976 & 80.26706696 & 4.123864174 & 0.583087683 \\
\hline 10D THF Insoluble & 0.924294233 & 83.76509857 & 4.256327152 & 0.700130343 \\
\hline 11B Pitch & 1.298616171 & 89.80078888 & 5.242455482 & 0.65870893 \\
\hline 11B Pitch & 1.633161306 & 89.37313843 & 5.110965252 & 0.628293216 \\
\hline 11B THF Insoluble & 1.480561495 & 77.2186203 & 3.998501539 & 0.664203823 \\
\hline 11B THF Insoluble & 1.919276714 & 77.84881592 & 3.898455858 & 0.759484112 \\
\hline 10D Recycle Solvent & 0.883579671 & 89.75298309 & 5.607596397 & 0.552561283 \\
\hline 10D Recycle Solvent & 0.660242021 & 89.41329193 & 5.333270073 & 0.372020066 \\
\hline 11B Recycle Solvent & 0.891836584 & 90.4691391 & 5.688763142 & 0.401919603 \\
\hline 11B Recycle Solvent & 0.804223597 & 90.17233276 & 5.189516068 & 0.368410617 \\
\hline 12C Pitch & 1.577460408 & 87.77875519 & 5.434559822 & 0.665524304 \\
\hline 12C Pitch & 0.612488925 & 86.80805206 & 5.248411655 & 0.616027951 \\
\hline 12C THF Insoluble & 1.572936773 & 76.87220764 & 4.223587513 & 0.716712952 \\
\hline 12C THF Insoluble & 1.151239634 & 76.7490387 & 3.991147995 & 0.719765246 \\
\hline 12C Recycle Solvent & 0.672605038 & 90.575737 & 5.792259693 & 0.439225942 \\
\hline 12C Recycle Solvent & 0.652494192 & 90.34770203 & 5.68773365 & 0.400908679 \\
\hline
\end{tabular}

